\title{
Adiposity in COPD
}

Citation for published version (APA):

Breyer, M. K. (2013). Adiposity in COPD. [Doctoral Thesis, Maastricht University]. Maastricht University. https://doi.org/10.26481/dis.20131003mb

Document status and date:

Published: 01/01/2013

DOI:

10.26481/dis.20131003mb

Document Version:

Publisher's PDF, also known as Version of record

\section{Please check the document version of this publication:}

- A submitted manuscript is the version of the article upon submission and before peer-review. There can be important differences between the submitted version and the official published version of record.

People interested in the research are advised to contact the author for the final version of the publication, or visit the DOI to the publisher's website.

- The final author version and the galley proof are versions of the publication after peer review.

- The final published version features the final layout of the paper including the volume, issue and page numbers.

Link to publication

\footnotetext{
General rights rights.

- You may freely distribute the URL identifying the publication in the public portal. please follow below link for the End User Agreement:

www.umlib.nl/taverne-license

Take down policy

If you believe that this document breaches copyright please contact us at:

repository@maastrichtuniversity.nl

providing details and we will investigate your claim.
}

Copyright and moral rights for the publications made accessible in the public portal are retained by the authors and/or other copyright owners and it is a condition of accessing publications that users recognise and abide by the legal requirements associated with these

- Users may download and print one copy of any publication from the public portal for the purpose of private study or research.

- You may not further distribute the material or use it for any profit-making activity or commercial gain

If the publication is distributed under the terms of Article $25 \mathrm{fa}$ of the Dutch Copyright Act, indicated by the "Taverne" license above, 
Adiposity in COPD 
(C) Marie-Kathrin Breyer

ISBN: 978-3-200-03188-3

Layout: Sabine Weiland

Cover: Wolfgang Herzig

Production: Grasl FairPrint, Vienna, Austria

The studies presented in this thesis were performed at the Nutrition and Toxicology Research Institute Maastricht (NUTRIM), Maastricht University Maastricht, the Netherlands, at the Center of expertise for chronic organ failu-re (CIRO), Horn, the Netherlands as well as at the Department of Respiratory and Critical Care Medicine and Ludwig Boltzmann Institute for COPD and Pulmonary Epidemiology, Otto Wagner Hospital, Vienna, Austria. 


\section{Adiposity in COPD}

\section{DISSERTATION}

to obtain the degree of Doctor at the Maastricht University, on the authority of the Rector Magnificus Prof. dr. L.L.G. Soete, in accordance with the decision of the Board of Deans, to be defended in public on Thursday, 03rd of October, 2013, at 12.00 hours

by

Marie-Kathrin Breyer 


\section{Supervisors}

Prof. dr. O.C. Burghuber, Vienna

Prof. dr. E.F.M. Wouters

Co-supervisor

Dr. E.P.A Rutten, CIRO+, Horn

Dr. M.A. Spruit, CIRO+, Horn

\section{Assessment Committee}

Prof. dr. E. Blaak (Chair)

Prof. dr. E. Derom, Gent

Prof. dr. R. Koopmans

Prof. dr. N. Schaper

Prof. dr. H. Watz, Großhansdorf 


\section{Table of contents}

\section{Chapter 1}

General introduction

29 Chapter 2

Highly elevated C-reactive protein levels in obese patients with COPD: a fat chance?

45 Chapter 3

Abdominal fat mass contributes to the systemic inflammation in chronic obstructive pulmonary disease

61 Chapter 4 Systemic inflammation in patients with chronic obstructive pulmonary disease: results from the COSMIC study

79 Chapter 5

Gender differences in the adipose secretome system in chronic obstructive pulmonary disease (COPD): a pivotal role of leptin

97 Chapter 6

Dysregulated adipokine metabolism in chronic obstructive pulmonary disease

115 Chapter 7

Nordic Walking improves daily physical activities in COPD: a randomised controlled trial

\section{Chapter 8}

Comparison of daily physical activity between COPD patients from Central-Europe and South-America

147 Chapter 9

Prevalence of metabolic syndrome in COPD patients and its consequences

165 Chapter 10

General discussion

181 Summary

187 Zusammenfassung

193 Sammenvatting

199 Word of gratitude

203 Curriculum vitae

207 List of publications 



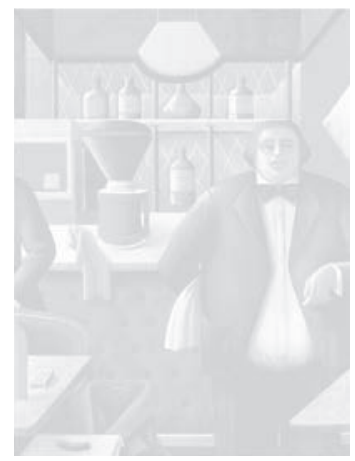

\section{CHAPTER 1}

\section{General introduction}

Part of this general introduction was published as:

Co-morbid manifestations in COPD

Wouters EFM, Celis MPM, Breyer MK, Rutten EPA, Graat-Verboom L, Spruit MA Respiratory Medicine: COPD Update, Vol. 3, Issue 4, Nov. 2007, p.135-151. 



\section{General introduction}

The first part of this introduction will provide a brief background of COPD; describe the latest definition, the worldwide economic and human negative impact as well as how to diagnose COPD according to the newest GOLD strategy (Global Initiative of Obstructive Lung Disease). The second part will deal with the complexity of systemic inflammation in COPD, including the hypothesis of local 'spill over' into the systemic circulation and other possible underlying mechanisms. Furthermore we will discuss the importance of daily physical activity in chronically ill patients. In addition the extra-pulmonary features; overweight and obesity and the role of the adipose tissue and its adipokines will be described and a link with the development of low-grade systemic inflammation in COPD will be proposed. Furthermore the metabolic syndrome will be defined and its role as an important co-morbidity factor in COPD will be elucidated as the fourth part of this introduction. Finally, an overview on the studies discussed in this thesis will be provided.

\section{Definition, diagnosis and burden of COPD}

Today chronic obstructive pulmonary disease (COPD) is defined as a common preventable and treatable disease characterised by persistent airflow limitation that is usually progressive and is associated with an enhanced chronic inflammatory response in the airways and the lung to noxious particles or gases ${ }^{1}$. Exacerbations and co-morbidities contribute to the overall severity in individual patients ${ }^{1}$. Pathophysiology in COPD involves multiple complex factors. The wide range of pathologies associated with COPD affect the large and small airways, the lung parenchyma, pulmonary circulation, as well as local and systemic inflammatory and remodelling processes ${ }^{2}$. The pathological alterations associated with COPD include airway narrowing with a subsequent increase in airway resistance as well as loss of lung parenchyma and a subsequent loss of lung elastic recoil. This process is termed hyperinflation. In addition, narrowing of bronchial lumen due to bronchial wall thickening, intra-luminal mucous plug-in and constriction of bronchial smooth muscles further enhance airflow obstruction/limitation².

In recent years COPD has become a tremendous worldwide health problem. By 2030 COPD is predicted to become the fourth leading cause of death worldwide and will therefore account for about $7.8 \%$ of total deaths ${ }^{3}$. In middle-income countries COPD ranks even third and will cause about $12 \%$ of total deaths ${ }^{3}$. The underlying causes are driven by smoking, particularly in the developed world ${ }^{4}$, occupational and indoor air pollution ${ }^{5}$ and exposure to biomass fuels, especially in the developing countries 6 . Furthermore the increasing age of the world's population and the reduced mortality of other chronic diseases, such as ischemic heart disease influence the worldwide increase of $\mathrm{COPD}^{3}$. Other risk factors contributing to the development of COPD include infections in early life ${ }^{7}$, genetic susceptibility ${ }^{8}$, 
malnutrition ${ }^{9}$, and airway hyper-reactivity and asthma ${ }^{10}$. COPD is associated with an enormous economic burden. Of the total US health care budget, respiratory diseases are estimated to account for about 6\%, with COPD accounting for 56\% (38.6 billion EURO) of the costs of respiratory diseases ${ }^{11}$. The economic and human negative impact of disease is considerable and now is able to be measured with the Disability Adjusted Life Years Scale (DALY). This is a tool which measures the loss of years of a specific condition due to premature mortality and years of disability adjusted for the severity of disability ${ }^{12}$. This has far reaching consequences as COPD will be the seventh leading cause of lost DALYs worldwide in $2030^{3}$.

Today the severity of the disease is not only assessed by the airflow limitation but also by the experienced symptoms ${ }^{1}$. Severity of disease is nowadays based on COPD assessments such as patients' current level of symptoms, spirometry result, and exacerbation rate. These factors impact significantly on patients' health status, future exacerbation and hospital readmission rate as well as death"1. Primary objective testing with spirometry, which is inexpensive and can be done in primary care settings, confirm the presence of persistent airflow limitation. Currently a post-bronchodilator forced expiratory volume in the first second/ forced vital capacity $\left(\mathrm{FEV}_{1} / \mathrm{FVC}\right)$ ratio below the fixed ratio of 0.70 is used to diagnose airflow obstruction ${ }^{1}$. The cardinal symptoms of COPD are dyspnoea, chronic cough, and sputum production. Symptoms are assessed using either the Modified British Medical Research Council Questionnaire (mMRC), which has shown to predict future mortality risk ${ }^{13}$ or by using the COPD Assessment Test (CAT) ${ }^{14}$, which correlates closely with patients' disease-specific health status ${ }^{15}$. COPD exacerbation is defined as an acute event characterised by a worsening of the patients respiratory symptoms that are beyond day-to-day variations and lead to a change in medication ${ }^{16}$. Exacerbations are commonly associated with a decline in lung function, health status and an increased risk of death ${ }^{17}$ and the risk increases with the number of exacerbations per year $(\geq 2)^{18}$. Independently of severity of disease, COPD is associated with various co-morbidities such as cardiovascular disease, metabolic syndrome, osteoporosis, depression and lung cancer. Co-morbidities have to be assessed and treated appropriately in every patient ${ }^{1}$.

\section{Systemic low-grade inflammation}

The word inflammation originally comes from the Latin inflammare - set on fire. In ancient times Cornelius Celsus, a roman patrician wrote in his book De Medicinae: 'Notae inflammationis vero sunt quatour: rubor et tumor cum calore et dolore' Now there are four diagnostics signs of inflammation: redness, swelling, heat, and pain ${ }^{19}$. In the second century A.D. Galen added the fifth sign Functio laesa - loss of function to the Celsian tetrad, completing the five cardinal symptoms of inflammation ${ }^{20}$.

Today inflammation is known to be a part of the non-specific immune response that occurs as a reaction to any injury ${ }^{21}$. The cardinal signs of acute inflammation 
are characterised by vasodilatation, increased blood flow, release of various soluble mediators, extravasation of fluids, and cellular influx ${ }^{21}$. In most cases these inflammatory processes are self-limiting but however, in some conditions they become continuous and chronic inflammatory disease develops subsequently.

Regardless of inflammation being acute or chronic, the process has very specific characteristics and the innate immune system plays a major role as it mediates the first response. While neutrophils and macrophages characterise acute inflammation, infiltration of T-lymphocytes and plasma cells are a feature of chronic inflammation ${ }^{21}$. Macrophages and also monocytes contribute to the final consequence of chronic inflammation which is represented by the loss of tissue function due to fibrosis ${ }^{22}$. Monocytes produce one of the main soluble mediators of inflammation; interleukin 1 (IL-1), particularly IL-1B, which mediates a wide range of reactions involved in the acute phase response. It generates fever, hypotension and is responsible for the production of cytokines such as IL-6, which in turn, stimulates hepatic acute phase proteins such as serum amyloid $A$ as well as $C$ reactive protein $(C R P)^{23}$. CRP, named after its ability to precipitate with the somatic C-polysaccharide of Streptococcus pneumoniae, was the first acute phase protein described in $1930^{24}$. The acute phase response includes the non-specific physiological response to most forms of infection, inflammation, tissue damage, and malignancy. Therefore CRP is a selected sensitive systemic marker reflecting ongoing inflammation and/ or tissue damage. Increased circulating levels are associated with various chronic inflammatory diseases such as rheumatoid arthritis, crohns' disease or cardiovascular disease ${ }^{25}$.

Various small-sized sample studies in the late 90ies suggested a state of permanent low-grade systemic inflammation present in COPD, as various inflammatory biomarkers were found to be increased compared to healthy subjects ${ }^{26,27}$. Based on this data, Gan et al. created a systematic review including fourteen studies with the primary outcome of comparing different systemic inflammatory biomarkers, such as CRP, fibrinogen, leucocytes but also tumor necrosis factor alpha (TNF $\alpha$ ), IL-6 and 8 in COPD patients and healthy subjects ${ }^{28}$. According to the authors, individuals with chronic airflow limitation had significantly raised levels of CRP, fibrinogen, leukocytes, and TNF $\alpha$ compared with age-matched healthy subjects. This data indicates that systemic inflammation is present in all COPD patients. Worth noting is the fact that all studies included in the systematic review were cross-sectional by nature, varied in the way in which inflammatory markers were sampled and analysed and also had a wide heterogeneity with regard to for example nutritional status. Shortly after Franciosi et al. challenged this data with a systematic review including more than 140.000 subjects, of which $46 \%$ were healthy subjects and $26 \%$ mild, $16 \%$ moderate, and $13 \%$ severe COPD patients ${ }^{29}$. The authors found no statistical difference in serum levels of CRP or TNF $\alpha$ in healthy subjects and any of the COPD stages despite a trend of increased levels with increasing severity of the disease, based on lung function decline measured 
by FEV ${ }_{1}$. Therefore it seems as some COPD patients do have increased levels of systemic inflammatory biomarkers but some don't. For the first time a possible heterogeneity of systemic inflammation in COPD was considered, even though very cautiously.

Over the past years it has been established that a mechanism-based approach is necessary in order to define and classify disease markers. Several attempts have therefore been made to elucidate the origin of systemic inflammation in patients with COPD. One concept is the so called 'spill over' theory, implying a spill over of local inflammation from the lungs into the systemic circulation. The local inflammatory process in the airways, parenchyma and pulmonary vasculature is characterised by an increased number of neutrophils ${ }^{30}$, macrophages and T-lymphocytes ${ }^{31}$ as well as increased levels of pro-inflammatory cytokines such as Leucotriene B4 (LTB4) ${ }^{32}, 11-6$ and $8^{33}$ and TNF $\alpha^{34}$. A possible pathway might be due to an increased epithelial leakability, caused by inflammation, which in turn facilitates proteins to move from the lung surface into the circulation causing an additional inflammatory reaction ${ }^{35-37}$. Furthermore inhaled air pollutants can lead to a subsequent systemic inflammatory response due to alveolar macrophages which ingest and clear the inhaled particles ${ }^{38}$. In addition alveolar macrophages stimulate the production of pro-inflammatory cytokines, such as TNF $\alpha$, which are increased in the blood of subjects during an episode of acute air pollution, suggesting a possible link between these cytokines and the systemic inflammatory response ${ }^{39}$. Alternatively evidence suggests that inhaled ultrafine particles are able to translocate from the lung into the systemic circulation and directly activate a systemic response ${ }^{40}$. Clinical evidence which might support the 'spill over' theory has been found by Sapey et al. who report sputum levels of IL-1B, TNF $\alpha$ and LTB4 correlating negatively with body mass index in patients with COPD ${ }^{41}$. This data might confirm the hypothesis that increased lung inflammation is associated with a lower body weight in COPD patients as indicated in earlier studies which linked a low body weight with systemic inflammation ${ }^{42}$. Difficulties in proving the 'spill over' concept are substantiated by the fact that there is a clear lack of correlation between airway cytokine levels and those in the circulation. The lack of a clear established relationship between airway and circulating $\mathrm{TNF} \alpha^{43}$ as well as IL-1 levels ${ }^{44}$ question the mechanism of 'spill over' in COPD. In addition, sputum neutrophils are thought to be mechanistically involved in the disease pathophysiology of COPD ${ }^{45}$, as they can secrete a wide variety of pro-inflammatory cytokines and chemokines ${ }^{46,47}$. However, up until now there has been no evidence proving any association between sputum neutrophils and markers of systemic inflammation including blood neutrophils count, CRP, and surfactant protein $\mathrm{D}^{48}$. Besides the 'spill over' theory, other mechanisms have been suggested as being partially responsible for the systemic inflammatory state present in patients with COPD. Cigarette smoking seems to have an effect on the bronchial epithelial cells by increasing the trans-epithelial permeability and reducing the protective 
role of cellular glutathione (an important intracellular antioxidant) ${ }^{49}$. Additionally, an increased release of pro-inflammatory mediators such as IL-1B was found in epithelial cells from COPD patients after cigarette smoke exposure ${ }^{49}$. Cigarette smoking is also known to substantially contribute to the development of clinical cardiovascular disease resulting from direct effects on atherosclerosis and haemostasis $^{50}$. Another origin of systemic inflammation is the bone marrow. Due to inhaled particles alveolar macrophages increase their phagocytic activity and release pro-inflammatory cytokines which in turn stimulate the bone marrow to mobilise platelets and leucocytes ${ }^{51,52}$. Both animal ${ }^{53}$ and human studies ${ }^{54}$ have shown that particle exposure leads to acute leucocytosis supporting this concept. Lastly tissue hypoxia ${ }^{55}$ or skeletal muscle hypoxia ${ }^{56,57}$ are both associated with increased levels of TNF $\alpha$. This may contribute to the state of low-grade systemic inflammation in COPD.

When looking at other chronic diseases characterised by a state of chronic lowgrade inflammation for example cardiovascular disease or obesity, the adipose tissue has been proposed as a possible origin of systemic inflammation ${ }^{58,59}$. In general the adipose tissue is a highly active metabolic and endocrine organ expressing and secreting various bioactive peptides, so called adipokines, which are acting locally (autocrine/ paracrine) as well as systemic (endocrine) ) $^{59,60}$. Besides these efferent functions the adipose tissue expresses various receptors responding to afferent signals from hormone systems as well as from the central nervous system ${ }^{61}$. Therefore besides its function in storing and releasing energy, the adipose tissue permits communication with distant organs. Proteins released from the adipose tissue include leptin ${ }^{62}$, adiponectin ${ }^{62}$, plasminogen activator inhibitor ${ }^{63}$, $\operatorname{adipsin}^{64}$, resistin ${ }^{65}, T N F \alpha^{62}$, and IL-6 $6^{62}$. Circulating IL-6, expressed by adipocytes and adipose tissue matrix is positively correlated with obesity and insulin resistance $^{66}$. In addition plasma IL-6 levels predict future onset of type II diabetes and cardiovascular disease ${ }^{66}$. Expression and secretion of IL-6 is two to three times greater in visceral relative to subcutaneous adipose tissue ${ }^{62}$. In this context the visceral, mainly abdominal adipose tissue is of particular interest due to its favoured access to the portal circulation. IL-6 is thought to drain directly from the visceral adipose tissue into the portal circulation causing the obesity-linked rise of hepatic CRP production ${ }^{67}$. Therefore the adipose tissue is thought to be the initial driving force for the up-regulation of some liver derived inflammatory proteins. Indeed, CRP has been positively correlated with visceral adipose tissue emphasising the mechanistic link between adiposity and systemic inflammation ${ }^{68}$.

Whether or not these findings can be allocated to patients with COPD has never been investigated. Recent evidence indicates a prevalence of obesity [defined by a body mass index (BMI; weight in kilograms divided by square height in meters; $\mathrm{kg} / \mathrm{m}^{2}$ ) of $>30 \mathrm{~kg} / \mathrm{m}^{2}$ ] in about $40 \%$ of male and $20 \%$ of female patients with mild to moderate COPD ${ }^{69}$. Worth noting is the fact that in the same report about $70 \%$ of men and $45 \%$ of women showed abdominal obesity defined by an 
increased waist circumference ( $>102 \mathrm{~cm}$ for men and $>80 \mathrm{~cm}$ for women). This finding clearly indicates that a subgroup of patients with normal weight still have abdominal obesity. To date, no studies exist investigating possible systemic consequences of abdominal obesity in COPD including the hypothesis of a visceral adipose tissue derived contribution to the state of low-grade systemic inflammation in COPD.

Two main factors cause abdominal obesity: firstly an increased intake of energydense foods that are high in energy density and secondarily a decrease in physical activity due to the increasingly sedentary nature ${ }^{70}$. Physical inactivity is thought to play an important role in the development of dementia ${ }^{71}$ and depression ${ }^{72}$ and physical inactivity is known to increase the risk of type II diabetes ${ }^{73}$, cardiovascular disease ${ }^{74}$, colon ${ }^{75}$, and breast cancer ${ }^{76}$, all of which are associated with an enhanced risk for premature morbidity and mortality. The health consequences of abdominal obesity and physical inactivity are therefore comparable. Interestingly, regular exercise seems to have an anti-inflammatory effect ${ }^{77}$, as levels of IL-6 and CRP are linearly associated with physical inactivity ${ }^{78}$, suggesting physical inactivity to contribute to systemic low-grade inflammation. Indeed, low physical activity levels were associated with markedly higher levels of IL-6 and CRP in both obese and non-obese subjects ${ }^{78}$.

Therefore quantifying daily physical activities is of great interest, particularly in chronically ill patients. However, assessing daily physical activity levels were challenging as only subjective measurements for example questionnaires or diaries were available for a long time ${ }^{79}$. In 2005 however new diagnostic tools, triaxial accelerometers became available and for the first time, time spent on different activities (walking, cycling) and body position (standing, sitting, lying) could be quantified precisely ${ }^{80}$. Not surprisingly COPD patients who frequently experience dyspnoea, suffer from symptom-induced inactivity compared to healthy subjects ${ }^{81}$. Comprehensive pulmonary rehabilitation programs improve functional exercise capacity and daily symptoms of dyspnoea in COPD patients ${ }^{82}$. However most studies lack to transfer these achievements into long-term observation ${ }^{83}$. Furthermore no studies are available investigating the effects of pulmonary rehabilitation on patients' daily physical activity levels measured objectively by triaxial accelerometers.

In conclusion, elucidating the origin of systemic inflammation in COPD is challenging. Although various theories have been proposed, none have been proven suggesting that heterogeneity of determinants of systemic inflammation in COPD has to be considered. A new pathway, the adipose tissue as the source of systemic inflammation in COPD, has opened up and seems worth investigating. Physical inactivity is also associated with systemic inflammation in the general population; however no data exists in connection with patients with COPD. Furthermore quantifying physical activity seems of particular interest in chronically ill patients as physical inactivity has various detrimental effects on patients' morbidity and mortality. 


\section{Body composition}

In COPD changes in body composition are the most intensively investigated systemic manifestation. In particular low body weight and muscle mass have been well recognized in the 90ies and were associated with extra-pulmonary symptoms like exercise intolerance ${ }^{84}$, muscle weakness ${ }^{85}$ and an impaired disease-specific health status $^{86}$. Moreover, fat free mass index (FFMl; fat free mass (FFM) in kilogram divided by square height in meters) as an indirect marker for skeletal muscle mass is a significant predictor of mortality independent of sex, smoking, lung function and BM ${ }^{87,88}$. The prevalence of FFM depletion is about 25\% in patients with an impaired lung function and higher in patients with COPD compared to healthy subjects ${ }^{89}$. Overweight and obesity, defined by an increased BMI of $>25 \mathrm{~kg} / \mathrm{m}^{2}$ for overweight and $>30 \mathrm{~kg} / \mathrm{m}^{2}$ for obesity, have gained some attention during the last years in connection with COPD. In general overweight and obesity have become a global health problem affecting nowadays 1.5 billion adults around the world ${ }^{90}$. Therefore in 2008 the World Health Organisation ranked overweight and obesity as being the fifth leading risk for global death ${ }^{70}$. Overweight and obesity have been associated with increased death rates from cardiovascular and cerebrovascular disease and different types of cancer ${ }^{91}$. Moreover in large pooled analyses of prospective studies including 1.46 million participants, overweight and obesity were associated with an increased all cause mortality within analyses restricted to never smoking participants without diagnosed heart disease or cancer ${ }^{92}$.

In a large COPD primary care population the prevalence of obesity was about $18 \%$ in the total population with the highest prevalence of about $24 \%$ in mild to moderate COPD ${ }^{93}$. Data from an U.S. COPD sample show even a much higher prevalence of about $50 \% \%^{94}$. In contrast, in the U.S. the prevalence of obesity in the general population was about $24 \%{ }^{95}$, suggesting that the prevalence of obesity in COPD is higher compared to the general population. In addition the prevalence of obesity might differ between various clinical phenotypes of COPD (emphysema versus chronic bronchitis) ${ }^{96}$. The detrimental effects of obesity and COPD seem obvious, though no mechanistic studies have explored the exact pathophysiological interactions that occur when both conditions exist in the same individual. Decreased chest wall and lung compliance, small airway dysfunction and expiratory flow limitation, preservation of $\mathrm{FEV}_{1} / \mathrm{FVC}$ ratio, and an increased work and oxygen cost of breathing are only some effects to be mentioned ${ }^{97}$. Interestingly when looking at the prognostic value of obesity in COPD, the relative risk of mortality in overweight and obese COPD patients seems increased in severe to very severe patients and decreased in mild to moderate patients ${ }^{98,99}$. This is of particular interest as in the general population several studies investigating the relation between $\mathrm{BMI}$ and all-cause mortality indicate the optimal BMI between $21-25 \mathrm{~kg} / \mathrm{m}^{2} 100,101$. This phenomenon is referred to as the 'obesity paradox' or the 'reverse epidemiology of obesity' and has already been described 
in other chronic diseases like chronic heart and kidney failure, and rheumatoid arthritis ${ }^{102}$. The exact pathophysiological pathways are yet to be elucidated. Important to note is that BMI can cover a decreased FFM if fat mass is increased. Indeed while FFM depletion is more pronounced in COPD patients with GOLD Stage 4, FFM depletion still occurs in the overweight to obese patients ${ }^{93}$. In the general population sarcopenic obesity, the loss of muscle mass co-occurring with an increased fat mass, has gained research interest as the prevalence in older-age individuals is increasing ${ }^{103}$. It is assumed that sarcopenic obesity may carry the cumulative risk derived from each of the two including hypertension, dyslipidaemia, and insulin resistance associated with obesity as well as physical inactivity, frailty, falls and fractures associated with the loss of muscle mass ${ }^{104}$. The pathogenesis is complex and multi-factorial incorporating lifestyle (physical inactivity, diet, smoking), endocrine (corticosteroids, insulin), but also immunological (inflammation, reactive oxygen species) factors ${ }^{105,106}$. Therefore using only $\mathrm{BMI}$ to predict patients' future outcomes is no longer valid. Other objective measuring methods like bioelectrical impedance analyses (BIA) or dual-energy X-ray absorptiometry (DXA) have been developed to accurately distinct between fat free and fat mass in the individual patient ${ }^{107,108}$.

Adipose tissue contains approximately 30 billion adipocytes which undertake various physiological functions; most importantly producing and secreting various proteins, so called adipokines ${ }^{109}$. Adiponectin and leptin make up the majority of adipokines. Circulating leptin is originally described as an adipoctye derived hormone involved in the progress of limiting food intake, increasing energy expenditure and decreasing metabolic efficiency by activating its functional receptor $(\mathrm{Ob}-\mathrm{Rb})$ in the hypothalamus ${ }^{110}$. The structure of leptin and its receptor classify leptin as a type I cytokine, which increases acutely by inflammatory and infectious stimuli such as TNF $\alpha$ and lipopolysaccharide ${ }^{111}$. Leptin secretion and expression are also regulated by a variety of other factors. For example directly proportional to adipose tissue mass and nutritional status, adipocytes secrete leptin and hereby leptin is positively linked with $\mathrm{BMI}$ and fat mass ${ }^{112}$. Furthermore leptin levels are also increased by insulin, glucocorticoids, and estrogens and decreased by androgens, free fatty acids, and growth hormone ${ }^{113}$. In the general population circulating leptin levels have been positively related to cardiovascular disease ${ }^{114,115}$ and in addition are gender related and higher in healthy women compared to healthy men, independent of BMI ${ }^{116}$. The role of circulating leptin in the involvement of the systemic inflammation in COPD has not been thoroughly researched and only in connection with male COPD patients with a low BMI $\left(<21 \mathrm{~kg} / \mathrm{m}^{2}\right)^{117}$. From this study it is concluded that circulating leptin plays a physiological role in COPD, even in underweight patients.

Adiponectin, almost exclusively produced by adipocytes, has a collagen-like domain followed by a globular domain that is similar to complement factor $\mathrm{C}^{1} \mathrm{q}^{118}$. Adiponectins globular domain is able to form trimers and then assemblies into higher- 
order oligomeric structures ${ }^{118}$. Its effects are mediated through two receptors, adiponectin receptors 1 and 2, which show different tissue distribution and different affinity for their ligand ${ }^{119}$. Plasma adiponectin is known to increase fatty acid oxidation and to reduce the synthesis of glucose in the liver ${ }^{120}$. Adiponectin has various protective anti-inflammatory effects on the metabolic derangements that may result in a lower risk for the development of atherosclerosis and type II diabetes ${ }^{121}$. In general, circulating levels of adiponectin are higher in women compared to men, and decrease with increasing BMI ${ }^{122}$. Plasma adiponectin levels are negatively correlated with CRP levels in obesity or patients with type II diabetes ${ }^{123}$. Despite its role in improvement of insulin sensitivity, increased levels of adiponectin seem to be able to decrease cardiovascular risk. Clinical studies have identified an association between low serum levels of adiponectin and coronary artery disease, hypertension, left ventricular hypertrophy and a greater risk of myocardial infarction ${ }^{124-126}$. Despite these direct beneficial effects of adiponectin in the development of cardiovascular morbidity, the role of adiponectin in clinical practice remains unclear. Indeed, in patients with chronic heart failure as well as chronic renal failure, higher adiponectin levels have been associated with an increased cardiac and all-cause mortality ${ }^{127,128}$. Limited data and inconclusive results are available related to the involvement of adiponectin in the pathophysiology of COPD. A previous report suggests an altered adipokine metabolism with increased levels of adiponectin that is related to the inflammatory reaction in COPD-related cachexia ${ }^{129}$. However the role of an adipokine imbalance in relation to systemic inflammatory biomarkers has never been investigated so far in COPD.

In conclusion the prevalence of obesity in COPD is high. In COPD the systemic effects of adipocytes derived adipokines are so far limited to underweight men. While circulating leptin might be a pro-inflammatory cytokine worth investigating in the state of low-grade systemic inflammation in COPD, adiponectin may be, besides its beneficial biological effects, an indirect marker of the multi-component severity in COPD. Further studies need to be done in order to explore the potential role of adipokines as a contributing factor in the disease progression in COPD.

\section{Metabolic syndrome}

The general definition on the diagnosis of the metabolic syndrome has a long history. Starting back in the beginning of the $20^{\text {th }}$ century first attempts were made to cluster various symptoms like obesity, glucose intolerance and hyperinsulinemia together and draw an association between them. Upper body obesity and the predisposition for developing type II diabetes, hypercholesterolemia, and hyperuricemia has gained even more attention as an positive association between arteriosclerosis and obesity has been established ${ }^{130}$. In this context, additive effects of risk factors for atherosclerosis were firstly described as 'the metabolic syndrome' in the 1970ies. However, other terms such as 'insulin resistance syndrome'131, 'syndrome $X^{\prime 132}$ or 'the deadly quartet'133 have been used for the last decades. 
The main risk factors for developing the metabolic syndrome include obesity, endocrine disorders as well as physical inactivity. Although a lot of effort has been made to elucidate the mechanisms of possible pathophysiological pathways of the metabolic syndrome many questions remain unanswered. Briefly, the most accepted hypothesis to describe the pathophysiology of the syndrome is insulin resistance. Of note, the most important action of insulin is the inhibition of lipolysis from adipose tissue ${ }^{134}$. One of the main contributors to insulin resistance is an overabundant of free fatty acids, which derive through lipolysis ${ }^{135}$. Therefore, when insulin resistance develops, the increased amount of lipolysis in adipose tissue stimulates the production of more free fatty acids which in turn inhibit the anti-lipolytic effect of insulin, creating additional lipolysis.

Several expert groups have developed clinical criteria for the metabolic syndrome (World Health Organisation, National Cholesterol Education Program-Third Adult Treatment Panel; ATP III), but conflicting results and most of all the lack of clinical feasibility led to the need of a single, universally accepted diagnostic tool. In 2006 the International Diabetes Federation (IDF) modified the ATP III definition of the diagnosis of the metabolic syndrome and published updated criteria which are the most widely used now ${ }^{136}$. Central (abdominal) obesity is used as a cornerstone for the diagnosis of the metabolic syndrome since central obesity has been acknowledged as a causative factor ${ }^{137}$. Central obesity is easily measured by using waist circumference and is independently associated with each of the other metabolic syndrome components including the consequences of insulin resistance ${ }^{138-140}$. Although insulin resistance is a prerequisite risk factor within the guidelines, insulin resistance is not an essential requirement for the diagnosis of metabolic syndrome, mostly because of the difficulties in assessing it in day-to-day clinical practice. Measuring waist circumference follows gender and ethical group specific cut-offs. For European men a waist circumference of $\geq 94 \mathrm{~cm}$ and for European women a cut off of $\geq 80 \mathrm{~cm}$ is used to define central obesity ${ }^{136}$. Dyslipidaemia describes the combination of low levels of high-density-lipoprotein $(\mathrm{HDL})$ along with raised triglycerides, all of which are atherogenic ${ }^{141}$. In addition, both disorders are commonly observed in patients with type II diabetes and are associated with coronary heart disease ${ }^{142,143}$. Increased levels of systolic or diastolic blood pressure fulfil the criteria on the definition of the metabolic syndrome (Table 1). 
Table 1. Definition of the metabolic syndrome according to the IDF

\begin{tabular}{|l|l|}
\hline Definition of the metabolic syndrome (International Diabetes Federation; IDF) \\
\hline $\begin{array}{l}\text { For a person to be defined as having the metabolic syndrome they must have: } \\
\text { Central obesity (defined as waist circumference* with ethnicity specific values) } \\
\text { plus any two of the following four factors: }\end{array}$ \\
\hline raised triglycerides & $\begin{array}{l}\geq 150 \mathrm{mg} / \mathrm{d}(1.7 \mathrm{mmol} / \mathrm{L}) \\
\text { or specific treatment for this lipid abnormality }\end{array}$ \\
\hline $\begin{array}{l}\text { reduced HDL } \\
\text { cholesterol }\end{array}$ & $\begin{array}{l}<40 \mathrm{mg} / \mathrm{dL}(1.03 \mathrm{mmol} / \mathrm{L}) \text { in males } \\
\text { or specific treatment for this lipid abnormality }\end{array}$ \\
\hline $\begin{array}{l}\text { raised blood } \\
\text { pressure }\end{array}$ & $\begin{array}{l}\text { systolic blood pressure } \geq 130 \text { or diastolic blood pressure } \geq 85 \mathrm{mmHg} \\
\text { or treatment of previously diagnosed hypertension }\end{array}$ \\
\hline $\begin{array}{l}\geq 100 \mathrm{mg} / \mathrm{dl}(5.6 \mathrm{mmol} / \mathrm{L}), \\
\text { raised fasting } \\
\text { plasma glucose }\end{array}$ & $\begin{array}{l}\text { or previously diagnosed type } \mathrm{II} \text { diabetes } \\
\text { is not necessary to define presence of the syndrome. } 5.6 \mathrm{mmol} / \mathrm{L} \text { or } 100 \mathrm{mg} / \mathrm{dL}, \text { OGT is strongly recommended but }\end{array}$ \\
\hline
\end{tabular}

* If BMl is $>30 \mathrm{~kg} / \mathrm{m}^{2}$ central obesity can be assumed and waist circumference does not need to be measured.

It is estimated that around $25 \%$ of the world's adult population suffer from the metabolic syndrome which is associated with the global epidemic of obesity and type II diabetes ${ }^{136}$. Having the metabolic syndrome is linked to an increased risk of cardiovascular mortality and an increased incidence of cardiovascular disease even among populations initially free of type II diabetes and cardiovascular diseas $\mathrm{e}^{144}$. In addition, the risk of developing type II diabetes is fivefold greater in people with metabolic syndrome ${ }^{145}$. The IDF mentioned the fact that criteria used in Asian and other populations could be different from those used in the west. Indeed, the effect of ethnic origin is reflected in a comparison of the prevalence of metabolic syndrome within U.S. adults ${ }^{146}$. Interestingly it has been established that the prevalence of the metabolic syndrome is highly-age dependent. Several reports from different geographical areas such as Iran and France ${ }^{147}$ as well as from the U.S. ${ }^{146}$ clearly show a prevalence of less than 10\% for both men and women in the below 30 years age group, rising up to 40\% for those aged 60-69 years. Until recently the metabolic syndrome and type II diabetes were regarded as diseases of older age. However, rates of obesity are increasing in the younger age groups and are also evident in childhood ${ }^{148}$.

It is well recognised that multi-morbidity - two or more chronic morbidities becomes more common with age ${ }^{149}$ and is associated with a reduced functional status ${ }^{150,151}$, high mortality 152 , and an increased use of health care utilities ${ }^{153,154}$. Interestingly, more than half of people with multi-morbidity are younger than 65 years $^{155}$. As COPD is a disease of older age an interrelationship between 
COPD and the metabolic syndrome deserves more research. When starting this $\mathrm{PhD}$ only one small sized sample study investigating the prevalence of the metabolic syndrome in COPD and healthy subjects was available ${ }^{69}$. The authors reported a prevalence of around $4 \%$ in a sample of 38 COPD patients using the NCEP/ ATP III criteria ${ }^{69}$. Based on these findings, but also due to the increased risk of developing type II diabetes ${ }^{156}$ and cardiovascular disease in COPD ${ }^{157}$ the metabolic syndrome was incorporated into the panel of 'diagnostic components of the chronic systemic inflammatory syndrome'158. This panel has been proposed as an overarching approach to diagnose, assess, and manage COPD and its frequent co-morbidities.

In conclusion the metabolic syndrome seems highly prevalent in patients with COPD. Therefore further studies are needed to investigate the prevalence of the metabolic syndrome compared to healthy subjects, as well as to elucidate possible contributions of the syndrome on patient related outcomes such as functional exercise intolerance or disease-specific health status. 


\section{Research questions}

- Are obese COPD patients more likely to have highly elevated CRP levels compared to normal weight COPD patients?

- In COPD is abdominal fat mass, measured by DXA-scan, associated with plasma CRP levels?

- Is there a positive association between host related factors such as age, gender, and body composition with different systemic inflammatory biomarkers in COPD? And furthermore, is there an interrelationship between these systemic inflammatory biomarkers including CRP, fibrinogen and TNFa and its soluble receptors $\mathrm{R} 1$ and $\mathrm{R} 2$ ?

Is there an association between circulating adipokines and systemic inflammatory biomarkers in COPD compared to healthy subjects?

Are there gender related differences in the adipokine metabolism in relation to systemic low-grade inflammation in COPD?

Is Nordic walking a feasible training method and is Nordic Walking able to increase the daily physical activity pattern in patients with COPD?

Is the daily physical activity pattern comparable in patients with COPD from two different origins as Europe and South America?

Is the prevalence of the metabolic syndrome in COPD comparable to healthy subjects and does the metabolic syndrome contributes to patients related outcomes such as functional exercise intolerance, disease-specific health status and/ or co-morbidity profile in COPD? 


\section{Outline of the thesis}

Chapter 2 focuses on an overweight and obese BMI in patients with COPD and on the likelihood of having increased systemic inflammatory biomarkers in particular CRP compared to normal weight COPD patients.

- Chapter 3 describes the relevance of abdominal fat mass in COPD and a possible link with the presence of a state of low-grade systemic inflammation.

Chapter 4 focuses on the influence of host related factors including age, gender, and body composition on different systemic inflammatory biomarkers. Moreover the interrelationship between these inflammatory biomarkers will be described.

Chapter 5 aims to compare plasma levels of adipokines like leptin and adiponectin with systemic inflammatory biomarkers such as CRP, IL-6, TNF $\alpha$ in COPD and healthy subjects.

Chapter 6 focuses on the complex relationship between adipokine metabolism and systemic low-grade inflammation in male and female COPD patients and healthy subjects.

Chapter 7 determines the feasibility of Nordic Walking in COPD patients at different disease stages and the long-term effect of Nordic Walking on patients' daily physical activity pattern.

Chapter 8 compares the daily physical activity pattern of patients with COPD from Brazil and Austria.

Chapter 9 focuses on the prevalence and a possible impact of the metabolic syndrome in COPD patients on patient related outcome parameters such as functional exercise capacity, disease-specific health status and co-morbidity profile. 


\section{References}

1. Global Strategy for Diagnosis, Management, and Prevention of COPD (GOLD). 2011. (Accessed at http://www.goldcopd.org/.)

2. Barnes PJ, Jeffrey M, Drazen S, Rennard I, Thomson NC. Asthma and Copd: Basic Mechanisms and Clinical Management. Second Edition 2009 ed: Elsevier LtD.; 2009.

3. Mathers CD, Loncar D. Projections of global mortality and burden of disease from 2002 to 2030 . PLoS Med 2006:3:e442.

4. Mannino DM. COPD: epidemiology, prevalence, morbidity and mortality, and disease heterogeneity. Chest 2002:121:121S-6S.

5. Trupin L, Earnest G, San Pedro M, et al. The occupational burden of chronic obstructive pulmonary disease. Eur Respir J 2003;22:462-9.

6. Doll R, Peto R, Boreham J, Sutherland I. Mortality in relation to smoking: 50 years' observations on male British doctors. Bmj 2004;328:1519.

7. Shaheen SO, Barker DJ, Holgate ST. Do lower respiratory tract infections in early childhood cause chronic obstructive pulmonary disease? Am J Respir Crit Care Med 1995;151:1649-51; discussion 51-2.

8. Lomas DA, Silverman EK. The genetics of chronic obstructive pulmonary disease. Respir Res 2001;2:20-6.

9. Romieu I, Trenga C. Diet and obstructive lung diseases. Epidemiol Rev 2001;23:268-87.

10. Sparrow D, O'Connor G, Weiss ST. The relation of airways responsiveness and atopy to the development of chronic obstructive lung disease. Epidemiol Rev 1988;10:29-47.

11. Loddenkemper R, Gibson GJ, Sibille Y. The burden of lung disease in Europe: why a European White Book on lung disease? Eur Respir J 2003;22:869.

12. Lopez AD, Shibuya K, Rao C, et al. Chronic obstructive pulmonary disease: current burden and future projections. Eur Respir J 2006;27:397-412.

13. Nishimura K, Izumi T, Tsukino M, Oga T. Dyspnea is a better predictor of 5-year survival than airway obstruction in patients with COPD. Chest 2002;121:1434-40.

14. Jones PW, Harding G, Berry P, Wiklund I, Chen WH, Kline Leidy N. Development and first validation of the COPD Assessment Test. Eur Respir J 2009;34:648-54.

15. Dodd JW, Hogg L, Nolan J, et al. The COPD assessment test (CAT): response to pulmonary rehabilitation. A multicentre, prospective study. Thorax 2011;66:425-9.

16. Rodriguez-Roisin R. Toward a consensus definition for COPD exacerbations. Chest 2000;117:398S-401S.

17. Puhan M, Scharplatz M, Troosters T, Walters EH, Steurer J. Pulmonary rehabilitation following exacerbations of chronic obstructive pulmonary disease. Cochrane Database Syst Rev 2009:CD005305.

18. Hurst JR, Vestbo J, Anzueto A, et al. Susceptibility to exacerbation in chronic obstructive pulmonary disease. N Engl J Med 2010;363:1128-38.

19. Celsi AC. Medicinae; 1831.

20. Rather LJ. Disturbance of function (functio laesa): the legendary fifth cardinal sign of inflammation, added by Galen to the four cardinal signs of Celsus. Bull N Y Acad Med 1971;47:303-22.

21. Abbas AK, Janeway CA, Jr. Immunology: improving on nature in the twenty-first century. Cell 2000;100:12938.

22. Laskin DL, Sunil VR, Gardner CR, Laskin JD. Macrophages and tissue injury: agents of defense or destruction? Annu Rev Pharmacol Toxicol 2011;51:267-88.

23. Jain S, Gautam V, Naseem S. Acute-phase proteins: As diagnostic tool. J Pharm Bioallied Sci 2011;3:118-27.

24. Pepys MB, Baltz ML. Acute phase proteins with special reference to $C$-reactive protein and related proteins (pentaxins) and serum amyloid A protein. Adv Immunol 1983;34:141-212.

25. Pepys MB, Hirschfield GM. C-reactive protein: a critical update. J Clin Invest 2003;111:1805-12.

26. Schols AM, Buurman WA, Staal van den Brekel AJ, Dentener MA, Wouters EF. Evidence for a relation between metabolic derangements and increased levels of inflammatory mediators in a subgroup of patients with chronic obstructive pulmonary disease. Thorax 1996;51:819-24.

27. Di Francia M, Barbier D, Mege JL, Orehek J. Tumor necrosis factor-alpha levels and weight loss in chronic obstructive pulmonary disease. Am J Respir Crit Care Med 1994;150:1453-5.

28. Gan WQ, Man SF, Senthilselvan A, Sin DD. Association between chronic obstructive pulmonary disease and systemic inflammation: a systematic review and a meta-analysis. Thorax 2004:59:574-80.

29. Franciosi $L G$, Page CP, Celli BR, et al. Markers of disease severity in chronic obstructive pulmonary disease. Pulm Pharmacol Ther 2006;19:189-99. 
30. Keatings VM, Barnes PJ. Granulocyte activation markers in induced sputum: comparison between chronic obstructive pulmonary disease, asthma, and normal subjects. Am J Respir Crit Care Med 1997;155:449-53.

31. Saetta M, Di Stefano A, Maestrelli P, et al. Activated T-lymphocytes and macrophages in bronchial mucosa of subjects with chronic bronchitis. Am Rev Respir Dis 1993;147:301-6.

32. Profita M, Giorgi RD, Sala A, et al. Muscarinic receptors, leukotriene B4 production and neutrophilic inflammation in COPD patients. Allergy 2005;60:1361-9.

33. Chung KF. Inflammatory mediators in chronic obstructive pulmonary disease. Curr Drug Targets Inflamm Allergy 2005;4:619-25.

34. Keatings VM, Collins PD, Scott DM, Barnes PJ. Differences in interleukin-8 and tumor necrosis factor-alpha in induced sputum from patients with chronic obstructive pulmonary disease or asthma. Am J Respir Crit Care Med 1996;153:530-4.

35. Smith RM, Traber LD, Traber DL, Spragg RG. Pulmonary deposition and clearance of aerosolized alpha1-proteinase inhibitor administered to dogs and to sheep. J Clin Invest 1989;84:1145-54.

36. Vogelmeier C, Buhl R, Hoyt RF, et al. Aerosolization of recombinant SLPI to augment antineutrophil elastase protection of pulmonary epithelium. J Appl Physiol 1990;69:1843-8.

37. Hubbard RC, Brantly ML, Sellers SE, Mitchell ME, Crystal RG. Anti-neutrophil-elastase defenses of the lower respiratory tract in alpha 1-antitrypsin deficiency directly augmented with an aerosol of alpha 1-antitrypsin. Ann Intern Med 1989;111:206-12.

38. Lohmann-Matthes ML, Steinmuller C, Franke-Ullmann G. Pulmonary macrophages. Eur Respir J 1994;7:1678-89.

39. van Eeden SF, Tan WC, Suwa T, et al. Cytokines involved in the systemic inflammatory response induced by exposure to particulate matter air pollutants (PM(10)). Am J Respir Crit Care Med 2001;164:826-30.

40. Nemmar A, Hoylaerts MF, Hoet PH, Nemery B. Possible mechanisms of the cardiovascular effects of inhaled particles: systemic translocation and prothrombotic effects. Toxicol Lett 2004;149:243-53.

41. Sapey E, Bayley D, Ahmad A, Newbold P, Snell N, Stockley RA. Inter-relationships between inflammatory markers in patients with stable COPD with bronchitis: intra-patient and inter-patient variability. Thorax 2008;63:493-9.

42. Eid AA, lonescu AA, Nixon LS, et al. Inflammatory response and body composition in chronic obstructive pulmonary disease. Am J Respir Crit Care Med 2001;164:1414-8.

43. Vernooy JH, Kucukaycan M, Jacobs JA, et al. Local and systemic inflammation in patients with chronic obstructive pulmonary disease: soluble tumor necrosis factor receptors are increased in sputum. Am J Respir Crit Care Med 2002;166:1218-24.

44. Sapey E, Ahmad A, Bayley D, et al. Imbalances between interleukin-1 and tumor necrosis factor agonists and antagonists in stable COPD.J Clin Immunol 2009;29:508-16.

45. Cowburn AS, Condliffe AM, Farahi N, Summers C, Chilvers ER. Advances in neutrophil biology: clinical implications. Chest 2008;134:606-12.

46. Hogg JC, Chu F, Utokaparch S, et al. The nature of small-airway obstruction in chronic obstructive pulmonary disease. N Engl J Med 2004;350:2645-53.

47. Barnes PJ, Chowdhury B, Kharitonov SA, et al. Pulmonary biomarkers in chronic obstructive pulmonary disease. Am J Respir Crit Care Med 2006;174:6-14.

48. Singh D, Edwards L, Tal-Singer R, Rennard S. Sputum neutrophils as a biomarker in COPD: findings from the ECLIPSE study. Respir Res 2010;11:77.

49. Rusznak C, Mills PR, Devalia JL, Sapsford RJ, Davies RJ, Lozewicz S. Effect of cigarette smoke on the permeability and IL-1beta and sICAM-1 release from cultured human bronchial epithelial cells of neversmokers, smokers, and patients with chronic obstructive pulmonary disease. Am J Respir Cell Mol Biol 2000;23:530-6.

50. The Health Consequences of Smoking: Cardiovascular Diseases: A Report of the Surgeon General. In. Washington, DC: US Government Printing Office; 1989.

51. Goldsmith CA, Imrich A, Danaee H, Ning YY, Kobzik L. Analysis of air pollution particulate-mediated oxidant stress in alveolar macrophages. J Toxicol Environ Health A 1998;54:529-45.

52. Becker S, Soukup JM, Gilmour MI, Devlin RB. Stimulation of human and rat alveolar macrophages by urban air particulates: effects on oxidant radical generation and cytokine production. Toxicol Appl Pharmacol 1996;141:637-48.

53. Terashima T, Wiggs B, English D, Hogg JC, van Eeden SF. Phagocytosis of small carbon particles (PM10) by alveolar macrophages stimulates the release of polymorphonuclear leukocytes from bone marrow. Am J Respir Crit Care Med 1997;155:1441-7. 
54. Tan WC, Qiu D, Liam BL, et al. The human bone marrow response to acute air pollution caused by forest fires. Am J Respir Crit Care Med 2000;161:1213-7.

55. Takabatake N, Nakamura $\mathrm{H}$, Abe $\mathrm{S}$, et al. The relationship between chronic hypoxemia and activation of the tumor necrosis factor-alpha system in patients with chronic obstructive pulmonary disease. Am J Respir Crit Care Med 2000;161:1179-84.

56. Couillard A, Maltais F, Saey D, et al. Exercise-induced quadriceps oxidative stress and peripheral muscle dysfunction in patients with chronic obstructive pulmonary disease. Am J Respir Crit Care Med 2003:167:1664-9.

57. Koechlin C, Couillard A, Cristol JP, et al. Does systemic inflammation trigger local exercise-induced oxidative stress in COPD? Eur Respir J 2004;23:538-44.

58. Siiteri PK. Adipose tissue as a source of hormones. Am J Clin Nutr 1987;45:277-82.

59. Flier JS, Cook KS, Usher P, Spiegelman BM. Severely impaired adipsin expression in genetic and acquired obesity. Science 1987;237:405-8.

60. Zhang Y, Proenca R, Maffei M, Barone M, Leopold L, Friedman JM. Positional cloning of the mouse obese gene and its human homologue. Nature 1994;372:425-32.

61. Ahima RS, Flier JS. Adipose tissue as an endocrine organ. Trends Endocrinol Metab 2000;11:327-32.

62. Fain JN, Madan AK, Hiler ML, Cheema P, Bahouth SW. Comparison of the release of adipokines by adipose tissue, adipose tissue matrix, and adipocytes from visceral and subcutaneous abdominal adipose tissues of obese humans. Endocrinology 2004;145:2273-82.

63. Wellen KE, Hotamisligil GS. Obesity-induced inflammatory changes in adipose tissue. J Clin Invest 2003:112:1785-8.

64. Cianflone K, Xia Z, Chen LY. Critical review of acylation-stimulating protein physiology in humans and rodents. Biochim Biophys Acta 2003;1609:127-43.

65. Banerjee RR, Lazar MA. Resistin: molecular history and prognosis. J Mol Med (Berl) 2003;81:218-26.

66. Fernandez-Real JM, Ricart W. Insulin resistance and chronic cardiovascular inflammatory syndrome. Endocr Rev 2003;24:278-301

67. Yudkin JS, Kumari M, Humphries SE, Mohamed-Ali V. Inflammation, obesity, stress and coronary heart disease: is interleukin-6 the link? Atherosclerosis 2000;148:209-14.

68. Pou KM, Massaro JM, Hoffmann U, et al. Visceral and subcutaneous adipose tissue volumes are cross-sectionally related to markers of inflammation and oxidative stress: the Framingham Heart Study. Circulation 2007;116:1234-41.

69. Marquis K, Maltais F, Duguay V, et al. The metabolic syndrome in patients with chronic obstructive pulmonary disease. J Cardiopulm Rehabil 2005;25:226-32; discussion 33-4.

70. WorldHeathOrganisation. Obesity and Overweight. FactsheetNo311 2012.

71. Rovio S, Kareholt I, Helkala EL, et al. Leisure-time physical activity at midlife and the risk of dementia and Alzheimer's disease. Lancet Neurol 2005;4:705-11.

72. Paffenbarger RS, Jr., Lee IM, Leung R. Physical activity and personal characteristics associated with depression and suicide in American college men. Acta Psychiatr Scand Suppl 1994;377:16-22.

73. Tuomilehto J, Lindstrom J, Eriksson JG, et al. Prevention of type 2 diabetes mellitus by changes in lifestyle among subjects with impaired glucose tolerance. N Engl J Med 2001;344:1343-50.

74. Nocon M, Hiemann T, Muller-Riemenschneider F, Thalau F, Roll S, Willich SN. Association of physical activity with all-cause and cardiovascular mortality: a systematic review and meta-analysis. Eur J Cardiovasc Prev Rehabil 2008;15:239-46.

75. Wolin KY, Yan Y, Colditz GA, Lee IM. Physical activity and colon cancer prevention: a meta-analysis. Br J Cancer 2009;100:611-6.

76. Monninkhof EM, Elias SG, Vlems FA, et al. Physical activity and breast cancer: a systematic review. Epidemiology 2007;18:137-57.

77. Petersen AM, Pedersen BK. The anti-inflammatory effect of exercise. J Appl Physiol 2005;98:1154-62.

78. Fischer CP, Berntsen A, Perstrup LB, Eskildsen P, Pedersen BK. Plasma levels of interleukin-6 and Creactive protein are associated with physical inactivity independent of obesity. Scand J Med Sci Sports 2007;17:580-7.

79. Jacobs DR, Jr., Ainsworth BE, Hartman TJ, Leon AS. A simultaneous evaluation of 10 commonly used physical activity questionnaires. Med Sci Sports Exerc 1993;25:81-91.

80. Pitta F, Troosters T, Spruit MA, Decramer M, Gosselink R. Activity monitoring for assessment of physical activities in daily life in patients with chronic obstructive pulmonary disease. Arch Phys Med Rehabil 2005;86:1979-85 
81. Pitta F, Troosters T, Spruit MA, Probst VS, Decramer M, Gosselink R. Characteristics of physical activities in daily life in chronic obstructive pulmonary disease. Am J Respir Crit Care Med 2005;171:972-7.

82. Nici L, Donner C, Wouters E, et al. American Thoracic Society/European Respiratory Society statement on pulmonary rehabilitation. Am J Respir Crit Care Med 2006;173:1390-413.

83. Lacasse $Y$, Goldstein R, Lasserson TJ, Martin S. Pulmonary rehabilitation for chronic obstructive pulmonary disease. Cochrane Database Syst Rev 2006:CD003793.

84. Baarends EM, Schols AM, Mostert R, Wouters EF. Peak exercise response in relation to tissue depletion in patients with chronic obstructive pulmonary disease. Eur Respir J 1997;10:2807-13.

85. Bernard S, LeBlanc P, Whittom F, et al. Peripheral muscle weakness in patients with chronic obstructive pulmonary disease. Am J Respir Crit Care Med 1998;158:629-34.

86. Mostert R, Goris A, Weling-Scheepers C, Wouters EF, Schols AM. Tissue depletion and health related quality of life in patients with chronic obstructive pulmonary disease. Respir Med 2000;94:859-67.

87. Schols AM, Broekhuizen R, Weling-Scheepers CA, Wouters EF. Body composition and mortality in chronic obstructive pulmonary disease. Am J Clin Nutr 2005;82:53-9.

88. Vestbo J. Clinical assessment, staging, and epidemiology of chronic obstructive pulmonary disease exacerbations. Proc Am Thorac Soc 2006;3:252-6.

89. Vermeeren MA, Creutzberg EC, Schols AM, et al. Prevalence of nutritional depletion in a large out-patient population of patients with COPD. Respir Med 2006;100:1349-55.

90. Alwan AD, Galea G, Stuckler D. Development at risk: addressing noncommunicable diseases at the United Nations high-level meeting. Bull World Health Organ 2011;89:546-A.

91. Whitlock G, Lewington S, Sherliker P, et al. Body-mass index and cause-specific mortality in 900000 adults: collaborative analyses of 57 prospective studies. Lancet 2009;373:1083-96.

92. Berrington de Gonzalez A, Hartge P, Cerhan JR, et al. Body-mass index and mortality among 1.46 million white adults. N Engl J Med 2010;363:2211-9.

93. Steuten LM, Creutzberg EC, Vrijhoef HJ, Wouters EF. COPD as a multicomponent disease: inventory of dyspnoea, underweight, obesity and fat free mass depletion in primary care. Prim Care Respir J 2006;15:84-91.

94. Eisner MD, Blanc PD, Sidney S, et al. Body composition and functional limitation in COPD. Respir Res 2007:8:7.

95. BehaviouralRiskFactorSurveillanceSystem. www.cdc.gov/BRFSS/. 2008.

96. Guerra S, Sherrill DL, Bobadilla A, Martinez FD, Barbee RA. The relation of body mass index to asthma, chronic bronchitis, and emphysema. Chest 2002;122:1256-63.

97. Poulain $M$, Doucet $M$, Drapeau $\mathrm{V}$, et al. Metabolic and inflammatory profile in obese patients with chronic obstructive pulmonary disease. Chron Respir Dis 2008;5:35-41.

98. Landbo C, Prescott E, Lange P, Vestbo J, Almdal TP. Prognostic value of nutritional status in chronic obstructive pulmonary disease. Am J Respir Crit Care Med 1999;160:1856-61.

99. Chailleux E, Laaban JP, Veale D. Prognostic value of nutritional depletion in patients with COPD treated by long-term oxygen therapy: data from the ANTADIR observatory. Chest 2003;123:1460-6.

100. Manson JE, Willett WC, Stampfer MJ, et al. Body weight and mortality among women. N Engl J Med 1995;333:677-85.

101. Vandenbroucke JP, Mauritz BJ, de Bruin A, Verheesen JH, van der Heide-Wessel C, van der Heide RM. Weight, smoking, and mortality. Jama 1984;252:2859-60.

102. Kalantar-Zadeh K, Horwich TB, Oreopoulos A, et al. Risk factor paradox in wasting diseases. Curr Opin Clin Nutr Metab Care 2007;10:433-42.

103. Bouchard DR, Dionne IJ, Brochu M. Sarcopenic/obesity and physical capacity in older men and women: data from the Nutrition as a Determinant of Successful Aging (NuAge)-the Quebec longitudinal Study. Obesity (Silver Spring) 2009;17:2082-8.

104. Roubenoff R. Sarcopenic obesity: the confluence of two epidemics. Obes Res 2004;12:887-8.

105. Walrand S, Guillet C, Salles J, Cano N, Boirie Y. Physiopathological mechanism of sarcopenia. Clin Geriatr Med 2011;27:365-85.

106. Zamboni M, Mazzali G, Fantin F, Rossi A, Di Francesco V. Sarcopenic obesity: a new category of obesity in the elderly. Nutr Metab Cardiovasc Dis 2008;18:388-95.

107. Kyle UG, Genton L, Slosman DO, Pichard C. Fat-free and fat mass percentiles in 5225 healthy subjects aged 15 to 98 years. Nutrition 2001;17:534-41.

108. Coin A, Sergi G, Minicuci N, et al. Fat-free mass and fat mass reference values by dual-energy $X$-ray absorptiometry (DEXA) in a 20-80 year-old Italian population. Clin Nutr 2008;27:87-94. 
109. Fantuzzi G. Adipose tissue, adipokines, and inflammation. J Allergy Clin Immunol 2005;115:911-9; quiz 20.

110. Zabeau L, Lavens D, Peelman F, Eyckerman S, Vandekerckhove J, Tavernier J. The ins and outs of leptin receptor activation. FEBS Lett 2003;546:45-50.

111. Grunfeld C, Zhao C, Fuller J, et al. Endotoxin and cytokines induce expression of leptin, the ob gene product, in hamsters. J Clin Invest 1996;97:2152-7.

112. Friedman JM. The function of leptin in nutrition, weight, and physiology. Nutr Rev 2002;60:S1-14; discussion S68-84, 5-7.

113. Margetic S, Gazzola C, Pegg GG, Hill RA. Leptin: a review of its peripheral actions and interactions. Int J Obes Relat Metab Disord 2002;26:1407-33.

114. Soderberg S, Ahren B, Jansson JH, et al. Leptin is associated with increased risk of myocardial infarction. J Intern Med 1999;246:409-18.

115. Soderberg S, Ahren B, Stegmayr B, et al. Leptin is a risk marker for first-ever hemorrhagic stroke in a population-based cohort. Stroke 1999;30:328-37.

116. Abdullah SM, Khera A, Leonard D, et al. Sex differences in the association between leptin and CRP: results from the Dallas Heart Study. Atherosclerosis 2007;195:404-10.

117. Takabatake N, Nakamura H, Abe S, et al. Circulating leptin in patients with chronic obstructive pulmonary disease. Am J Respir Crit Care Med 1999;159:1215-9.

118. Ouchi N, Kihara S, Funahashi T, Matsuzawa Y, Walsh K. Obesity, adiponectin and vascular inflammatory disease. Curr Opin Lipidol 2003;14:561-6.

119. Yamauchi T, Kamon J, Ito Y, et al. Cloning of adiponectin receptors that mediate antidiabetic metabolic effects. Nature 2003;423:762-9.

120. Lago F, Dieguez C, Gomez-Reino J, Gualillo O. Adipokines as emerging mediators of immune response and inflammation. Nat Clin Pract Rheumatol 2007;3:716-24.

121. Diez JJ, Iglesias P. The role of the novel adipocyte-derived hormone adiponectin in human disease. Eur J Endocrinol 2003;148:293-300.

122. Ahonen TM, Kautiainen HJ, Keinanen-Kiukaanniemi SM, Kumpusalo EA, Vanhala MJ. Gender difference among smoking, adiponectin, and high-sensitivity C-reactive protein. Am J Prev Med 2008;35:598-601.

123. Ouchi N, Kihara S, Funahashi T, et al. Reciprocal association of C-reactive protein with adiponectin in blood stream and adipose tissue. Circulation 2003;107:671-4.

124. Sattar N, Wannamethee G, Sarwar N, et al. Adiponectin and coronary heart disease: a prospective study and meta-analysis. Circulation 2006;114:623-9.

125. Iwashima Y, Katsuya T, Ishikawa K, et al. Hypoadiponectinemia is an independent risk factor for hypertension. Hypertension 2004;43:1318-23.

126. Pischon T, Girman C], Hotamisligil GS, Rifai N, Hu FB, Rimm EB. Plasma adiponectin levels and risk of myocardial infarction in men. Jama 2004;291:1730-7.

127. Cavusoglu E, Ruwende C, Chopra V, et al. Adiponectin is an independent predictor of all-cause mortality, cardiac mortality, and myocardial infarction in patients presenting with chest pain. Eur Heart J 2006;27:2300-9.

128. Kistorp C, Faber J, Galatius S, et al. Plasma adiponectin, body mass index, and mortality in patients with chronic heart failure. Circulation 2005;112:1756-62.

129. Tomoda K, Yoshikawa M, Itoh T, et al. Elevated circulating plasma adiponectin in underweight patients with COPD. Chest 2007;132:135-40.

130. Haller H. [Epidermiology and associated risk factors of hyperlipoproteinemia]. Z Gesamte Inn Med 1977;32:124-8.

131. DeFronzo RA, Ferrannini E. Insulin resistance. A multifaceted syndrome responsible for NIDDM, obesity, hypertension, dyslipidemia, and atherosclerotic cardiovascular disease. Diabetes Care 1991;14:173-94.

132. Reaven GM. Banting lecture 1988. Role of insulin resistance in human disease. Diabetes 1988;37:1595-607.

133. Kaplan NM. The deadly quartet. Upper-body obesity, glucose intolerance, hypertriglyceridemia, and hypertension. Arch Intern Med 1989;149:1514-20.

134. Jensen MD, Caruso M, Heiling V, Miles JM. Insulin regulation of lipolysis in nondiabetic and IDDM subjects. Diabetes 1989;38:1595-601.

135. Eckel RH. Lipoprotein lipase. A multifunctional enzyme relevant to common metabolic diseases. $N$ Engl J Med 1989;320:1060-8

136. Alberti KG, Zimmet P, Shaw J. Metabolic syndrome--a new world-wide definition. A Consensus Statement from the International Diabetes Federation. Diabet Med 2006;23:469-80. 
137. Anderson PJ, Critchley JA, Chan JC, et al. Factor analysis of the metabolic syndrome: obesity vs insulin resistance as the central abnormality. Int J Obes Relat Metab Disord 2001;25:1782-8.

138. Nakamura T, Tokunaga $K$, Shimomura I, et al. Contribution of visceral fat accumulation to the development of coronary artery disease in non-obese men. Atherosclerosis 1994;107:239-46.

139. Bonora E, Kiechl S, Willeit J, et al. Prevalence of insulin resistance in metabolic disorders: the Bruneck Study. Diabetes 1998;47:1643-9.

140. Nesto RW. The relation of insulin resistance syndromes to risk of cardiovascular disease. Rev Cardiovasc Med 2003;4 Suppl 6:S11-8.

141. Robins SJ, Rubins HB, Faas FH, et al. Insulin resistance and cardiovascular events with low HDL cholesterol: the Veterans Affairs HDL Intervention Trial (VA-HIT). Diabetes Care 2003;26:1513-7.

142. Steinmetz A, Fenselau S, Schrezenmeir J. Treatment of dyslipoproteinemia in the metabolic syndrome. Exp Clin Endocrinol Diabetes 2001;109:S548-59.

143. Robins SJ, Collins D, Wittes JT, et al. Relation of gemfibrozil treatment and lipid levels with major coronary events: VA-HIT: a randomized controlled trial. Jama 2001;285:1585-91.

144. Galassi A, Reynolds K, He J. Metabolic syndrome and risk of cardiovascular disease: a meta-analysis. Am J Med 2006;119:812-9.

145. Stern MP, Williams K, Gonzalez-Villalpando C, Hunt KJ, Haffner SM. Does the metabolic syndrome improve identification of individuals at risk of type 2 diabetes and/or cardiovascular disease? Diabetes Care 2004;27:2676-81.

146. Ford ES, Giles WH, Dietz WH. Prevalence of the metabolic syndrome among US adults: findings from the third National Health and Nutrition Examination Survey. Jama 2002;287:356-9.

147. Azizi F, Salehi P, Etemadi A, Zahedi-Asl S. Prevalence of metabolic syndrome in an urban population: Tehran Lipid and Glucose Study. Diabetes Res Clin Pract 2003;61:29-37.

148. Sinha R, Fisch G, Teague B, et al. Prevalence of impaired glucose tolerance among children and adolescents with marked obesity. N Engl J Med 2002;346:802-10.

149. van den Akker M, Buntinx F, Metsemakers JF, Roos S, Knottnerus JA. Multimorbidity in general practice: prevalence, incidence, and determinants of co-occurring chronic and recurrent diseases. J Clin Epidemiol 1998;51:367-75.

150. Kadam UT, Croft PR. Clinical multimorbidity and physical function in older adults: a record and health status linkage study in general practice. Fam Pract 2007;24:412-9.

151. Fortin M, Lapointe L, Hudon C, Vanasse A, Ntetu AL, Maltais D. Multimorbidity and quality of life in primary care: a systematic review. Health Qual Life Outcomes 2004;2:51.

152. Gijsen R, Hoeymans N, Schellevis FG, Ruwaard D, Satariano WA, van den Bos GA. Causes and consequences of comorbidity: a review. J Clin Epidemiol 2001;54:661-74.

153. Wolff JL, Starfield B, Anderson G. Prevalence, expenditures, and complications of multiple chronic conditions in the elderly. Arch Intern Med 2002;162:2269-76.

154. Salisbury C, Johnson L, Purdy S, Valderas JM, Montgomery AA. Epidemiology and impact of multimorbidity in primary care: a retrospective cohort study. Br J Gen Pract 2011;61:e12-21.

155. Barnett K, Mercer SW, Norbury M, Watt G, Wyke S, Guthrie B. Epidemiology of multimorbidity and implications for health care, research, and medical education: a cross-sectional study. Lancet 2012;380:37-43.

156. Rana JS, Mittleman MA, Sheikh J, et al. Chronic obstructive pulmonary disease, asthma, and risk of type 2 diabetes in women. Diabetes Care 2004;27:2478-84.

157. Sin DD, Man SF. Why are patients with chronic obstructive pulmonary disease at increased risk of cardiovascular diseases? The potential role of systemic inflammation in chronic obstructive pulmonary disease. Circulation 2003;107:1514-9.

158. Fabbri LM, Rabe KF. From COPD to chronic systemic inflammatory syndrome? Lancet 2007;370:797-9. 


\section{CHAPTER 2}

\section{Highly elevated C-reactive protein levels in obese patients with COPD: a fat chance?}





\section{Abstract}

\section{Background and Aims}

Chronic obstructive pulmonary disease (COPD) has been recognized as a multi component disease. Currently, limited data are available about determining factors of systemic inflammation in COPD, in particular C-reactive protein (CRP). The aim was to determine whether and to what extent COPD patients with a low, high or obese body mass index (BMI) are more likely to have elevated CRP levels compared to normal-weight COPD patients. Furthermore, we aimed to explore the effects of clinical relevant covariates on the likelihood of having elevated CRP levels.

\section{Methods}

In 628 elderly patients with moderate to severe COPD (61\% male), lung function and $\mathrm{BMI}$ were assessed before entering pulmonary rehabilitation. In addition, blood was collected in the fasted state. High sensitive C-reactive protein (CRP) was classified into: normal, $\leq 3$; elevated, $>3-5$ and highly elevated, $>5 \mathrm{mg} / \mathrm{l}$.

\section{Results}

Obese COPD patients (BMI $\geq 30 \mathrm{~kg} / \mathrm{m}^{2}$ ) were 3.3 times more likely $(95 \% \mathrm{Cl}$, 1.5-7.0, $\mathrm{p}=0.002$ ) to have highly elevated CRP levels compared to normal weight (BMI 25-29.9 kg/m²) COPD patients after taking clinical relevant confounders into account. In contrast, COPD patients with a low BMI $\left(<21 \mathrm{~kg} / \mathrm{m}^{2}\right)$ were 2 times less likely $(\mathrm{OR}, 0.5 ; 95 \% \mathrm{Cl}, 0.3-0.9, \mathrm{p}=0.022)$ to have highly elevated CRP levels compared to normal weight peers.

\section{Conclusion}

Obese BMI is associated with highly elevated CRP levels in patients with COPD. These findings are suggestive for an adipocyte-induced systemic inflammation in COPD. 


\section{Introduction}

Chronic obstructive pulmonary disease (COPD) is a disease characterized by a partially reversible airflow limitation'. Additionally, COPD has been recognized as a multi component disease in which extra-pulmonary features like exercise intolerance and abnormal changes in body composition may adversely affect health status and survival, irrespective of the degree of airflow limitation ${ }^{2-6}$. Low-grade systemic inflammation has also been shown to be a systemic feature in patients with clinically stable COPD compared to healthy peers ${ }^{7}$, which transiently increases during acute COPD exacerbations ${ }^{8}$. In particular, elevated C-reactive protein (CRP) levels have been related to adverse clinical outcomes in COPD, like a decreased functional exercise capacity ${ }^{9}$, a reduced daily physical activity level ${ }^{10}$, a decreased health status ${ }^{9}$, an increased risk for cardiac injury ${ }^{11}$, increased arterial stiffness $^{12}$, an increased risk for hospitalizations ${ }^{13}$ and worse survival ${ }^{14}$. In fact, increased CRP levels have been suggested as one of the diagnostic components of the chronic systemic inflammatory syndrome ${ }^{15}$.

Limited data are available about the determining factors of elevated CRP levels in patients with COPD. Currently, elevated CRP levels have been shown to be positively related to the degree of airflow limitation ${ }^{16}$ and to body mass index (BMI; body weight in kilograms divided by squared height in meters) in patients with COPD $9,17,18$. Nevertheless, the positive relationship between highly elevated CRP levels and increased BMI in COPD has only been studied in limited sample sizes and has not been corrected for all confounding variables together, like the degree of airflow limitation ${ }^{7}$ and age ${ }^{17}$. In fact, the latter positive relationship has also been recognized in patients with coronary heart disease ${ }^{19}$ and in overweight and obese participants of the Third National Health and Nutrition Examination Survey, who were more likely to have elevated CRP levels compared to their normal-weight peers $^{20}$. It may therefore be reasonable to hypothesize those COPD patients with a high BMI (25 to $\left.29.9 \mathrm{~kg} / \mathrm{m}^{2}\right)$ or an obese BMI $\left(\geq 30 \mathrm{~kg} / \mathrm{m}^{2}\right)$ are more likely to have elevated CRP levels than COPD patients with a normal BMI (21 to $\left.24,9 \mathrm{~kg} / \mathrm{m}^{2}\right)$ or a low BMI $\left(21 \mathrm{~kg} / \mathrm{m}^{2}\right)$. Surprisingly, this hypothesis has never been studied and the likelihood of having highly elevated CRP levels in high or obese BMI patients with COPD has not been investigated so far.

Therefore, the aim of the present study was to determine whether and to what extent COPD patients with a low, high or obese BMI are more likely to have elevated CRP levels compared to normal-weight COPD patients and to explore the effects of clinically relevant covariates like age, sex, disease severity, long-term oxygen therapy (LTOT), co-morbidities and current pharmacological therapy, on the likelihood of having elevated CRP levels. 


\section{Methods}

\section{Study population}

Data were collected prospectively in 628 consecutive COPD patients entering pulmonary rehabilitation between January 2005 and March 2007 at the Centre for Integrated Rehabilitation of Organ failure (CIRO) in Horn, the Netherlands. All patients gave informed consent. The local ethical committee, Maastricht, the Netherlands, approved the study. Some of the patients were part of a previous study ${ }^{21}$. Additionally, patients' smoking status (never-, former- and current-smoker), self-reported co-morbidities (Charlson co-morbidity index ${ }^{22}$ ), and use LTOT were recorded. Furthermore, patients' current pharmacological treatment was registered (inhaled and oral corticosteroids, anti-hypertensive treatment, statins, anti-inflammatory drugs and others).

\section{Lung function assessment}

Lung function parameters (forced expiratory volume in the first second, $\mathrm{FEV}_{1}$; forced vital capacity, FVC) were collected using standardized spirometry (Masterlab, Viasys, Germany). The degree of severity of airflow limitation was classified according to the GOLD guidelines (GOLD stage 1: $\mathrm{FEV}_{1} / \mathrm{FVC}<70 \%$ and $\mathrm{FEV}_{1}>80 \%$ of the predicted values; GOLD stage 2 : $\mathrm{FEV}_{1} / \mathrm{FVC}<70 \%$ and $\mathrm{FEV}_{1}$ between 80 and $50 \%$ of the predicted values; GOLD stage 3: $\mathrm{FEV}_{1} / \mathrm{FVC}<70 \%$ and FEV1 between 50 to $30 \%$ of the predicted values; and GOLD stage 4: $\mathrm{FEV}_{1}$ / $\mathrm{FVC}<70 \%$ and $\mathrm{FEV}_{1}<30 \%$ of the predicted values or $\mathrm{FEV}_{1}<50 \%$ of the predicted values plus chronic respiratory failure) ${ }^{1}$.

\section{Body composition analyses}

Body height was measured to the nearest $0.1 \mathrm{~cm}$. Body weight was assessed by using an electronic beam scale with digital readout to the nearest $0.1 \mathrm{~kg}$ after emptying the bladder and with the subjects standing barefoot and wearing light indoor clothing. BMI was calculated as body weight / height ${ }^{2}$. A priori, BMI was categorized into low $\left(21 \mathrm{~kg} / \mathrm{m}^{2}\right)$, normal (21 to $\left.24.9 \mathrm{~kg} / \mathrm{m}^{2}\right)$, high (25 to $29.9 \mathrm{~kg} / \mathrm{m}^{2}$ ) and obese $\left(\geq 30 \mathrm{~kg} / \mathrm{m}^{2}\right)^{23}$. Body composition (fat free mass, FFM and fat mass, FM) has been assessed using an overnight-fasting bioelectrical impedance assessment (Bodystat ${ }^{\circledR}$ ). FFM was calculated by using disease and gender-specific equations ${ }^{24}$. FFM index (FFMI) was calculated as FFM in kilogram divided by squared height in meters. FFM depletion was defined as FFMI $\leq 15$ (females) or $\leq 16$ (males) $\mathrm{kg} / \mathrm{m}^{225}$. FM in kilogram was calculated as total body weight minus FFM, while FM percentage (FM\%) as FM in kilogram divided by the total body weight multiplied by 100 . A high FM\% was defined after correction for age and gender ${ }^{26}$. 


\section{Laboratory analysis}

A venous blood sample was collected from all patients in the fasted state. Highsensitive CRP was chosen as a marker of systemic inflammation, assessed in duplicate by high-sensitivity particle-enhanced immunoassay (COBAS Micra, Radiometer, Copenhagen). CRP levels were categorized into three groups: normal $(\leq 3 \mathrm{mg} / \mathrm{L})$, elevated $(>3-5 \mathrm{mg} / \mathrm{L})$ and highly elevated $(>5 \mathrm{mg} / \mathrm{L})^{27}$.

\section{Statistical analyses}

Kruskal-Wallis Test for independent samples was performed to assess differences in median CRP levels after stratification for GOLD, BMI, FFMI, FM and use/non use of antibiotics. The association between CRP levels and BMI was examined by using multinomial logistic regression. CRP levels were defined as dependent variable with normal CRP levels as the reference category. BMI was classified as independent variable using normal $\mathrm{BMI}$ as the reference category. Additionally, adjustment for potential confounders were made: age (groups: $<55,55-64,65-74, \geq 75$ years $)^{17}$, smoking ${ }^{28}$, disease severity ${ }^{7}$, LTOT $^{29}$, presence of co-existing morbidities s1,30,31 $^{1}$ and current medication like inhaled and oral corticosteroids ${ }^{32}$, antihypertensive treatment ${ }^{33}$, statins $\mathrm{s}^{34}$ and others. Odds ratios (OR) accompanied by the 95\% confidence intervals $(\mathrm{Cl})$ were recorded. Analyses were performed using Statistical Package for the Social Sciences (SPSS) version 15.01. for Windows. A $p$-value of $\leq 0.05$ was considered significant. 


\section{Results}

On average, the elderly patients had moderate to severe COPD, a high BMI, a normal FFMI and a normal FM (Table 1). FEV ${ }_{1}$, forced expiratory volume in 1 second; FVC, forced vital capacity; FFMI, fat free mass index; FM, fat mass; SEM, standard error of the mean. Although patients had to be clinically stable at the time they were entering pulmonary rehabilitation, 57 patients (9\%) were finishing a course of oral antibiotics. These patients were equally distributed over the four BMI categories (low BMI: 6\%; normal BMI 10\%; high BMI: 9\%; obese BMI: 10\%; $\mathrm{p}=0.470$ ).

Table 1. Baseline characteristics

\begin{tabular}{|l|l|l|}
\hline $\mathrm{N}=628$ & Mean & SEM \\
\hline Age, years & 64.0 & 0.4 \\
\hline Male sex, \% & 61 & - \\
\hline FEV $_{1} ; \%$ predicted & 42.1 & 0.6 \\
\hline FEV $_{1} /$ FVC; \% predicted & 41.5 & 0.5 \\
\hline GOLD I, II, III, IV; \% & $3,23,48,26$ & - \\
\hline BMI; kg/m² & 25.1 & 0.2 \\
\hline BMI low, normal, high, obese; \% & $23,33,28,16$ & - \\
\hline FFMI; kg/m² & 16.3 & 0.1 \\
\hline FFMI low, normal; \% & 43,57 & - \\
\hline FM; kg & 24.8 & 0.4 \\
\hline FM low, normal, high; \% & $1,53,46$ & - \\
\hline smoking status & & \\
\hline never, former, current smoker, \% & $2,73,25$ & - \\
\hline
\end{tabular}

$\mathrm{FEV}_{1}$, forced expiratory volume in 1 second; FVC, forced vital capacity; FFMI, fat free mass index; FM, fat mass; SEM, standard error of the mean. 


\section{CRP levels}

Median CRP levels for the whole group were $4.6 \mathrm{mg} / \mathrm{L}\left(25^{\text {th }}-75^{\text {th }}\right.$ percentile: $1.4^{-}$ 11.1). Median CRP levels were not different after stratification for GOLD stages $(p=0.712)$, users/non-users of antibiotics $(p=0.944)$, users/non-users of inhaled $(p=0.241)$, or users/non-users of oral corticosteroids $(p=0.557)$. Contrary, significant differences in median CRP levels were found after stratification for body composition and smoking status (Table 2). CRP was elevated or highly elevated in $11.2 \%$ and $47.8 \%$ of the COPD patients, respectively. Highly elevated CRP levels were significantly more prevalent in obese COPD patients compared to patients with a low, normal or high BMI $(p<0.01$; Figure 1). Furthermore, normal CRP levels were significantly less prevalent in obese COPD patients compared to patients with a low, normal or high BMI $(p<0.01)$. Additionally, $59 \%$ of the patients with an abnormal low FFMI had CRP levels $<5 \mathrm{mg} /$, while none of the obese patients with highly elevated CRP levels $(>5 \mathrm{mg} / \mathrm{l})$ had an abnormal low FFMI. Finally, patients with an abnormal low FFMI plus a low BMI $(n=135)$ had significantly lower median CRP levels $\left(2.00 \mathrm{mg} / \mathrm{l}, 25^{\text {th }}-75^{\text {th }}\right.$ percentile: $\left.0.8-9.0\right)$ than patients with an abnormal low FFMI plus a normal $(n=119)$ or high BMI $(n=14)$ ( $4.00 \mathrm{mg} / \mathrm{l}, 25^{\text {th }}-75^{\text {th }}$ percentile: $1.4-9.3$; and $8.18 \mathrm{mg} / \mathrm{l}, 25^{\text {th }}-75^{\text {th }}$ percentile: $2.4^{-}$ 33.5; both: $p<0.05)$, respectively. None of the patients with an abnormal low FFMI had an obese BMI. Mean (SE) transfer factor for carbon monoxide was similar after stratification for CRP strata (normal CRP: 51.4 (0.3)\% predicted, elevated CRP: 51.5 (0.3)\% predicted; and highly elevated CRP: 51.5 (0.3)\% predicted). Idem for arterial oxygen pressure: 9.2 (0.1) kPa; 9.1 (0.1) kPa; and 9.1 (0.1) $\mathrm{kPa}$, respectively.

Figure 1. Prevalence of normal, elevated or highly elevated CRP levels after stratification for BMI $(\mathrm{N}=628)$.

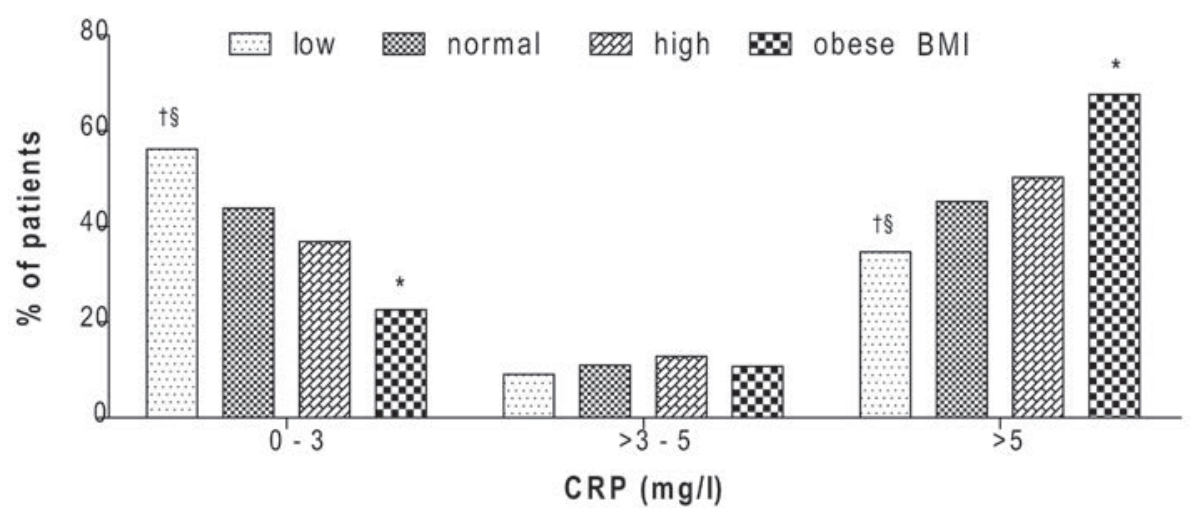

CRP, C-reactive protein.

${ }^{*} \mathrm{p}<0.01$ vs. low, normal and high BMI; ${ }^{\dagger} \mathrm{p}<0.05$ vs. normal BMI; ${ }^{\S} \mathrm{p}<0.01$ vs. high BMI. 
Table 2. Median CRP levels after stratification for GOLD, body composition, use/ non-use of antibiotics, inhaled and oral corticosteroids and smoking status

\begin{tabular}{|c|c|c|c|c|}
\hline & \multicolumn{4}{|c|}{ CRP } \\
\hline & \multirow[b]{2}{*}{$N$} & \multirow[b]{2}{*}{ Median } & \multicolumn{2}{|c|}{ Percentiles } \\
\hline & & & $25^{\text {th }}$ & $75^{\text {th }}$ \\
\hline GOLD & 628 & & & \\
\hline I & 18 & 4.2 & 0.7 & 12.5 \\
\hline II & 147 & 4.2 & 1.5 & 11.1 \\
\hline III & 303 & 4.4 & 1.4 & 11.0 \\
\hline IV & 160 & 5.2 & 1.5 & 11.7 \\
\hline BMI; kg/m² & 628 & & & \\
\hline low & 144 & $2.0^{*}$ & 0.8 & 8.7 \\
\hline normal & 210 & $3.8^{*+}$ & 1.3 & 10.2 \\
\hline high & 172 & $5.0^{*+}$ & 2.0 & 11.5 \\
\hline obese & 102 & 7.9 & 3.4 & 14.0 \\
\hline FFMI; kg/m² & 628 & & & \\
\hline low & 268 & $3.0^{5}$ & 1.0 & 9.4 \\
\hline normal & 360 & 5.4 & 2.0 & 11.9 \\
\hline $\mathrm{FM} ; \mathrm{kg} / \mathrm{m}^{2}$ & 628 & & & \\
\hline low & 5 & $2.3^{\$}$ & 1.1 & 19.4 \\
\hline normal & 331 & $3.3^{\$}$ & 1.0 & 9.6 \\
\hline high & 292 & 5.7 & 2.1 & 12.6 \\
\hline antibiotics & 628 & & & \\
\hline user & 57 & 5.7 & 1.4 & 11.6 \\
\hline non-user & 571 & 4.5 & 1.4 & 11.1 \\
\hline inhaled CS & 628 & & & \\
\hline user & 544 & 4.6 & 1.5 & 11.3 \\
\hline non-user & 84 & 4.4 & 1.1 & 9.3 \\
\hline oral CS & 628 & & & \\
\hline user & 136 & 5.8 & 1.6 & 14.9 \\
\hline non-user & 492 & 4.4 & 1.4 & 10.2 \\
\hline smoking status & 624 & & & \\
\hline never smoker & 14 & 5.0 & 1.4 & 17.6 \\
\hline former smoker & 458 & 3.4 & 1.1 & 8.1 \\
\hline current smoker & 152 & $8.7^{\#}$ & 3.3 & 10.5 \\
\hline
\end{tabular}

CRP, C-reactive protein; GOLD, Global initiative for Chronic Obstructive Lung Disease; FFMI, fat free mass index; FM, fat mass; CS, corticosteroids.

${ }^{*} \mathrm{p}<0.01$ vs. obese BMI; ${ }^{\dagger} p<0.01$ vs. low BMI; ${ }^{\S} p<0.01$ vs. normal FFMI; ${ }^{\$} p<0.01$ vs. high FM. \# $p<0.01$ compared to former smoker. 


\section{Multinomial logistic regression}

BMI did not affect the likelihood of having elevated CRP levels $(3-5 \mathrm{mg} / \mathrm{L})$ in patients with COPD. However, the use of LTOT (OR, 2.6; 95\% Cl, 1.2-5.3; $p=0.011$ ) did increase the likelihood of having elevated CRP levels. Other covariates did not contribute significant to the model of elevated CRP levels.

Obese COPD patients were 3.3 times more likely $(95 \% \mathrm{Cl}, 1.5-7.0, \mathrm{p}=0.002)$ to have highly elevated CRP levels ( $>5 \mathrm{mg} / \mathrm{L}$ ) than normal-weight COPD patients. Contrary, COPD patients with a low BMI were 2 times less likely (OR, 0.5; 95\% $\mathrm{Cl}, 0.3-0.9, \mathrm{p}=0.022)$ to have highly elevated $\mathrm{CRP}$ levels than normal-weight COPD patients. Younger patients were also less likely (OR, 0.4; 95\% Cl, 0.2-0.8, $\mathrm{P}=0.009)$ to have highly elevated CRP levels than older COPD patients. Additionally, an increased likelihood for highly elevated CRP levels has been shown in male patients $(O R, 1.8 ; 95 \% \mathrm{Cl}, 1.2-2.8, p=0.004)$, patients on LTOT (OR, 2.0; $95 \% \mathrm{Cl}, 1.2-3.3 ; \mathrm{p}=0.005)$ and in patients who used cardiac medication (betablockers: OR, 2.5; 95\% Cl, 1.3-4.9; $p=0.006$; $A C E$ inhibitors: $O R, 1.9,95 \% \mathrm{Cl}$, $1.1-3.4 ; p=0.03)$. Then again, use of statins ( $O R, 0.5 ; 95 \% C l, 0.3-0.9 ; p=0.018)$ showed a decreased likelihood of having highly elevated CRP levels compared to non-users (Table 3). Other covariates did not reach the level of significance.

Table 3. Variables and covariates of the highly elevated CRP model ${ }^{\dagger}$

\begin{tabular}{|l|l|l|l|l|l|}
\hline & $\mathrm{N}$ & $\mathrm{B}$ & $\mathrm{OR}$ & $95 \% \mathrm{Cl}$ & $\mathrm{p}$-value \\
\hline BMI obese & 102 & 1.184 & 3.27 & $1.5-7.0$ & $0.002^{*}$ \\
\hline BMI high & 169 & 0.264 & 1.30 & $0.7-2.3$ & 0.379 \\
\hline BMI low & 144 & -0.660 & 0.52 & $0.3-0.9$ & $0.022^{*}$ \\
\hline Age, years $<65$ & 315 & -0.980 & 0.38 & $0.2-0.8$ & $0.009^{*}$ \\
\hline Male & 381 & 0.612 & 1.84 & $1.2-2.8$ & $0.004^{*}$ \\
\hline LTOT & 148 & 0.692 & 2.00 & $1.2-3.3$ & $0.005^{*}$ \\
\hline Beta-blocker & 67 & 0.923 & 2.52 & $1.3-4.9$ & $0.006^{*}$ \\
\hline ACE inhibitors & 87 & 0.638 & 1.89 & $1.1-3.4$ & $0.030^{*}$ \\
\hline Statins & 113 & -0.668 & 0.51 & $0.3-0.9$ & $0.018^{*}$ \\
\hline CVD & 145 & 0.168 & 1.18 & $0.7-2.0$ & 0.513 \\
\hline DM & 53 & 0.424 & 1.52 & $0.8-3.0$ & 0.216 \\
\hline ID & 16 & 0.382 & 1.47 & $0.4-5.3$ & 0.559 \\
\hline
\end{tabular}

${ }^{\dagger}$ Data are adjusted for age, sex, smoking, disease severity, co-morbidities, FFMI, FM\%, LTOT, pharmacological treatment.

OR, odds ratio for CRP $>5$ mg/l; $\mathrm{Cl}$, confidence interval; BMl, body mass imdex; LTOT, long term oxygen therapy; ACE inhibitors, Angiotensin converting enzyme inhibitors; CVD, cardiovascular disease; DM, diabetes mellitus Type II; ID, inflammatory disease. ${ }^{*} \mathrm{p}<0.05$. 


\section{Discussion}

This is the first study demonstrating an increased likelihood of having highly elevated CRP levels in obese patients with COPD compared to normal-weight peers after taking clinically relevant confounders into account.

\section{Obesity and CRP}

Obese COPD patients were 3.3 times more likely to have highly elevated CRP levels compared to normal weight COPD patients. These findings confirm our hypothesis and are in line with previous findings, where a positive relationship has been found between CRP levels and BMI in patients with COPD, irrespective of FFMI $19,17,18$. Nevertheless, the present study is the first to take into account clinically relevant confounders. A close relationship between elevated CRP levels and an obese BMI has also been found in healthy and cardiac populations ${ }^{19,35,36}$.

An increased likelihood of having highly elevated CRP levels in humans with an obese BMI may in part be explained by the fact that increased adipose tissue induces increased levels of adipocytokines which in turn may stimulate production of CRP in the liver ${ }^{37}$. Indeed, interleukin 6 and tumor necrosis factor alpha have been shown to stimulate the production of the acute phase protein CRP through facilitating hepatocytes ${ }^{37}$. This may be the simplest explanation for an increased likelihood of having highly elevated CRP levels in obese COPD. To date, however, it remains unknown whether disease-specific factors like hypoxia influence fat mass metabolism, as indicated in a recent published review ${ }^{38}$. In addition, research exposed that the fat mass in patients with COPD is a risk factor in the metabolic disarrangements ${ }^{39}$. Even, in COPD patients with a comparable body composition the control group showed greater extent of insulin resistance ${ }^{40}$. More research is however needed to confirm the hypothesis.

The adverse clinical consequences of having highly elevated CRP levels in COPD remain currently unknown. Nevertheless, it seems reasonable to hypothesise that highly elevated CRP levels in combination with an obese BMI may contribute to the development of co-existing morbidities in COPD, like insulin resistance ${ }^{40}$, metabolic syndrome $\mathrm{e}^{41}$, type II diabetes ${ }^{30,42}$ and cardiovascular disease ${ }^{35}$.

Unfortunately, outcomes of cardiovascular diseases were not included in the present study. However, increased CRP and obese BMI have both been shown to decrease the survival in patients with mild to severe COPD compared to patients with normal CRP or $\mathrm{BMI}$, respectively ${ }^{13,43}$. Currently it remains unknown why an obese $\mathrm{BMI}$ in patients with severe COPD is associated with better survival compared to low BMI patients ${ }^{43}$. In the general population, obesity is associated with worse survival ${ }^{44}$, which paradoxically cannot be applied to chronic organ failure ${ }^{45}$, leading to the so-called term 'obesity paradox'.

The findings of the present study support the hypothesis that CRP itself is not the source of adverse events but the reason for its production is the important 
feature ${ }^{46}$, which would explain a decreased mortality in obese patients. Following, this hypothesis may imply that different 'normal' ranges of CRP levels should be developed for different BMI strata in COPD.

\section{Loss of fat-free mass and CRP}

Highly elevated CRP levels have been presumed to be partially responsible for an abnormal low FFMI and an involuntary loss of body weight in COPD ${ }^{47}$. Additionally increased CRP levels were found in COPD patients with a low creatinineheight index in combination with low $\mathrm{BM} \mathrm{P}^{48}$.

Albeit the current data do not exclude the possible presence of highly elevated CRP levels in COPD patients with a low BMI, the present results do show a clear reduction in the likelihood of having highly elevated CRP levels in COPD patients with a low BMI compared to normal weight peers. In addition, it may even be reasonable to hypothesize that different inflammatory 'systems' are involved in different phenotypes of COPD defined by BMI. In fact, a majority of the patients with an abnormal loss of fat-free mass (59\%) did not have highly elevated CRP levels.

This may in part be explained by the fact that a reduced daily physical activity level resulting in muscle atrophy can be the main cause of loss of muscle mass in COPD 49,50 . This theory is partly supported by two important findings:

1) an abnormal loss of fat-free mass can partly be restored by performing specific physical exercises (i.e. resistance training ${ }^{51}$ ) and

2) Crul and colleagues ${ }^{52}$ and Barreiro and colleagues ${ }^{53}$ both have shown that markers of inflammation were not increased in quadriceps muscle of COPD patients compared to healthy peers.

So, whether or not highly elevated CRP levels may play a role in the development and/or maintenance of an abnormal loss of muscle mass in COPD remains currently unknown. Nevertheless, when highly elevated CRP levels play partly a role this seems to be counteracted by an increased daily mechanical load on the muscles of ambulation in obese COPD patients. Indeed, none of the obese COPD patients with highly elevated CRP levels had an abnormal low FFMI.

\section{Methodological considerations}

The following methodological limitations have to be considered: The study population consisted of an older age group of COPD patients entering pulmonary rehabilitation. However, many studies looking at body composition enrolled COPD patients entering pulmonary rehabilitation ${ }^{6,47}$.

Additionally, prevalence of an increased BMI (44\%) was comparable to a random COPD cohort ${ }^{2}$. Obviously the present results have to be corroborated in a longitudinal study. In addition, the present study stated that patients with a low BMI have a lower likelihood of having highly elevated CRP levels. Nevertheless, there 
is still no consistency whether or not CRP is the sentinel biomarker for systemic inflammation. So, patients with normal CRP levels do not have per se no systemic inflammation. Nevertheless, changes in weight over time may be more closely related to systemic inflammation. For this purpose, longitudinal studies are warranted.

Although CRP has been shown to be a possible biomarker for separation between disease stages ${ }^{16}$, there was no significant entry of disease severity to our multinomial logistic regression model. Previous cross-sectional studies have shown also an inverse relationship between $\mathrm{FEV}_{1}$ and circulating CRP levels in $\mathrm{COPD}^{16,54}$. However this relationship is lost in longitudinal studies ${ }^{54}$.

Co-existing morbidities did not enter the multinomial logistic regression model significantly, while cardiovascular medication and statins did. At first sight, this may be somewhat surprising, however the Charlson co-morbidity index does not report all cardiovascular diseases which maybe related with Beta-blockers, ACEinhibitors or statins.

The present study did not include a control group. However, future studies should focus on the effect of disease specific factors like hypoxia on the adipocyte induced inflammation in patients with COPD and healthy control subjects.

\section{Conclusion}

In conclusion, COPD patients with an obese BMI are more likely to have highly elevated CRP levels compared to normal weight COPD patients. Moreover, COPD patients with a low BMI were less likely to have highly elevated CRP levels compared to normal weight COPD patients. These findings are suggestive for an adipocyte-induced systemic inflammation in COPD. 


\section{References}

1. Pauwels RA, Buist AS, Calverley PM, Jenkins CR, Hurd SS. Global strategy for the diagnosis, management, and prevention of chronic obstructive pulmonary disease. NHLBI/WHO Global Initiative for Chronic Obstructive Lung Disease (GOLD) Workshop summary. Am J Respir Crit Care Med 2001;163:1256-76.

2. Vestbo J, Prescott E, Almdal T, et al. Body mass, fat-free body mass, and prognosis in patients with chronic obstructive pulmonary disease from a random population sample: findings from the Copenhagen City Heart Study. Am J Respir Crit Care Med 2006;173:79-83.

3. Oga T, Nishimura K, Tsukino M, Sato S, Hajiro T. Analysis of the factors related to mortality in chronic obstructive pulmonary disease: role of exercise capacity and health status. Am J Respir Crit Care Med 2003;167:544-9.

4. Mostert R, Goris A, Weling-Scheepers C, Wouters EF, Schols AM. Tissue depletion and health related quality of life in patients with chronic obstructive pulmonary disease. Respir Med 2000;94:859-67.

5. Pinto-Plata VM, Cote C, Cabral H, Taylor J, Celli BR. The 6-min walk distance: change over time and value as a predictor of survival in severe COPD. Eur Respir J 2004;23:28-33.

6. Schols AM, Broekhuizen R, Weling-Scheepers CA, Wouters EF. Body composition and mortality in chronic obstructive pulmonary disease. Am J Clin Nutr 2005;82:53-9.

7. Gan WQ, Man SF, Senthilselvan A, Sin DD. Association between chronic obstructive pulmonary disease and systemic inflammation: a systematic review and a meta-analysis. Thorax 2004:59:574-80.

8. Spruit MA, Gosselink R, Troosters T, et al. Muscle force during an acute exacerbation in hospitalised patients with COPD and its relationship with CXCL8 and IGF-I. Thorax 2003;58:752-6.

9. Broekhuizen R, Wouters EF, Creutzberg EC, Schols AM. Raised CRP levels mark metabolic and functional impairment in advanced COPD. Thorax 2006;61:17-22.

10. Watz H, Waschki B, Boehme C, Claussen M, Meyer T, Magnussen H. Extrapulmonary effects of chronic obstructive pulmonary disease on physical activity: a cross-sectional study. Am J Respir Crit Care Med 2008;177:743-51.

11. Sin DD, Man SF. Why are patients with chronic obstructive pulmonary disease at increased risk of cardiovascular diseases? The potential role of systemic inflammation in chronic obstructive pulmonary disease. Circulation 2003;107:1514-9.

12. Mills NL, Miller JJ, Anand A, et al. Increased arterial stiffness in patients with chronic obstructive pulmonary disease: a mechanism for increased cardiovascular risk. Thorax 2008;63:306-11.

13. Dahl M, Vestbo J, Lange P, Bojesen SE, Tybjaerg-Hansen A, Nordestgaard BG. C-reactive protein as a predictor of prognosis in chronic obstructive pulmonary disease. Am J Respir Crit Care Med 2007;175:250-5.

14. Man SF, ConnettJE, Anthonisen NR, Wise RA, Tashkin DP, Sin DD. C-reactive protein and mortality in mild to moderate chronic obstructive pulmonary disease. Thorax 2006;61:849-53.

15. Fabbri LM, Rabe KF. From COPD to chronic systemic inflammatory syndrome? Lancet 2007;370:797-9.

16. Franciosi LG, Page CP, Celli BR, et al. Markers of disease severity in chronic obstructive pulmonary disease. Pulm Pharmacol Ther 2006;19:189-99.

17. Pinto-Plata VM, Mullerova $\mathrm{H}$, Toso JF, et al. C-reactive protein in patients with COPD, control smokers and non-smokers. Thorax 2006;61:23-8.

18. Melbye $H$, Halvorsen DS, Hartz I, et al. Bronchial airflow limitation, smoking, body mass index, and statin use are strongly associated with the C-reactive protein level in the elderly. The Tromso Study 2001. Respir Med 2007;101:2541-9.

19. Mendall MA, Patel P, Ballam L, Strachan D, Northfield TC. C reactive protein and its relation to cardiovascular risk factors: a population based cross sectional study. Bmj 1996;312:1061-5.

20. Visser M, Bouter LM, McQuillan GM, Wener MH, Harris TB. Elevated C-reactive protein levels in overweight and obese adults. Jama 1999;282:2131-5.

21. Spruit MA, Pennings HJ, Janssen PP, et al. Extra-pulmonary features in COPD patients entering rehabilitation after stratification for MRC dyspnea grade. Respir Med 2007;101:2454-63.

22. Charlson ME, Pompei P, Ales KL, MacKenzie CR. A new method of classifying prognostic comorbidity in longitudinal studies: development and validation. J Chronic Dis 1987;40:373-83.

23. WHO. The world health report 2002, Reducing Risks, Promoting Healthy Life. 2002.

24. Steiner MC, Barton RL, Singh SJ, Morgan MD. Bedside methods versus dual energy X-ray absorptiometry for body composition measurement in COPD. Eur Respir J 2002;19:626-31. 
25. Baarends EM, Schols AM, Mostert R, Wouters EF. Peak exercise response in relation to tissue depletion in patients with chronic obstructive pulmonary disease. Eur Respir J 1997;10:2807-13.

26. Kyle UG, Genton L, Slosman DO, Pichard C. Fat-free and fat mass percentiles in 5225 healthy subjects aged 15 to 98 years. Nutrition 2001;17:534-41.

27. Pearson TA, Mensah GA, Alexander RW, et al. Markers of inflammation and cardiovascular disease: application to clinical and public health practice: A statement for healthcare professionals from the Centers for Disease Control and Prevention and the American Heart Association. Circulation 2003;107:499-511.

28. Gan WQ, Man SF, Sin DD. The interactions between cigarette smoking and reduced lung function on systemic inflammation. Chest 2005;127:558-64.

29. Cano NJ, Pichard C, Roth $\mathrm{H}$, et al. C-reactive protein and body mass index predict outcome in end-stage respiratory failure. Chest 2004;126:540-6.

30. Rana JS, Mittleman MA, Sheikh J, et al. Chronic obstructive pulmonary disease, asthma, and risk of type 2 diabetes in women. Diabetes Care 2004;27:2478-84.

31. Blackburn WD, Jr. Validity of acute phase proteins as markers of disease activity. J Rheumatol Suppl 1994:42:9-13.

32. Sin DD, Lacy P, York E, Man SF. Effects of fluticasone on systemic markers of inflammation in chronic obstructive pulmonary disease. Am J Respir Crit Care Med 2004;170:760-5.

33. Palmas W, Ma S, Psaty B, Goff DC, Jr., Darwin C, Barr RG. Antihypertensive medications and C-reactive protein in the multi-ethnic study of atherosclerosis. Am J Hypertens 2007;20:233-41.

34. Albert MA, Staggers J, Chew P, Ridker PM. The pravastatin inflammation CRP evaluation (PRINCE): rationale and design. Am Heart J 2001;141:893-8.

35. Yudkin JS, Stehouwer CD, Emeis JJ, Coppack SW. C-reactive protein in healthy subjects: associations with obesity, insulin resistance, and endothelial dysfunction: a potential role for cytokines originating from adipose tissue? Arterioscler Thromb Vasc Biol 1999;19:972-8.

36. Kuller LH, Tracy RP, Shaten J, Meilahn EN. Relation of C-reactive protein and coronary heart disease in the MRFIT nested case-control study. Multiple Risk Factor Intervention Trial. Am J Epidemiol 1996;144:537-47.

37. Fantuzzi G, Mazzone T. Adipose tissue and atherosclerosis: exploring the connection. Arterioscler Thromb Vasc Biol 2007;27:996-1003.

38. Franssen FM, O'Donnell DE, Goossens GH, Blaak EE, Schols AM. Obesity and the lung: 5. Obesity and COPD. Thorax 2008;63:1110-7.

39. Poulain M, Doucet M, Drapeau V, et al. Metabolic and inflammatory profile in obese patients with chronic obstructive pulmonary disease. Chron Respir Dis 2008;5:35-41.

40. Bolton $C E$, Evans $M$, lonescu $A A$, et al. Insulin resistance and inflammation - A further systemic complication of COPD. Copd 2007:4:121-6.

41. Marquis $\mathrm{K}$, Maltais $F$, Duguay $\mathrm{V}$, et al. The metabolic syndrome in patients with chronic obstructive pulmonary disease. J Cardiopulm Rehabil 2005;25:226-32; discussion 33-4.

42. Hole DJ, Watt GC, Davey-Smith G, Hart CL, Gillis CR, Hawthorne VM. Impaired lung function and mortality risk in men and women: findings from the Renfrew and Paisley prospective population study. Bmj 1996;313:711-5; discussion 5-6.

43. Landbo C, Prescott E, Lange P, Vestbo J, Almdal TP. Prognostic value of nutritional status in chronic obstructive pulmonary disease. Am J Respir Crit Care Med 1999;160:1856-61.

44. Calle EE, Thun MJ, Petrelli JM, Rodriguez C, Heath CW, Jr. Body-mass index and mortality in a prospective cohort of U.S. adults. N Engl J Med 1999;341:1097-105.

45. Curtis JP, Selter JG, Wang Y, et al. The obesity paradox: body mass index and outcomes in patients with heart failure. Arch Intern Med 2005;165:55-61.

46. Bassuk SS, Rifai N, Ridker PM. High-sensitivity C-reactive protein: clinical importance. Curr Probl Cardiol 2004:29:439-93.

47. Schols AM, Buurman WA, Staal van den Brekel AJ, Dentener MA, Wouters EF. Evidence for a relation between metabolic derangements and increased levels of inflammatory mediators in a subgroup of patients with chronic obstructive pulmonary disease. Thorax 1996;51:819-24.

48. Eid AA, lonescu AA, Nixon LS, et al. Inflammatory response and body composition in chronic obstructive pulmonary disease. Am J Respir Crit Care Med 2001;164:1414-8.

49. Bernard $\mathrm{S}$, LeBlanc $\mathrm{P}$, Whittom $\mathrm{F}$, et al. Peripheral muscle weakness in patients with chronic obstructive pulmonary disease. Am J Respir Crit Care Med 1998;158:629-34. 


\section{I CHAPTER 2}

50. Pitta F, Troosters T, Spruit MA, Probst VS, Decramer M, Gosselink R. Characteristics of physical activities in daily life in chronic obstructive pulmonary disease. Am J Respir Crit Care Med 2005;171:972-7.

51. Spruit MA, Gosselink R, Troosters T, De Paepe K, Decramer M. Resistance versus endurance training in patients with COPD and peripheral muscle weakness. Eur Respir J 2002;19:1072-8.

52. Crul T, Spruit MA, Gayan-Ramirez G, et al. Markers of inflammation and disuse in vastus lateralis of chronic obstructive pulmonary disease patients. Eur J Clin Invest 2007;37:897-904.

53. Barreiro E, Schols AM, Polkey MI, et al. Cytokine profile in quadriceps muscles of patients with severe COPD. Thorax 2008;63:100-7.

54. Fogarty AW, Jones S, Britton JR, Lewis SA, McKeever TM. Systemic inflammation and decline in lung function in a general population: a prospective study. Thorax 2007;62:515-20. 


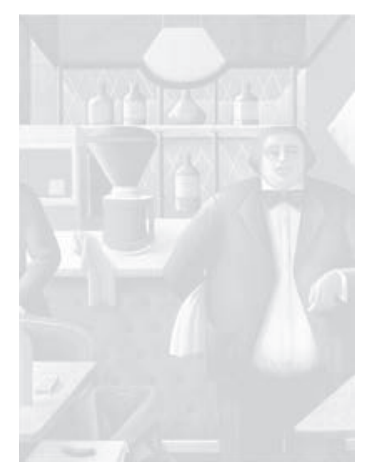

\section{CHAPTER 3}

\section{Abdominal fat mass contributes to the systemic inflammation in chronic obstructive pulmonary disease}

Rutten EPA, Breyer MK, Spruit MA, Hofstra T, van Melick PP, Schols AM, Wouters EFM

Clin Nutr. 2010 June 2, Dec; 29 (6): 756-6 



\section{Abstract}

\section{Back ground and aims}

Altered body composition in chronic obstructive pulmonary disease (COPD) is often reflected by muscle wasting, while only few studies have focused on abdominal fat mass. The contribution of abdominal fat mass to the systemic inflammation often present in COPD has not been examined yet. The aim of the present study was to investigate if abdominal fat mass contributes to the systemic inflammation in patients with moderate to severe COPD.

\section{Methods}

Muscle wasting (fat-free mass index $<17.1 \mathrm{~kg} / \mathrm{m}^{2}$ for men and $14.6 \mathrm{~kg} / \mathrm{m}^{2}$ for women) and abdominal fat mass (android/gynoid \%fat mass $>1.0$ for men and $>0.8$ for women) were assessed by dual energy $x$-ray absorptiometry in 295 patients with moderate to severe COPD (175 men). Plasma C-reactive protein (CRP) concentration was analysed by high sensitive (HS)-ELISA.

\section{Results}

Diffusion capacity was higher in patients with abdominal obesity. In addition, fat mass index was a significant determinant for plasma CRP concentration. In a subgroup of patients with $C R P<5 m g / l(n=168)$, CRP was positively associated with abdominal fat mass. In addition, a significant proportion of abdominal obese patients had muscle wasting, and CRP levels were higher in these patients compared to the patients without abdominal obesity.

\section{Conclusions}

Abdominal fat mass contributes to the systemic inflammation in COPD. This study provides further evidence for systemic phenotyping of patients with COPD incorporating besides markers of muscle mass also markers of abdominal obesity. 


\section{Introduction}

Chronic obstructive pulmonary disease (COPD) is traditionally characterized by partially irreversible airflow limitation, but nowadays, COPD is accepted as a systemic disorder reflected in a variety of extra-pulmonary features ${ }^{1}$. As one of these features, muscle wasting is often shown ${ }^{2}$ predominantly in the patients with emphysema ${ }^{3}$. Identifying causes and treatment of skeletal muscle wasting received a lot of attention ${ }^{4}$ as it is negatively associated with exercise capacity ${ }^{5}$, quality of life ${ }^{6}$ and survival' In contrast, the contribution of fat mass (FM) and its distribution in the systemic pathology of COPD have reached only just some attention. Available data indicate a prevalence of obesity (defined by BMI $>30 \mathrm{~kg} / \mathrm{m}^{2}$ ) in mild-tomoderate COPD patients of about $20 \%{ }^{8}$. In addition, about $40 \%$ of male and $20 \%$ of female patients with COPD entering a cardiopulmonary rehabilitation in Canada were obese ${ }^{9}$. Remarkably, in the same manuscript, about $70 \%$ of the men and $45 \%$ of the women showed abdominal obesity (defined by waist circumference $>102 \mathrm{~cm}$ for men, $>88 \mathrm{~cm}$ for women). These data indicate that there is a subgroup of patients with normal weight but abdominal obesity. However, the systemic consequences of abdominal obesity in patients with COPD are not investigated yet.

As another extra-pulmonary consequence, COPD is characterized by low-grade systemic inflammation, which is often reflected by increased plasma levels of Creactive protein $(C R P)^{10}$. Moreover, in a review it was stated that the co-presence of COPD and cardiovascular co-morbidity is high in a susceptible subgroup of elderly people ${ }^{11}$ and the Third National Health and Nutrition Examination Survey concluded that the presence of elevated plasma CRP levels in subjects with COPD are associated with an increased risk for the development of cardiovascular co-morbidity ${ }^{12}$. The underlying causes of increased plasma CRP concentration in COPD are not clear yet. Studies investigating an association between plasma CRP concentration and markers of pulmonary inflammation in COPD are inconsistent ${ }^{13}$. In healthy obese subjects, abdominal fat mass is recognized as a source for low grade systemic inflammation defined by plasma CRP concentration (in the range of 0-3 $\mathrm{mg} / \mathrm{L})^{14}$. In addition, it has been shown that the ratio of the android to the gynoid \% FM is a determinant for cardiovascular risk in healthy women ${ }^{15}$. Referring to the higher prevalence of cardiovascular co-morbidity in COPD, it is relevant to investigate if the abdominal fat mass is also linked to the systemic inflammation in patients with COPD.

In the present study, we hypothesized that abdominal fat mass in patients with COPD does significantly contribute to the low grade systemic inflammation measured by plasma CRP concentration. 


\section{Methods}

Data were collected in 295 patients with COPD (175 men) who were screened for pulmonary rehabilitation at the Centre of expertise for chronic organ failure (ciro), the Netherlands ${ }^{16}$ and retrospectively analyzed. All subjects were clinically stable for at least 4 weeks prior participation. Lung function parameters (forced expiratory volume in the first second, $\mathrm{FEV}_{1}$; forced vital capacity, FVC) were collected using standardized spirometry (Masterlab ${ }^{\circledR}$, Viasys, Germany). Diffusion capacity of carbon monoxide (DLCO) was assessed by using single-breath method (Masterlab ${ }^{\circledR}$, Jaeger, Germany). All values obtained were compared with a reference value and expressed as percentages of the predicted value ${ }^{17}$. Arterial oxygen pressure $\left(\mathrm{P}_{\mathrm{a}} \mathrm{O}_{2}\right)$ was determined in an arterial blood sample obtained by puncture of the artery radial while breathing room air and in the sitting position. The degree of co-morbidities was measured using the modified Charlson comorbidity index ${ }^{18}$.

A total body scan was performed by dual-energy $x$-ray absorptiometry (DEXA) using a Lunar Prodigy ${ }^{\circledR}$ system (GE Healthcare, Madison, WI, USA). From the total body scan, body composition was assessed: BMI, fat free mass index (FFMI) $=$ fat free mass (lean mass + bone mineral content)/length ${ }^{2}$ and fat mass index $(\mathrm{FMI})=\mathrm{FM} /$ length $^{2}$. The location of the android and gynoid region was situated as described previously by Eis et $\mathrm{al}^{15}$. The ratio of the percentage FM in the android region to the percentage $F M$ in the gynoid region (A/G FM) is used to indicate abdominal obesity. In addition, a post-absorptive venous blood sample was collected from the patients to analyse CRP as a biomarker of systemic inflammation. CRP was assessed in duplicate by high-sensitivity particle-enhanced immunoassay (COBAS Mira ${ }^{\circledR}$, Radiometer, Copenhagen).

\section{Statistical analysis}

Data are described as mean \pm SD and checked for normality. CRP was not normally divided and thus log transformed for analyses. The study group was poststratified for abdominal obesity defined as A/G FM $>1.0$ for men and $>0.8$ for women $^{19}$. To define muscle wasting, we used the criteria of Vestbo et al (FFMI $<17.1 \mathrm{~kg} / \mathrm{m}^{2}$ for men and $14.6 \mathrm{~kg} / \mathrm{m}^{2}$ for women $)^{20}$. Additional analyses were performed in a subgroup of subjects with only clinically normal CRP levels $(<5 \mathrm{mg} / \mathrm{L}$, $n=168)^{21}$ in order to prevent that the contribution of the abdominal FM to the systemic inflammation in COPD was covered by other disease relating factors. CRP levels were compared in the subgroup after stratification into 4 groups based on abdominal obesity and muscle wasting: abdominal obese subjects, subjects with muscle wasting, subjects with both abdominal obesity and muscle wasting and subjects with neither abdominal obesity nor muscle wasting. Comparison between groups was done by the analysis of variance test and the post hoc LSD 
test for normal divided variables and the Tukey Cramer test for CRP. Pearson's correlation coefficient was calculated to determine significant covariates of abdominal fat mass and CRP levels. Subsequently, multivariate stepwise regression analyses was performed to investigate a relationship between log(CRP) levels and marker for body composition. Analyses were performed using Statistical Package for the Social Sciences (SPSS) version 15.01 for Windows ${ }^{\circledR}$. A p-value $<5 \%$ was considered statistically significant.

\section{Results}

The study group was characterized by moderate to severe COPD, and in general normal BMI and FFMI (Table 1). In both sexes, the patients with abdominal obesity had higher values of BMI, FFMI, FMI, FEV1/FVC and DLCO. In addition, the women with abdominal obesity were older compared to those without abdominal obesity. The Charlson co-morbidity index was not different between the patients with abdominal obesity and those without abdominal obesity. Plasma CRP concentration was higher in the women with abdominal obesity compared their counterparts without abdominal obesity (Figure 1). There was a significant correlation between plasma CRP concentration and gender, age, BMI, FFMI, FMI, A/G FM but not with $\mathrm{PaO}_{2}$ (data not shown). The multivariate stepwise regression analysis with $\log (\mathrm{CRP})$ as dependent variable and the significant covariates as independent variables, showed that gender, age and FMI were significant determinants in the way that men are more prone to have higher CRP levels (Table 2). The coefficient of determination of the regression model was however low (14\%).

In a subgroup of COPD patients with CRP $<5 \mathrm{mg} / \mathrm{L}(\mathrm{n}=168)$, CRP significantly correlated with gender, age, BMI, FFMI, FMI and A/G FM. Performing a stepwise multiple regression analysis with $\log (\mathrm{CRP})$ as dependent variable in the subgroup of patients, the only covariate that remained in the model was A/G FM (Table 3). If CRP levels are presented in the subjects after stratification in 4 groups based on nutritional status, both the subjects with abdominal obesity and the subjects with muscle wasting and abdominal obesity had significantly higher levels of CRP than the subjects with only muscle wasting and compared than the subjects with neither muscle wasting nor abdominal obesity (Figure 2). 
Table 1. Characteristics of the study group stratified for sex and abdominal obesity

\begin{tabular}{|c|c|c|c|c|}
\hline & \multicolumn{2}{|l|}{ Men } & \multicolumn{2}{|l|}{ Women } \\
\hline & $\begin{array}{l}\text { Abdominal } \\
\text { obese }\end{array}$ & $\begin{array}{l}\text { Not abdominal } \\
\text { obese }\end{array}$ & $\begin{array}{l}\text { Abdominal } \\
\text { obese }\end{array}$ & $\begin{array}{l}\text { Not abdominal } \\
\text { obese }\end{array}$ \\
\hline Number of patients, $n$ & 126 & 49 & 73 & 47 \\
\hline Age, y & $66.6 \pm 9.3$ & $65.4 \pm 9.8$ & $61.7 \pm 9.3$ & $57.0 \pm 9.1^{* *}$ \\
\hline \multicolumn{5}{|l|}{ Body composition } \\
\hline BMI, kg/m² & $26.1 \pm 4.2$ & $20.8 \pm 3.7^{* *}$ & $25.7 \pm 4.8$ & $19.6 \pm 2.4^{* *}$ \\
\hline FFMI, $\mathrm{kg} / \mathrm{m}^{2}$ & $18.5 \pm 2.0$ & $16.9 \pm 1.8^{* *}$ & $15.9 \pm 1.7$ & $14.6 \pm 1.3^{* *}$ \\
\hline $\mathrm{FMI}, \mathrm{kg} / \mathrm{m}^{2}$ & $7.6 \pm 2.8$ & $3.5 \pm 2.3^{* *}$ & $9.7 \pm 3.7$ & $5.0 \pm 1.9^{* *}$ \\
\hline Muscle wasting, \% & 26.2 & $51.0^{* *}$ & 30.4 & $48.9^{* *}$ \\
\hline \multicolumn{5}{|l|}{$\begin{array}{l}\text { Lung function } \\
\text { parameters }\end{array}$} \\
\hline $\mathrm{FEV}_{1}, \mathrm{l}$ & $1.31 \pm 0.53$ & $1.16 \pm 0.42$ & $1.00 \pm 0.46$ & $0.89 \pm 0.40$ \\
\hline $\mathrm{FEV}_{1}, \%$ pred & $44.5 \pm 15.5$ & $40.9 \pm 15.0$ & $44.6 \pm 17.7$ & $38.2 \pm 16.9$ \\
\hline FVC, I & $3.19 \pm 0.89$ & $3.23 \pm 0.85$ & $2.43 \pm 0.70$ & $2.36 \pm 0.86$ \\
\hline FVC, \%pred & $83.6 \pm 19.6$ & $87.9 \pm 21.2$ & $88.0 \pm 24.9$ & $88.4 \pm 24.6$ \\
\hline $\mathrm{FEV}_{1} / \mathrm{FVC}, \%$ pred & $40.5 \pm 11.5$ & $36.1 \pm 9.6^{*}$ & $41.1 \pm 11.6$ & $35.5 \pm 9.7^{* *}$ \\
\hline DLCO, \%pred & $56.9 \pm 19.3$ & $44.9 \pm 14.6^{* *}$ & $53.1 \pm 16.5$ & $38.6 \pm 14.2^{* *}$ \\
\hline $\mathrm{PaO}_{2}, \mathrm{KPa}$ & $9.2 \pm 1.2$ & $9.1 \pm 1.3$ & $9.3 \pm 1.4$ & $9.1 \pm 1.4$ \\
\hline \multicolumn{5}{|l|}{$\begin{array}{l}\text { Charlson } \\
\text { co-morbidity index }\end{array}$} \\
\hline 1 & 55 & 24 & 34 & 23 \\
\hline 2 & 32 & 8 & 9 & 9 \\
\hline 3 & 12 & 7 & 9 & 3 \\
\hline$>3$ & 5 & 3 & 5 & 1 \\
\hline
\end{tabular}

Data are mean $\pm \mathrm{SD}$. Abbreviations: $\mathrm{FEV}_{1}$ : forced expiratory volume expressed in one second; FVC: functional volume capacity; $F E V_{1} / F V C$ : tiffeneau index; DLCO: diffusing capacity for carbon monoxide; $\mathrm{PaO}_{2}$ : arterial oxygen pressure; $\mathrm{BMI}$ : body mass index; FFMI: fat free mass index; FMI: fat mass index. Symbols indicate significant differences with abdominal obesity: ${ }^{*} p<0.05,{ }^{* *} p<0.01$. 
Figure 1. Plasma CRP concentration in men (figure 1a) and women (figure 1b) with COPD after stratification for abdominal obesity.

Figure 1a

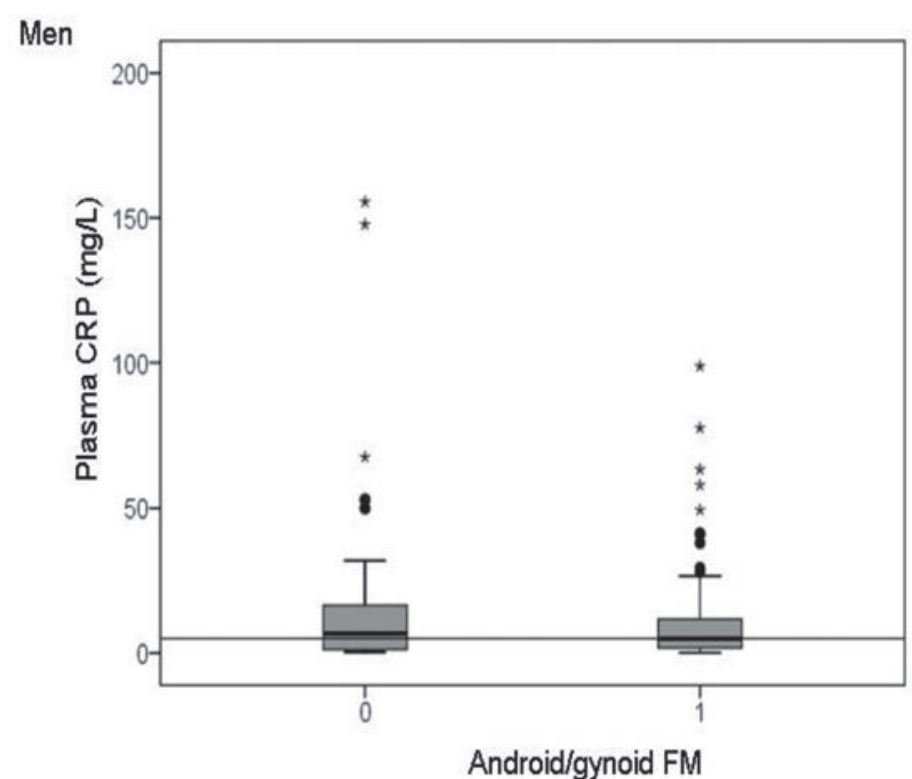

Figure 1b

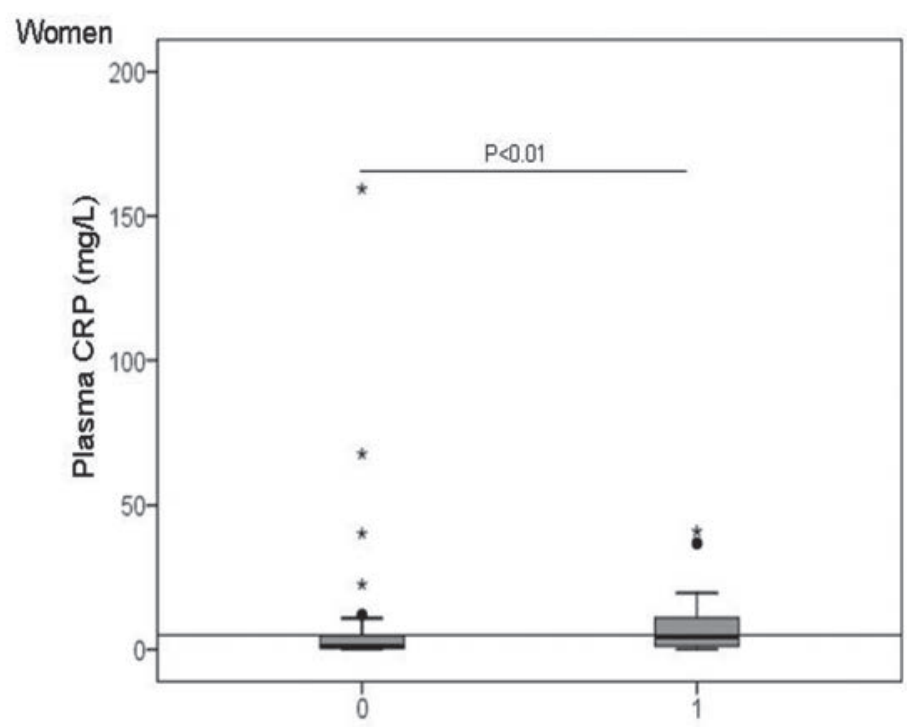

Android/gynoid FM 
Table 2. Stepwise multiple regression analysis with log (CRP) as dependent variable in the whole group

\begin{tabular}{|l|l|l|l|}
\hline \multicolumn{2}{|l|}{ Dependent variable: Log (CRP) } \\
\hline $\mathrm{R}^{2}=$ & 0.14 & & \\
\hline & & B & P-value \\
\hline Age & & 0.19 & $<0.01$ \\
\hline Gender & & 0.22 & $<0.01$ \\
\hline FMI & & 0.23 & $<0.01$ \\
\hline
\end{tabular}

Independent variables: sex, age, BMI, FFMI, FMI, A/G FM.

Abbreviations: CRP: C-reactive protein; BMI: body mass index; FFMI: fat free mass index; FMI: fat mass index, A/G FM: android \%FM / gynoid \%FM.

Table 3. Stepwise multiple regression analysis with log (CRP) as dependent variable in a subgroup of subjects with CRP $<5 \mathrm{mg} / \mathrm{l}$

$(n=168)$

\begin{tabular}{|l|l|l|l|}
\hline \multicolumn{4}{|l|}{ Dependent variable: $\log (\mathrm{CRP})$} \\
\hline $\mathrm{R}^{2}=$ & 0.10 & & \\
\hline & & $\mathrm{B}$ & P-value \\
\hline A/G FM & & 0.32 & $<0.01$ \\
\hline
\end{tabular}

Independent variables: sex, age, BMI, FFMI, FMI, A/G FM.

Abbreviations: CRP: C-reactive protein; BMI: body mass index; FFMI: fat free mass index; FMI: fat mass index, A/G FM: android \%FM / gynoid \%FM. 
Figure 2. Plasma CRP concentration after stratification the subgroup of COPD subjects with CRP levels $<5 \mathrm{mg} / \mathrm{L}$ in 4 groups based on abdominal obesity and muscle wasting.

Significant differences: "with the abdominal obese subjects, twith the subjects with both abdominal obesity and muscle wasting. One symbol indicates $p<0.05$, two $p<0.01$.

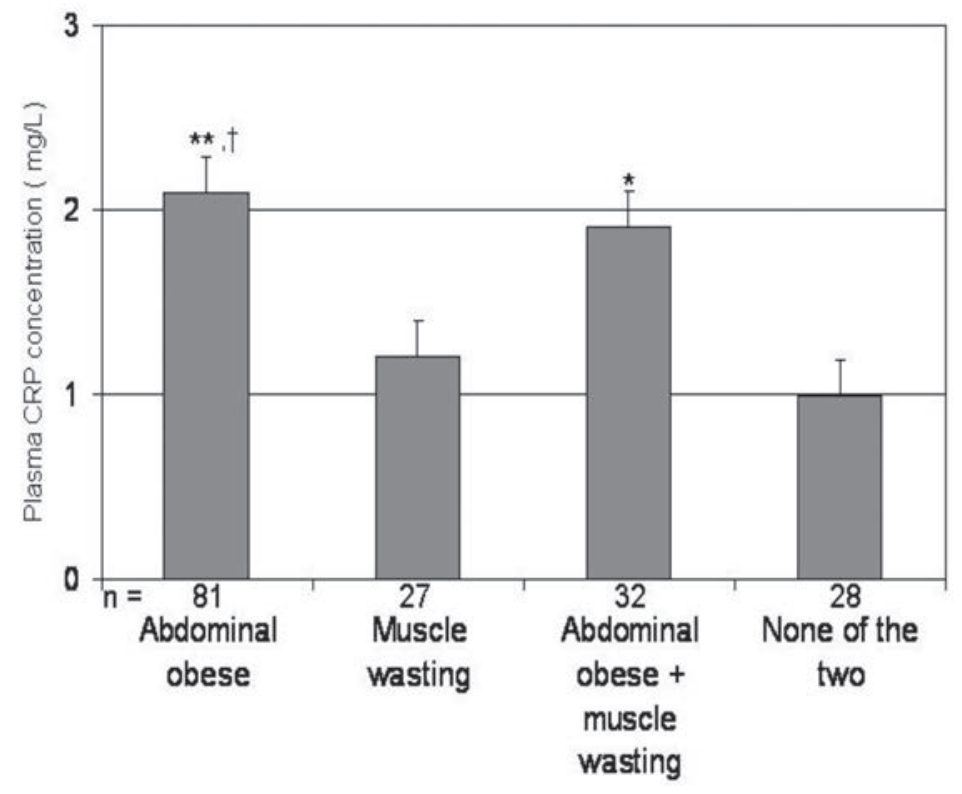

\section{Discussion}

To the best of the authors' knowledge, this study is the first that carefully evaluated fat mass distribution by DEXA scan in relation to systemic inflammation and the presence of muscle wasting in a large group of patients with moderate to severe COPD. The results of the present study indicate that plasma CRP concentration is positively associated with both FMI and abdominal FM in clinically stable patients with COPD. A substantial proportion of patients had both muscle wasting and abdominal obesity and are thus at risk for both functional impairment and increased cardio-metabolic co-morbidity.

The patients with abdominal obesity had higher diffusion capacity and $\mathrm{FEV}_{1} / \mathrm{FVC}$ but the other lung function parameters were not different between the patients with abdominal obesity and those without abdominal obesity, indicating no association between disease severity per se and abdominal FM. This finding appears to be in contrast with the finding that obesity was particularly present in mild-to- 
moderate COPD patients ${ }^{8}$. The latter study was however performed in primary care patients, who's disease condition is likely less complicated with fewer comorbidities than the patients admitted for pulmonary rehabilitation, as included in the present study. It is on the other side previously demonstrated that BMI is, independent of FEV1, positively associated with diffusion capacity in subjects with COPD ${ }^{22}$. A recent report showed a decreased fat free mass and fat mass in emphysematous patients with lower diffusion capacity ${ }^{23}$. On the other side, an increased BMI has been described in chronic bronchitis patients compared to both emphysema patients and healthy control subjects ${ }^{24}$. The result of the present study of a higher diffusion capacity in patients with abdominal obesity is in line with the findings mentioned above. These findings do however not allow us to determine the mechanism between abdominal FM and diffusion capacity. In addition, the question arises if abdominal FM in more advanced COPD has a beneficial or detrimental influence on the disease progression. It has recently been shown that obesity in COPD is associated with a spectrum of metabolic and inflammatory abnormalities ${ }^{25}$, but in contrast, increased BMI seems to play a protective role on survival in more advanced COPD patients ${ }^{26,27}$. The interrelated mechanism of abdominal FM on the disease progression and its metabolic effects and consequences has to be further elucidated.

In the whole study group, plasma CRP concentration was significantly associated with FMI. The association between circulating CRP levels and BMI in patients with COPD has been shown in previous reports 28,29 , but the present study is the first that shows a direct relation between abdominal FM and CRP. Selecting patients with clinically normal CRP concentration showed that plasma CRP concentration was significantly and independently associated with abdominal fat mass. In addition, CRP concentration was higher in the patients with abdominal obesity compared to those without abdominal fat mass, independent of the presence of muscle wasting. The authors performed the analysis in a subgroup of subjects because they believe that the contribution of abdominal fat mass to the systemic inflammation can be covered by other disease related factors, since patients with plasma $C R P>5 \mathrm{mg} / \mathrm{L}$ were defined by an acute phase response ${ }^{21}$. The presence of elevated plasma CRP concentration in patients with COPD has been associated with an increased risk for the development of cardiovascular co-morbidity ${ }^{12}$. However, in the present study, Charlson co-morbidity index was not increased in the patients with abdominal obesity. Although the present study is not able to detect if the contribution of abdominal fat mass to the systemic inflammation is COPD specific, the recognition of the abdominal fat mass as a contributing source for systemic inflammation in COPD is of relevance. However, the clinical relevance of the abdominal fat mass in the systemic pathology of COPD has to be further investigated. 
In the whole study group, men with COPD were more prone to have higher plasma CRP concentration than women. This contrasts with findings of elevated CRP concentrations in women in the healthy population ${ }^{30,31}$, but is in line with previous results in patients with COPD ${ }^{28}$. The reason for this gender related discrepancy is not clear yet; the men in the present study had the same degree of lung function impairment and Charlson co-morbidity score compared to the women. Although we did not report smoking data, a higher amount of pack years in the men can contribute to the higher CRP levels ${ }^{32}$. Moreover, a gender dependent association between abdominal obesity and CRP is supported in the healthy. The relation between fat mass and CRP is stronger in women compared to men $^{30}$; but the gender difference disappeared after correction for subcutaneous adipose tissue in women ${ }^{31}$. These findings are in line with the results of the present study as the android/gynoid fat mass does particularly reflect visceral adipose tissue. Indeed, the multivariate regression model in the subgroup of patients did not include gender.

The results of the present study indicate that body compositional phenotyping muscle wasting and abdominal fat mass might be of importance in the screening of COPD. Subsequently, it can be desirable to detect abdominal obesity in patients with COPD. The clinically accepted bio-electrical impedance has been validated as a suitable tool to assess skeletal muscle mass in the general population as well as in patients with chronic diseases like COPD ${ }^{33}$ and chronic heart failure ${ }^{34}$, but the two-compartment method does not give an appropriate indication for FM distribution. The present study supports the relevance of the assessment of abdominal fat mass (i.e. by waist circumference, DEXA scan), and emphasis the presence of abdominal obesity in about $50 \%$ of the patients with COPD and muscle wasting (in the total group), implying that muscle wasting is not discriminative for abdominal obesity.

Various limitations of the study have to be considered. Firstly, the study is crosssectional and longitudinal data have to confirm our findings. Secondly, there was no age-matched healthy control group included in the present study. It is of relevance to investigate in a subsequent study if the contribution of the abdominal FM on the inflammatory response in subjects with COPD differs from healthy elderly. Thirdly, A/G FM was used to specify abdominal FM. However, there is no cut-off-point for abdominal obesity for measurements by the DEXA technique yet, but an increased A/G FM has been shown to be positively associated with cardiovascular risk ${ }^{15}$ and plasma lipid concentration ${ }^{35}$. In the present study, we used the cut-offs of the waist / hip circumference to define abdominal obesity ${ }^{19}$, but future research is necessary to implement consistent reference values for abdominal obesity with DEXA measurement. Last, in the present study, only plasma levels of CRP are evaluated as CRP is most extensively investigated in 
relation to fat mass ${ }^{36,37}$. Systemic inflammation can however is however also reflected by other cytokines which are not analyzed in the present study.

In conclusion, the present study demonstrated that abdominal fat mass is a significant contributor of the systemic inflammation in clinically stable moderate to severe patients with COPD. Case control studies should be performed to investigate if the extent of the contribution is COPD specific, but the results of the present study indicate that including the assessment of abdominal obesity, besides the screening for muscle wasting in the systemic phenotyping of subjects with COPD is of relevance. 


\section{References}

1. Rabe KF, Beghe B, Luppi F, Fabbri LM. Update in chronic obstructive pulmonary disease 2006. Am J Respir Crit Care Med 2007;175:1222-32.

2. Vermeeren MA, Creutzberg EC, Schols AM, et al. Prevalence of nutritional depletion in a large out-patient population of patients with COPD. Respir Med 2006;100:1349-55.

3. Engelen MP, Schols AM, Lamers RJ, Wouters EF. Different patterns of chronic tissue wasting among patients with chronic obstructive pulmonary disease. Clin Nutr 1999;18:275-80.

4. Gosker HR, Bast $\mathrm{A}$, Haenen $\mathrm{GR}$, et al. Altered antioxidant status in peripheral skeletal muscle of patients with COPD. Respir Med 2005;99:118-25.

5. Baarends EM, Schols AM, Mostert R, Wouters EF. Peak exercise response in relation to tissue depletion in patients with chronic obstructive pulmonary disease. Eur Respir J 1997;10:2807-13.

6. Mostert R, Goris A, Weling-Scheepers C, Wouters EF, Schols AM. Tissue depletion and health related quality of life in patients with chronic obstructive pulmonary disease. Respir Med 2000;94:859-67.

7. Schols AM, Broekhuizen R, Weling-Scheepers CA, Wouters EF. Body composition and mortality in chronic obstructive pulmonary disease. Am J Clin Nutr 2005;82:53-9.

8. Steuten LM, Creutzberg EC, Vrijhoef HJ, Wouters EF. COPD as a multicomponent disease: inventory of dyspnoea, underweight, obesity and fat free mass depletion in primary care. Prim Care Respir J 2006;15:8491.

9. Marquis $\mathrm{K}$, Maltais $\mathrm{F}$, Duguay $\mathrm{V}$, et al. The metabolic syndrome in patients with chronic obstructive pulmonary disease. J Cardiopulm Rehabil 2005;25:226-32; discussion 33-4.

10. Pinto-Plata VM, Mullerova H, Toso JF, et al. C-reactive protein in patients with COPD, control smokers and non-smokers. Thorax 2006;61:23-8.

11. Pistelli R, Lange P, Miller DL. Determinants of prognosis of COPD in the elderly: mucus hypersecretion, infections, cardiovascular comorbidity. Eur Respir J Suppl 2003;40:10s-4s.

12. Sin DD, Man SF. Why are patients with chronic obstructive pulmonary disease at increased risk of cardiovascular diseases? The potential role of systemic inflammation in chronic obstructive pulmonary disease. Circulation 2003;107:1514-9.

13. Vernooy JH, Kucukaycan M, Jacobs JA, et al. Local and systemic inflammation in patients with chronic obstructive pulmonary disease: soluble tumor necrosis factor receptors are increased in sputum. Am J Respir Crit Care Med 2002;166:1218-24.

14. Forouhi NG, Sattar N, McKeigue PM. Relation of C-reactive protein to body fat distribution and features of the metabolic syndrome in Europeans and South Asians. Int J Obes Relat Metab Disord 2001;25:1327-31.

15. Eis SR, Barros SA, Machado RR, Albergaria B, Moana EJ, Borges JC. Fat Mass Measured by DXA and Risk of Cardiovascular Disease. Journal of Bone and Mineral Research 2005;20 Suppl 1:s1-s512.

16. Spruit MA, Vanderhoven-Augustin I, Janssen PP, Wouters EF. Integration of pulmonary rehabilitation in COPD. Lancet 2008;371:12-3.

17. Clausen JL, Coates AL, Quanjer PH. Measurement of lung volumes in humans: review and recommendations from an ATS/ERS workshop. Eur Respir J 1997;10:1205-6.

18. Charlson M, Szatrowski TP, Peterson J, Gold J. Validation of a combined comorbidity index.J Clin Epidemiol 1994:47:1245-51.

19. Heitmann BL. Body fat in the adult Danish population aged 35-65 years: an epidemiological study. Int J Obes 1991;15:535-45.

20. Vestbo J, Prescott E, Almdal T, et al. Body mass, fat-free body mass, and prognosis in patients with chronic obstructive pulmonary disease from a random population sample: findings from the Copenhagen City Heart Study. Am J Respir Crit Care Med 2006;173:79-83.

21. Schols AM, Buurman WA, Staal van den Brekel AJ, Dentener MA, Wouters EF. Evidence for a relation between metabolic derangements and increased levels of inflammatory mediators in a subgroup of patients with chronic obstructive pulmonary disease. Thorax 1996;51:819-24.

22. Baldi S, Pinna GD, Crotti P, et al. Nutritional status and airflow obstruction: two independent contributors to CO diffusing capacity impairment in COPD. Monaldi Arch Chest Dis 2005;63:13-6.

23. Ogawa E, Nakano Y, Ohara T, et al. Body Mass Index in Male Patients with Chronic Obstructive Pulmonary Disease; Correlation with Low Attenuation Areas on CT. Thorax 2009;64:20-5.

24. Guerra S, Sherrill DL, Bobadilla A, Martinez FD, Barbee RA. The relation of body mass index to asthma, chronic bronchitis, and emphysema. Chest 2002;122:1256-63. 
25. Poulain $M$, Doucet $M$, Drapeau $V$, et al. Metabolic and inflammatory profile in obese patients with chronic obstructive pulmonary disease. Chron Respir Dis 2008;5:35-41.

26. Chailleux E, Laaban JP, Veale D. Prognostic value of nutritional depletion in patients with COPD treated by long-term oxygen therapy: data from the ANTADIR observatory. Chest 2003;123:1460-6.

27. Landbo C, Prescott E, Lange P, Vestbo J, Almdal TP. Prognostic value of nutritional status in chronic obstructive pulmonary disease. Am J Respir Crit Care Med 1999;160:1856-61.

28. Breyer MK, Spruit MA, Celis AP, Rutten EP, Janssen PP, Wouters EF. Highly elevated C-reactive protein levels in obese patients with COPD: a fat chance? Clin Nutr 2009;28:642-7.

29. Broekhuizen R, Wouters EF, Creutzberg EC, Schols AM. Raised CRP levels mark metabolic and functional impairment in advanced COPD. Thorax 2006;61:17-22.

30. Abdullah SM, Khera A, Leonard D, et al. Sex differences in the association between leptin and CRP: results from the Dallas Heart Study. Atherosclerosis 2007;195:404-10.

31. Cartier A, Cote M, Lemieux I, et al. Sex differences in inflammatory markers: what is the contribution of visceral adiposity? Am J Clin Nutr 2009;89:1307-14.

32. Bridevaux PO, Gerbase MW, Schindler C, et al. Sex-specific Effect of Body Weight Gain on Systemic Inflammation in Subjects with COPD. Eur Respir J 2009.

33. Schols AM, Wouters EF, Soeters PB, Westerterp KR. Body composition by bioelectrical-impedance analysis compared with deuterium dilution and skinfold anthropometry in patients with chronic obstructive pulmonary disease. Am J Clin Nutr 1991;53:421-4.

34. Uszko-Lencer NH, Bothmer F, van Pol PE, Schols AM. Measuring body composition in chronic heart failure: a comparison of methods. Eur J Heart Fail 2006;8:208-14.

35. Niederauer CM, Binkley TL, Specker BL. Effect of truncal adiposity on plasma lipid and lipoprotein concentrations. J Nutr Health Aging 2006;10:154-60.

36. Cesari M, Kritchevsky SB, Baumgartner RN, et al. Sarcopenia, obesity, and inflammation--results from the Trial of Angiotensin Converting Enzyme Inhibition and Novel Cardiovascular Risk Factors study. Am J Clin Nutr 2005;82:428-34.

37. Festa A, D'Agostino R, Jr., Williams $K$, et al. The relation of body fat mass and distribution to markers of chronic inflammation. Int J Obes Relat Metab Disord 2001;25:1407-15. 



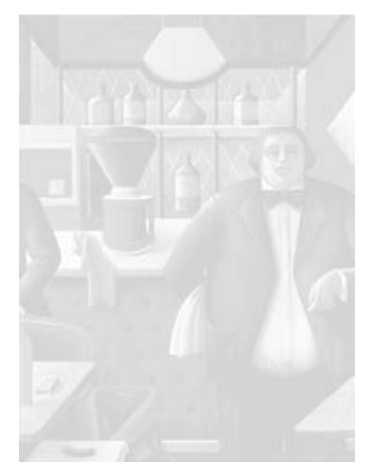

\section{CHAPTER 4}

Systemic inflammation in patients with chronic obstructive pulmonary disease: results from the COSMIC study 



\section{Abstract}

\section{Objective}

The study aims to elucidate the association of host-related factors on systemic inflammation in COPD patients.

\section{Methods}

In 295 clinically stable and optimally treated COPD patients from 39 outpatient centres, age, gender, and body composition (body mass index, BMI; fat-free mass index, FFMI; fat mass index, FMI) were related to inflammatory biomarkers: CRP, fibrinogen, TNF $\alpha$, and its soluble receptors (s)TNF $\alpha$ R1 and sTNF $\alpha$ R2. Furthermore, forced expiratory volume in the first second $\left(\mathrm{FEV}_{1}\right), \mathrm{BMI}, \mathrm{FFMI}$, and FMI were stratified by quartiles to elucidate the influence on inflammatory biomarkers. Monovariate and multivariate regression analyses were performed for associations between inflammatory biomarkers.

\section{Results}

Positive correlations were found for FFMI with sTNF $\alpha$ R1, FMI with CRP and age with TNF $\alpha$, sTNF $\alpha R 1$ and sTNF $\alpha R 2(p<0.01)$. FEV 1 was not correlated with body composition and inflammatory markers. Mono- and multivariate analysis showed weak correlations between the acute phase markers and the TNF $\alpha$ system after correcting for multiple co-variants.

\section{Conclusions}

This study highlights the modest role of age and body composition on levels of systemic inflammatory biomarkers in COPD. Results show the degree of airflow limitation does not affect systemic inflammation. Last, a weak relationship between acute phase markers and markers of the TNF $\alpha$ system is present in COPD. 


\section{Introduction}

Chronic obstructive pulmonary disease (COPD), until recently exclusively characterized by poorly reversible airflow limitation, is now approached as a heterogeneous, multi-component disease condition'. Supporting this notion, patients with COPD generally have low-grade systemic inflammation compared with healthy elderly subjects ${ }^{2-4}$.

With respect to the high heterogeneity of systemic inflammation, serum C-reactive protein (CRP), fibrinogen, and Tumour Necrosis Factor alpha (TNF $\alpha$ ) and its soluble receptors (s)TNF $\alpha R 1$ and 2 have been typically studied as systemic inflammatory biomarkers, yet in rather small-sized studies 3,5 . CRP, a systemic biomarker of the acute-phase response, is increased in COPD compared to healthy subjects $^{6}$ and is related to an increased risk for cardiac injury ${ }^{7}$, hospitalizations 8 , and worse survival ${ }^{9}$. Fibrinogen is associated with worse lung function and poor prognosis in COPD ${ }^{5,10}$. The TNF $\alpha$ system is often investigated in relation to the genesis of cachexia in COPD ${ }^{11}$. Together, available data show that increased systemic inflammation results in clinically relevant events in COPD.

Chronic low-grade systemic inflammation is present in all subjects with stable COPD and reflects spill-over of the airways and parenchyma, promoting a generalised inflammatory reaction ${ }^{2}$. However, this concept has not been proven so $\mathrm{far}^{3}$. Indeed, others could only find little or no statistically significant association between disease severity based on airflow limitation and CRP and TNF $\alpha$ in $\mathrm{COPD}^{12}$. Besides lung inflammation, host-related factors, such as higher age, female sex, higher body mass index, and smoking contribute to increased systemic inflammation in COPD ${ }^{13-15}$.

The aim of the present study was to evaluate the influence of host-related determinants, including age, gender, body composition, and smoking status on systemic inflammatory biomarkers in a large sample of clinically stable, optimally treated outpatients with COPD. Furthermore, the interrelationship between these circulating inflammatory biomarkers is studied.

\section{Methods}

\section{Study population}

Data were collected from 295 COPD patients participating in the COSMIC (COPD and Seretide: a Multi-Center Intervention and Characterization) study (post-bronchodilator $\mathrm{FEV}_{1}$ between 30 and $80 \%$ predicted; $\mathrm{FEV}_{1} / \mathrm{FVC}$ ratio $<70 \%$ predicted) at 39 outpatient centers in the Netherlands ${ }^{16}$. The central ethi- 
cal committee in the Netherlands and the local medical ethics committees of the participating centers approved the study. All subjects gave written informed consent. Patients between 40 and 75 years of age, current or ex-smokers and with established COPD were included. Performance of lung function and measurement of body composition parameters have been reported elsewhere ${ }^{17}$. Briefly, body-, fat free-, and fat mass index (BMI, FFMI, FMI) were calculated. All patients were inhaling a combination therapy including a beta ${ }^{2}$ agonist as well as a corticosteroid twice daily for at least 12 weeks prior to study entry $(25 \mu \mathrm{g}$ Salmeterol and 50 (COPD II), 125 (COPD III), and 250 Hg (COPD IV) Fluticasone propionate $=$ Seretide ${ }^{\circledR}$. In this period, patients had no exacerbations to obtain maximum stability in the clinical condition of the COPD patients included. The clinical records were searched for the number of pack years (PY; the number of packs of cigarettes smoked per day multiplied by the number of years) and patients smoking status (current or former smoker).

\section{Measurements}

Plasma high-sensitivity CRP was assessed by a particle-enhanced immune-nephelometry (BN Prospec, Dade Behring). The lower detection level for hs-CRP was $0.175 \mathrm{mg} / \mathrm{L}$ with a range of $0.175-1100 \mathrm{mg} / \mathrm{L}$, depending on the dilution. Fibrinogen was assessed on Sysmex (Dade-Behring) CA-7000 coagulation analyzer according to the Clauss method and calculated from EDTA to citrate plasma values. The measuring range was 0.3-10.0 $\mathrm{g} / \mathrm{L}$. TNF $\alpha$ was determined with the Quantikine ${ }^{\circledR}$ high sensitivity ELISA from R\&D systems (Minneapolis, USA). sTNF $\alpha$ R1 and R2 were measured by enzyme-linked immunosorbent assay (ELI$\mathrm{SA}$ ) as described previously18. Lower detection level for TNF $\alpha$ was $0.5 \mathrm{pg} / \mathrm{mL}$. Lower detection levels for the assays were $40 \mathrm{ng} / \mathrm{mL}$ for sTNF $\alpha R 1$ and $70 \mathrm{ng} /$ $\mathrm{mL}$ for $\mathrm{sTNF} \alpha \mathrm{R} 2$.

\section{Statistical analyses}

Values are given by median and $25^{\text {th }}-75^{\text {th }}$ percentiles. The Kruskal-Wallis nonparametric test was performed to evaluate differences in median levels of systemic inflammatory biomarkers and body composition markers by quartiles. Afterwards, the post-hoc nonparametric Mann Whitney $U$ Test was performed. Linear dependency between the systemic inflammatory biomarkers and the host-related determinants were tested using the Pearson correlation coefficient and non-parametric dependency within the systemic inflammatory biomarkers was calculated using the Spearman correlation coefficient. The stepwise multivariate linear regression model was performed with a single systemic inflammatory biomarker as dependent variables and the host-relating factors and the remaining inflammatory biomarkers as independent variables. In these analyses all systemic inflammatory biomarkers, except fibrinogen, were transformed logarithmically to approximate 
normal distributions; the body composition markers BMI, FFMI and FMI showed no co-linearity. Analyses were performed using Statistical Package for the Social Sciences (SPSS) version 15.01 for Windows. A priori, $\mathrm{p}<0.05$ (two-sided) was considered the level of significance.

\section{Results}

\section{Characteristics}

Patients were generally having mild to moderate COPD, a high BMI and a normal FFMI (Table 1). Median levels of systemic inflammatory biomarkers were 3.88 $\mathrm{mg} / \mathrm{L}$ for CRP, $3.45 \mathrm{~g} / \mathrm{L}$ for fibrinogen, $1.63 \mathrm{pg} / \mathrm{mL}$ for $T N F \alpha, 0.83 \mathrm{ng} / \mathrm{mL}$ for sTNF $\alpha$ R1, and $1.81 \mathrm{ng} / \mathrm{mL}$ for sTNF $\alpha$ R2. Female COPD patients were younger, more frequently current smokers, had a higher FMI and lower median levels of sTNF $\alpha$ R1 than males.

In order to evaluate an effect of disease severity on systemic inflammatory biomarkers and body composition, patients were stratified into quartiles based on $\mathrm{FEV}_{1} \%$ predicted. No differences were found for CRP, fibrinogen, TNF $\alpha$ and its soluble receptors or any of the body composition markers between $\mathrm{FEV}_{1}$ quartiles (Table 1 in the online supplement). 
Table 1. Baseline characteristics

\begin{tabular}{|c|c|c|c|}
\hline \multirow[b]{2}{*}{$\mathrm{N}=295$} & \multicolumn{3}{|c|}{ Median $\left(25^{\text {th }}-75^{\text {th }}\right.$ percentile $)$} \\
\hline & All patients & male $(n=213)$ & female $(n=82)$ \\
\hline Age; years & $64.0(57.0-70.0)$ & $66.0(66.0-70.0)$ & $58.0 *(52.8-65.0)$ \\
\hline Gender; \% & & 72.1 & 27.9 \\
\hline Packyears & $33.0(24.5-44.0)$ & $33.0(24.5-50.0)$ & $32.0(24.0-40.0)$ \\
\hline \multicolumn{4}{|l|}{ Smoking status; \% } \\
\hline current & 62 & $33 *$ & 51 \\
\hline former & 38 & $67 *$ & 49 \\
\hline $\mathrm{FEV}_{1} ; \%$ predicted & $44.6(38.3-58.0)$ & $44.2(36.2-57.4)$ & $49.2(40.4-59.0)$ \\
\hline $\mathrm{FEV}_{1} / \mathrm{FVC} ; \%$ predicted & $44.8(37.6-53.7)$ & $43.4(36.2-52.3)$ & $48.7(42.3-56.1)$ \\
\hline GOLD I / II / III / IV; \% & $3 / 50 / 45 / 2$ & $2 / 47 / 48 / 3$ & $6 / 57 / 35 / 2$ \\
\hline $\mathrm{BMI} ; \mathrm{kg} / \mathrm{m}^{2}$ & $26.1(23.5-29.4)$ & $26.0(23.4-29.1)$ & $25.7(22.3-29.4)$ \\
\hline FFMI; kg/m² & $17.4(15.7-19.0)$ & $17.8(16.4-19.2)$ & $15.7(14.7-17.1)$ \\
\hline $\mathrm{FMl} ; \mathrm{kg} / \mathrm{m}^{2}$ & $8.63(6.85-10.7)$ & $8.21(6.64-10.1)$ & $10.0 *(7.37-12.8)$ \\
\hline CRP; mg/L & $3.88(1.78-7.90)$ & $3.77(1.82-7.57)$ & $4.29(1.59-8.29)$ \\
\hline Fibrinogen; g/L & $3.45(2.86-3.89)$ & $3.42(2.43-3.72)$ & $3.46(2.87-3.79)$ \\
\hline TNF $\alpha ; p g / m L$ & $1.63(1.30-2.15)$ & $1.63(1.32-2.20)$ & $1.62(1.22-2.11)$ \\
\hline sTNF $\alpha R 1 ; n g / m L$ & $0.83(0.66-1.01)$ & $0.86(0.69-1.00)$ & $0.78 \#(0.60-0.98)$ \\
\hline $\mathrm{sTNF} \alpha \mathrm{R} 2 ; \mathrm{ng} / \mathrm{mL}$ & $1.81(1.52-2.25)$ & $1.80(1.54-2.26)$ & $1.78(1.44-2.22)$ \\
\hline
\end{tabular}

$\mathrm{FEV}_{1}$, forced expiratory volume in the first second; FVC, forced vital capacity; BMI, body mass index; FFMI, fat free mass index; FMI, fat mass index; FM, fat mass; CRP, C-reactive protein; TNF $\alpha$, tumour necrosis factor $\alpha$; sTNF $\alpha$ R1, R2; soluble TNF $\alpha$ receptor 1, 2. * $p<0.01$, \#p<0.05 compared to males. 


\section{Influence of host-related factors on systemic inflammatory biomarkers (Table 2)}

While none of the systemic inflammatory biomarkers correlated with gender, and smoking status, fibrinogen, TNF $\alpha$ and its soluble receptors correlated positively with age. Additionally, sTNF $\alpha$ R1 levels correlated positively with gender. Both $\mathrm{BMI}$ and FMI were positively correlated with plasma levels of CRP, sTNF $\alpha$ R1 and sTNF $\alpha$ R2, while FFMI was positively correlated with sTNF $\alpha$ R1. Stratifying $\mathrm{BMI}, \mathrm{FFMI}$ and FMI into quartiles, median levels of CRP were lower in the first quartile of FMI compared to the third and fourth quartile (Figure 1A). Median levels of sTNF $\alpha$ R1 were significantly lower in the first and second quartiles of BMI compared to the fourth quartile (Figure 1B), and were lower in the first quartile of FFMI compared to the third and fourth quartile (Figure 1C). No differences in fibrinogen, TNF $\alpha$, and sTNF $\alpha$ R2 levels were observed with quartiles in body composition markers (Table 2 for BMI, Table 3 for FFMI, and Table 4 for FMI in the online supplement).

Table 2. Pearson monovariate correlation coefficients of the studied systemic inflammatory biomarkers with host-related determinants.

\begin{tabular}{|l|l|l|l|l|l|l|l|l|l|l|}
\hline & \multicolumn{2}{l}{ Log(CRP) } & \multicolumn{2}{l|}{ fibrinogen } & \multicolumn{2}{l|}{$\log (T N F \alpha)$} & \multicolumn{2}{l|}{ Log(sTNF $\alpha$ R1) } & \multicolumn{2}{l|}{ Log(sTNF $\alpha$ R2) } \\
\hline $\mathrm{n}=295$ & rho & $\mathrm{p}$-value & rho & $\mathrm{p}$-value & rho & $\mathrm{p}$-value & rho & $\mathrm{p}$-value & rho & $\mathrm{p}$-value \\
\hline age & 0.12 & 0.06 & 0.17 & $<0.01$ & 0.153 & 0.01 & 0.35 & $<0.01$ & 0.22 & $<0.01$ \\
\hline gender & -0.05 & 0.42 & -0.01 & 0.86 & -0.38 & 0.52 & -0.13 & 0.05 & -0.05 & 0.40 \\
\hline PY & 0.09 & 0.13 & 0.05 & 0.46 & 0.044 & 0.46 & 0.03 & 0.56 & 0.01 & 0.90 \\
\hline BMI & 0.15 & 0.012 & -0.02 & 0.74 & 0.07 & 0.25 & 0.22 & $<0.01$ & 0.14 & 0.02 \\
\hline FFMI & 0.10 & 0.09 & -0.05 & 0.41 & 0.08 & 0.18 & 0.22 & $<0.01$ & 0.12 & 0.05 \\
\hline FMI & 0.15 & 0.01 & 0.01 & 0.91 & 0.04 & 0.47 & 0.15 & $<0.01$ & 0.12 & 0.04 \\
\hline
\end{tabular}

PY, pack years; BMI, body mass index; FFMI, fat free mass index, FMI, fat mass index; Log(CRP), C-reactive protein; $\log (T N F \alpha)$, tumour necrosis factor $\alpha$; Log(sTNF $\alpha R 1)$, 2; soluble TNF $\alpha$ receptor 1,2 . 
Figure 1. Median levels of CRP after stratification of FMI by quartiles (A), median levels of sTNF $\alpha$ R1 after stratification of BMI by quartiles (B) as well as FFMI (C).

Figure 1.

A.

$$
p<0.01
$$

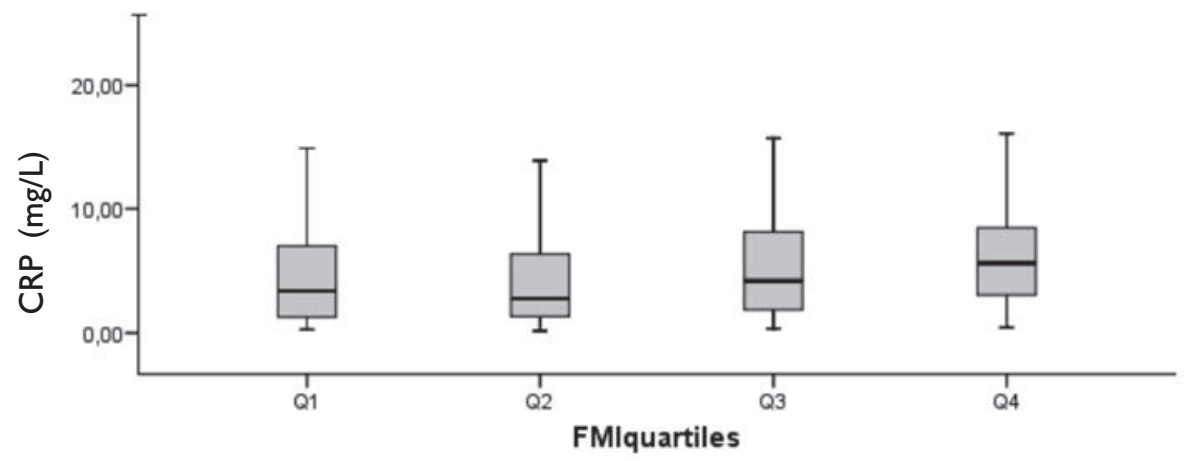

B.

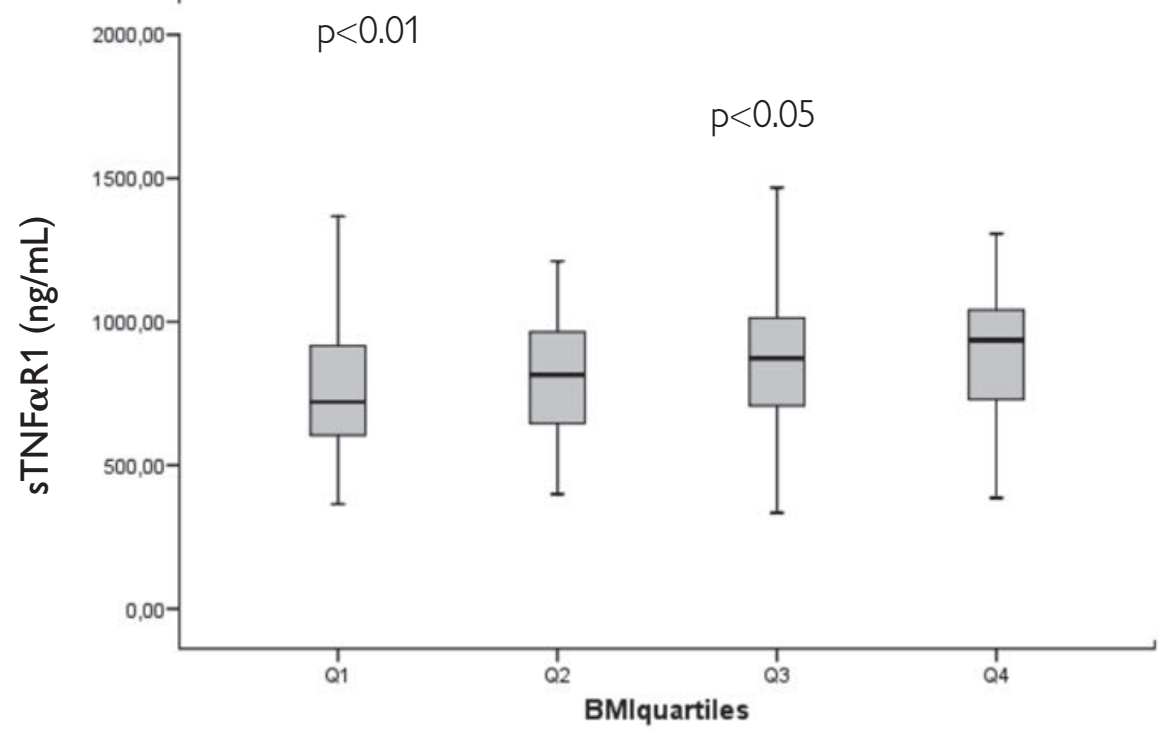


C.

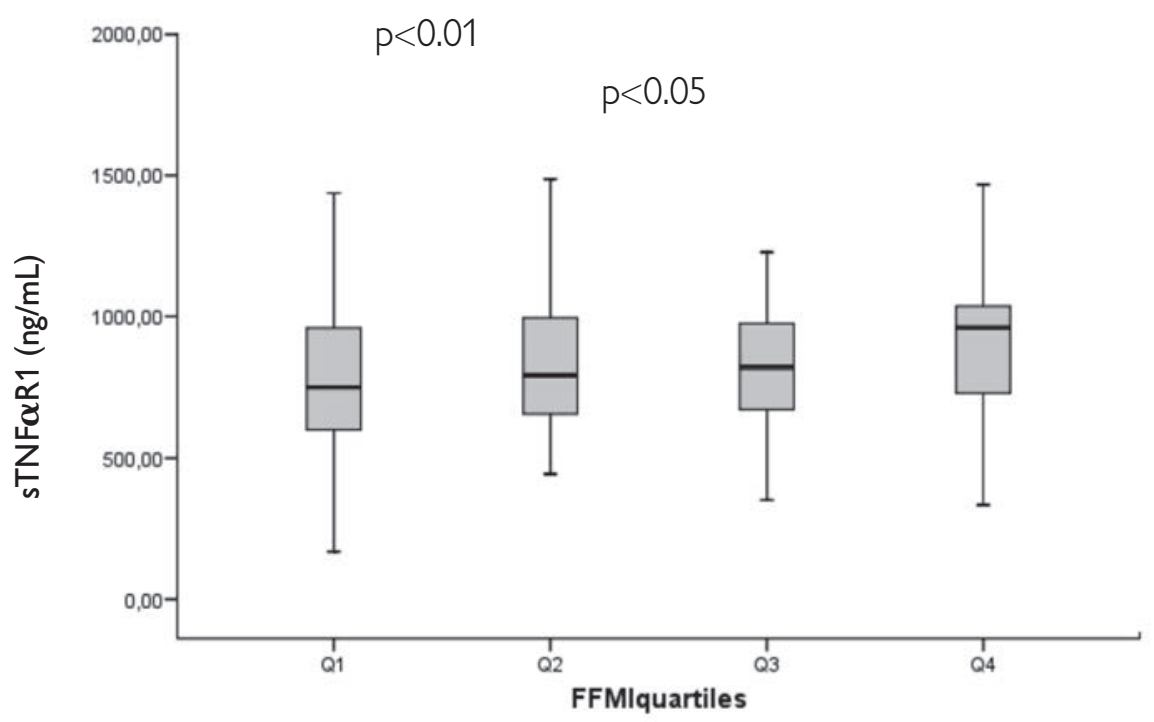

\section{Association between the different systemic inflammatory biomarkers (Table 3)}

A moderate correlation between CRP and fibrinogen was found, while weaker correlations were found between CRP and the TNF $\alpha$ system. TNF $\alpha$ correlated weakly with its soluble receptors. Moreover, the TNF $\alpha$ system correlated weakly with fibrinogen. All correlations showed a positive direction.

Table 3. Spearman monovariate correlation coefficients of the studied systemic inflammatory biomarkers

\begin{tabular}{|l|l|l|l|l|l|l|l|l|l|l|}
\hline & \multicolumn{3}{l}{ CRP } & fibrinogen & TNF $\alpha$ & \multicolumn{3}{l|}{ sTNF $\alpha$ R1 } & \multicolumn{2}{l|}{ sTNF $\alpha$ R2 } \\
\hline n=295 & rho & p-value & rho & p-value & rho & p-value & rho & p-value & rho & p-value \\
\hline CRP & - & - & 0.536 & 0.000 & 0.178 & 0.003 & 0.276 & 0.000 & 0.158 & 0.008 \\
\hline fibrinogen & 0.536 & 0.000 & - & - & 0.134 & 0.039 & 0.306 & 0.000 & 0.094 & 0.145 \\
\hline TNF $\alpha$ & 0.178 & 0.003 & 0.134 & 0.039 & - & - & 0.312 & 0.000 & 0.332 & 0.000 \\
\hline sTNF $\alpha$ R1 & 0.158 & 0.008 & 0.094 & 0.145 & 0.332 & 0.000 & - & - & 0.687 & 0.000 \\
\hline sTNF $\alpha$ R2 & 0.276 & 0.000 & 0.306 & 0.000 & 0.312 & 0.000 & 0.687 & 0.000 & - & - \\
\hline
\end{tabular}

CRP, C-reactive protein; TNF $\alpha$, tumour necrosis factor $\alpha$; sTNF $\alpha$ R1, R2; soluble TNF $\alpha$ receptor $1,2$. 


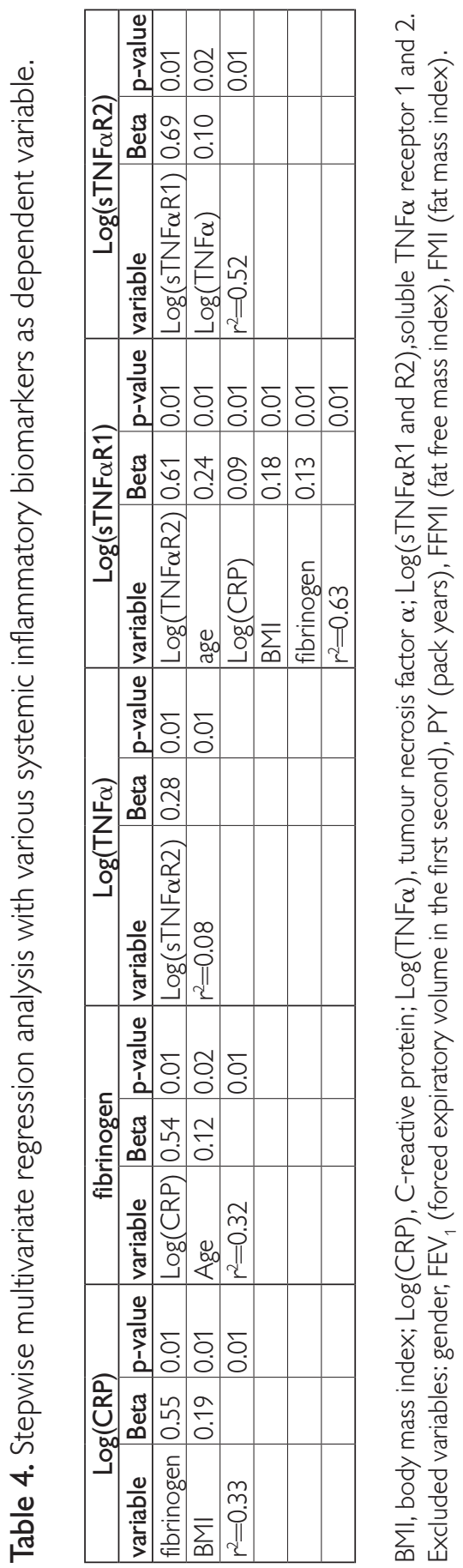




\section{Stepwise multivariate regression analysis of individual systemic inflammatory biomarkers}

Fibrinogen and BMI explained 33\% of the variance in CRP (Table 4), while CRP and age explained $32 \%$ of the variance in fibrinogen. When analysing TNF $\alpha$ as dependent variable, only sTNF $\alpha$ R2 remained in the model; using sTNF $\alpha R 1$ as dependent variable, TNF $\alpha$ R2, age, CRP, BMI and fibrinogen remained in the final model, while sTNF $\alpha R 1$ and TNF $\alpha$ were independent determinants of sTNF $\alpha R 2$.

\section{Discussion}

The present study confirms moderate associations of host-related factors, i.e. $\mathrm{BMI}$ and age, with systemic inflammatory biomarkers, such as CRP, fibrinogen and sTNF $\alpha$ R1. Otherwise, the degree of airflow limitation, gender, fat free mass index, fat mass index and smoking status do not seem to significantly explain the variance observed in the studied systemic inflammatory biomarkers in patients with mild-to-moderate COPD. Last, a weak relationship between acute phase markers and markers of the TNF $\alpha$ system is present in COPD patients.

\section{Disease-related factors}

The current study confirms previous reports that inflammatory markers cannot discriminate on disease stages of COPD ${ }^{12,19}$. However, one study found decreasing levels of sTNF $\alpha$ R1 with lower FEV 1 values in multiple regression analysis ${ }^{20}$. These data could not be confirmed in the present study. Others have reported that by applying protein microarray platform technology, systemic biomarkers are associated with different clinical variables including the degree of airflow limitation and carbon monoxide transfer factor ${ }^{21}$. Carbon monoxide transfer factor was not assessed in the present study. The last mentioned finding implies an association between systemic inflammation and the level of emphysema, which was not assessed in the present study. In addition, the study by Pinto-Plata and colleagues ${ }^{21}$ included other biomarkers as in the present study. Based on the concept of spill-over ${ }^{2}$ and the assumed progressive inflammation with more impaired lung function ${ }^{22}$, a more pronounced systemic inflammatory response with progressive airflow limitation could be hypothesised. However, an important overlap in airway inflammation has been reported between different GOLD stages as well as within each GOLD stage category ${ }^{23}$. The same authors reported no relationship between local and systemic inflammation, confirming previous reported data that challenge the spill-over theory ${ }^{3}$. These data favour the concept that additional confounders contribute to the systemic inflammation in COPD. The absence of a relationship between progressive airflow limitation and systemic inflammation we and others have found cannot rule out a contributing role of emphysema in this respect. Further studies using state of the art diagnostic procedures of emphysema are needed to unravel the influence of emphysema on systemic inflammation. 


\section{Host-related factors}

The results from the present study show increasing CRP levels with increasing $\mathrm{BMI}$ and $\mathrm{FMI}$ values. Furthermore, BMI remained in the final multivariate regression model on CRP which is in line with a positive relationship of increased levels of CRP in obese patients with COPD (BMI $\geq 30 \mathrm{~kg} / \mathrm{m}^{2}$ ) compared to normal peers ${ }^{13}$. Levels of fibrinogen showed no relation with body composition markers. The soluble TNF $\alpha$ receptor levels correlated positively with BMI in monovariate analyses and even after correcting for confounders in the multiple regression analyses, BMI independently determined levels of sTNF $\alpha$ R1. In line, Takabatake and colleagues reported an association between both sTNF $\alpha$ receptors and the percentage of fat mass in COPD ${ }^{24}$. A recent manuscript concluded that both circulating CRP and sTNF $\alpha$ R1 were positively associated with fat mass rather than fat free mass ${ }^{20}$, data which are confirmed in the present study.

Aging induces an inflammatory response and this has been proposed as a key for age-related diseases ${ }^{25,26}$. An age-dependent increase in the TNF $\alpha$ system in the elderly population has been reported ${ }^{27}$. Despite the small age range of the present study ( $25^{\text {th }}-75^{\text {th }}$ percentile: $57-70$ years), our analysis showed that age remained an independent determinant for TNF $\alpha$ R 1 and fibrinogen in the multivariate regression models. Epidemiological data suggest an age-related increase of serum levels of fibrinogen ${ }^{28}$, based on an age-related slower rate of disposal of fibrinogen ${ }^{29}$.

We did not find a gender effect on the analysed markers of systemic inflammation, which was also found in other studies ${ }^{20}$. However, worth noting, differences in other mediators as the adipokines seem gender related. Increased levels of leptin have been reported in obese COPD women compared to non-obese counterparts ${ }^{30}$. In addition, increased levels of circulating leptin might lead to an increased CRP production from hepatocytes due to direct signalling pathways ${ }^{31}$. This is in line with an observed increase in CRP levels with increasing body weight (reflecting an increased amount of adipose tissue) in female COPD patients ${ }^{32}$, implying that, although no gender differences could be detected in the present study, the signalling pathways of systemic inflammation could be gender dependent. Indeed, it has recently been shown that other inflammatory biomarkers like Interleukin-6, Interleukin-16 and the vascular endothelial growth factor are gender dependent in patients with $\mathrm{COPD}^{33}$.

The direct adverse effects of inhaled cigarette smoke on lung health ${ }^{34}$ and on other organ systems as the result of an indirect exposure are well established ${ }^{35}$. Although cigarette smoke is the main risk factor for COPD, the relationship between smoke exposure and the degree of airflow limitation is only poor ${ }^{36}$. In the present study no effect of pack years or smoking status was found on $\mathrm{FEV}_{1}$. In the general population a dose-response as well as a dose-effect (number of pack years) relationship between cigarette smoking and increased levels of CRP and fibrinogen is reported ${ }^{37-39}$. Interestingly, until 19 years after smoking cessation CRP levels are still increased and do not revert to levels of never smokers ${ }^{40}$. Indeed, 
no differences in CRP levels were found between current and former smokers in the present study (data not shown). However, a sample-size effect cannot be ruled out. Limited data are available on the effects of cigarette smoke on levels of TNF $\alpha$. While some report increased levels of TNF $\alpha$ in healthy smokers ${ }^{41}$ others failed to confirm these results ${ }^{42}$. We also found no effect of smoking status or pack years on levels of the TNF $\alpha$ system.

Consensus is growing that the inflammatory processes that underlie COPD are probably mediated by a multitude of cytokines. In the present study we have focused on the acute phase markers CRP and fibrinogen and on markers of the TNF $\alpha$ system. These markers are most typically studied in COPD patients. Increased levels of CRP and fibrinogen have been reported in stable COPD patients compared to healthy controls ${ }^{2}$, and both seem to rise even more during acute COPD exacerbations ${ }^{4,43}$. Furthermore, increased CRP and fibrinogen levels have both been shown to be associated with an increased risk for cardiovascular disease and mortality in COPD 7.9 . More conflicting is the role of the TNF $\alpha$ system in COPD: levels of TNF $\alpha$ have previously shown to be elevated in patients with COPD compared to healthy controls ${ }^{44,45}$, whereas more recent studies have not confirmed this ${ }^{11,46-48}$. Even more recently, reported absolute levels appeared even lower and no differences could be found based on severity of COPD ${ }^{49}$. These differences could be related to assay specificity in the past years ${ }^{11}$. Interestingly, a clinical trial of short-term anti-TNF $\alpha$ treatment in patients with COPD found no effect on the TNF $\alpha$ system ${ }^{50}$. Furthermore, using a broad panel of inflammation associated analytes, anti-TNF $\alpha$ treatment does not affect systemic inflammatory profile in COPD ${ }^{51}$. The present study is the first investigating the correlation between different markers for systemic inflammation, namely markers of the acute phase response and markers of the TNF $\alpha$ system. A previous research in a small cohort $(n=58)$ found no correlation between CRP and the TNF $\alpha$ system ${ }^{52}$. These data illustrate the complexity of the role of systemic inflammation in the pathogenesis of COPD and COPD related co-morbidities.

\section{Limitations}

The following limitations have to be recognised: Firstly, CRP, fibrinogen and TNF $\alpha$ measures are only parts of the pathological pathways proposed in the low-grade systemic inflammation in patients with COPD and other pathways might become identified to have a more prominent role in the low-grade systemic inflammation in patients with COPD. Secondly, the lack of a control group, however this is the first study taking blood samples from patients receiving standardized combination therapy as well as having a controlled exacerbation-free period. Thirdly, in the present study no information is included about direct or indirect assessment of activity patterns. Exercise is however suggested to have a benefit role on systemic inflammation in COPD, and as it is previously shown, physical activity is related to fibrinogen levels in $\mathrm{COPD}^{53}$, and registration of physical activity levels would be interesting. 


\section{Conclusion}

In conclusion, host-related factors like body composition and age have a modest role in the systemic inflammation in optimally treated and clinically stable mildto-moderate COPD patients. In addition, our study underscores the high heterogeneity among various biomarkers of systemic inflammation.

\section{Online Supplement}

Table 1. Systemic inflammatory and body composition markers after stratification for disease severity $\left(\mathrm{FEV}_{1}\right)$ by quartiles (Q1-Q4).

\begin{tabular}{|l|l|l|ll|}
\hline $\begin{array}{l}\text { FEV }_{1}, \% \text { predicted } \\
\left(25^{\text {th}}-75^{\text {th }} \text { percentile }\right)\end{array}$ & Q1 & Q2 & Q3 & Q4 \\
\hline CRP; $\mathrm{mg} / \mathrm{L}$ & $4.23(1.82-8.33)$ & $3.58(1.88-7.17)$ & $3.88(1.59-10.5)$ & $3.28(1.58-6.52)$ \\
\hline fibrinogen; g/L & $3.45(3.00-4.04)$ & $3.16(2.79-3.89)$ & $3.45(2.86-3.75)$ & $3.45(2.97-3.89)$ \\
\hline TNF $\alpha ; \mathrm{pg} / \mathrm{mL}$ & $1.62(1.30-2.06)$ & $1.76(1.28-2.24)$ & $1.52(1.27-1.96)$ & $1.77(1.40-2.37)$ \\
\hline sTNF $\alpha \mathrm{R} 1 ; \mathrm{ng} / \mathrm{mL}$ & $0.85(0.62-0.99)$ & $0.80(0.62-1.03)$ & $0.83(0.67-1.01)$ & $0.81(0.66-0.98)$ \\
\hline sTNF $\alpha R 2 ; \mathrm{ng} / \mathrm{mL}$ & $1.76(1.44-2.03)$ & $1.70(1.50-2.25)$ & $1.86(1.54-2.32)$ & $1.87(1.54-2.42)$ \\
\hline BMI; $\mathrm{kg} / \mathrm{m}^{2}$ & $25.4(22.5-29.4)$ & $25.5(22.7-29.0)$ & $25.5(23.1-29.1)$ & $26.9(24.6-29.8)$ \\
\hline FFMI; kg/m² & $17.3(15.7-19.0)$ & $16.9(15.5-18.4)$ & $17.3(15.7-18.6)$ & $17.7(15.9-19.2)$ \\
\hline FMI; kg/m² & $8.28(6.28-10.8)$ & $8.44(6.73-10.6)$ & $8.63(6.62-10.4)$ & $9.29(7.70-11.7)$ \\
\hline
\end{tabular}

$\mathrm{FEV}_{1}$, forced expiratory volume in the first second; CRP, C-reactive protein; $\mathrm{TNF} \alpha$, tumour necrosis factor $\alpha$; sTNF $\alpha$ R1, R2; soluble TNF $\alpha$ receptor 1, 2; BMI, body mass index; FFMI, fat free mass index; FMI, fat mass index.

Table 2. Systemic inflammatory biomarkers after stratification for BMI by quartiles (Q1-Q4).

\begin{tabular}{|l|l|l|l|l|}
\hline $\begin{array}{l}\text { BMl, } \mathrm{kg} / \mathrm{m}^{2} \\
\left(25^{\text {th-75 }} 5^{\text {th }} \text { percentile }\right)\end{array}$ & Q1 & Q2 & Q3 & Q4 \\
\hline CRP; $\mathrm{mg} / \mathrm{L}$ & $3.18(1.33-7.25)$ & $3.86(1.61-6.47)$ & $3.26(1.57-8.57)$ & $5.44(2.70-8.06)$ \\
\hline fibrinogen; g/L & $3.45(3.00-3.92)$ & $3.30(2.86-2.89)$ & $3.45(2.86-3.86)$ & $3.30(2.71-3.74)$ \\
\hline TNF $\alpha ; \mathrm{pg} / \mathrm{mL}$ & $1.57(1.19-1.99)$ & $1.75(1.29-2.54)$ & $1.64(1.35-2.14)$ & $1.62(1.32-2.33)$ \\
\hline sTNF $\alpha R 1 ; \mathrm{ng} / \mathrm{mL} *$ & $0.72(0.60-0.92)$ & $0.81(0.63-0.96)$ & $0.87(0.74-1.01)$ & $0.93(0.72-1.04)$ \\
\hline sTNF $\alpha R 2 ; \mathrm{ng} / \mathrm{mL}$ & $1.66(1.40-2.10)$ & $1.80(1.53-2.34)$ & $1.81(1.51-2.23)$ & $1.96(1.58-2.42)$ \\
\hline
\end{tabular}

BMI, body mass index; CRP, C-reactive protein; TNF $\alpha$, tumour necrosis factor $\alpha$; sTNF $\alpha$ R1, R2; soluble TNF $\alpha$ receptor $1,2$.

*With increasing BMI sTNF $\alpha$ R1 increased. 
Table 3. Systemic inflammatory biomarkers after stratification for FFMI by quartiles (Q1-Q4).

\begin{tabular}{|l|l|l|l|l|}
\hline $\begin{array}{l}\text { FFMI, } \mathrm{kg} / \mathrm{m}^{2} \\
\left(25^{\text {h }}-75^{\text {th }} \text { percentile }\right)\end{array}$ & Q1 & Q2 & Q3 & Q4 \\
\hline CRP; $\mathrm{mg} / \mathrm{L}$ & $4.29(1.34-8.47)$ & $3.68(1.74-7.40)$ & $3.45(1.83-6.61)$ & $4.38(2.15-8.43)$ \\
\hline fibrinogen; g/L & $3.45(2.89-4.04)$ & $3.45(2.86-3.89)$ & $3.03(2.86-3.74)$ & $3.45(2.78-3.81)$ \\
\hline TNF $\alpha ; \mathrm{pg} / \mathrm{mL}$ & $1.60(1.2-2.00)$ & $1.61(1.27-2.27)$ & $1.63(1.29-2.18)$ & $1.75(1.37-2.36)$ \\
\hline sTNF $\alpha R 1 ; \mathrm{ng} / \mathrm{mL} *$ & $0.75(0.59-0.96)$ & $0.79(0.65-0.99)$ & $0.82(0.66-0.98)$ & $0.96(0.73-1.04)$ \\
\hline sTNF $\alpha R 2 ; \mathrm{ng} / \mathrm{mL}$ & $1.74(1.51-2.14)$ & $1.73(1.51-2.22)$ & $1.78(1.42-2.25)$ & $1.88(1.57-2.38)$ \\
\hline
\end{tabular}

FFMI, fat free mass index; CRP, C-reactive protein; TNF $\alpha$, tumour necrosis factor $\alpha$; sTNF $\alpha$ R1, R2; soluble TNF $\alpha$ receptor $1,2$.

*With increasing FFMI sTNF $\alpha$ R1 increased.

Table 4. Systemic inflammatory biomarkers after stratification for FMI by quartiles (Q1-Q4).

\begin{tabular}{|c|c|c|c|c|}
\hline $\begin{array}{l}\mathrm{FMI}, \mathrm{kg} / \mathrm{m}^{2} \\
\left(25^{\text {th }}-75^{\text {th }} \text { percentile }\right)\end{array}$ & Q1 & Q2 & Q3 & Q4 \\
\hline CRP; mg/L* & $2.78(1.31-6.44)$ & $3.41(1.28-7.10)$ & $4.21(1.87-8.20)$ & $5.67(2.83-8.51)$ \\
\hline fibrinogen; g/L & $3.45(2.86-4.04)$ & $3.16(2.86-3.59)$ & $3.45(2.86-4.00)$ & $3.45(2.86-3.98)$ \\
\hline $\mathrm{TNF} \alpha ; p g / m L$ & $1.58(1.21-1.97)$ & $1.69(1.28-2.19)$ & $1.71(1.40-2.31)$ & $1.62(1.30-2.39)$ \\
\hline $\mathrm{sTNF} \alpha \mathrm{R} 1 ; \mathrm{ng} / \mathrm{mL}$ & $0.76(0.62-0.94)$ & $0.82(0.66-0.96)$ & $0.87(0.68-1.09)$ & $0.89(0.69-1.02)$ \\
\hline $\mathrm{sTNF} \alpha \mathrm{R} 2 ; \mathrm{ng} / \mathrm{mL}$ & $1.69(1.49-2.24)$ & $1.72(1.39-2.13)$ & $1.85(1.55-2.37)$ & $1.89(1.56-2.36)$ \\
\hline
\end{tabular}

FMI, fat mass index; CRP, C-reactive protein; TNF $\alpha$, tumour necrosis factor $\alpha$; sTNF $\alpha$ R1, R2; soluble TNF $\alpha$ receptor $1,2$.

*With increasing FMI CRP increased. 


\section{References}

1. Rabe KF, Hurd S, Anzueto A, et al. Global strategy for the diagnosis, management, and prevention of chronic obstructive pulmonary disease: GOLD executive summary. Am J Respir Crit Care Med 2007;176:532-55.

2. Gan WQ, Man SF, Senthilselvan A, Sin DD. Association between chronic obstructive pulmonary disease and systemic inflammation: a systematic review and a meta-analysis. Thorax 2004;59:574-80.

3. Vernooy JH, Kucukaycan M, Jacobs JA, et al. Local and systemic inflammation in patients with chronic obstructive pulmonary disease: soluble tumor necrosis factor receptors are increased in sputum. Am J Respir Crit Care Med 2002;166:1218-24.

4. Spruit MA, Gosselink R, Troosters T, et al. Muscle force during an acute exacerbation in hospitalised patients with COPD and its relationship with CXCL8 and IGF-I. Thorax 2003;58:752-6.

5. Dahl M, Tybjaerg-Hansen A, Vestbo J, Lange P, Nordestgaard BG. Elevated plasma fibrinogen associated with reduced pulmonary function and increased risk of chronic obstructive pulmonary disease. Am J Respir Crit Care Med 2001;164:1008-11.

6. Yanbaeva DG, Dentener MA, Spruit MA, et al. IL6 and CRP haplotypes are associated with COPD risk and systemic inflammation: a case-control study. BMC Med Genet 2009;10:23.

7. Sin DD, Man SF. Why are patients with chronic obstructive pulmonary disease at increased risk of cardiovascular diseases? The potential role of systemic inflammation in chronic obstructive pulmonary disease. Circulation 2003;107:1514-9.

8. Dahl M, Vestbo J, Lange P, Bojesen SE, Tybjaerg-Hansen A, Nordestgaard BG. C-reactive protein as a predictor of prognosis in chronic obstructive pulmonary disease. Am J Respir Crit Care Med 2007;175:250-5.

9. Man SF, Connett JE, Anthonisen NR, Wise RA, Tashkin DP, Sin DD. C-reactive protein and mortality in mild to moderate chronic obstructive pulmonary disease. Thorax 2006;61:849-53.

10. Groenewegen KH, Postma DS, Hop WC, Wielders PL, Schlosser NJ, Wouters EF. Increased systemic inflammation is a risk factor for COPD exacerbations. Chest 2008;133:350-7.

11. Wagner PD. Possible mechanisms underlying the development of cachexia in COPD. Eur Respir J 2008;31:492-501.

12. Franciosi LG, Page CP, Celli BR, et al. Markers of disease severity in chronic obstructive pulmonary disease. Pulm Pharmacol Ther 2006;19:189-99.

13. Breyer MK, Spruit MA, Celis AP, Rutten EP, Janssen PP, Wouters EF. Highly elevated C-reactive protein levels in obese patients with COPD: a fat chance? Clin Nutr 2009;28:642-7.

14. Sin DD, Man SF. Impaired lung function and serum leptin in men and women with normal body weight: a population based study. Thorax 2003;58:695-8.

15. Wouters EF, Creutzberg EC, Schols AM. Systemic effects in COPD. Chest 2002;121:127S-30S.

16. Wouters EF, Postma DS, Fokkens B, et al. Withdrawal of fluticasone propionate from combined salmeterol/fluticasone treatment in patients with COPD causes immediate and sustained disease deterioration: a randomised controlled trial. Thorax 2005;60:480-7.

17. Vermeeren MA, Creutzberg EC, Schols AM, et al. Prevalence of nutritional depletion in a large out-patient population of patients with COPD. Respir Med 2006;100:1349-55.

18. Leeuwenberg JF, Dentener MA, Buurman WA. Lipopolysaccharide LPS-mediated soluble TNF receptor release and TNF receptor expression by monocytes. Role of CD14, LPS binding protein, and bactericidal/ permeability-increasing protein. J Immunol 1994;152:5070-6.

19. Cazzola M, MacNee W, Martinez FJ, et al. Outcomes for COPD pharmacological trials: from lung function to biomarkers. Eur Respir J 2008;31:416-69.

20. Eagan TM, Aukrust P, Ueland T, et al. Body composition and plasma levels of inflammatory biomarkers in COPD. Eur Respir J 2010;36:1027-33.

21. Pinto-Plata V, Toso J, Lee K, et al. Profiling serum biomarkers in patients with COPD: associations with clinical parameters. Thorax 2007;62:595-601.

22. Hogg JC, Chu F, Utokaparch S, et al. The nature of small-airway obstruction in chronic obstructive pulmonary disease. N Engl J Med 2004;350:2645-53.

23. Singh $D$, Fox $S M$, Tal-Singer $R$, et al. Induced sputum genes associated with spirometric and radiological disease severity in COPD ex-smokers. Thorax 2011;66:489-95.

24. Takabatake N, Nakamura $\mathrm{H}$, Abe $\mathrm{S}$, et al. The relationship between chronic hypoxemia and activation of the tumor necrosis factor-alpha system in patients with chronic obstructive pulmonary disease. Am J Respir Crit Care Med 2000;161:1179-84. 
25. Licastro F, Candore G, Lio D, et al. Innate immunity and inflammation in ageing: a key for understanding age-related diseases. Immun Ageing 2005;2:8.

26. Provinciali M, Cardelli M, Marchegiani F. Inflammation, chronic obstructive pulmonary disease and aging. Curr Opin Pulm Med 2011;17 Suppl 1:S3-S10.

27. Bruunsgaard H, Pedersen BK. Age-related inflammatory cytokines and disease. Immunol Allergy Clin North Am 2003;23:15-39.

28. Folsom AR. Epidemiology of fibrinogen. Eur Heart J 1995;16 Suppl A:21-3; discussion 3-4.

29. Fu A, Nair KS. Age effect on fibrinogen and albumin synthesis in humans. Am J Physiol 1998;275:E1023-30.

30. Breyer MK, Rutten EP, Vernooy JH, et al. Gender differences in the adipose secretome system in chronic obstructive pulmonary disease (COPD): a pivotal role of leptin. Respir Med 2011;105:1046-53.

31. Fantuzzi G. Adipose tissue, adipokines, and inflammation. J Allergy Clin Immunol 2005;115:911-9; quiz 20.

32. Bridevaux PO, Gerbase MW, Schindler C, et al. Sex-specific effect of body weight gain on systemic inflammation in subjects with COPD: results from the SAPALDIA cohort study 2. Eur Respir J 2009;34:332-9.

33. de Torres JP, Casanova C, Pinto-Plata V, et al. Gender Differences in Plasma Biomarker Levels in a Cohort of COPD Patients: A Pilot Study. PLoS One 2011;6:e16021.

34. Crofton J, Bjartveit K. Smoking as a risk factor for chronic airways disease. Chest 1989;96:307S-12S.

35. Boyle P. Cancer, cigarette smoking and premature death in Europe: a review including the Recommendations of European Cancer Experts Consensus Meeting, Helsinki, October 1996. Lung Cancer 1997;17:1-60.

36. Agusti A, Calverley PM, Celli B, et al. Characterisation of COPD heterogeneity in the ECLIPSE cohort. Respir Res 2010;11:122.

37. Kannel WB, D'Agostino RB, Belanger AJ. Fibrinogen, cigarette smoking, and risk of cardiovascular disease: insights from the Framingham Study. Am Heart J 1987;113:1006-10.

38. Bazzano LA, He J, Muntner P, Vupputuri S, Whelton PK. Relationship between cigarette smoking and novel risk factors for cardiovascular disease in the United States. Ann Intern Med 2003;138:891-7.

39. Heinrich J, Balleisen L, Schulte H, Assmann G, van de Loo J. Fibrinogen and factor VII in the prediction of coronary risk. Results from the PROCAM study in healthy men. Arterioscler Thromb 1994;14:54-9.

40. Wannamethee SG, Lowe GD, Shaper AG, Rumley A, Lennon L, Whincup PH. Associations between cigarette smoking, pipe/cigar smoking, and smoking cessation, and haemostatic and inflammatory markers for cardiovascular disease. Eur Heart J 2005;26:1765-73.

41. Wirtz PH, von Kanel R, Kunz-Ebrecht S, Ehlert U, Fischer JE. Enhanced glucocorticoid sensitivity of cytokine release from circulating leukocytes stimulated with lipopolysaccharide in healthy male smokers. Brain Behav Immun 2004;18:536-43.

42. Gander ML, Fischer JE, Maly FE, von Kanel R. Effect of the G-308A polymorphism of the tumor necrosis factor (TNF)-alpha gene promoter site on plasma levels of TNF-alpha and C-reactive protein in smokers: a cross-sectional study. BMC Cardiovasc Disord 2004;4:17.

43. Stolz D, Christ-Crain M, Morgenthaler NG, et al. Copeptin, C-reactive protein, and procalcitonin as prognostic biomarkers in acute exacerbation of COPD. Chest 2007;131:1058-67.

44. Bolton CE, lonescu AA, Shiels KM, et al. Associated loss of fat-free mass and bone mineral density in chronic obstructive pulmonary disease. Am J Respir Crit Care Med 2004;170:1286-93.

45. Takabatake N, Nakamura $\mathrm{H}, \mathrm{Abe} \mathrm{S}$, et al. Circulating leptin in patients with chronic obstructive pulmonary disease. Am J Respir Crit Care Med 1999:159:1215-9.

46. Yende $\mathrm{S}$, Waterer $\mathrm{GW}$, Tolley $\mathrm{EA}$, et al. Inflammatory markers are associated with ventilatory limitation and muscle dysfunction in obstructive lung disease in well functioning elderly subjects. Thorax 2006;61:10-6.

47. Ito K, Barnes PJ. COPD as a disease of accelerated lung aging. Chest 2009;135:173-80.

48. Eid AA, lonescu AA, Nixon LS, et al. Inflammatory response and body composition in chronic obstructive pulmonary disease. Am J Respir Crit Care Med 2001;164:1414-8.

49. Van Helvoort HA, Heijdra YF, Thijs HM, Vina J, Wanten GJ, Dekhuijzen PN. Exercise-induced systemic effects in muscle-wasted patients with COPD. Med Sci Sports Exerc 2006;38:1543-52.

50. van der Vaart H, Koeter GH, Postma DS, Kauffman HF, ten Hacken NH. First study of infliximab treatment in patients with chronic obstructive pulmonary disease. Am J Respir Crit Care Med 2005;172:465-9.

51. Loza MJ, Watt R, Baribaud F, Barnathan ES, Rennard SI. Systemic inflammatory profile and response to antitumor necrosis factor therapy in chronic obstructive pulmonary disease. Respir Res 2012;13:12.

52. Kolsum U, Roy K, Starkey C, et al. The repeatability of interleukin-6, tumor necrosis factor-alpha, and Creactive protein in COPD patients over one year. Int J Chron Obstruct Pulmon Dis 2009;4:149-56.

53. Pedersen $\mathrm{BK}$, Bruunsgaard $\mathrm{H}$. Possible beneficial role of exercise in modulating low-grade inflammation in the elderly. Scand J Med Sci Sports 2003;13:56-62. 


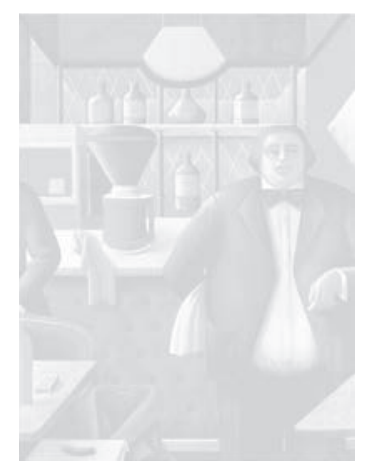

\section{CHAPTER 5}

Gender differences in the adipose secretome system in chronic obstructive pulmonary disease (COPD): a pivotal role of leptin

Breyer MK, Rutten EPA, Vernooy JH, Spruit MA, Dentener MA, van der Kallen C, Vangreevenbroek MM, Wouters EFM Respir Med. 2011 Jul;105(7):1046-53 



\section{Abstract}

\section{Background}

COPD is characterized by a multi-component character involving a state of lowgrade systemic inflammation and an increased prevalence of cardiovascular comorbidity. The role of circulating leptin and other adipokines in the involvement of the systemic inflammation in COPD is only studied scarcely.

\section{Objective}

To investigate gender related differences in the adipokine metabolism in relation to systemic inflammatory biomarkers in clinically stable subjects with COPD.

\section{Methods}

In total, 91 clinically stable COPD patients and 35 healthy control subjects, matched for body mass index (BMI) with the COPD subjects, were included. Lung function measurement and body composition were performed in patients with COPD. In the total group, plasma concentration of the adipokines (leptin, adiponectin and resistin) and systemic inflammatory biomarkers $C$-reactive protein (CRP), interleukin 6 (IL-6), tumor necrosis factor $\alpha(T N F \alpha)$, and its soluble receptors 55 and 75 (sTNF $\alpha$-R55, R75) were analyzed.

\section{Results}

The COPD group was characterized by increased levels of CRP, IL-6 and leptin. Plasma adiponectin and resistin concentrations were not different between the COPD and the control group. Within the COPD group, there was a significant interaction between gender and $\mathrm{BMI}$ on the leptin/fat mass ratio. In COPD women, a significant correlation between leptin and CRP was present.

\section{Conclusions}

In men with clinically stable COPD, leptin, adiponectin and resistin appear to be physiologically regulated, while in women, leptin metabolism is altered. Leptin secretion is increased in COPD women when compared to healthy women and compared to COPD men, and to a greater extent in overweight women with COPD. 


\section{Introduction}

Chronic obstructive pulmonary disease (COPD), a disease characterized by partially reversible airflow limitation, is usually progressive and associated with an abnormal inflammatory response of the lung to noxious particles or gases ${ }^{1}$. Furthermore, COPD is these days recognized as a multi-component disease, involving various extra-pulmonary manifestations like low-grade systemic inflammation and an increased prevalence of cardiovascular co-morbidity². Worldwide attention has been focused on COPD, as COPD is predicted to become the third leading cause of death worldwide by $2020^{1}$. Since recent years, the prevalence of COPD in women has been increasing, and the question arises if the nature of the biologic injury differs between COPD men and women ${ }^{3}$. Various gender differences are recognized in COPD, as women exhibit anatomically smaller airway lumens and they suffer from less extensive emphysema ${ }^{4}$. In addition, women with COPD experience more symptoms of depression compared to male ${ }^{5}$, and clinical data suggest sex hormones affecting airway function ${ }^{6}$.

Gender related differences in the extra-pulmonary manifestation of COPD are barely investigated. Interestingly, a recent study showed that systemic effects of smoking differ between men and women. The authors demonstrated decreased plasma concentrations of the anti-inflammatory adipokine adiponectin in women. In addition, the same authors reported increased plasma levels of high sensitive C-reactive protein (CRP) in men ${ }^{7}$. These differences may contribute to a different aetiology of extra pulmonary manifestations of COPD among men and women.

Circulating leptin is originally described as an adipocyte-derived hormone involved in the processes of limiting food intake, increasing energy expenditure and decreasing metabolic efficiency by activating its functional receptor (Ob-Rb) in the hypothalamus ${ }^{8}$. Hereby, leptin is positively linked with body mass index (BMI; weight in kilograms divided by squared height in meters) and fat mass. The structure of leptin and its receptor classify leptin as a type I cytokine, increasing acutely by inflammatory and infectious stimuli, such as tumor necrosis factor (TNF) $\alpha$ and lipopolysaccharide?. In general, circulating leptin levels have been shown to be positively related to cardiovascular disease ${ }^{10,11}$ and in addition are gender related and higher in healthy women compared to healthy men, independent of BMI. Indeed, for the same amount of fat mass, women have higher circulating leptin levels compared to men ${ }^{12}$. The role of circulating leptin and other adipokines in the involvement of the systemic inflammation in COPD is only studied scarcely and mainly in male COPD patients with a low BMI $\left(<21 \mathrm{~kg} / \mathrm{m}^{2}\right)^{13-16}$. From these studies, it is concluded that circulating leptin plays a physiological role in COPD, even in underweight patients. 
The present study primarily aimed to unravel gender related differences in the adipokine metabolism in clinically stable subjects with COPD. Secondarily, we aimed to compare plasma levels of adipokines (leptin, adiponectin and resistin) with systemic inflammatory biomarkers, such as CRP, interleukin 6 (IL-6), tumor necrosis factor $\alpha$ (TNF $\alpha$ ), and its soluble receptors 55 and 75 (sTNF $\alpha-R 55$, $\mathrm{R} 75$ ) in COPD and in healthy control subjects.

\section{Materials and methods}

\section{Study population}

Data were collected from 91 subjects with COPD, stratified in 4 groups by BMI and matched for age, gender and disease severity. All patients were entering pulmonary rehabilitation at the Centre of expertise for chronic organ failure (Ciro), Horn, the Netherlands. Patients were excluded, if they had an exacerbation within the last 4 weeks before study entry. All patients were free of taking oral corticosteroids or antibiotics. Other current medication use was recorded, particularly the use of inhaled corticosteroids, and any anti-inflammatory medication, particularly NSAR, and statins). The control group is composed of 35 Caucasian nondiabetic genetically independent subjects. They were extracted from the spouses databank of Familial Combined Hyperlipidemia families.The study protocol has been described in detail elsewhere ${ }^{13}$. Any lipid-lowering medication had been withdrawn during the last 2 weeks before blood sampling. The healthy subjects were age and BMI matched with the COPD patients. The Medical Ethical Committee of the University Hospital Maastricht approved the study, and all subjects gave written informed consent.

\section{Lung function, arterial blood gases and body composition in the subjects with COPD}

In all patients, lung function parameters were collected using standardized spirometry (Masterlab, Viasys, Germany). The degree of severity of airflow limitation was classified according to the GOLD guidelines (GOLD stage 1: $F E V_{1} / F V C<70 \%$ and $\mathrm{FEV}_{1}>80 \%$ of the predicted values; GOLD stage $2: \mathrm{FEV}_{1} / \mathrm{FVC}<70 \%$ and $\mathrm{FEV}$ between 80 and 50\% of the predicted values; GOLD stage 3: FEV $/$ /FVC $<70 \%$ and $\mathrm{FEV}_{1}$ between 50 to $30 \%$ of the predicted values; and GOLD stage 4: $\mathrm{FEV}_{1} /$ $\mathrm{FVC}<70 \%$ and $\mathrm{FEV}_{1}<30 \%$ of the predicted values or $\mathrm{FEV}_{1}<50 \%$ of the predicted values plus chronic respiratory failure $)^{1}$. Arterial oxygen tension $\left(\mathrm{PaO}_{2}\right)$ and arterial carbon dioxide tension $\left(\mathrm{PaCO}_{2}\right)$ were measured while patients were breathing room air or when on long term oxygen therapy (LTOT; $n=4$ ) when breathing oxygen and have been analyzed with a blood gas analyzer (ABL 700, Radiometer, Copenhagen, Denmark). 
Body height was measured to the nearest $0.1 \mathrm{~cm}$. Body weight was assessed by using an electronic beam scale with digital readout to the nearest $0.1 \mathrm{~kg}$ after emptying the bladder and with the subjects standing barefoot and wearing light indoor clothing. BMI was calculated as body weight/ height2 $\left(\mathrm{kg} / \mathrm{m}^{2}\right)$. A priori, BMI was categorized into low $\left(<21 \mathrm{~kg} / \mathrm{m}^{2}\right)$, normal $\left(21-24.9 \mathrm{~kg} / \mathrm{m}^{2}\right)$, high $\left(25-29.9 \mathrm{~kg} / \mathrm{m}^{2}\right)$ and obese $\left(\geq 30 \mathrm{~kg} / \mathrm{m}^{2}\right)$. Body composition (fat free mass, FFM, and fat mass, FM) has been assessed using an overnight-fasting bioelectrical impedance analysis $\left(\right.$ Bodystat $\left.^{\circledR}\right)$. FFM was calculated by using disease and gender-specific equations ${ }^{14}$. FFM index (FFMI) was calculated as FFM in kilogram divided by squared height in meters. FFM depletion was defined as FFMI $\leq 15$ (females) and $\leq 16$ (males) kg/ $\mathrm{m}^{214}$. FM in kilogram was calculated as total body weight minus FFM. Additionally, patients' smoking status (never, former, current smoker), amount of packs smoked per year (PY) and patients' co-morbidities were recorded.

\section{Blood sample analyses}

Blood sampling occurred after overnight fast. In all participants blood samples were analysed with the same, most recent available kits. HsCRP was assessed in duplicate by high-sensitivity particle-enhanced immunoassay (COBAS Micra, Radiometer, Copenhagen, Denmark). IL-6 was determined with the PeliKine CompactTM human IL-6 ELISA kit (Sanquin Reagents, Amsterdam, the Netherlands). Circulating leptin, adiponectin and resistin were assessed using a human leptin ELISA, a human high sensitivity adiponectin ELISA and a human resistin ELISA, respectively (BioVendor, Brno, Czech Republic). TNF $\alpha$ was determined using Qauntikine HS-human TNF $\alpha$ /NTFSF1A immunoassay (R\&D, Minneapolis, USA). ELISA kits for detection of the sTNF $\alpha-R 55$ and sTNF $\alpha-R 75$ were purchased from HyCult Biotechnology (Uden, the Netherlands). Detection limits of the single assays were: $0.23 \mathrm{mg} / \mathrm{l}$ for hsCRP; $0.2 \mathrm{pg} / \mathrm{ml}$ for IL6; $1.5 \mathrm{ng} / \mathrm{ml}$ for leptin; $5 \mathrm{ng} / \mathrm{ml}$ for adiponectin; $1 \mu \mathrm{g} / \mathrm{ml}$ for resistin; $0.5 \mathrm{pg} / \mathrm{ml}$ for TNF $\alpha ; 16 \mathrm{pg} / \mathrm{ml}$ for both sTNF $\alpha$-R55 and sTNF $\alpha$-R75. Only in 2 healthy control subjects, levels of circulating leptin were below the defined lower level of detection.

\section{Statistical analyses}

All analyses were performed using Statistical Package for the Social Sciences (SPSS) version 15.01. for Windows. Metabolic data of the COPD subjects were stratified for BMI. Categorical variables have been described as frequencies, while continuous variables are presented as median and 25th to 75th percentile, due to their skewed distribution. Evaluation of differences in continuous variables between two groups was done using the non-parametric Mann-Whitney $U$ test, while differences between more than two groups were tested using the KruskalWallis test. Categorical variables were tested using the chi2-test. In addition, due to the high degree of correlation between circulating leptin and total body fat 
mass ( $r=0.79 ; p<0.01$ ), leptin to fat mass ratio (leptin/FM) was created. The interaction between $\mathrm{BMI}$ and gender on leptin/FM was tested by general linear model. The Bonferroni correction was performed to correct for multiple comparison. Spearman correlation coefficient was calculated to test correlations between adipokines and biomarkers for systemic inflammation in the COPD group. A $p$-value of $\leq 0.05$ was considered significant.

\section{Results}

On average, subjects with COPD had moderate to severe COPD, a normal BMI, FFMI and normal arterial blood gases (Table 1). In total, $80 \%$ of COPD patients inhaled corticosteroids and $40 \%$ were using any anti-inflammatory medication. After stratification for gender, both men and women with COPD showed normal BMI and arterial blood gases. Age, FMI, FFMI, and the amount of PY were significantly different between male and female COPD patients. No differences were found in use of inhaled corticosteroids or anti-inflammatory medication, after stratification for gender.

Table 1. Baseline characteristics of subjects with COPD

\begin{tabular}{|c|c|c|c|c|}
\hline median $\left(25^{\text {th }}-75^{\text {th }}\right.$ percentiles $)$ & total $(n=91)$ & male $(n=46)$ & female $(n=45)$ & $p$-value \\
\hline age, years & $62.0(55.0-70.0)$ & $65.5(55.8-73.0)$ & $59.0(54.0-64.5)$ & 0.013 \\
\hline $\mathrm{BMI}, \mathrm{kg} / \mathrm{m}^{2}$ & $24.2(20.6-29.4)$ & $23.5(20.6-29.8)$ & $24.8(20.7-29.2)$ & 0.694 \\
\hline $\mathrm{FMI}, \mathrm{kg} / \mathrm{m}^{2}$ & $10.7(8.56-12.5)$ & $8.93(7.24-11.4)$ & $12.0(9.39-14.3)$ & $<0.01$ \\
\hline $\mathrm{FFMI}, \mathrm{kg} / \mathrm{m}^{2}$ & $15.7(14.2-17.7)$ & $16.5(14.9-19.4)$ & $14.9(13.6-16.2)$ & $<0.01$ \\
\hline $\mathrm{FEV}_{1}, \%$ predicted & $40.0(27.0-53.2)$ & $40.6(25.5-54.2)$ & $30.0(27.3-53.0)$ & 0.877 \\
\hline $\mathrm{FEV}_{1} / \mathrm{FVC}$ & $40.9(32.9-48.0)$ & $40.3(29.5-46.3)$ & $41.5(33.8-50.9)$ & 0.446 \\
\hline GOLD II, III, IV, \% & $35,36,29$ & $37,37,26$ & $33,36,31$ & 0.610 \\
\hline $\mathrm{PaO} 2, \mathrm{kPa}$ & $9.10(8.20-10.3)$ & $9.15(8.17-10.2)$ & $9.10(8.30-10.3)$ & 0.946 \\
\hline $\mathrm{PaCO} 2, \mathrm{kPa}$ & $5.30(5.00-5.90)$ & $5.30(4.90-6.19)$ & $5.40(5.00-5.85)$ & 0.921 \\
\hline smoking status, n (\%) & & & & 0.959 \\
\hline never smoker & $1(1)$ & 0 & $1(2)$ & \\
\hline former smoker & $65(72)$ & $34(74)$ & $31(69)$ & \\
\hline current smoker & $25(27)$ & $12(26)$ & $13(29)$ & \\
\hline pack years & $40(30-46)$ & $40(33-50)$ & $38(25-41)$ & 0.011 \\
\hline
\end{tabular}

BMI, body mass index; FMI, fat mass index; FFMI, fat free mass index; $\mathrm{FEV}_{1}$, forced expiratory volume in 1s; FVC, forced vital capacity.

When comparing subjects with COPD to healthy age [median age: 60 years (53.3-65.8, $25^{\text {th }}-75^{\text {th }}$ percentile), sex (67\% male) $]$, and BMI matched subjects [median BMI: $26.6 \mathrm{~kg} / \mathrm{m}^{2}\left(23.1-29.5,25^{\text {th }}-75^{\text {th }}\right.$ percentile)] significantly higher 
levels of CRP, IL-6, and circulating leptin were found in the COPD group (Table 2). After stratification for gender, men with COPD had higher levels of CRP and IL-6 compared to their healthy peers. Women with COPD had higher levels of circulating leptin compared to their healthy peers. When comparing men and women, men with COPD had lower circulating levels of adiponectin and leptin and lower leptin/FM compared to their female counterparts. Within the healthy subjects, men showed lower levels of adiponectin compared to women. There were no differences in plasma concentration of TNF $\alpha$, its soluble receptors R55 and R75, and resistin between the groups.

Table 3 shows age, lung function parameters, pack years, and plasma concentration of systemic inflammatory biomarkers and adipokines in subjects with COPD after stratification for gender and BMI.

Age, the degree of lung function impairment, the amount of PY, and the use of inhaled corticosteroids and any anti-inflammatory medication were not different between the BMI strata, neither in male nor in female. After correcting for these potential confounders, there was a significant increase in CRP levels toward higher BMI strata in women, and increased leptin levels toward higher BMI strata for both men and women. There was no difference in the levels of other systemic inflammatory biomarkers and plasma adiponectin and resistin levels among BMI strata. 


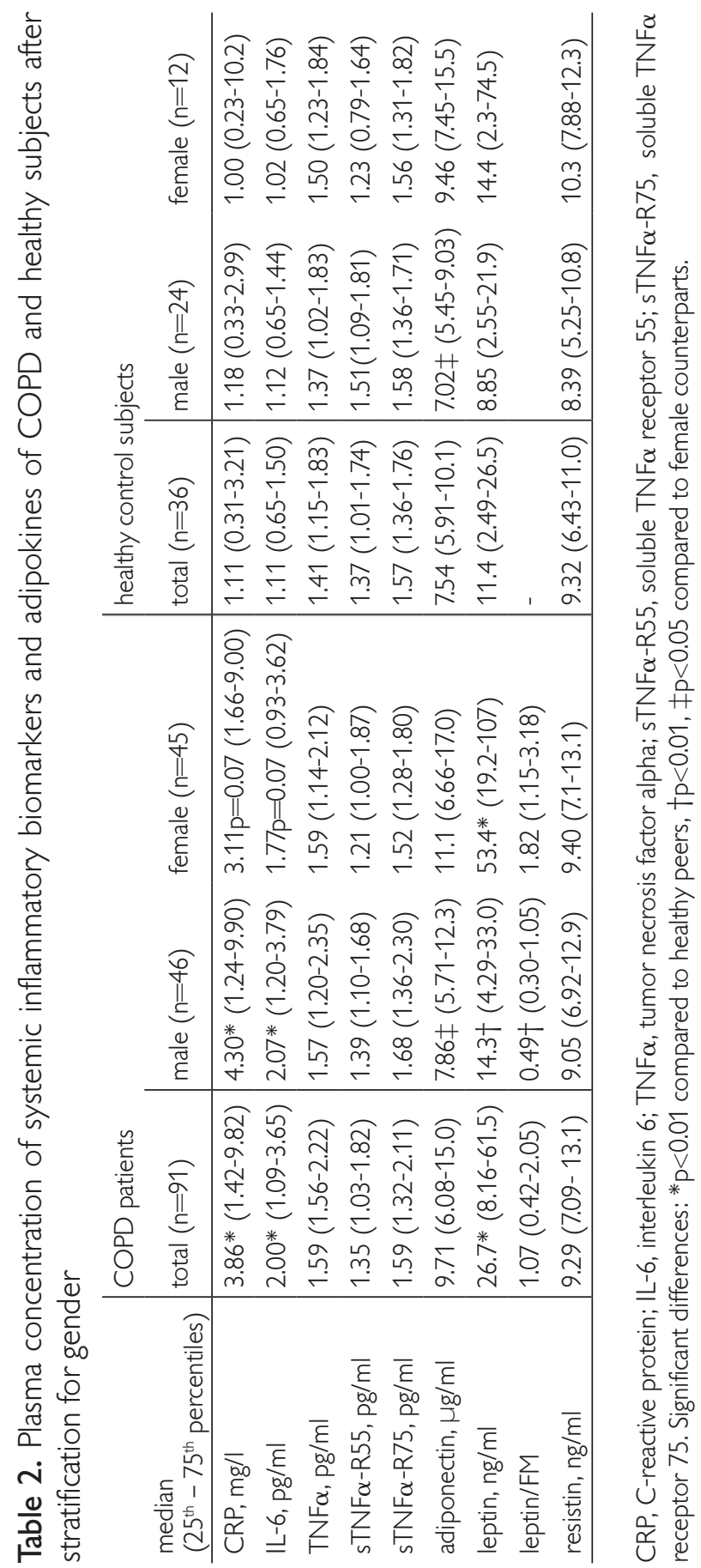




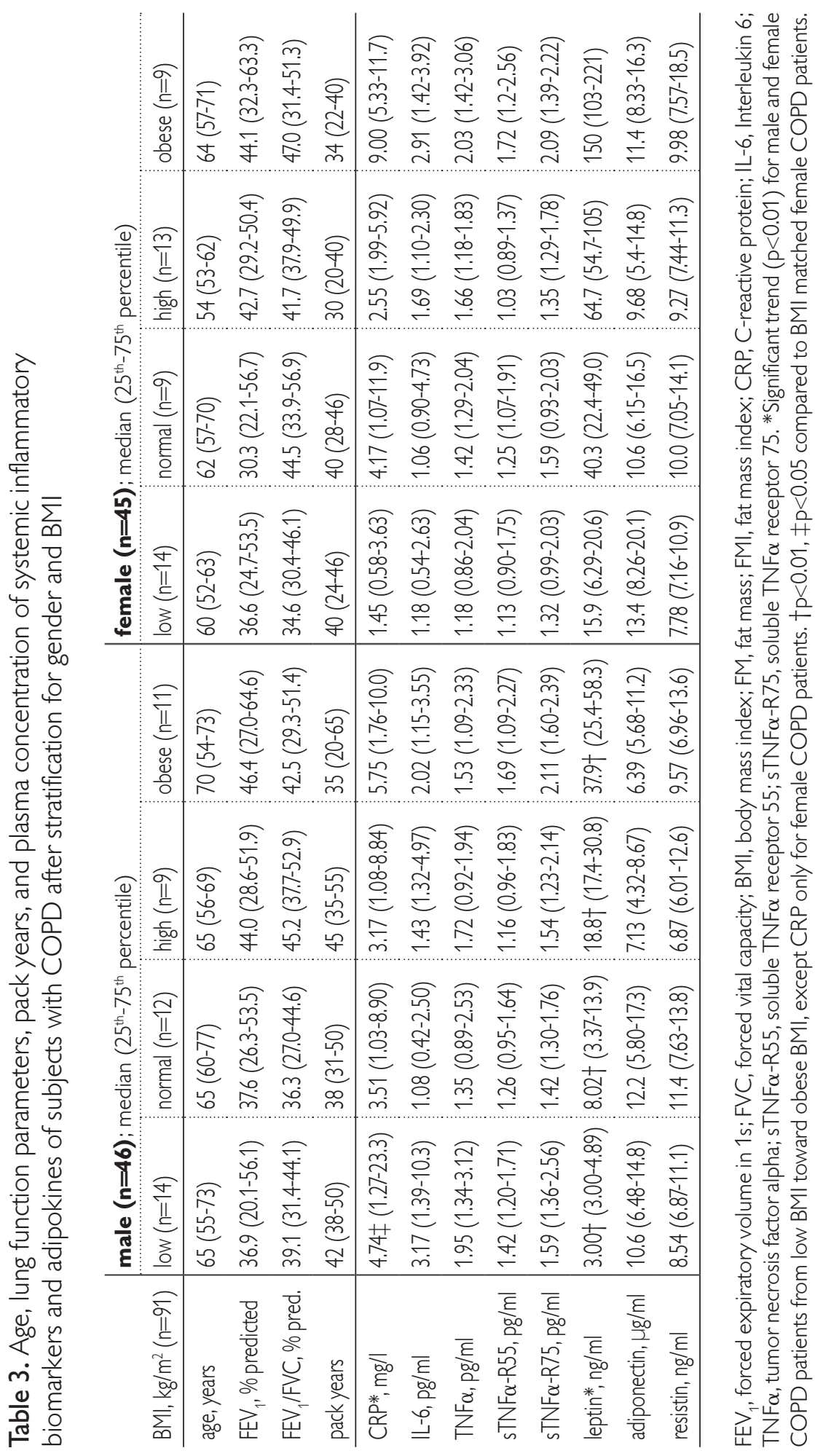


Leptin/FM for different BMI categories and gender in COPD is shown in Figure 1. In both men and women, leptin/FM increased with increasing BMI, and there was a significant interaction between gender and $\mathrm{BMI}$ to a higher increase in the women with COPD $(p<0.01)$.

When COPD subjects were stratified for gender, no significant Spearman's correlation coefficient was $f$ und between plasma leptin and adiponectin concentration and plasma CRP ( $p=0.721, p=0.647), \operatorname{IL}-6(p=0.745, p=0.621), T N F \alpha(p=0.332$, $p=0.449)$ and its soluble receptors $55(p=0.989, p=0.297)$ and $75(p=0.514$, $p=0.860$ ) for men. For women, plasma leptin concentration was significantly correlated with plasma CRP concentration $(r=0.40, p<0.01)$. For both men and women, plasma resistin concentration was significantly correlated with CRP $(r=0.23, p<0.05), I L-6(r=0.41, p<0.01)$, sTNF $\alpha-R 55(r=0.44, p<0.01)$, and sTNF $\alpha-R 75(r=0.38, p<0.01)$.

Figure 1. Leptin/fat mass for different BMI categories and gender in COPD

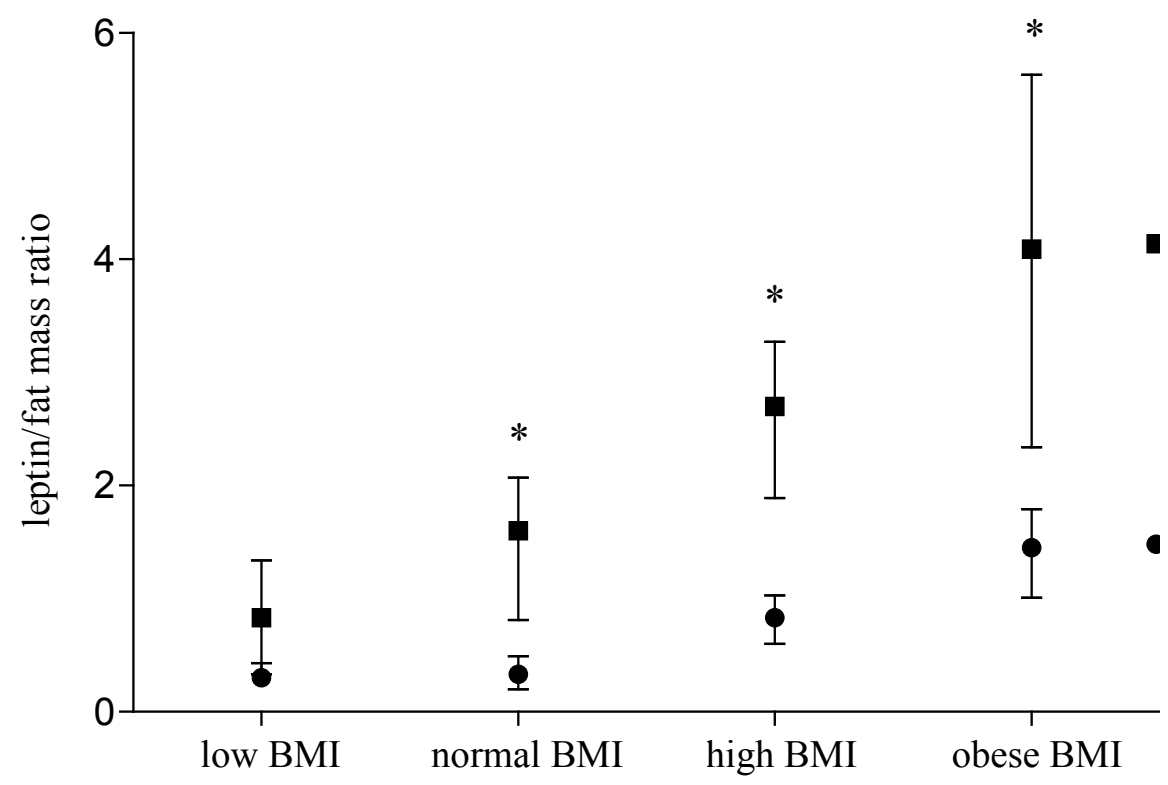

BMI, body mass index. ${ }^{*} p<0.01$ : significant interaction between gender and BMI $(p<0.01)$. 


\section{Discussion}

The present study is the first that evaluated various adipokines, such as leptin, adiponectin and resistin and biomarkers of systemic inflammation in men and women with COPD compared to healthy subjects and after stratification for BMI. Subjects with COPD were characterized by systemic inflammation which was reflected in increased levels of CRP and IL-6. TNF $\alpha$, its soluble receptors R55 and $R 75$, circulating levels of adiponectin and resistin were not different between the COPD and the healthy subjects. In women with COPD, leptin concentration was increased when compared to men with COPD as well as when compared to healthy women. Moreover, leptin secretion increased with increasing fat mass to a greater extent in COPD women compared to their male counterparts, confirming our hypothesis of a gender specific leptin metabolism in COPD.

It is well recognized that even clinically stable subjects with COPD are characterized by low-grade systemic inflammation. This is reflected by an increase of various inflammatory biomarkers, such as $\mathrm{CRP}, \mathrm{TNF} \alpha$, its soluble receptors, IL8, lipopolysaccharide binding protein (LBP), and fibrinogen ${ }^{15}$. However, to date no 'sentinel biomarker' indicating (low-grade) systemic inflammation in COPD exists. In the present study, the systemic low-grade inflammation in COPD was reflected by increased levels of CRP and IL-6, whereas plasma levels of TNF $\alpha$ and its soluble receptors were not different between the COPD group and the healthy subjects. Furthermore, within the COPD group, the CRP concentration increased with increasing BMI, while this trend was not seen for the other systemic inflammatory biomarkers. Comparison of studies concerning systemic inflammation in patients with COPD with different nutritional status is challenging as no consistent definition for the nutritional status is used among these studies. In the present study, subjects with COPD were clinically stable and stratification for nutritional status was based on BMI. The finding of constant TNF $\alpha$ levels between the groups can imply a contribution of TNF $\alpha$ in weight losing or muscle wasting patients, but not in weight stable patients. This assumption is strengthened by a recent paper which demonstrated increased plasma levels of CRP and IL-18 but constant levels of TNF $\alpha$ in patients with COPD compared to BMI matched healthy subjects ${ }^{16}$. Plasma CRP concentration on the other hand, has been consistently related to increased $\mathrm{BMI}$ and $\mathrm{FM}$, suggesting a pivotal role of CRP in the adipocyte induced systemic inflammation, which also has been recently confirmed ${ }^{17}$.

The role of circulating leptin in the systemic manifestation of COPD has gained attention as leptin is linked to a pro-inflammatory state ${ }^{22}$. However until now, studies concerning circulating leptin concentration in clinically stable subjects with COPD found no significant differences in COPD and control subjects ${ }^{18}$. Possible reasons might be the limited number of patients included in these studies 
and the fact that only males and/or underweight patients were included. In the present study however, we showed a significant interaction between gender and BMI. Circulating leptin concentration was increased in overweight women with COPD, even after correction for fat mass. The cause for this phenomenon remains unclear. In the healthy population, it is well recognized that women have higher circulating leptin concentration compared to men ${ }^{19}$. Women have a higher fat mass percentage than men, resulting in higher circulating leptin secretion in women. Moreover, animal and in vitro studies confirmed that androgens have an inhibitory effect on circulating leptin secretion, whereas estradiol has a stimulatory effect ${ }^{20}$. Our study population consists of women with a median age of 59 years, implying that most women are post-menopausal, characterized by low estrogen levels. The changes in body composition occurring after the menopause (increase of body fat), induced by low estrogen concentrations, may lead to higher circulating leptin secretion ${ }^{21}$. It is therefore tempting to speculate that overweight COPD women suffer from an imbalance in sex hormones, which may explain the increased circulating plasma leptin levels in this COPD subgroup. Disturbances in the estrogen metabolism in women with COPD are not investigated yet, although estrogens are thought to be involved in the biological difference in susceptibility of the development of COPD 22 .

No studies yet exist investigating the clinical outcomes of increased leptin concentrations in women with COPD. So, we can only speculate about possible consequences of an increased circulating leptin concentration, as the secretion of circulating leptin is an inter-player in the complex adipose secretory system. Nevertheless, there is evidence that leptin metabolism is linked to the inflammatory system, and in healthy, circulating leptin is more associated with plasma CRP concentration in women than in men ${ }^{12}$. In the present study, circulating leptin correlated with plasma CRP concentration in women with COPD, but not in men. Furthermore, the association of weight gain on systemic inflammation in subjects with COPD is higher in women than in men ${ }^{23}$, which is in line with the higher circulating leptin concentration in women with COPD that we found in our study. Moreover, circulating leptin was correlated with total glutathione concentration in elderly women, but neither in elderly men nor in younger peers ${ }^{19}$. Higher glutathione concentration in elderly women can favour systemic inflammation. As leptin is known to enhance the production of reactive oxygen species by leukocytes ${ }^{24}$, one could speculate that the increased leptin concentration in women with COPD is associated with increased oxidative stress. Herewith inline, Sin et al recently proposed a mechanism by which women with COPD are more susceptible to COPD via a disbalance in the oxidant/ anti-oxidant patway ${ }^{22}$. Whether the increased leptin concentration in women with COPD per se is associated with increased oxidative stress is not known yet, but COPD is generally characterized by a reduced anti-oxidant capacity and increased production of reactive oxygen species ${ }^{25}$. In healthy subjects, circulating leptin is a strong predictor for 
first-ever hemorhagic stroke and myocardial infarction ${ }^{10,11,}$ suggesting that leptin is an important link in the development of cardiovascular disease. In postmenopausal women, circulating leptin is besides BMI a predictor for insulin resistance ${ }^{26}$. Whether women with COPD, particularly those who are overweight, suffer from more co-morbidities compared to their male counterparts is not known yet. As the lung is highly vascularized, the increased circulating levels of leptin may also contribute to the pathogenesis of lung inflammation and injury in COPD. Leptin is detectable in the pulmonary compartment ${ }^{27,28}$ of COPD patients, and leptin levels in induced sputum showed a positive correlation with those of CRP and TNF $\alpha^{27}$. In addition, we recently demonstrated that a functional leptin signalling pathway is present in both bronchial and alveolar epithelial cells ${ }^{28}$, indicating that leptin may be involved in the local inflammatory response in COPD. Further studies are warranted to investigate this hypothesis.

Plasma adiponectin, a protein largely secreted from adipose tissue, is known to increase fatty acid oxidation and reduce the synthesis of glucose in the liver ${ }^{29}$. Adiponectin has various protective anti-inflammatory effects on the metabolic derangements that may result in a lower risk for the development of atherosclerosis and type 2 diabetes $^{30}$. Data about adiponectin concentration in patients with COPD are scarce and with inconclusive results. In the present study, circulating levels of adiponectin were higher in women compared to men, and tended to decrease with increasing BMI. These results are in consistence with previous reports concerning healthy subjects? ${ }^{7}$, implying a physiological role of adiponectin in this cohort of COPD patients. Resistin is an adipocyte derived protein that is positively associated with insulin resistance in rodents and humans ${ }^{31}$. Furthermore, it seems to induce, and also being induced by other pro-inflammatory cytokines, such as IL-6 and TNF $\alpha$ in humans ${ }^{29}$. To date, limited data are available on the exact role of resistin and the association of various pathological conditions, such as an increased insulin sensitivity, type 2 diabetes or factors related to the metabolic syndrome ${ }^{32}$. Data about levels of resistin in patients with COPD are limited, and in the present study, levels of plasma resistin concentration were not different between the COPD group and their healthy peers. The association between resistin and systemic inflammatory biomarkers found in the present study was also confirmed by others ${ }^{33}$, implying that resistin is also physiologically regulated in clinically stable patients with COPD.

\section{Limitations of the study}

One limitation of the study might be the small sample size, especially after stratifying the COPD patients into subgroups. However, other studies investigating plasma levels of adipokines in COPD patients have comparably small sample sizes $^{34,35}$ and moreover, the results of our study showed statistical significant dif- 
ferences emphasising considerable results. Another limitation is the lack of a direct outcome and possible consequences of increased levels of circulating leptin in COPD women. However, the present study is the first to show gender related differences in the adipose secretome system in COPD and further research will lead to a better understanding of the precise role of circulating leptin in COPD.

In conclusion, the results of the present study underscore gender related differences in the systemic biology of COPD. In men with clinically stable COPD, leptin, adiponectin and resistin appear to be physiologically regulated, while in women, leptin metabolism is likely altered. Leptin secretion is increased in women with COPD when compared to healthy women and compared to men with COPD, particularly in overweight women with COPD. Moreover, the present study confirms that subjects with COPD are characterized by low-grade systemic inflammation reflected in increased levels of CRP and IL-6. 


\section{References}

1. Rabe KF, Hurd S, Anzueto A, et al. Global strategy for the diagnosis, management, and prevention of chronic obstructive pulmonary disease: GOLD executive summary. Am J Respir Crit Care Med 2007;176:53255.

2. Wouters EF. COPD: from an organ- to a disease-oriented approach. COPD 2008;5:73-4.

3. Han MK, Postma D, Mannino DM, et al. Gender and chronic obstructive pulmonary disease: why it matters. Am J Respir Crit Care Med 2007;176:1179-84.

4. Martinez FJ, Curtis JL, Sciurba F, et al. Sex differences in severe pulmonary emphysema. Am J Respir Crit Care Med 2007;176:243-52.

5. Chavannes NH, Huibers MJ, Schermer TR, et al. Associations of depressive symptoms with gender, body mass index and dyspnea in primary care COPD patients. Fam Pract 2005;22:604-7.

6. Becklake MR, Kauffmann F. Gender differences in airway behaviour over the human life span. Thorax 1999:54:1119-38.

7. Ahonen TM, Kautiainen HJ, Keinanen-Kiukaanniemi SM, Kumpusalo EA, Vanhala MJ. Gender difference among smoking, adiponectin, and high-sensitivity C-reactive protein. Am J Prev Med 2008;35:598-601.

8. Zabeau L, Lavens D, Peelman F, Eyckerman S, Vandekerckhove J, Tavernier J. The ins and outs of leptin receptor activation. FEBS Lett 2003;546:45-50.

9. Grunfeld C, Zhao C, Fuller J, et al. Endotoxin and cytokines induce expression of leptin, the ob gene product, in hamsters. J Clin Invest 1996;97:2152-7.

10. Soderberg S, Ahren B, Jansson JH, et al. Leptin is associated with increased risk of myocardial infarction. J Intern Med 1999;246:409-18.

11. Soderberg S, Ahren B, Stegmayr B, et al. Leptin is a risk marker for first-ever hemorrhagic stroke in a population-based cohort. Stroke 1999;30:328-37.

12. Abdullah SM, Khera A, Leonard D, et al. Sex differences in the association between leptin and CRP: results from the Dallas Heart Study. Atherosclerosis 2007;195:404-10.

13. Brouwers MC, Bilderbeek-Beckers MA, Georgieva AM, van der Kallen C], van Greevenbroek MM, de Bruin TW. Fatty liver is an integral feature of familial combined hyperlipidaemia: relationship with fat distribution and plasma lipids. Clin Sci (Lond) 2007;112:123-30.

14. Steiner MC, Barton RL, Singh SJ, Morgan MD. Bedside methods versus dual energy X-ray absorptiometry for body composition measurement in COPD. Eur Respir J 2002;19:626-31.

15. Pouw EM, Schols AM, Deutz NE, Wouters EF. Plasma and muscle amino acid levels in relation to resting energy expenditure and inflammation in stable chronic obstructive pulmonary disease. Am J Respir Crit Care Med 1998;158:797-801.

16. Petersen AM, Penkowa M, Iversen M, et al. Elevated levels of IL-18 in plasma and skeletal muscle in chronic obstructive pulmonary disease. Lung 2007;185:161-71.

17. Breyer MK, Spruit MA, Celis AP, Rutten EP, Janssen PP, Wouters EF. Highly elevated C-reactive protein levels in obese patients with COPD: A fat chance? Clin Nutr 2009.

18. Kirdar S, Serter M, Ceylan E, Sener AG, Kavak T, Karadag F. Adiponectin as a biomarker of systemic inflammatory response in smoker patients with stable and exacerbation phases of chronic obstructive pulmonary disease. Scand J Clin Lab Invest 2009;69:219-24.

19. Agrawal A, Lourenco EV, Gupta S, La Cava A. Gender-Based Differences in Leptinemia in Healthy Aging, Non-obese Individuals Associate with Increased Marker of Oxidative Stress. Int J Clin Exp Med 2008;1:3059.

20. Machinal-Quelin F, Dieudonne MN, Pecquery R, Leneveu MC, Giudicelli Y. Direct in vitro effects of androgens and estrogens on ob gene expression and leptin secretion in human adipose tissue. Endocrine 2002;18:179-84.

21. Tommaselli GA, Di Carlo C, Di Spiezio Sardo A, et al. Serum leptin levels and body composition in postmenopausal women treated with tibolone and raloxifene. Menopause 2006;13:660-8.

22. Sin DD, Cohen SB, Day A, Coxson H, Pare PD. Understanding the biological differences in susceptibility to chronic obstructive pulmonary disease between men and women. Proc Am Thorac Soc 2007;4:671-4.

23. Bridevaux PO, Gerbase MW, Schindler C, et al. Sex-specific Effect of Body Weight Gain on Systemic Inflammation in Subjects with COPD. Eur Respir 2009.

24. Caldefie-Chezet F, Poulin A, Tridon A, Sion B, Vasson MP. Leptin: a potential regulator of polymorphonuclear neutrophil bactericidal action? J Leukoc Biol 2001;69:414-8. 
25. Mercken EM, Hageman GJ, Schols AM, Akkermans MA, Bast A, Wouters EF. Rehabilitation decreases exercise-induced oxidative stress in chronic obstructive pulmonary disease. Am J Respir Crit Care Med 2005;172:994-1001.

26. Chu MC, Cosper P, Orio F, Carmina E, Lobo RA. Insulin resistance in postmenopausal women with metabolic syndrome and the measurements of adiponectin, leptin, resistin, and ghrelin. Am J Obstet Gynecol 2006;194:100-4.

27. Broekhuizen R, Vernooy JH, Schols AM, Dentener MA, Wouters EF. Leptin as local inflammatory marker in COPD. Respir Med 2005;99:70-4.

28. Vernooy JH, Drummen NE, van Suylen RJ, et al. Enhanced pulmonary leptin expression in patients with severe COPD and asymptomatic smokers. Thorax 2009;64:26-32.

29. Lago F, Dieguez C, Gomez-Reino J, Gualillo O. Adipokines as emerging mediators of immune response and inflammation. Nat Clin Pract Rheumatol 2007;3:716-24.

30. Diez JJ, Iglesias P. The role of the novel adipocyte-derived hormone adiponectin in human disease. Eur J Endocrinol 2003;148:293-300.

31. Mojiminiyi OA, Abdella NA. Associations of resistin with inflammation and insulin resistance in patients with type 2 diabetes mellitus. Scand J Clin Lab Invest 2007;67:215-25.

32. Osawa $\mathrm{H}$, Ochi M, Tabara $\mathrm{Y}$, et al. Serum resistin is positively correlated with the accumulation of metabolic syndrome factors in type 2 diabetes. Clin Endocrinol (Oxf) 2008;69:74-80.

33. Fontana L, Eagon JC, Trujillo ME, Scherer PE, Klein S. Visceral fat adipokine secretion is associated with systemic inflammation in obese humans. Diabetes 2007;56:1010-3.

34. Schols AM, Creutzberg EC, Buurman WA, Campfield LA, Saris WH, Wouters EF. Plasma leptin is related to proinflammatory status and dietary intake in patients with chronic obstructive pulmonary disease. Am J Respir Crit Care Med 1999;160:1220-6.

35. Takabatake N, Nakamura H, Abe S, et al. Circulating leptin in patients with chronic obstructive pulmonary disease. Am J Respir Crit Care Med 1999;159:1215-9. 



\section{CHAPTER 6}

\section{Dysregulated adipokine metabolism in chronic obstructive pulmonary disease}





\section{Abstract}

\section{Background}

Research concerning the involvement of body composition and systemic inflammatory markers in adipokine metabolism in chronic obstructive pulmonary disease (COPD) is still limited. Therefore we primarily aimed to investigate the adipokine metabolism in relation to these systemic inflammatory biomarkers and to evaluate possible gender related differences in the adipokine metabolism in COPD patients.

\section{Materials and methods}

186 subjects with COPD [mean (SD) FEV \%pred: $50( \pm 16)$ ] and 113 controls, matched for age, gender, and body composition were selected from the ECLIPSE cohort. The following serological data were collected: serum levels of leptin, adiponectin, and systemic inflammatory biomarkers such as C-reactive protein (CRP), Interleukin-6 (IL-6), and fibrinogen.

\section{Results}

Compared to controls, COPD patients had higher levels of CRP, IL-6, fibrinogen and adiponectin. After stratification for gender, men with COPD had higher CRP, IL6 and fibrinogen levels compared to male controls, while women with COPD had higher levels of CRP and fibrinogen compared to the female controls. Moreover, in both female controls and COPD patients, leptin correlated with CRP and fibrinogen, while leptin only correlated with CRP in male controls. Adiponectin correlated negatively with CRP, only in COPD patients. Body mass index and gender were the strongest determinants for both leptin and adiponectin.

\section{Conclusions}

The present study shows a gender dependent dysregulation of adipokine metabolism in COPD patients compared to BMI matched controls. Furthermore, results from the present study suggest a more prominent role of adiponectin in the systemic response of COPD.

\section{Trial registration}

NCT00292552; http://clinicaltrials.gov/ct2/results?term=NCT00292552 


\section{Introduction}

Chronic obstructive pulmonary disease (COPD) causes 2.75 million deaths per year worldwide, representing the fourth leading cause of death worldwide ${ }^{1}$. The substantial morbidity is caused by the multi-component character of COPD. Besides the usually progressive chronic airflow limitation, COPD is also fraught with considerable amounts of extra-pulmonary complications and co-morbidities including osteoporosis, and cardiovascular co-morbidity and mortality². Low-grade systemic inflammation is thought to contribute to the complex pathogenesis of COPD. Increased levels of various systemic inflammatory biomarkers, like Creactive Protein (CRP), Interleukin-6 (IL-6) and fibrinogen have been repeatedly reported in stable COPD patients ${ }^{3}$ and rise even more during acute exacerbations ${ }^{4}$. The importance of systemic inflammation in COPD is strengthened by the fact that increased levels of circulating CRP and fibrinogen are predictors of cardiovascular events ${ }^{5}$ and are associated with an increased mortality in COPD ${ }^{6-8}$. However, the origin of systemic inflammation in COPD is still under debate.

In COPD the theory of a 'spill over' from local inflammation of the lungs into the systemic circulation is often suggested ${ }^{9}$, although not proven ${ }^{10}$. However, accumulating evidence indicates that the fat tissue is involved in the development of low-grade systemic inflammation and that the adipose tissue is a key endocrine organ due to releasing a wide variety of bio-active substances ${ }^{11,12}$. Dysregulated production of adipose-derived factors or adipokines with pro-inflammatory or anti-inflammatory activities can contribute to the pathogenesis of low-grade systemic inflammation ${ }^{13}$. Leptin is widely recognized as a pro-inflammatory adipokine, as it is structurally similar to the family of helical cytokines ${ }^{12,14}$. Circulating leptin levels are positively correlated with the adipose mass ${ }^{15}$ and besides its proinflammatory activities, involved in regulating feeding behaviour, insulin resistance and vascular dysfunction ${ }^{16,17}$. In addition to the numerous pro-inflammatory adipokines, adipose tissue also secretes a smaller number of anti-inflammatory mediators such as adiponectin. Adiponectin is almost exclusively synthesised by adipocytes and adiponectin levels are reduced in the plasma of obese individuals ${ }^{15}$. Adiponectin protects against obesity-linked metabolic dysfunction and, plays an important role in controlling inflammation ${ }^{18,19}$. Moreover, adiponectin is also recognized as an important molecular link between adipose and cardiovascular tissues $^{20,21}$.

Research concerning the involvement of the adipose tissue and a dysregulated balance between pro- and anti-inflammatory adipokines in COPD is still limited. Previous reports suggested an altered adipokine (leptin and adiponectin) metabolism, with decreased levels of leptin and increased levels of adiponectin, that is related to the inflammatory reaction in COPD related cachexia ${ }^{22,23}$. The involvement of an altered adipokine metabolism to the systemic manifestations of 
COPD suggested that the adipokine metabolism is particularly altered in women suffering from $\mathrm{COPD}^{24}$. In COPD, the role of an adipokine imbalance in relation to markers of systemic inflammation such as CRP, IL-6 and fibrinogen has not been investigated so far.

Therefore, we primarily aimed to investigate the adipokine metabolism in relation to these systemic inflammatory biomarkers and to evaluate possible gender related differences in adipokine metabolism in COPD patients.

\section{Methods and materials}

This study was part of the ECLIPSE study (Evaluation of COPD Longitudinally to Identify Predictive Surrogate End Points). Data were collected cross-sectional and detailed information on the purpose and design of the ECLIPSE study is given elsewhere ${ }^{25}$. Detailed information on the IRB approval is given in the online supplement. The study is registered on ClinicalTrials.gov with identifier NCT00292552; GSKStudyNo. SCO104960 (http://clinicaltrials.gov/ct2/show/ NCT00292552). Reporting of the study conforms to STROBE statement along with references to STROBE statement and the broader EQUATOR guidelines ${ }^{26}$.

\section{Participants}

In total 186 COPD patients and 113 control subjects, matched for age, gender and BMI were included in the present study. General inclusion criteria for COPD patients were age $\geq 40-75$ years, with a baseline post-bronchodilator forced expiratory volume in the first second $\left(\mathrm{FEV}_{1}\right)$ of $<80 \%$ of the predicted value (\% predicted), as well as a baseline post-bronchodilator $\mathrm{FEV}_{1} /$ forced vital capacity (FVC) of $\leq 70 \%$ and a smoking history of $\geq 10$ pack years (PY). For control subjects a post-bronchodilator $\mathrm{FEV}_{1}$ of $>85 \%$ predicted and a $\mathrm{FEV}_{1} / \mathrm{FVC}$ of $>70 \%$ was mandatory to be enrolled. Exclusion criteria were related to diagnosis of known respiratory disorders other than COPD, known history of significant inflammatory disease other than COPD, a COPD exacerbation within 4 weeks of enrolment, lung surgery, and long term ( $>3$ consecutive months) oral corticosteroids at time of inclusion. For the sub-study, subjects with manifested skeletal muscle wasting (based on a fat free mass index (FFMI) $<15$ for women and $<17$ for men), and subjects with reported cardiovascular co-morbidity were excluded. In addition, the usual criteria of uncontrolled disease likely to interfere with the study or impact on subject safety and substance abuse were applied.

\section{Lung function, body composition, and smoking status}

All subjects performed baseline post-bronchodilator spirometry according to international standards ${ }^{27}$. The degree of severity of airflow limitation was classified according to the GOLD guidelines (GOLD stage 2: $\mathrm{FEV}_{1} / \mathrm{FVC}<70 \%$ and $\mathrm{FEV}_{1}$ 
between 80 and 50\% predicted; GOLD stage 3: $\mathrm{FEV}_{1} / \mathrm{FVC}<70 \%$ and $\mathrm{FEV}_{1}$ between 50 to $30 \%$ predicted; and GOLD stage 4: $\mathrm{FEV}_{1} / \mathrm{FVC}<70 \%$ and $\mathrm{FEV}_{1}<30 \%$ predicted or $\mathrm{FEV}_{1}<50 \%$ predicted plus chronic respiratory failure) 1 .

Body height and weight were measured and body mass index (BMI) was calculated as body weight/ height ${ }^{2}$. Body composition (fat free mass, FFM and fat mass, FM) was assessed using an overnight-fasting bioelectrical impedance assessment (Bodystat 1500). FFM was calculated for COPD subjects ${ }^{28}$ and controls ${ }^{29}$ by using disease and gender-specific equations. FM in kilograms was calculated as total body weight minus FFM. FFM index (FFMI) and fat mass index (FMI) was calculated as respectively FFM and FM in kilograms divided by (height in meters) ${ }^{2}$. Controls smoking history was identified as never, former or current smokers, while COPD patients were identified as former or current smokers. Pack year smoking history was calculated as number of cigarettes smoked per day / 20) multiplied by number of years smoked.

\section{Laboratory analysis}

Venous blood samples were collected into Vacutainer tubes from subjects in the fasted state. Serum was obtained by allowing the blood to clot for $30 \mathrm{~min}$ utes at room temperature followed by centrifugation (1500g for 10 minutes.) Plasma was obtained from EDTA anti-coagulated whole blood by centrifugation (2000g for 15 minutes). Serum and plasma samples were stored at $-80^{\circ} \mathrm{C}$ until analyzed. IL-6, and leptin were measured in serum samples using validated chemiluminescent-based immunoassays (SearchLight Protein Array Technology Platform, Aushon Biosystems, Billerica, MA, USA). Adiponectin was measured using a validated colorimetric-based immunoassay (Linco Research, St. Charles, MO, USA). hsCRP were measured using validated chemiluminescent-based immunoassays (Immulite, Siemens Medical Solutions Diagnostics, Los Angeles, CA, USA). Fibrinogen was measured using an immunoturbiometric assay validated for use with EDTA plasma (K-ASSAY fibrinogen test, Kamiya Biomedical Co., Seattle, WA, USA). The lower limit of quantification for each analyte was as follows: $160 \mathrm{ng} / \mathrm{mL}$ for adiponectin, $0.03 \mathrm{mg} / \mathrm{dL}$ for hsCRP, 0.78pg/mL for IL-6, $31.25 \mathrm{pg} /$ $\mathrm{mL}$ for leptin, and $5.4 \mathrm{mg} / \mathrm{dL}$ for fibrinogen.

\section{Statistical analyses}

All descriptors were assessed from measures collected at the year one visit. As some data were not normally distributed, medians and inter-quartile ranges $(\mathrm{IQR})$ were computed for the continuous variables, with frequencies calculated for categorical variables. For testing differences between populations or across covariate groups within a population for any given parameter, a non-parametric Kruskal-Wallis test was performed. Spearman correlation coefficients were calculated between adipokines and descriptor variables. Results were processed 
graphically and visualised by scatterplots. The stepwise multivariate linear regression model was performed with the adipokines (leptin, adiponectin, and leptin/ adiponectin) as dependent variables and age, gender, cohort, BMI, FMI, pack year history, and the systemic inflammatory biomarkers (IL6, fibrinogen, and CRP) as independent variables. In these analyses all adipokines and systemic inflammatory biomarkers were transformed logarithmically to approximate normal distributions. All p-values are nominal and are not adjusted for multiple comparisons. All analyses were run using SAS Version 9.2 (Cary, NC, USA).

\section{Results}

A comparison of the COPD subjects and controls matched for age, gender, and $\mathrm{BMI}$ revealed a lower FFMI and higher levels of CRP, IL-6, and adiponectin in the COPD group (Table 1). Furthermore, COPD subjects were more often current and former smokers compared to controls. Similar findings were observed after stratification for gender between COPD and controls (Table 2).

Within the COPD population, male subjects compared to female subjects had a higher FFMI, higher amount of pack-years, and higher levels of IL-6. Conversely, female COPD subjects compared to male COPD subjects had a higher FMI, levels of fibrinogen, adiponectin, leptin, and higher ratios of leptin/ FM and leptin/ adiponectin. Within controls, male subjects compared to female subjects had a higher FFMI, lower FMI, lower adiponectin and leptin levels, and a lower leptin/ FM and leptin/ adiponectin ratio.

The frequency of elevated systemic inflammatory biomarkers in COPD patients by gender defined by percentage of patients with levels above the 95 percentile of controls showed no significant differences between male and female COPD patients (Table 2).

\section{Spearman correlations for adipokines with systemic inflammatory biomarkers by cohort and gender}

In COPD patients (Table 3a) and controls (Table 3b) leptin correlated with CRP $(r=0.34 ; r=0.51 ; p<0.01)$ and fibrinogen $(r=0.20 ; r=0.33 ; p<0.01)$ but not with IL-6. Only in COPD patients, adiponectin correlated inversely with CRP $(r=-0.28 ; p<0.01)$. The leptin/ adiponectin ratio correlated significantly with CRP (COPD: $r=0.39$; controls: $r=0.49 ; p<0.01$ ), and fibrinogen in both groups (COPD: $r=0.19, p<0.01$; controls: $r=0.24 ; p=0.012$ ). Important differences between adipokines and inflammatory biomarkers were found after gender stratification. While similar correlations persisted in male and female controls as in the whole group with the exception of the correlation between fibrinogen and the leptin/ adiponectin ratio in the male controls, the correlation between leptin and $\mathrm{CRP}$ in female controls is high $(r=0.71 ; p<0.01$; Figure 1$)$. A similar relationship was found in female COPD patients (Figure 1), but the significant relationship 
between leptin and CRP and fibrinogen disappeared in male COPD patients. The inverse relationship between adiponectin and CRP in COPD was unrelated to gender (male: $r=-0.21 ; p=0.04$; female: $r=-0.37 p<0.01$ ).

Table 1. Population characteristics

\begin{tabular}{|c|c|c|}
\hline median $[\mathrm{IQR}]$ & $\begin{array}{l}\text { All COPD } \\
(n=186)\end{array}$ & $\begin{array}{l}\text { All Controls } \\
(n=113)\end{array}$ \\
\hline Age (years) & 58 [52-63] & 58 [51-63] \\
\hline $\mathrm{BMI}\left(\mathrm{kg} / \mathrm{m}^{2}\right)$ & 28 [23-32] & 29 [25-33] \\
\hline $\mathrm{FMI}\left(\mathrm{kg} / \mathrm{m}^{2}\right)$ & $10.1[6.5-13.0]$ & $10.1[7.4-12.2]$ \\
\hline FFMI $\left(\mathrm{kg} / \mathrm{m}^{2}\right)$ & $18.1[16.1-20.1]^{\dagger}$ & $19.3[17.2-20.6]$ \\
\hline Pack-year History & $40[28-52]^{\dagger}$ & $32[22-44]$ \\
\hline Smoking status: never smoker & - & 58 \\
\hline former smoker & $91^{\dagger}$ & 10 \\
\hline current smoker & $95^{\dagger}$ & 45 \\
\hline FEV $1 \%$ predicted & $51[39-62]^{\dagger}$ & 108 [100-118] \\
\hline $\mathrm{FEV}_{1} / \mathrm{FVC} \%$ & $45[38-58]^{\dagger}$ & $80[76-84]$ \\
\hline Adiponectin (ug/mL) & $9.8[6.6-13.2]^{\dagger}$ & $8.2[5.0-10.9]$ \\
\hline Adiponectin/ FM (ng/mL*kg) & 369 [199-626] & 308 [179-520] \\
\hline Leptin $(\mathrm{ng} / \mathrm{mL})$ & $17.7[7.5-40.6]$ & $14.6[7.2-27.2]$ \\
\hline Leptin/ FM (pg/mL*kg) & $684[362-1160]$ & 542 [316-921] \\
\hline Leptin/ Adiponectin (1/1000) & $1.9[0.7-5.2]$ & $1.9[0.8-4.1]$ \\
\hline $\mathrm{CRP}(\mathrm{mg} / \mathrm{dL})$ & $0.40[0.15-0.78]^{\dagger}$ & $0.18[0.09-0.38]$ \\
\hline IL-6 (pg/mL) & $11.5[6.9-23.2]^{\dagger}$ & $8.4[5.2-15.4]$ \\
\hline Fibrinogen $(\mathrm{mg} / \mathrm{dL})$ & $445[381-510]^{+}$ & 391 [347-446] \\
\hline CRP (\%; >95\% percentile of controls) & 17 & - \\
\hline IL-6 (\%; >95\% percentile of controls) & 9 & - \\
\hline $\begin{array}{l}\text { Fibrinogen } \\
(\% ;>95 \% \text { percentile of controls) }\end{array}$ & 23 & - \\
\hline
\end{tabular}

BMI, body mass index; FMI, fat mass index; FFMI, fat free mass index; FEV ${ }_{1}$, forced expiratory volume; FVC, forced vital capacity; CRP, C-reactive Protein; IL-6, Interleukin 6. †p<0.01 compared to controls. 
Table 2. Population characteristics by gender

\begin{tabular}{|c|c|c|c|c|}
\hline \multirow{2}{*}{ median $[\mathrm{IQR}]$} & \multicolumn{2}{|l|}{ COPD } & \multicolumn{2}{|l|}{ controls } \\
\hline & male $(n=94)$ & female $(n=92)$ & male $(n=59)$ & female $(n=54)$ \\
\hline Age (years) & 58 [52-63] & 58 [52-63] & 57 [51-63] & 58 [51-62] \\
\hline BMI $\left(\mathrm{kg} / \mathrm{m}^{2}\right)$ & 28 [24-32] & 27 [23-32] & 29 [26-33] & 29 [24-32] \\
\hline $\mathrm{FMI}\left(\mathrm{kg} / \mathrm{m}^{2}\right)$ & 8.0 [5.8-11.2]* & 10.7 [8.1-14.3] & $8.6[6.5-11.1]^{*}$ & $11.1[8.0-13.6]$ \\
\hline FFMI $\left(\mathrm{kg} / \mathrm{m}^{2}\right)$ & $\begin{array}{l}19.4 \\
{[17.8-21.4]^{\dagger *}}\end{array}$ & 16.5 [15.1-18.7] & $20.3[19.0-21.8]^{*}$ & 17.1 [15.9-18.8] \\
\hline Pack-year History & $45[34-56]^{+*}$ & 36 [26-36] & 36 [28-44] & 28 [19-40] \\
\hline $\begin{array}{l}\text { Smoking status, \%: } \\
\text { never smoker }\end{array}$ & 0 & 0 & 28 & 30 \\
\hline former smoker & 44 & 47 & 7 & 3 \\
\hline current smoker & 50 & 45 & 24 & 21 \\
\hline $\mathrm{FEV}_{1} \%$ predicted & $49[35-58]^{\dagger *}$ & $53[41-65]^{\dagger}$ & 108 [96-117] & 110 [102-121] \\
\hline $\mathrm{FEV}_{1} / \mathrm{FVC} \%$ & $43[36-54]^{\dagger *}$ & $49[39-60]^{\dagger}$ & 78 [74-82]* & 81 [79-86] \\
\hline $\begin{array}{l}\text { Adiponectin } \\
(\mathrm{ug} / \mathrm{mL})\end{array}$ & $9.0[6.3-11.7]^{*}$ & 10.2 [7.5-14.7] & $6.7[4.7-9.6]^{*}$ & 9.8 [5.9-12.0] \\
\hline $\begin{array}{l}\text { Adiponectin/FM } \\
\left(\mathrm{ng} / \mathrm{mL}^{*} \mathrm{~kg}\right)\end{array}$ & 372 [213-667] & 366 [191-602] & 296 [163-456] & 356 [179-528] \\
\hline Leptin (ng/mL) & $11.3[5.0-22.6]^{*}$ & 30.7 [15.9-58.9] & $10.6[4.6-16.1]^{*}$ & 24.6 [12.6-45.7] \\
\hline $\begin{array}{l}\text { Leptin/ FM } \\
\left(\mathrm{pg} / \mathrm{mL}^{*} \mathrm{~kg}\right)\end{array}$ & $430[251-768]^{*}$ & 1020 [609-1459] & 384 [237-543]* & 876 [583-1323] \\
\hline $\begin{array}{l}\text { Leptin/ Adiponectin } \\
(1 / 1000)\end{array}$ & $1.2[0.4-3.5]^{*}$ & $2.8[1.3-6.7]$ & $1.4[0.6-3.2]^{*}$ & $2.9[1.2-6.5]$ \\
\hline CRP (mg/dL) & $0.36[0.15-0.71]^{\dagger}$ & $0.42[0.15-0.82]^{\dagger}$ & 0.17 [0.09-0.35] & 0.20 [0.09-0.40] \\
\hline IL-6 (pg/mL) & $13.9[7.9-28.7]^{\dagger *}$ & 10.7 [5.4-19.1] & 10.0 [5.5-15.5] & $8.0[4.6-13.9]$ \\
\hline Fibrinogen (mg/dL) & $421[343-496]^{\dagger *}$ & $460[404-520]^{\dagger}$ & 387 [340-434] & 395 [350-457] \\
\hline $\begin{array}{l}\text { CRP } \\
\text { (\%;>95\% percentile } \\
\text { of controls) }\end{array}$ & 15 & 18 & - & - \\
\hline $\begin{array}{l}\text { IL-6 } \\
\text { (\%;>95\% percentile } \\
\text { of controls) }\end{array}$ & 13 & 5 & - & - \\
\hline $\begin{array}{l}\text { Fibrinogen } \\
\text { (\%;> } 95 \% \text { percentile } \\
\text { of controls) }\end{array}$ & 19 & 27 & - & - \\
\hline
\end{tabular}

$\mathrm{BMI}$, body mass index; FMI, fat mass index; FFMI, fat free mass index; FEV1, forced expiratory volume in the first second; FVC, forced vital capacity; CRP, C-reactive Protein; IL-6, Interleukin 6. $\dagger p<0.01$ compared to controls. ${ }^{*} p<0.01$ (except fibrinogen $p=0.036$ ) compared to female counterparts. 


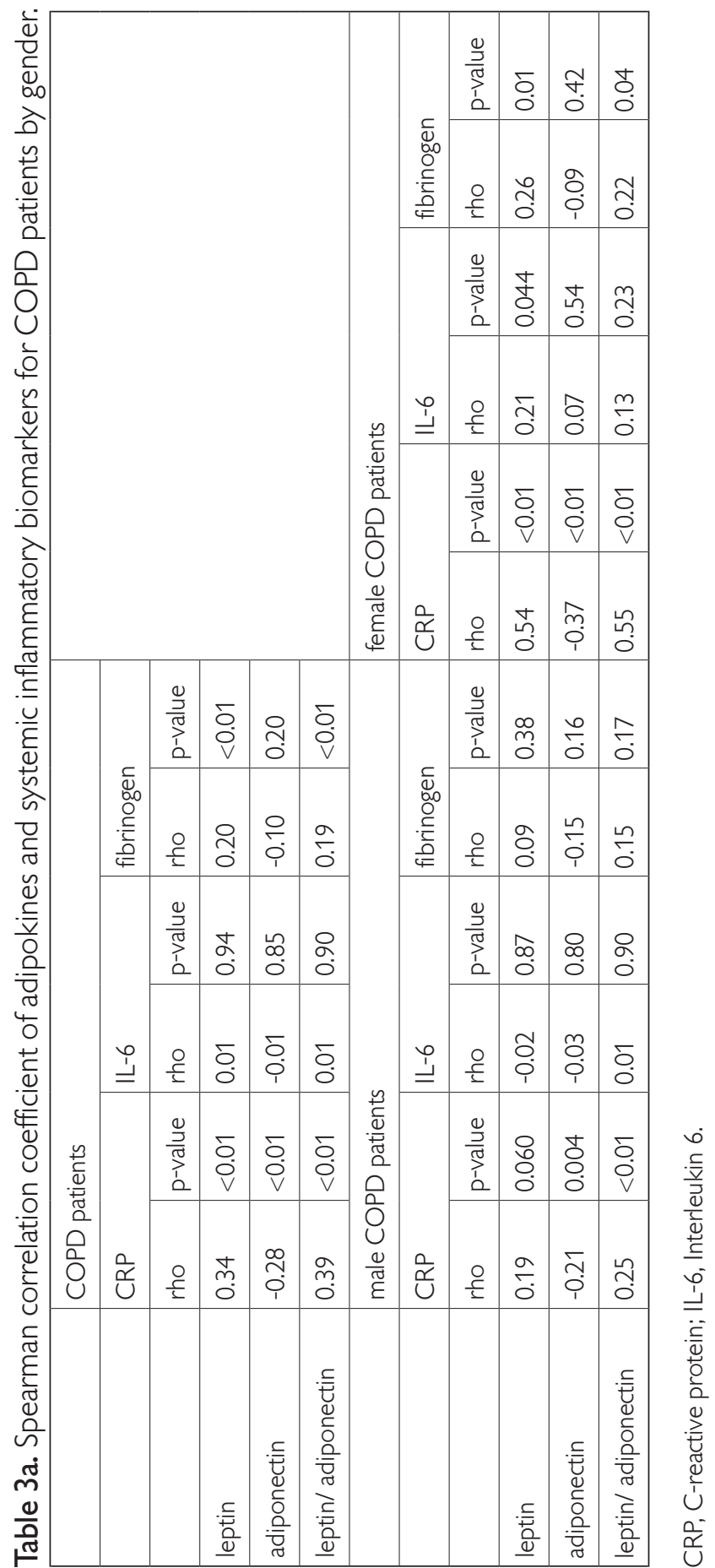




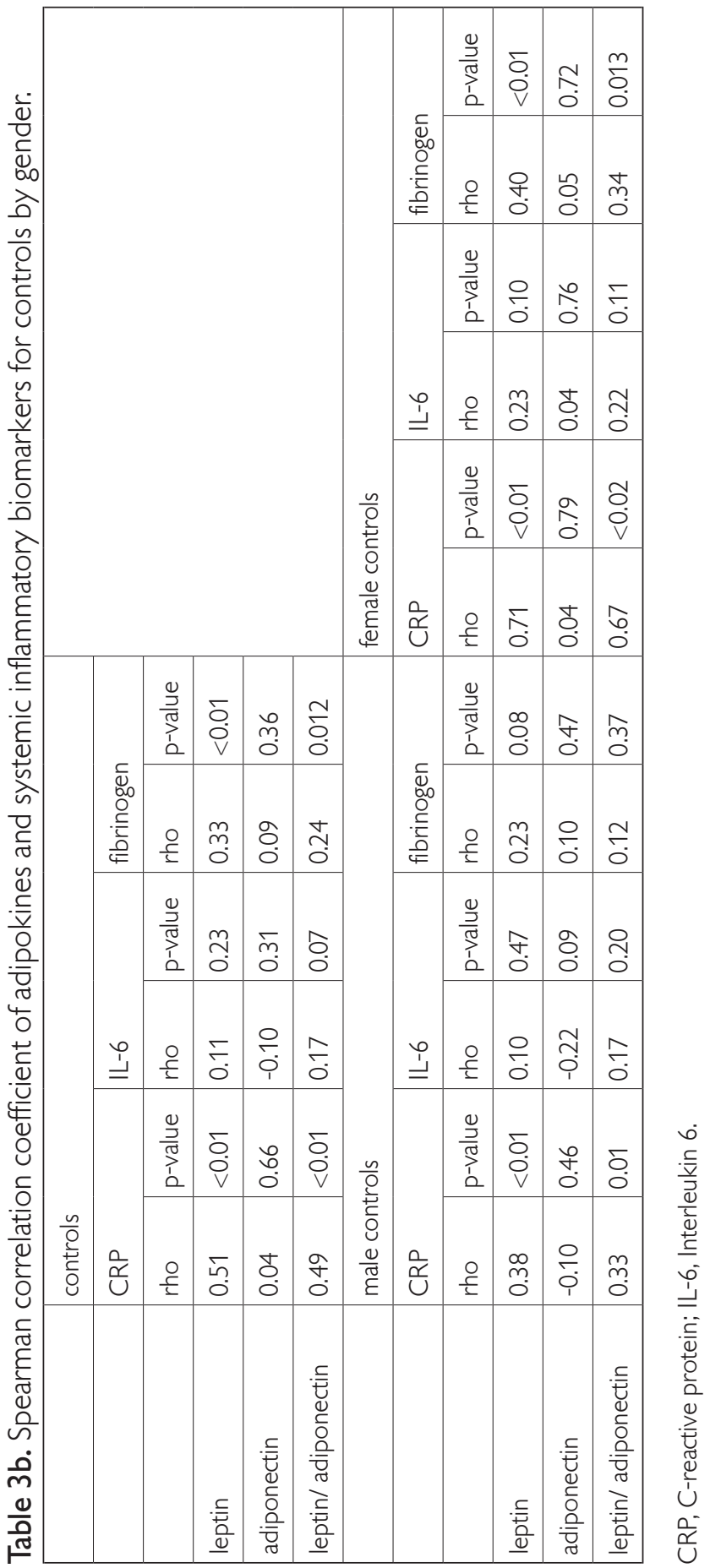




\section{Stepwise multiple regression analysis for adipokines (Table 4)}

In the total cohort, BMI, gender, and CRP were positively associated with leptin with circulating leptin. In total, the adjusted $r_{2}$ for leptin was $0.67(p<0.01)$. For adiponectin, BMI, and cohort were negatively associated and gender was positively associated, resulting in a $r_{2}$ of $0.24(p<0.01)$. The leptin/ adiponectin ratio was positively associated with BMI, and gender resulting in an $r_{2}$ of $0.58(p<0.01)$.

Table 4. Stepwise multiple regression analysis for Log(leptin), Log(adiponectin), and the Log(leptin)/ Log(adiponectin) ratio.

\begin{tabular}{|l|l|l|l|l|l|l|l|l|}
\hline Log(leptin) & \multicolumn{3}{l|}{ Log(adiponectin) } & \multicolumn{3}{l|}{ Log(leptin)/Log(adiponectin) } \\
\hline variable & Beta & p-value & variable & Beta & p-value & variable & Beta & -value \\
\hline BMI & 0.64 & $<0.01$ & BMI & -0.39 & $<0.01$ & BMI & 0.70 & $<0.01$ \\
\hline gender & 0.43 & $<0.01$ & cohort & -0.21 & $<0.01$ & gender & 0.29 & $<0.01$ \\
\hline Log(CRP)Age & 0.11 & 0.01 & gender & 0.20 & $<0.01$ & rho=0.58 & & $<0.01$ \\
\hline rho=0.67 & & 0.01 & rho=0.24 & & $<0.01$ & & & \\
\hline
\end{tabular}

BMI, Body mass index; Log(CRP), C-reactive Protein; FMI, fat mass index. Excluded Variables: Log(IL-6; interleukin-6), fibrinogen.

\section{Discussion}

The present study reports the complex relationship between adipokine metabolism and low-grade systemic inflammation in COPD. COPD patients have higher adiponectin levels compared with controls and serum adiponectin levels are negatively related to CRP in male and female COPD patients. In female COPD patients, the significant relationship between leptin and CRP and fibrinogen, observed in male and female controls, persisted. Although CRP is a significant contributor for leptin and cohort for adiponectin, body mass index and gender are the dominant determinants of the adipokines.

There is limited data available concerning the role of adiponectin in the pathophysiology of COPD. Adiponectin, almost exclusively produced by adipocytes, has a collagen-like domain followed by a globular domain that is similar to complement factor C1q. Similar to C1q, adiponectin forms trimers thorough collagen-like domain interactions that can further associate to form stable multimeric oligomers ${ }^{12}$. Its effects are mediated through two receptors, adiponectin receptor 1 and 2, which show different tissue distribution and different affinity for their ligand $^{30}$. Besides the inverse relationship with BMI, this study clearly demonstrates that adiponectin levels are increased in stable COPD patients and are inversely related to CRP. One previous fair sample-sized study reports on elevated serum 
adiponectin concentration in female COPD patients compared to male peers ${ }^{24}$. Furthermore, in a rather small-sized Chinese COPD cohort, adiponectin levels were elevated in male and female patients ${ }^{31}$. These data confirm findings of the association between adiponectin levels and pro-inflammatory markers as in various other disease settings. Plasma adiponectin levels are negatively correlated with CRP levels in obese or diabetic patients ${ }^{19}$. The association between adiponectin and CRP levels in non-diabetic or controls could not be reproduced in our study. Despite its role in improvement of insulin sensitivity, increased levels of adiponectin seem beneficial to decrease cardiovascular risk ${ }^{13}$. Clinical studies have identified an association between low serum levels of adiponectin and coronary artery disease, hypertension, left ventricular hypertrophy and a greater risk of myocardial infarction ${ }^{32-34}$. Despite these direct beneficial effects of adiponectin in the development of cardiovascular morbidity, the role of adiponectin in clinical practice remains unclear yet. Indeed, in patients with chronic heart failure as well as chronic renal failure, higher adiponectin levels have been associated with an increased cardiac and all-cause mortality20,21,35. Similar findings were recently confirmed in a rather small COPD cohort: higher levels of adiponectin were associated with an increased overall mortality ${ }^{36}$. These data possibly suggest that adiponectin, besides its beneficial biological effects, is an indirect marker of the multi-component severity in COPD. Further studies need to explore these hypotheses as well as the potential role of adiponectin as a contributing factor in the disease progression.

Consistent with previous studies, COPD is characterized by low-grade systemic inflammation reflected by increased levels of CRP, IL-6 and fibrinogen in men and higher levels of CRP and fibrinogen in women ${ }^{37}$. Low-grade systemic inflammation present in COPD is one of the main extra pulmonary features of COPD as it is thought to play a major role in the pathogenesis of COPD. However, the exact mechanisms inducing systemic inflammation in COPD are still not fully elucidated and the origin is most probably multi-factorial. While some still position the not proven ${ }^{10}$ 'spill over' theory from local pulmonary inflammation into the systemic circulation, others position lung hyperinflation, smoking or the bone marrow as the origin of systemic inflammation in COPD ${ }^{38,39}$. Recently, the adipose tissue is suggested as being one of the possible sources of systemic inflammation in $\mathrm{COPD}^{40}$. Indeed, adipose tissue macrophages infiltration was higher in high-CRP COPD patients compared to low-CRP peers, indicating a possible relationship between systemic inflammation and adipose tissue in COPD ${ }^{41}$. In general, the adipose tissue is known to actively secret the pro-inflammatory and pro-atherogenic cytokine leptin which is, by nature highly correlated with adipose tissue mass ${ }^{14}$. Furthermore, levels of circulating leptin are associated with CRP independent of gender ${ }^{42}$, although higher levels are reported in healthy women compared to healthy men ${ }^{43}$. Results from the present study show increased levels of circulat- 
ing leptin in women with COPD as well as in female controls compared to male counterparts. Furthermore, in order to reveal a possible relationship between leptin and various systemic inflammatory biomarkers, circulating leptin was correlated with the inflammatory markers. Interestingly, particularly in COPD and female controls, leptin was correlated with CRP and fibrinogen, while in COPD men, leptin correlated with none of the systemic inflammatory biomarkers. In the multivariate regression analysis, CRP was independently associated with leptin. This is in line with a previous small-sample-sized study reporting a positive correlation between CRP and leptin in COPD women ${ }^{24}$. The linkage between leptin and CRP in the general population and particularly in women is not clear. However, a simple explanation for this linkage may be that leptin induces production of IL-6 which in turn stimulates the production of CRP from hepatocytes and vice verse, in the setting of inflammation, CRP and IL-6 induce production of leptin from fat cells $s^{14}$. A more complicated explanation may involve the association of adipose tissue with oxidative stress (via isoprostanes and myeloperoxidase) and circulating leptin enhancing the production of oxidative species by leukocytes ${ }^{44}$. Although COPD patients are generally characterised by a reduced anti-oxidant capacity and an enhanced production of reactive oxygen species ${ }^{45}$, it can only be speculated if this hypothesis is also transferable to patients with COPD. Finally, the exact role of fibrinogen in the adipokine metabolism in COPD is unexplored. In the general population, some studies report on a positive relationship between levels of fibrinogen and circulating leptin levels ${ }^{46}$, while others do not ${ }^{47}$. However, similar to CRP and IL-6 a possible linkage might be via leptin and the induction of hepatic expression of fibrinogen. Taken together, the present study firstly reveals that the acute phase metabolism is related to leptin in COPD women compared to the male COPD patients, indicating a gender dependent adipokine metabolism in patients with COPD. Future research has to gain better insights on the impact/ function of circulating leptin on systemic inflammation, particularly in COPD women.

Worth noting, is the fact that circulating leptin levels are a strong predictor for myocardial infarction and first-ever hemorrhagic stroke in the general population ${ }^{48,49}$. These data suggest a possible link between the pro-inflammatory cytokine and the development of cardiovascular disease. Interestingly, in the present study COPD patients with self-reported cardiovascular co-morbidities were excluded from the study in order to avoid other chronic inflammatory diseases interfering with our results, although some patients still might have had unknown cardiovascular co-morbidity. However, to speculate, circulating leptin might therefore be one additional pro-inflammatory cytokine contributing to the increased cardiovascular morbidity and mortality observed in patients with COPD compared to healthy controls ${ }^{37}$. Thus far, this hypothesis has never been investigated. 
The following methodological considerations have to be taken into account. Firstly, although the present study is the largest, controlled trial available at the moment, longitudinal data are needed to confirm the present results. Secondarily, although various clinically relevant findings were revealed in the present study, more direct outcomes and possible consequences are necessary to get more insight into the gender related differences in adipokine metabolism and its association with systemic inflammation in patients with COPD.

In conclusion, the present study shows a gender dependent dysregulated adipokine metabolism in relation to systemic inflammatory biomarkers in COPD patients compared to BMI matched controls. Furthermore, results from the present study suggest a more prominent role of adiponectin in the systemic pathogenesis of COPD. 


\section{References}

1. Rabe KF, Hurd S, Anzueto A, et al. Global strategy for the diagnosis, management, and prevention of chronic obstructive pulmonary disease: GOLD executive summary. Am J Respir Crit Care Med 2007;176:53255.

2. Wouters EF. COPD: from an organ- to a disease-oriented approach. Copd 2008;5:73-4.

3. Gan WQ, Man SF, Senthilselvan A, Sin DD. Association between chronic obstructive pulmonary disease and systemic inflammation: a systematic review and a meta-analysis. Thorax 2004;59:574-80.

4. Stolz D, Christ-Crain M, Morgenthaler NG, et al. Copeptin, C-reactive protein, and procalcitonin as prognostic biomarkers in acute exacerbation of COPD. Chest 2007;131:1058-67.

5. Ridker PM, Buring JE, Shih J, Matias M, Hennekens CH. Prospective study of C-reactive protein and the risk of future cardiovascular events among apparently healthy women. Circulation 1998;98:731-3.

6. Man SF, Connett JE, Anthonisen NR, Wise RA, Tashkin DP, Sin DD. C-reactive protein and mortality in mild to moderate chronic obstructive pulmonary disease. Thorax 2006;61:849-53.

7. Dahl M, Vestbo J, Lange P, Bojesen SE, Tybjaerg-Hansen A, Nordestgaard BG. C-reactive protein as a predictor of prognosis in chronic obstructive pulmonary disease. Am J Respir Crit Care Med 2007;175:250-5.

8. Dahl M, Tybjaerg-Hansen A, Vestbo J, Lange P, Nordestgaard BG. Elevated plasma fibrinogen associated with reduced pulmonary function and increased risk of chronic obstructive pulmonary disease. Am J Respir Crit Care Med 2001;164:1008-11.

9. Wouters EF. COPD: a chronic and overlooked pulmonary disease. Lancet 2007;370:715-6.

10. Vernooy JH, Kucukaycan M, Jacobs JA, et al. Local and systemic inflammation in patients with chronic obstructive pulmonary disease: soluble tumor necrosis factor receptors are increased in sputum. Am J Respir Crit Care Med 2002;166:1218-24.

11. Berg AH, Scherer PE. Adipose tissue, inflammation, and cardiovascular disease. Circ Res 2005;96:939-49.

12. Ouchi N, Kihara S, Funahashi T, Matsuzawa Y, Walsh K. Obesity, adiponectin and vascular inflammatory disease. Curr Opin Lipidol 2003;14:561-6.

13. Ouchi N, Parker JL, Lugus JJ, Walsh K. Adipokines in inflammation and metabolic disease. Nat Rev Immunol 2011;11:85-97.

14. Fantuzzi G. Adipose tissue, adipokines, and inflammation. J Allergy Clin Immunol 2005;115:911-9; quiz 20.

15. Weyer C, Funahashi T, Tanaka S, et al. Hypoadiponectinemia in obesity and type 2 diabetes: close association with insulin resistance and hyperinsulinemia. J Clin Endocrinol Metab 2001;86:1930-5.

16. Zabeau L, Lavens D, Peelman F, Eyckerman S, Vandekerckhove J, Tavernier J. The ins and outs of leptin receptor activation. FEBS Lett 2003;546:45-50.

17. Soderberg $\mathrm{S}$, Ahren B, Jansson JH, et al. Leptin is associated with increased risk of myocardial infarction. J Intern Med 1999;246:409-18.

18. Diez JJ, Iglesias P. The role of the novel adipocyte-derived hormone adiponectin in human disease. Eur J Endocrinol 2003;148:293-300.

19. Ouchi N, Kihara S, Funahashi T, et al. Reciprocal association of C-reactive protein with adiponectin in blood stream and adipose tissue. Circulation 2003;107:671-4.

20. Cavusoglu E, Ruwende C, Chopra V, et al. Adiponectin is an independent predictor of all-cause mortality, cardiac mortality, and myocardial infarction in patients presenting with chest pain. Eur Heart 1 2006;27:23009.

21. Kistorp C, Faber J, Galatius S, et al. Plasma adiponectin, body mass index, and mortality in patients with chronic heart failure. Circulation 2005;112:1756-62.

22. Tomoda K, Yoshikawa M, Itoh T, et al. Elevated circulating plasma adiponectin in underweight patients with COPD. Chest 2007;132:135-40.

23. Schols AM, Creutzberg EC, Buurman WA, Campfield LA, Saris WH, Wouters EF. Plasma leptin is related to proinflammatory status and dietary intake in patients with chronic obstructive pulmonary disease. Am J Respir Crit Care Med 1999;160:1220-6.

24. Breyer MK, Rutten EP, Vernooy JH, et al. Gender differences in the adipose secretome system in chronic obstructive pulmonary disease (COPD): a pivotal role of leptin. Respir Med 2011;105:1046-53.

25. Vestbo J, Anderson W, Coxson HO, et al. Evaluation of COPD Longitudinally to Identify Predictive Surrogate End-points (ECLIPSE). Eur Respir J 2008;31:869-73.

26. Simera I, Moher D, Hoey J, Schulz KF, Altman DG. A catalogue of reporting guidelines for health research. Eur J Clin Invest 2010;40:35-53.

27. Miller MR, Hankinson J, Brusasco V, et al. Standardisation of spirometry. Eur Respir J 2005;26:319-38. 
28. Vestbo J, Prescott E, Almdal T, et al. Body mass, fat-free body mass, and prognosis in patients with chronic obstructive pulmonary disease from a random population sample: findings from the Copenhagen City Heart Study. Am J Respir Crit Care Med 2006;173:79-83.

29. Dey DK, Bosaeus I, Lissner L, Steen B. Body composition estimated by bioelectrical impedance in the Swedish elderly. Development of population-based prediction equation and reference values of fat-free mass and body fat for 70- and 75-y olds. Eur J Clin Nutr 2003;57:909-16.

30. Yamauchi T, Kamon J, Ito $Y$, et al. Cloning of adiponectin receptors that mediate antidiabetic metabolic effects. Nature 2003;423:762-9.

31. Chan $\mathrm{KH}$, Yeung SC, Yao TJ, et al. Elevated plasma adiponectin levels in patients with chronic obstructive pulmonary disease. Int J Tuberc Lung Dis 2010;14:1193-200.

32. Sattar N, Wannamethee G, Sarwar N, et al. Adiponectin and coronary heart disease: a prospective study and meta-analysis. Circulation 2006;114:623-9.

33. Iwashima Y, Katsuya T, Ishikawa $\mathrm{K}$, et al. Hypoadiponectinemia is an independent risk factor for hypertension. Hypertension 2004:43:1318-23.

34. Pischon T, Girman CJ, Hotamisligil GS, Rifai N, Hu FB, Rimm EB. Plasma adiponectin levels and risk of myocardial infarction in men. Jama 2004;291:1730-7.

35. Ohashi N, Kato A, Misaki T, et al. Association of serum adiponectin levels with all-cause mortality in hemodialysis patients. Intern Med 2008:47:485-91.

36. Waschki B, Kirsten A, Holz O, et al. Physical activity is the strongest predictor of all-cause mortality in patients with COPD: a prospective cohort study. Chest 2011;140:331-42.

37. Sin DD, Man SF. Why are patients with chronic obstructive pulmonary disease at increased risk of cardiovascular diseases? The potential role of systemic inflammation in chronic obstructive pulmonary disease. Circulation 2003;107:1514-9.

38. Vassilakopoulos T, Zakynthinos S, Roussos C. Strenuous resistive breathing induces proinflammatory cytokines and stimulates the HPA axis in humans. Am J Physiol 1999;277:R1013-9.

39. van Eeden SF, Hogg JC. The response of human bone marrow to chronic cigarette smoking. Eur Respir J 2000;15:915-21.

40. Breyer MK, Spruit MA, Celis AP, Rutten EP, Janssen PP, Wouters EF. Highly elevated C-reactive protein levels in obese patients with COPD: a fat chance? Clin Nutr 2009;28:642-7.

41. van den Borst B, Gosker HR, Wesseling G, et al. Low-grade adipose tissue inflammation in patients with mild-to-moderate chronic obstructive pulmonary disease. Am J Clin Nutr 2011.

42. Shamsuzzaman AS, Winnicki M, Wolk R, et al. Independent association between plasma leptin and Creactive protein in healthy humans. Circulation 2004;109:2181-5.

43. Marques-Vidal P, Bochud M, Paccaud F, Mooser V, Waeber G, Vollenweider P. Distribution of plasma levels of adiponectin and leptin in an adult Caucasian population. Clin Endocrinol (Oxf);72:38-46.

44. Caldefie-Chezet F, Poulin A, Tridon A, Sion B, Vasson MP. Leptin: a potential regulator of polymorphonuclear neutrophil bactericidal action? J Leukoc Biol 2001;69:414-8.

45. Mercken EM, Hageman G], Schols AM, Akkermans MA, Bast A, Wouters EF. Rehabilitation decreases exercise-induced oxidative stress in chronic obstructive pulmonary disease. Am J Respir Crit Care Med 2005;172:994-1001.

46. Gomez-Ambrosi J, Salvador J, Paramo JA, et al. Involvement of leptin in the association between percentage of body fat and cardiovascular risk factors. Clin Biochem 2002;35:315-20.

47. Mertens I, Considine RV, Van der Planken M, Van Gaal LF. Hemostasis and fibrinolysis in non-diabetic overweight and obese men and women. Is there still a role for leptin? Eur J Endocrinol 2006;155:477-84.

48. Soderberg S, Ahren B, Stegmayr B, et al. Leptin is a risk marker for first-ever hemorrhagic stroke in a population-based cohort. Stroke 1999;30:328-37.

49. Soderberg S, Olsson T, Eliasson M, Johnson O, Ahren B. Plasma leptin levels are associated with abnormal fibrinolysis in men and postmenopausal women. J Intern Med 1999;245:533-43. 



\section{CHAPTER 7}

\section{Nordic Walking improves daily physical activities in COPD: a randomised controlled trial}

Breyer MK, Breyer-Kohansal R, Funk GC, Dornhofer N, Spruit MA, Wouters EF, Burghuber OC, Hartl S

Respir. Res. 2010 Aug. 22, 11:112 



\section{Abstract}

\section{Background}

In patients with COPD progressive dyspnoea leads to a sedentary lifestyle. To date, no studies exist investigating the effects of Nordic Walking in patients with COPD. Therefore, the aim was to determine the feasibility of Nordic Walking in COPD patients at different disease stages. Furthermore we aimed to determine the short- and long-term effects of Nordic Walking on COPD patients' daily physical activity pattern as well as on patients exercise capacity.

\section{Methods}

Sixty COPD patients were randomised to either Nordic Walking or to a control group. Patients of the Nordic Walking group ( $n=30$; age: $62 \pm 9$ years; FEV: $48 \pm 19 \%$ predicted) underwent a three-month outdoor Nordic Walking exercise program consisting of one hour walking at $75 \%$ of their initial maximum heart rate three times per week, whereas controls had no exercise intervention. Primary endpoint: daily physical activities (measured by a validated tri-axial accelerometer); secondary endpoint: functional exercise capacity (measured by the six-minute walking distance; 6MWD). Assessment time points in both groups: baseline, after three, six and nine months.

\section{Results}

After three month training period, in the Nordic Walking group time spent walking and standing as well as intensity of walking increased ( $\triangle$ walking time: $+14.9 \pm 1.9 \mathrm{~min} /$ day; $\triangle$ standing time: $+129 \pm 26 \mathrm{~min} /$ day; $\triangle$ movement intensity: $+0.40 \pm 0.14 \mathrm{~m} / \mathrm{s}^{2}$ ) while time spent sitting decreased ( $\triangle$ sitting time: $-128 \pm 15$ $\mathrm{min} /$ day) compared to baseline (all: $p<0.01$ ) as well as compared to controls (all: $p<0.01$ ). Furthermore, 6MWD significantly increased compared to baseline ( $\triangle$ 6MWD: $+79 \pm 28$ meters) as well as compared to controls (both: $p<0.01$ ). These significant improvements were sustained six and nine months after baseline. In contrast, controls showed unchanged daily physical activities and 6MWD compared to baseline for all time points.

\section{Conclusions}

Nordic Walking is a feasible, simple and effective physical training modality in COPD. In addition, Nordic Walking has proven to positively impact the daily physical activity pattern of COPD patients under short- and long-term observation.

\section{Clinical trial registration}

Nordic Walking improves daily physical activities in COPD: a randomised controlled trial - ISRCTN31525632 


\section{Introduction}

Despite optimal pulmonary drug treatment, patients with chronic obstructive pulmonary disease (COPD) frequently experience dyspnoea and fatigue during everyday life, which may result in daily physical inactivity'. Indeed, COPD patients are significantly less active compared to healthy controls, spending most of the day sitting or lying ${ }^{2,3}$. Moreover, low daily physical activity levels decrease during acute exacerbation, followed by only partial recovery 4 . This 'downward disease spiral' is one of the major challenges in the long term management of COPD 5 . In fact, higher dyspnea symptoms have been related to worse exercise performance, health status and poor survival in COPD ${ }^{6,7}$. Moreover, lower levels of physical activity in daily life may contribute to a higher risk of hospital readmission ${ }^{8}$ and shorter survival ${ }^{9}$. Changing patients' behaviour, such as from a sedentary to a more active lifestyle, has been set as one of the key goals of pulmonary rehabilitation ${ }^{10}$.

Comprehensive pulmonary rehabilitation programs improve COPD patients' peripheral muscle function, functional exercise capacity, daily symptoms of dyspnoea, fatigue, anxiety and depression, and health status ${ }^{10}$. However, most of the studies lack to transfer these achievements into long-term observation ${ }^{11}$, indicating that an improvement in functional exercise capacity does not automatically turn into a more active lifestyle. The effects of pulmonary rehabilitation on daily physical activity level in COPD have been scarcely studied in non-randomised and/or non-controlled trial designs with no or modest effects ${ }^{12-14}$.

We hypothesised that physical training modalities copying everyday-life activities might translate better into patients' physical performance status ${ }^{15}$. Nordic Walking, which involves, by definition, walking with specially designed poles, proved to be a safe and effective physical training method in cardiac rehabilitation ${ }^{16}$. Moreover, Nordic Walking had been revealed to enhance oxygen uptake and to consecutively increase caloric expenditure on the treadmill as well as in field testing in healthy ${ }^{17-19}$.

To date, no studies are available investigating the effects of Nordic Walking in COPD. Therefore our primary aim was to determine the feasibility of Nordic Walking in COPD patients at different disease stages, more precisely if training walking speed can achieve preset heart rate directed training goals. Furthermore we aimed to determine the long-term effect of Nordic Walking on patients' daily physical activity pattern. Finally, we investigated the effects of Nordic Walking on COPD patients' functional exercise capacity, exercise induced dyspnoea, mood status, and health-related quality of life in short- and long-term observation. 


\section{Methods}

\section{Design}

The present study was designed as a prospective, randomised, controlled trial. Local ethics committee approved the study and all patients gave written informed consent before participating in the study. The study is registered in the ISRCTN Register (ISRCTN31525632 - http://www.controlled-trials.com/ISRCTN31525632). Some of the baseline data have been presented in a previous study ${ }^{3}$. All patients were retired at time of inclusion or on sick leave. Randomisation to either the Nordic Walking or the control group was done by a computergenerated algorithm maintained by SPSS version 15.01. The present study was the first to investigate the effect of Nordic Walking on the physical activity of COPD patients. Therefore, we were unable to reliably estimate the effect size and variances prior to the study. Hence, for both groups we chose a large sample size of $n=28$, which was judged to allow detection of relevant between-group differences in a two-factorial ANOVA with repeated measurements.

\section{Participants}

COPD patients were initially screened from March 2006 until March 2007. Exclusion criteria: self reported exacerbation < twelve weeks, myocardial infarction $<$ six month, cardiac arrhythmias > Lown Illb, or walking disturbances due to muscle or bone diseases. All participants attended one educational session/ week ${ }^{20}$ on pulmonary pathophysiology, the management of breathlessness and exacerbations, the clearance of pulmonary secretions, smoking cessation, medication and nutrition.

\section{Nordic Walking group}

Patients performed maximal exercise testing to obtain maximum heart rate (HR). The preset goal for training efficiency was set at $75 \%$ of the initial maximum HR, three times a week according to international recommendations ${ }^{10}$. Patients were matched for initially obtained maximum $\mathrm{HR}$ during maximal exercise testing to ascertain similar walking speeds. Patients received a two-hour instruction by a professional Nordic Walking instructor. None of the patients had any difficulties in performing Nordic Walking adequately. HR was monitored by a pulse watch (HRT 1100, Innovit GmBH; Frechen, Germany), and oxygen saturation was measured by a portable pulse oximeter (OxiPrint, Vivisol; Wisconsin, USA). Patients on long term oxygen therapy (LTOT) were using their LTOT during the intervention as recommended ${ }^{10}$. During training all patients were supervised as well as data were recorded by medical staff and walking speed was, if necessary, adapted to bearable dyspnoea and optimal oxygen saturation. 


\section{Nordic Walking}

The International Nordic Walking Federation (INWA) is the official worldwide international federation promoting Nordic Walking and was founded in Finland in 2000 (http://inwa-nordicwalking.com). The principle is that walking with the poles increases muscle use and walking speed, both of them increasing $\mathrm{VO}^{2}$ and lactate ${ }^{21}$. Nordic Walking is mostly performed outdoors and due to the specially constructed poles Nordic Walking can be performed independent of ground quality (asphalt, meadow; additional file). The type of walking poles used in the present study was Power Poles (LEKI; Hamburg, Germany). Power Poles are built of light-weight aluminium and weigh approximately 440 grams each. The body of the pole is constructed in such a way that it compresses during initial contact with the ground and then springs back to its normal length through the push-off phase of the walking stride. Additionally, the body of the poles are made to be adjustable to the height of the user. The tip of the pole is made of $100 \%$ rubber and is designed to be shock absorbent and slip resistant. The handles of the Power Poles are anatomically designed to fit the hand. The current costs for LEKI power poles currently ranges (April 2010) between 25. - 80. - EURO.

\section{Primary endpoint Daily physical activities}

Physical activity is defined as any bodily movement produced by skeletal muscles ${ }^{22}$, such as standing or walking that result in energy expenditure beyond the resting expenditure. A tri-axial accelerometer (DynaPort Activity Monitor; McRoberts BV; Den Haag, the Netherlands) was used to assess the daily physical activities of the COPD patients. The DynaPort consists of a small lightweight box enclosed in a belt that is worn around the waist and a leg sensor that is worn around the left upper leg. Multi-axial devices are able to detect motion in more than one plane of movement and therefore time spent walking, standing, sitting or lying, as well as the movement intensity, which is given in meters divided by seconds squared $\left(\mathrm{m} / \mathrm{s}^{2}\right)$, during walking can precisely be measured. The DynaPort is validated in patients with COPD ${ }^{23,24}$. Technical specifications of the activity monitor are described elsewhere ${ }^{24}$. Data were collected during three consecutive week days for 12-hours after the patient woke up ${ }^{25}$. No data were recorded during sleep, weekend or Nordic Walking. The average of the three recorded assessment days was used for analysis. All subjects were carefully instructed on how to position the device, and they received a manual with clear figures and instructions. In addition, patients had to fill in a daily checklist to verify if the day had been representative. Daily physical activities were assessed at baseline, after three, six, and nine month in both groups. 


\section{Secondary endpoints}

Functional exercise capacity, exercise-induced dyspnoea, mood status, and health-related quality of life

Functional exercise capacity was assessed using the six-minute walking test $(6 \mathrm{MWT})^{26}$ expressed as a percentage of the predicted distance ${ }^{27}$. Perceived dyspnoea after the 6MWT was recorded using the modified BORG dyspnoea scale $^{28}$. The assessment of mood status was performed using the hospital anxiety and depression scale (HADS $)^{29}$ with a cut-off $\geq 7$ points for each scale to identify the presence of symptoms of anxiety and/or depression. Generic quality of life was evaluated using the Medical Outcomes Study 36-item short form (SF-36) ${ }^{30}$. Scores for the Physical Component Summary (PCS) and the Mental Component Summary (MCS) range from 0 to 100 , with scores $>50$ points representing better generic quality of life.

\section{Additional variables}

Lung function data were collected using standardised spirometry ${ }^{31}$ (Sensor Medics Vmax 22, Viasys Healthcare; California, USA). Airflow limitation was classified according to the latest ERS/ATS guidelines ${ }^{1}$. Additionally, patients' height and weight were measured, body mass index was calculated and relevant co-morbidities, such as cardiovascular disease, and the use of LTOT were recorded.

\section{Statistical analyses}

Categorical variables were described as frequencies. Continuous variables were tested for normality by a normal plot and presented as mean \pm standard deviation (SD). Evaluation of differences in mean levels for baseline characteristics between the Nordic Walking and the control group was done using one-way ANOVA. Between group and within group differences in outcome parameters were tested using ANOVA accounting for repeated-measurements. The sphericity assumption was assessed by Mauchly's test, and $p$ values were corrected by the Greenhouse-Geisser method, if required. All analyses were performed using SPSS version 15.01. A p-value of $\leq 0.05$ was considered to be significant. 


\section{Results}

In total 60 COPD patients completed the study and were included into the analyses. A diagram of participant flow is shown in Figure 1. The baseline characteristics of both groups are shown in Table 1. No statistical significances were found between the two groups at baseline.

Figure 1. Patient flow diagram

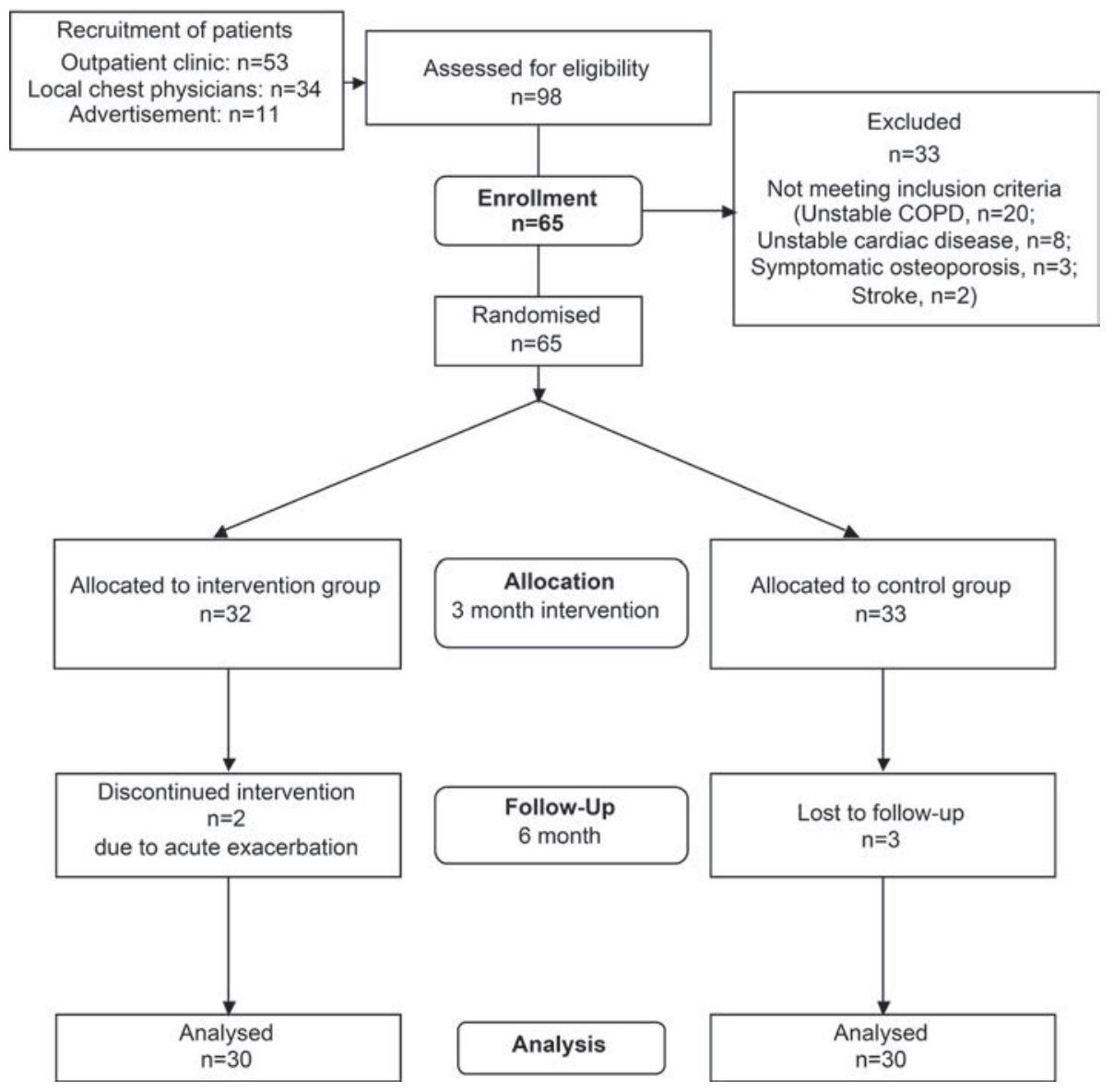


Table 1. Baseline characteristics

\begin{tabular}{|c|c|c|c|}
\hline & $\begin{array}{l}\text { total }(n=60) \\
\text { mean }( \pm S D)\end{array}$ & $\begin{array}{l}\text { Nordic Walking group } \\
(n=30)\end{array}$ & control group $(n=30)$ \\
\hline age, years & $60.3(8.45)$ & $61.9(8.87)$ & $59.0(8.02)$ \\
\hline male sex, $\%$ & 45 & 47 & 43 \\
\hline LTOT, n (\%) & $5(8.3)$ & $2(3.3)$ & $3(5.0)$ \\
\hline $\mathrm{FEV}_{1}, \%$ predicted & $46.3(17.6)$ & $48.1(19.1)$ & $47.1(16.3)$ \\
\hline $\begin{array}{l}\mathrm{FEV}_{1} / \mathrm{FVC} \\
\% \text { predicted }\end{array}$ & $44.9(10.7)$ & $45.2(11.6)$ & $45.3(10.5)$ \\
\hline GOLD II, III, IV, (\%) & $\begin{array}{l}27(45), 14(23), \\
19(32)\end{array}$ & $\begin{array}{l}13(43), 7(24), \\
10(33)\end{array}$ & $\begin{array}{l}14(47), 7(23), \\
9(30)\end{array}$ \\
\hline $\mathrm{BMI}, \mathrm{kg} / \mathrm{m}^{2}$ & $26.2(4.6)$ & $25.9(4.5)$ & $26.5(4.9)$ \\
\hline 6MWD, m & $446(140)$ & $461(154)$ & $436(128)$ \\
\hline 6MWD, \% predicted & $66.9(19.6)$ & $66.4(22.1)$ & $67.3(17.3)$ \\
\hline peak load, watts & - & $68.0(24.1)$ & - \\
\hline $\begin{array}{l}\text { peak load, } \\
\% \text { predicted }\end{array}$ & - & $54.6(14.3)$ & - \\
\hline BORG score, points & $4.3(2.1)$ & $4.4(2.2)$ & $3.9(1.9)$ \\
\hline $\begin{array}{l}\text { HADS anxiety, } \\
\geq 7 \text { points }\end{array}$ & $9.7(3.8 ; n=32)$ & $8.8(2.4 ; n=15)$ & $10.5(3.6 ; n=17)$ \\
\hline $\begin{array}{l}\text { HADS depression, } \\
\geq 7 \text { points }\end{array}$ & $10.7(3.2 ; n=27)$ & $9.9(3.2 ; n=12)$ & $11.3(3.1 ; n=15)$ \\
\hline SF 36 PCS, $<50$ points & $32.0(6.13 ; n=53)$ & $32.2(6.50 ; n=28)$ & $31.7(5.79 ; n=25)$ \\
\hline MCS, $<50$ points & $40.9(8.59 ; n=30)$ & $42.8(7.41 ; n=14)$ & $39.2(9.40 ; n=16)$ \\
\hline \multicolumn{4}{|l|}{ daily physical activities } \\
\hline $\begin{array}{l}\text { movement intensity, } \\
\mathrm{m} / \mathrm{s}^{2}\end{array}$ & $1.55(0.39)$ & $1.59(0.47)$ & $1.50(0.29)$ \\
\hline walking, min/day & $44.5(35.6)$ & $46.7(35.2)$ & $42.3(36.5)$ \\
\hline standing, min/day & $218(138)$ & $215(182)$ & $222(169)$ \\
\hline sitting, min/day & $348(200)$ & $334(208)$ & $362(195)$ \\
\hline lying, min/day & $106(118)$ & $123(138)$ & $88.7(91.5)$ \\
\hline
\end{tabular}

$\mathrm{SD}$, standard deviation; $\mathrm{FEV}_{1}$, forced expiratory volume in 1 second; FVC, forced vital capacity; BMI, body mass index; 6MWD, six-minute walking distance; BORG, BORG dyspnoea score after 6MWT; HADS, Hospital Anxiety and Depression Scale; SF 36, Short Form 36; PCS, Physical Component Score; MCS, Mental Component Score; min/day, minutes per day. 


\section{Primary endpoint}

\section{Feasibility of Nordic Walking}

All patients achieved the preset goal for maximum $\mathrm{HR}$ to ensure training efficiency ( $>75 \%$ of the initial maximum HR), even though walking at different speed levels according to the severity of COPD. None of the patients had any difficulties in performing Nordic Walking adequately. It seemed to be an advantage over cycling that walking speed could be adapted to dyspnoea levels without missing the preset HR goa ${ }^{32}$. No (serious) adverse events were reported.

\section{Daily physical activities}

After the three-month training period, movement intensity increased in the Nordic Walking group compared to their baseline ( $\triangle$ movement intensity: $+0.40 \pm 0.14$ $\mathrm{m} / \mathrm{s}^{2}, \mathrm{p}<0.01$ ) as well as compared to controls ( $<<0.01$; Figure 2 ), while controls remained unchanged $(p=0.385)$. Movement intensity increased in the six-month un-coached observation period in Nordic Walking patients compared to baseline ( $\triangle$ movement intensity: $+0.25 \pm 0.09 \mathrm{~m} / \mathrm{s}^{2}, \mathrm{p}<0.01$ ) and compared to controls $(p<0.01)$. Controls movement intensity slowly declined and was below their baseline levels after nine month $(p<0.01)$.

Training increased the walking and standing time of the Nordic Walking group significantly $(\triangle$ walking time: $+14.9 \pm 1.9 \mathrm{~min} /$ day, $\mathrm{p}<0.01 ; \triangle$ standing time: $+129 \pm 26$ $\mathrm{min} /$ day, $\mathrm{P}<0.01)$ at the expense of their sitting time ( $\triangle$ sitting time: $-128 \pm 15 \mathrm{~min} /$ day, $p<0.01$ ). Same results were found compared to controls (walking: $p=0.034$; sitting: $p=0.014$; Figure 3 ). Walking time remained increased (six month: $\Delta$ walking time: $+12.7 \pm 1.8 \mathrm{~min} /$ day, $\mathrm{p}=0.024$; nine month: $\triangle$ walking time: $+9.2 \pm 2.9$ $\mathrm{min} /$ day, $\mathrm{p}=0.036$ ), and sitting time remained decreased (six month: $\Delta$ sitting time: $-120 \pm 32 \mathrm{~min} /$ day, $\mathrm{p}=0.016$; nine month: $\triangle$ sitting time: $-101 \pm 36 \mathrm{~min} /$ day, $p=0.032$ ) compared to baseline as well as compared to controls at follow up (six month: $p<0.05$; nine month: $p<0.01$ ). Finally, initial increase of standing time was preserved in the Nordic Walking group compared to baseline (six month: $\triangle$ standing time: $+133 \pm 14 \mathrm{~min} /$ day, $\mathrm{p}<0.01$; nine month: $\triangle$ standing time: $+105 \pm 4$ $\mathrm{min} /$ day, $\mathrm{p}<0.01$ ) as well as compared to controls (six month, nine month: both: $p<0.05$ ). Controls did not show any significant change in their daily physical activities at any time point compared to baseline. 
Figure 2. Movement intensity of COPD patients of intervention and control group over time.

Statistical comparisons within groups: * $p<0.01$ compared to baseline. Statistical comparison between groups (intervention vs. control): $\uparrow p<0.01$ at all times. (Whiskers represent SD).

\section{movement intensity}

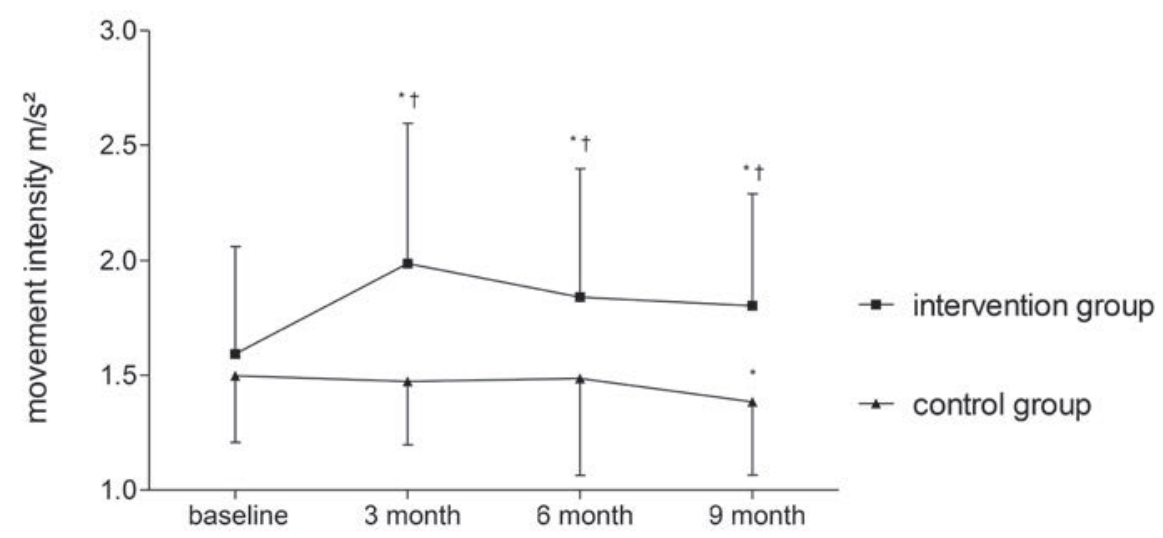

Figure 3. Daily physical activities of COPD patients of intervention and control group over time.

\section{daily physical activities}

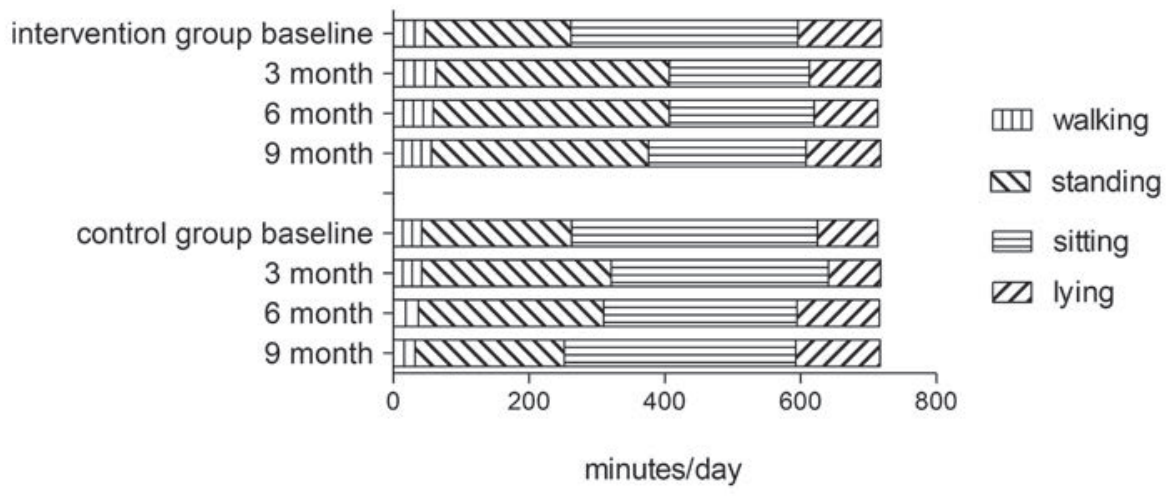




\section{Secondary endpoints}

\section{Functional exercise capacity}

Training increased the 6MWD in the Nordic Walking group compared to baseline $(\triangle 6 M W D:+79 \pm 28$ meters; $p<0.01$; Figure 4$)$ and controls $(p<0.01)$. This increase lasted over the un-coached observation period (six month: $\triangle 6 \mathrm{MWD}$ : $+70 \pm 16$ meters; nine month: $\triangle 6 \mathrm{MWD}:+58 \pm 17$ meters; both compared to baseline: $p<0.01$ ) and was different compared to controls (six month: $p=0.01$; nine month: $p=0.013)$. Controls showed a decrease in their 6MWD after six $(p=0.036)$ and nine months $(p<0.01)$ compared to baseline.

Figure 4. Six-minute walking distance of COPD patients of intervention and control group over time.

Statistical comparisons within groups: * $p<0.01$ compared to baseline; $\uparrow p<0.05$ compared to baseline; statistical comparison between groups (intervention vs. control): $\neq p<0.01$ at all times. (Whiskers represent SD).

\section{six minute walking distance}

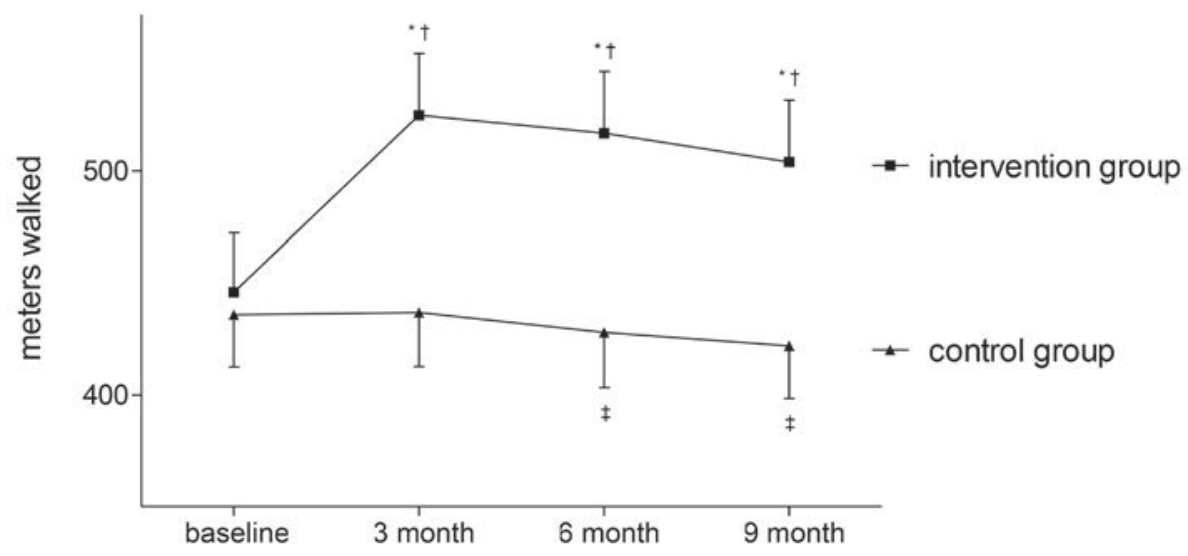

\section{Exercise-induced dyspnoea}

Training improved the BORG dyspnoea score in the Nordic Walking compared to baseline $(p<0.01$; Table 2$)$ and remained decreased after six and nine months (both: $p<0.01)$. In the controls, the BORG dyspnoea score remained unchanged after three $(p=0.712)$, six $(p=0.202)$ and nine months $(p=0.178)$ compared to baseline. 


\section{Mood status}

According to baseline HADS, 32 patients had symptoms of anxiety ( $\geq 7$ points) and 27 patients had symptoms of depression ( $\geq 7$ points). HADS in the Nordic Walking group decreased compared to baseline and to controls (both: $p<0.01$ ) after three month training and remained decreased after six and nine months (all: $p<0.01)$ whereas controls did not change their HADS after three $(p=0.104$, $p=0.242)$, six $(p=0.213, p=0.253)$, and nine months $(p=0.190, p=0.260)$ compared to baseline.

\section{Health-related quality of life}

Generic quality of life was impaired ( $<50$ points) according to the baseline SF-36 PCS and MCS, respectively in 53 and 30 patients. The Nordic Walking group increased their PCS points compared to baseline and controls (both: $p<0.01$ ) and PCS points remained increased after six and nine months (all: $p<0.01$; except compared to controls after nine month: $p<0.05)$. In contrast, controls showed no differences after three $(p=0.989)$, six $(p=0.763)$, and nine months $(p=0.698)$ compared to baseline. The MCS remained unchanged in both groups at any time points.

\section{Discussion}

Nordic Walking has proven to be a simple, safe, and effective physical training modality for patients with COPD. Indeed, this is the first study demonstrating that Nordic Walking is feasible in patients with COPD and can improve COPD patients' daily physical activity levels. In addition to the positive short-term effects of Nordic Walking on the physical exercise performance and daily symptoms of COPD patients, Nordic Walking created a long-term effect on the training results even after an un-coached observation period of six months.

COPD patients are a target group for exercise-based rehabilitation as they spend most of their time sitting or lying compared to healthy subjects ${ }^{23}$. In fact, even COPD patients at GOLD stage II significantly limit their daily physical activities compared to patients with chronic bronchitis (former GOLD stage 0$)^{33}$. The efficacy of pulmonary rehabilitation programs on functional exercise capacity and oxygen uptake capacity are of proven evidence and have led to recommendation of pulmonary rehabilitation for patients with chronic pulmonary diseases in international guidelines ${ }^{10}$. Unfortunately, access to pulmonary rehabilitation programs are limited and in most countries underfunded. Nordic Walking could provide an alternative, cheap and easy accessible physical training modality. Another key goal of pulmonary rehabilitation is to create long-lasting health effects by changing patients' lifestyle. However, in COPD patients long-term effects of rehabilitation ad- 
dressed in few studies have shown no or modest success ${ }^{12-14}$. We hypothesised that those physical training modalities, which imitate everyday life movements, might lead to long-term improvement of daily physical activities.

Nordic Walking increases exercise intensity of walking due to the use of the typical Nordic Walking poles ${ }^{17}$. It enhances maximum oxygen consumption and heart rate by an average of $20 \%$ compared to walking without poles in healthy subjects ${ }^{17,18}$. The use of these poles while walking implies an additional motion that leads to larger oxygen consumption as well as to an increase in heart rate ${ }^{17,18}$. In cardiac rehabilitation, Nordic Walking has proven to be safe and effective ${ }^{16}$.

To the authors' best knowledge, there have been no studies of Nordic Walking in COPD so far. The aims of the study were to test whether Nordic Walking is feasible in terms of reaching the preset HR directed training goal while controlling for dyspnoea and oxygen saturation and whether training results in a significant improve in functional exercise capacity. Indeed, all COPD patients had no difficulties to perform Nordic Walking within the preset aerobic training level throughout the whole session, even patients on long term oxygen. Nordic Walking was effective in alleviation of dyspnoea, increased health related quality of life and functional exercise capacity after three month according to recommendations ${ }^{10}$. In contrast to other studies ${ }^{11}$, the three-month results were maintained after an un-coached observation period of six months suggesting that Nordic Walking creates not only a short-, but also a long-term training effect in COPD patients. After nine month of follow-up 63\% of the COPD patients have adopted Nordic Walking as regular physical exercise. A recently published study on short- (three month) and long-term (six month) effects of pulmonary rehabilitation on the daily physical activity pattern of COPD patients found modest effects even in the long-term program ${ }^{14}$. The maintained increase in daily physical activities in our COPD patients might be due to the type of training method used, a modified everyday movement, walking, which resulted in a transfer into patients' daily life.

Besides physical symptoms, patients with COPD also experience a higher psychological distress, especially symptoms of anxiety and depression, compared to healthy subjects ${ }^{34}$. Nordic Walking improved COPD patients' mood status, as symptoms of anxiety and depression decreased after the three-month training period and lasted throughout the long-term observation. In fact, symptoms of anxiety and depression in patients with COPD are risks factors for re-hospitalisation, and co-morbid depression is associated with poorer survival in COPD ${ }^{35}$. Therefore, the relevant objective of pulmonary rehabilitation to relief psychosocial burden ${ }^{10}$ seems to be achieved by Nordic Walking. 


\section{Methodological considerations}

The results might be biased by the selection of very motivated patients. However, motivation is required in rehabilitation in order to achieve the fullest benefits from rehabilitation ${ }^{10}$. The low number of drop-outs in the present study might be a signal towards this direction. On the other hand the cheap technical equipment and the independence from specific locations might open an effective training method to a large number of COPD patients. Our patients felt very encouraged by the distances they walked outside and finally were empowered to leave their homes on their own which might not have been the case in all patients. Furthermore, to gain more insight into the physiological effects of Nordic Walking further studies are needed to investigate e.g. the effects of Nordic Walking on muscle force/ weakness.

\section{Conclusions}

A three-month supervised Nordic Walking training program has proven to be a safe training method to increase the daily physical activity levels in clinically stable outpatients with COPD. Beyond that, Nordic Walking had a long-term effect on the patients' daily physical activity pattern and a reduction in patients' daily symptoms.

\section{Additional file}

Additional file. Male COPD patient performing Nordic Walking.

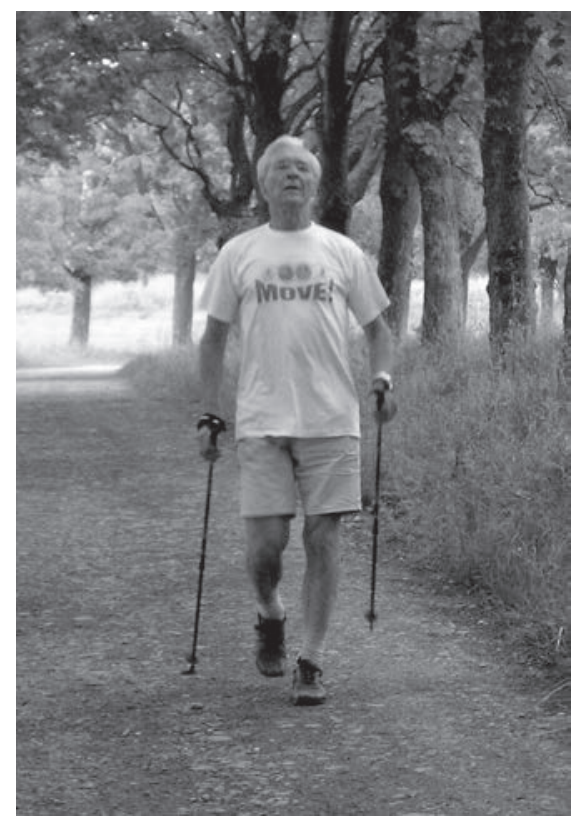




\section{References}

1. Rabe KF, Hurd S, Anzueto A, et al. Global strategy for the diagnosis, management, and prevention of chronic obstructive pulmonary disease: GOLD executive summary. Am J Respir Crit Care Med 2007;176:53255.

2. Pitta F, Troosters T, Spruit MA, Probst VS, Decramer M, Gosselink R. Characteristics of physical activities in daily life in chronic obstructive pulmonary disease. Am J Respir Crit Care Med 2005;171:972-7.

3. Pitta F, Breyer MK, Hernandes NA, et al. Comparison of daily physical activity between COPD patients from Central Europe and South America. Respir Med 2009;103:421-6.

4. Pitta F, Troosters T, Probst VS, Spruit MA, Decramer M, Gosselink R. Physical activity and hospitalization for exacerbation of COPD. Chest 2006;129:536-44.

5. Polkey MI, Moxham J. Attacking the disease spiral in chronic obstructive pulmonary disease. Clin Med 2006;6:190-6.

6. Spruit MA, Pennings $H J$, Janssen PP, et al. Extra-pulmonary features in COPD patients entering rehabilitation after stratification for MRC dyspnea grade. Respir Med 2007;101:2454-63.

7. Nishimura K, Izumi T, Tsukino M, Oga T. Dyspnea is a better predictor of 5-year survival than airway obstruction in patients with COPD. Chest 2002;121:1434-40.

8. Garcia-Aymerich J, Farrero E, Felez MA, Izquierdo J, Marrades RM, Anto JM. Risk factors of readmission to hospital for a COPD exacerbation: a prospective study. Thorax 2003;58:100-5.

9. Yohannes AM, Baldwin RC, Connolly M. Mortality predictors in disabling chronic obstructive pulmonary disease in old age. Age Ageing 2002;31:137-40.

10. Nici L, Donner C, Wouters E, et al. American Thoracic Society/European Respiratory Society statement on pulmonary rehabilitation. Am J Respir Crit Care Med 2006;173:1390-413.

11. Lacasse $Y$, Goldstein R, Lasserson TJ, Martin S. Pulmonary rehabilitation for chronic obstructive pulmonary disease. Cochrane Database Syst Rev 2006:CD003793.

12. Steele BG, Belza B, Hunziker J, et al. Monitoring daily activity during pulmonary rehabilitation using a triaxial accelerometer. J Cardiopulm Rehabil 2003;23:139-42.

13. Coronado M, Janssens JP, de Muralt B, Terrier P, Schutz Y, Fitting JW. Walking activity measured by accelerometry during respiratory rehabilitation. J Cardiopulm Rehabil 2003;23:357-64.

14. Pitta F, Troosters T, Probst VS, Langer D, Decramer M, Gosselink R. Are patients with COPD more active after pulmonary rehabilitation? Chest 2008;134:273-80.

15. Sewell L, Singh SJ, Williams JE, Collier R, Morgan MD. Can individualized rehabilitation improve functional independence in elderly patients with COPD? Chest 2005;128:1194-200.

16. Walter PR, Porcari JP, Brice G, Terry L. Acute responses to using walking poles in patients with coronary artery disease. J Cardiopulm Rehabil 1996;16:245-50.

17. Rodgers $C D$, VanHeest JL, Schachter CL. Energy expenditure during submaximal walking with Exerstriders. Med Sci Sports Exerc 1995;27:607-11.

18. Church TS, Earnest CP, Morss GM. Field testing of physiological responses associated with Nordic Walking. Res Q Exerc Sport 2002;73:296-300.

19. Porcari JP, Hendrickson TL, Walter PR, Terry L, Walsko G. The physiological responses to walking with and without Power Poles on treadmill exercise. Res Q Exerc Sport 1997;68:161-6.

20. Bendstrup KE, Ingemann Jensen J, Holm S, Bengtsson B. Out-patient rehabilitation improves activities of daily living, quality of life and exercise tolerance in chronic obstructive pulmonary disease. Eur Respir J 1997;10:2801-6.

21. Schiffer T, Knicker A, Hoffman U, Harwig B, Hollmann W, Struder HK. Physiological responses to nordic walking, walking and jogging. Eur J Appl Physiol 2006;98:56-61.

22. Thompson PD, Buchner D, Pina IL, et al. Exercise and physical activity in the prevention and treatment of atherosclerotic cardiovascular disease: a statement from the Council on Clinical Cardiology (Subcommittee on Exercise, Rehabilitation, and Prevention) and the Council on Nutrition, Physical Activity, and Metabolism (Subcommittee on Physical Activity). Circulation 2003;107:3109-16.

23. Pitta F, Troosters T, Spruit MA, Decramer M, Gosselink R. Activity monitoring for assessment of physical activities in daily life in patients with chronic obstructive pulmonary disease. Arch Phys Med Rehabil 2005;86:1979-85.

24. Brandes M, Rosenbaum D. Correlations between the step activity monitor and the DynaPort ADL-monitor. Clin Biomech (Bristol, Avon) 2004;19:91-4. 
25. Trost SG, Mclver KL, Pate RR. Conducting accelerometer-based activity assessments in field-based research. Med Sci Sports Exerc 2005;37:S531-43.

26. ATS statement: guidelines for the six-minute walk test. Am J Respir Crit Care Med 2002;166:111-7.

27. Troosters T, Gosselink R, Decramer M. Six minute walking distance in healthy elderly subjects. Eur Respir J 1999:14:270-4.

28. Borg GA. Psychophysical bases of perceived exertion. Med Sci Sports Exerc 1982;14:377-81.

29. Zigmond AS, Snaith RP. The hospital anxiety and depression scale. Acta Psychiatr Scand 1983;67:361-70.

30. Mahler DA, Mackowiak JI. Evaluation of the short-form 36-item questionnaire to measure health-related quality of life in patients with COPD. Chest 1995;107:1585-9.

31. Miller MR, Hankinson J, Brusasco V, et al. Standardisation of spirometry. Eur Respir J 2005;26:319-38.

32. Pepin $V$, Saey D, Whittom F, LeBlanc P, Maltais F. Walking versus cycling: sensitivity to bronchodilation in chronic obstructive pulmonary disease. Am J Respir Crit Care Med 2005;172:1517-22.

33. Watz H, Waschki B, Meyer T, Magnussen H. Physical activity in patients with COPD. Eur Respir J 2009;33:262-72

34. van Manen JG, Bindels PJ, Dekker FW, C) IJ, van der Zee JS, Schade E. Risk of depression in patients with chronic obstructive pulmonary disease and its determinants. Thorax 2002;57:412-6.

35. Ng TP, Niti M, Tan WC, Cao Z, Ong KC, Eng P. Depressive symptoms and chronic obstructive pulmonary disease: effect on mortality, hospital readmission, symptom burden, functional status, and quality of life. Arch Intern Med 2007;167:60-7 



\section{CHAPTER 8}

\section{Comparison of daily physical activity between COPD patients from Central-Europe and South-America}

Pitta F*, Breyer MK*, Hernandes NA, Teixeira D, Sant'Anna TJP, Fontana AD, Probst VS, Brunetto AF, Spruit MA, Wouters EFM, Burghuber OC, Hartl S *contributed equally Respir Med. 2009 Mar, 103(3):421-6 



\section{Abstract}

\section{Background}

In healthy elderly and adults, lower physical activity level in daily life has been associated with lower socio-economic level and non-Caucasian race. The objective of this study was to determine if this is also applicable in Chronic Obstructive Pulmonary Disease (COPD) by comparing physical activity levels in daily life in stable patients from two countries (Austria and Brazil) with different socio-economic and ethnic characteristics.

\section{Methods}

Physical activity in daily life was objectively assessed in 40 Austrian and 40 Brazilian COPD patients. Groups were matched for age, gender, body mass index, disease severity, smoking history, presence of concomitant heart disease, lung function, dyspnea and functional exercise capacity. In addition, climatic conditions were similar during the period of data collection in the two groups.

\section{Results}

In comparison to Brazilian patients, Austrian patients had significantly lower walking time $(p=0.04)$, higher sitting time $(p=0.02)$ and lower movement intensity $(p=0.0001)$. The proportion of patients who did not reach an average of 30 minutes of walking per day was $48 \%$ in the Austrian group and $23 \%$ in the Brazilian group.

\section{Conclusions}

Austrian patients with COPD showed a significantly lower daily physical activity level in comparison to matched Brazilian patients. Socio-economic and ethnic factors appear to influence stable COPD patients differently than described in previous studies including healthy subjects. 


\section{Introduction}

Objective and accurate assessment of physical activity level in daily life has been made more widely available due to recent technological advances. The use of real-life activity monitors has allowed to study, in detail, the characteristics of daily physical activity patterns in various populations, including patients with Chronic Obstructive Pulmonary Disease (COPD) 1 . Previous investigations have demonstrated, for example, that patients with COPD from Belgium are significantly less active compared to age- and gender-matched healthy controls². Similar findings were reported in studies performed in cohorts from European countries such as England ${ }^{3}$, Germany $^{4}$, and Switzerland ${ }^{5}$. However, to the authors' knowledge, a comparison of time spent actively in daily life between COPD patients from different countries and continents, using advanced activity monitors, have never been performed. This may be of clinical interest since it allows investigating whether and to what extent COPD patients' profile of daily physical activity differs across diverse world regions.

In healthy elderly and adult populations, studies performed in different countries have shown that the amount of physical activity performed in daily life may vary considerably depending on various factors such as ethnicity, education level and socioeconomic status ${ }^{6-10}$. In general, a lower physical activity level appears to be associated with non-caucasian race ${ }^{6,7}$, lower educational level ${ }^{8,9}$ and lower income ${ }^{9,10}$. However, it is unknown whether these same factors have a similar influence on the physical activity level of a generally sedentary population diagnosed with a chronic disease, such as patients with COPD. If the trends demonstrated in healthy cohorts translate to individuals diagnosed with a chronic disease, it is likely that patients from a country with a multi-racial population, lower educational level and social status, such as Brazil, will have lower physical activity level in comparison to a country with disparate characteristics, such as Austria.

Given the present knowledged gaps in the literature, the purpose of the present study was to compare the daily physical activity patterns of patients with COPD from Brazil and Austria.

\section{Methods}

\section{Design}

In this cross-sectional study, the level of physical activity in daily life was assessed using an advanced activity monitor in two COPD cohorts from Brazil and Austria, respectively. Austrian and Brazilian patients were matched for age, gender, body mass index (BMI), smoking history, presence of concomitant heart disease, lung function (spirometry), self-reported degree of dyspnea in daily life (modified version of the Medical Research Council scale - MMRC), functional exercise 
capacity (6-minute walking test - 6MWT) and disease severity as assessed by the GOLD stage and the BODE index. In addition, climatic conditions were similar during the period of data collection in both groups since data in Brazil were collected during the whole year of 2006, whereas data collection in Austria occurred almost entirely during the summer and spring seasons of 2006 (see more details below).

\section{Subjects}

The study included 40 Brazilian patients with COPD (18 male; 66 \pm 8 years; forced expiratory volume in one second $\left[\mathrm{FEV}_{1}\right] 46 \pm 17 \%$ predicted; BMI $26 \pm 6 \mathrm{~kg} / \mathrm{m}^{2}$ ) and 40 matched Austrian patients with COPD (21 male; 63 7 years; FEV $48 \pm 17$ $\%$ predicted; BMI $26 \pm 4 \mathrm{~kg} / \mathrm{m}^{2}$ ). All subjects included in the study were recruited during the initial screening for admission to a pulmonary rehabilitation program in their respective centers. The diagnosis of COPD was established based on internationally accepted criteria determined by the Global Initiative for Chronic Obstructive Lung Disease (GOLD) ${ }^{11}$. No patient included in this study was using domiciliary long-term oxygen therapy (LTOT). Moreover, all subjects were officially retired, although 5 patients in the Austrian group (12.5\%) and 14 patients in the Brazilian group (35\%) were still performing "informal" professional activities defined as occasional and not registered work (few hours per week, not every day). No patients in either the Brazilian or Austrian groups took part in any rehabilitation program in the last year prior to initiation of this study. Inclusion criteria were: 1) clinical stability (absence of exacerbations) for at least 3 months prior to study initiation and 2) the absence of osteo-neuro-muscular co-morbidities that might interfere in the performance of physical activities in daily life. The study was approved by the Committee for Ethics in Research of both institutions involved, and all subjects gave formal written consent to participate.

\section{Data from Brazil}

In Brazil, data from all subjects were collected at the Laboratory of Research in Respiratory Physiotherapy (Laboratório de Pesquisa em Fisioterapia Pulmonar LFIP) from the Department of Physiotherapy, Universidade Estadual de Londrina (UEL) and Hospital Universitário Regional Norte do Paraná (HURNPR), Londrina. Londrina is situated in the southern region of Brazil and has approximately 500,000 inhabitants as of July 2008. Londrina's only mean of public transport is by bus. In the Brazilian group, 30 patients (75\%) depended on public transportation (bus), 7 patients (17.5\%) used a privately owned car and 3 patients (7.5\%) used an ambulance transportation service. All Brazilian subjects were living in their own home: 34 patients (85\%) were living with a spouse or relative(s) and 6 (15\%) were living alone. 
During the data collection period (throughout the whole year of 2006), Londrina's average temperature in the 4 seasons was: Winter $17.3^{\circ} \mathrm{C}$; Spring $21.1^{\circ}$ C; Summer $24^{\circ} \mathrm{C}$; Autumn $21.5^{\circ} \mathrm{C}$; precipitation was approximately $117 \mathrm{~mm} /$ month; and average humidity was 78\%12,13. Eight patients (20\%) were assessed during summer season, 8 (20\%) were assessed during autumn, 13 (32.5\%) were assessed during winter and 11 patients (27.5\%) were assessed during Spring.

With respect to level of education, 9 patients (22.5\%) were illiterate, 25 patients (62.5\%) were literate but did not complete primary level education, 2 patients (5\%) had completed primary level, 2 patients (5\%) had completed secondary level and 2 patients (5\%) had completed university level. Regarding race, 26 patients (65\%) were Caucasian, 4 (10\%) were black, 8 (20\%) were multi-ethnic (Caucasian and black) and 2 (5\%) were Asian (Japanese). As of 2006, monthly average income for retired individuals in Londrina, Brazil corresponded to $355 €^{14}$ (or R\$ 919 in Brazilian currency). Clinical characteristics of the group of Brazilian patients with COPD are described in Table 1.

\section{Data from Austria}

In Austria, data were collected at the Department of Respiratory and Critical Care Medicine, Otto-Wagner Hospital, Vienna. Vienna is situated in the eastern region of Austria and has approximately 1,675,000 inhabitants as of July 2008. Despite the fact that Vienna has a well developed public transport system (bus, tram and underground train), fewer Austrian patients (21, or 52.5\%) depended on these transit options compared to the Brazilian group. Conversely, more patients (14, or 35\%) used a privately owned car. No Austrian patient used ambulance service and two patients (5\%) reported use of a bicycle for transportation. In 3 patients, it was not possible to retrieve information concerning transportation mean. All Austrian subjects were living in their own home. Twenty-one patients (52.5\%) were living with a spouse or relative(s) and 19 (47.5\%) were living alone. The majority of patients (25, or 62.5\%) were assessed during summer; whereas 11 (or 27.5\%) were assessed during spring and only 4 (10\%) were assessed during autumn or winter. During the data collection period (mostly Spring and Summer of 2006), Vienna's average temperature was: Spring $13^{\circ} \mathrm{C}$; Summer $21.5^{\circ} \mathrm{C}$; precipitation was approximately $88 \mathrm{~mm} / \mathrm{month}$; and average humidity was $77 \% \%^{15}$. With respect to level of education, no Austrian patient was illiterate; 29 patients (72.5\%) completed primary level education, 6 patients (15\%) completed secondary level and 5 patients (12.5\%) completed university level. All Austrian patients were Caucasian. As of 2006, monthly average income for retired individuals in Vienna, Austria was $1286 €^{16}$. Clinical characteristics of the group of Austrian patients with COPD are described in Table 1. 
Table 1. Characteristics of the groups of patients with COPD from Austria and Brazil

\begin{tabular}{|c|c|c|}
\hline & $\begin{array}{l}\text { COPD Austria } \\
(\mathrm{n}=40)\end{array}$ & $\begin{array}{l}\text { COPD Brazil } \\
(n=40)\end{array}$ \\
\hline Age (years) & $63 \pm 7$ & $66 \pm 8$ \\
\hline $\begin{array}{l}\text { Gender (M / F) } \\
\text { Smoking (pack/years) }\end{array}$ & $\begin{array}{l}21 / 19 \\
44 \pm 13\end{array}$ & $\begin{array}{l}18 / 22 \\
40 \pm 34\end{array}$ \\
\hline BMI $\left(\mathrm{kg} / \mathrm{m}^{2}\right)$ & $26 \pm 4$ & $26 \pm 6$ \\
\hline GOLD (II / III / IV) & $17 / 14 / 9$ & $16 / 18 / 6$ \\
\hline $\mathrm{FEV}_{1}$ (\%predicted) & $48 \pm 17$ & $46 \pm 17$ \\
\hline FVC (\%predicted) & $78 \pm 17$ & $75 \pm 22$ \\
\hline MMRC (0 to 4) & $2.8 \pm 1.1$ & $2.4 \pm 1.1$ \\
\hline 6MWT (\%predicted) & $68 \pm 19$ & $71 \pm 19$ \\
\hline BODE index (0 to 10) & $4.0 \pm 2.6$ & $4.4 \pm 2.1$ \\
\hline
\end{tabular}

Data are shown as median \pm standard deviation (except for gender and GOLD stages). Comparison between patients with COPD from Austria and Brazil was performed with the unpaired $t$ test except for MMRC and BODE index, which were analyzed with the Mann-Whitney test. There were no statistically significant differences between the groups. COPD $=$ Chronic Obstructive Pulmonary Disease; $\mathrm{M}=$ male; $\mathrm{F}=$ female; $\mathrm{BMI}=$ body mass index; $\mathrm{kg} / \mathrm{m}^{2}=$ kilograms per meters squared; $\mathrm{GOLD}=$ Global Initiative for Obstructive Lung Disease (stages II, III and IV). FEV1 = Forced Expiratory Volume in the First Second; FVC = forced vital capacity; MMRC $=$ modified version of the Medical Research Council scale; $6 \mathrm{MWT}=6$-minute walking test.

\section{Data Collection}

The objective quantification of physical activity during in daily life was performed in both centers with an accelerometer-based activity monitor (DynaPort Activity Monitor ${ }^{\circledR}$ [DAM], McRoberts BV, The Hague, The Netherlands). The device consists of a small and lightweight box enclosed in a belt worn around the waist and a leg sensor (total weight $=375$ grams). The DAM was recently validated in patients with COPD, demonstrating the ability to quantify the time spent in walking, cycling, standing, sitting or lying as accurately as video recordings ${ }^{17}$. Technical specifications of the DAM can be found elsewhere ${ }^{17}$. Assessments were done on 2 consecutive week days for 12 consecutive hours per day once the subject awoke in the morning. The average of the 2 days of data collected was used to assess physical activity patterns since it was shown that this duration provides an acceptable intraclass correlation coefficient in patients with COPD2. Patients were aware of the assessments aim since this has been shown not to influence the results of activity monitoring in patients with $\mathrm{COPD}^{18}$. Both in the Austrian and Brazilian COPD groups, no assessments were done on days in which the patient performed any informal professional activity. 
In the Brazilian center, assessment of lung function was performed using the Pony Cosmed $^{\odot}$ spirometer (Cosmed, Italy). In the Austrian center, it was performed using the Spirometry PFT unit SensorMedics Vmax 22 (Viasys Healthcare, Germany). The technique in both centers followed the guidelines of the American Thoracic Society/European Respiratory Society ${ }^{19}$, and the reference values were those from Quanjer et al. ${ }^{20}$.

All patients with COPD reported the degree in which dyspnea influences their activities of daily living through the MMRC scale ${ }^{21}$. The 6MWT was performed in both centers according to the guidelines of the American Thoracic Society ${ }^{22}$. Two tests were performed with an interval of at least 30 minutes, and the highest $6 \mathrm{MWT}$ was used for the analysis. Reference values were those from Troosters et al. ${ }^{23}$. Results concerning $\mathrm{BMI}, \mathrm{FEV}_{1}, \mathrm{MMRC}$ and $6 \mathrm{MWT}$ were used to calculate the BODE index as described by Celli et al. ${ }^{24}$.

\section{Co-morbidities}

In the group of Brazilian patients with COPD, the number (and proportion) of subjects with clinically diagnosed co-morbidities was: 15 patients (37.5\%) with systemic hypertension, 13 (32.5\%) with stable cardiac disease, 13 (32.5\%) with diabetes mellitus, 5 (12.5\%) with osteoporosis and 9 (22.5\%) with obesity. In the group of Austrian patients with COPD, the number (and proportion) of subjects with clinically diagnosed co-morbidities was: 10 patients (25\%) with systemic hypertension, 15 (37.5\%) with stable cardiac disease, 5 (12.5\%) with diabetes mellitus, 3 (7.5\%) with osteoporosis and 8 (20\%) with obesity. Criteria for considering patients as having systemic hypertension was current use of antihypertensive medication; for stable cardiac disease was the presence of a medical diagnosis of mild atrial arrhythmia treated with medication, ischemic heart disease in the past or dilated cardiomyopathy without significant cardiac functional impairment; for diabetes mellitus and osteoporosis was the patient's self-report in addition to the presence of medical diagnosis of these conditions; and for obesity was BMl $>30$ $\mathrm{kg} / \mathrm{m}^{2}$.

\section{Statistical Analysis}

Statistical analysis was performed using the GraphPad Prism 3 (GraphPad Software, San Diego, USA). Normal distribution of data was assessed with the Kolmogorov-Smirnov test. Results were described as mean \pm standard deviation. Comparison between patients with COPD from Austria and Brazil was performed with the unpaired $t$ test except for MMRC and BODE index, which were analyzed with the Mann-Whitney test. Level of significance was set at $p<0.05$ for all statistical tests. 


\section{Results}

Table 1 shows that Brazilian and Austrian patients with COPD had similar age, $\mathrm{BMI}$, lung function, GOLD stage, 6MWT, MMRC and BODE index (all $\mathrm{p}>0.05$ ). Figure 1 illustrates that Austrian patients had significantly lower time spent walking $(40 \pm 36 \mathrm{~min} /$ day versus $56 \pm 32 \mathrm{~min} /$ day; $\mathrm{p}=0.04)$, lower movement intensity $\left(1.5 \pm 0.4 \mathrm{~m} / \mathrm{s}^{2}\right.$ versus $\left.1.9 \pm 0.4 \mathrm{~m} / \mathrm{s}^{2} ; \mathrm{p}=0.0001\right)$ and higher time spent sitting $(388 \pm 208 \mathrm{~min} /$ day versus $296 \pm 109 \mathrm{~min} /$ day; $\mathrm{p}=0.02)$ in comparison to the Brazilian patients. In addition, Austrian patients had lower time spent standing $(192 \pm 182 \mathrm{~min} /$ day versus $246 \pm 122 \mathrm{~min} /$ day $)$ and lower time spent lying ( $98 \pm 116 \mathrm{~min} /$ day versus $119 \pm 110 \mathrm{~min} /$ day), although these differences did not reach statistical significance $(p=0.12$ and 0.40 , respectively).

Figure 1. Comparison of time spent walking, standing, sitting and lying per day between Austrian patients with COPD $(n=40)$ and Brazilian patients with COPD $(n=40)$.

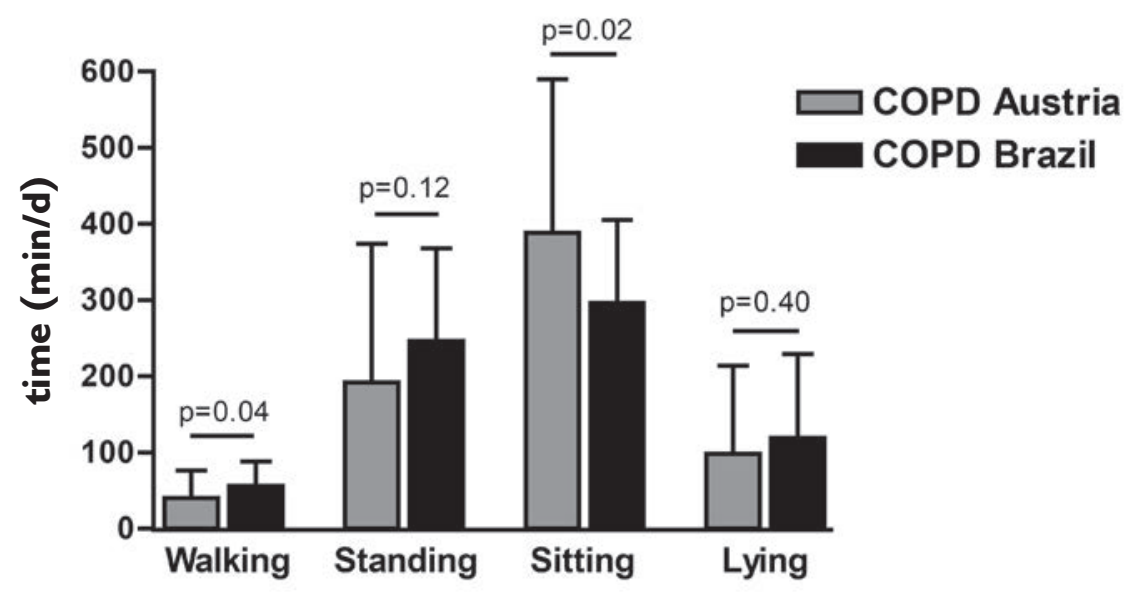

Statistical analysis was performed with the unpaired t test.

Brazilian patients with COPD were divided in two groups based on the involvement ( $n=14$ ) or not involvement $(n=26)$ in informal professional activities. These two groups did not show significant differences concerning time spent walking $(p=0.76), B O D E$ index $(p=0.54)$ and $F E V_{1}$ (both in absolute values $[p=0.62]$ and percentage of the predicted values $[p=0.56])$. Similarly, dividing the Austrian patients with COPD in two groups involved $(n=5)$ or not involved $(n=35)$ in informal professional activities, there were no differences concerning time spent walking $(p=0.57), B O D E$ index $(p=0.34)$ and $\mathrm{FEV}_{1}$ (both in absolute values $[p=0.97]$ and percentage of the predicted values $[p=0.27])$. 
In the Austrian group, 19 out of the 40 patients (48\%) did not reach an average of at least 30 minutes of time spent walking per day, which is the minimum amount of physical activity recommended by the American College of Sports Medicine (ACSM) (25). In the Brazilian group, 9 out of the 40 patients (23\%) did not reach this minimum level of physical activity.

\section{Discussion}

To the authors' best knowledge, this is the first study to compare the level of physical activity in daily life assessed by an advanced and validated activity monitor in patients with COPD from such different origins as Europe and South America, or more specifically Austria and Brazil. Several differences are readily apparent in the present study: firstly, the educational level and economic condition of Austrian patients is considerably higher, as one would expect when comparing a developed country with another one in development. Secondly, Brazil is a mixed country from an ethnic perspective, in contrast to the Caucasian population in Austria. However, despite the fact that lower physical activity level in healthy elderly and adult populations has been associated with non-Caucasian race ${ }^{6,7}$, lower educational leve ${ }^{8,9}$ and lower income ${ }^{9,10}$, Austrian patients with COPD showed a significantly lower time spent walking, higher time spent sitting and lower movement intensity in daily life in comparison to matched Brazilian patients. In addition, the lower physical activity level in daily life in Austrian patients occurred despite the fact that Brazilian patients had a higher prevalence of co-morbidities such as hypertension, diabetes and osteoporosis. These results suggest that, in an inactive population such as patients with COPD, the socio-economic and ethnic predictive factors for physical inactivity possibly play a different role than observed in healthy subjects (i.e., worse socio-economic conditions and ethnic miscegenation leads South American patients to be more active than Central-European patients). These results are supported by the fact that the time spent walking in daily life in the Brazilian COPD group (56 \pm 32 minutes per day) was also markedly higher than the observed in a previous sample from Belgium $\left.{ }^{2}\right](44 \pm 26$ minutes per day), which was very similar to the Austrian sample from the present study (40 \pm 36 minutes per day).

The differences in daily physical activity level between Austrian and Brazilian patients with COPD cannot be explained by anthropometrical and clinical differences between the groups. The groups were similar with respect to age, gender, $\mathrm{BMI}$, lung function, functional exercise capacity (as assessed by the 6MWT), disease severity (as measured both by the GOLD stages and the BODE index) and the presence of co-morbidities such as cardiac disease and obesity. Furthermore, LTOT, which has been shown to reduce daily physical activity level in patients with COPD ${ }^{18}$, was not used by any subject in this study. Given the control of con- 
founding factors, the findings of the present study appear to indicate that socioeconomic and ethnic factors influence daily physical activity differently in patients with COPD compared to the healthy population. To further support our findings, a study performed with a sample of Spanish patients with COPD has also shown that lower physical activity level is related to higher socioeconomic status ${ }^{26}$. The socio-economic factors which might lead patients in Brazil to be more active than patients in Austria include the fact that the proportion of Brazilian patients who have access to privately owned transportation (i.e. automobile) was half than that found in the Austrian patients. Therefore, Brazilian patients have to ambulate more for daily activities as well as to access public transport. Since $85 \%$ of Brazilian patients were living with spouse or relatives (in comparison to $52.5 \%$ in the Austrian group), it may also be argued that this can be a motivating factor in order to undertake more outdoor social activities with the other family members. Ethnic differences are likely linked to the socio-economic discrepancies between the groups.

A study by He et al. ${ }^{27}$ showed that leisure time physical activity in healthy adults between 51-61 years of age was higher in Caucasian than in non-Caucasian subjects. On the other hand, work-related physical activity showed the reverse pattern, being highest in non-Caucasian subjects with lower education. These variations in physical activity level related to work or leisure cannot explain the present results, since all patients in both groups were officially retired, the vast majority of them were in fact no longer involved in any professional activity and those still involved in informal professional activities were not more active than those not involved. Therefore, irrespective of the fact that more Brazilian patients were involved in informal professional activities, this did not appear to influence the results of the present study since daily physical activity assessments were not performed on days in which patients performed any professional activity. If assessments were performed on days in which the patients were involved in informal working, the differences in daily physical activity level between the Brazilian and Austrian groups would possibly have been even larger. On the other hand, it cannot be ruled out that the professional activity performed by these individuals before retirement might have influenced their current physical activity habits.

Environmental factors are also known to influence daily physical activity level. However, data collection in the present study was performed during a period in which mean temperatures, humidity and precipitation were similar between both countries. In addition, two other factors suggest that environmental factors did not play a role in the present results: Firstly, the city of Londrina is located in the southern region of Brazil, i.e., the less warm region in the country and with more resemblance to the European general climate. Secondly, Togo et al..$^{28}$ observed that, in an healthy elderly cohort, the amount of steps per day increased with the 
mean ambient temperature over the range of $-2^{\circ} \mathrm{C}$ to $17^{\circ} \mathrm{C}$, but decreased over the range of $17^{\circ} \mathrm{C}$ to $29^{\circ} \mathrm{C}$. Therefore, if weather was an influencing factor in the present results, previous research supports the contention that activity level would be lower in Brazilian compared to Austrian patients.

Another interesting finding from the present study was that the proportion of Brazilian patients with COPD who reached the minimum amount of daily physical activity recommended by the ACSM ${ }^{25}$ was more than twice the proportion of Austrian patients. These results directly affect treatment options, since they indicate that pulmonary rehabilitation programs in Central Europe, even more than in South America, should prioritize the goal of enhancing daily physical activity. Furthermore, since non-compliance with these recommendations is related to higher risk of death in retired elderly ${ }^{29,30}$, early mortality would be expected to be higher in Austrian patients than in Brazilian patients, although ethnicity and annual income were not predictive factors of mortality in a sample of American patients with severe emphysema ${ }^{31}$. Given the importance of compliance to physical activity recommendations, especially in chronic disease populations, future research in this area is certainly warranted.

In summary, Austrian patients with COPD demonstrated a significantly lower daily physical activity level in comparison to matched Brazilian patients with COPD. Socio-economic and ethnic factors appear to influence stable patients with COPD differently than described in previous studies including healthy individuals. 


\section{References}

1. Pitta F, Troosters T, Probst VS, Spruit MA, Decramer M, Gosselink R. Quantifying physical activit in daily life with questionnaires and motion sensors in COPD. Eur Respir J 2006 May;27 (5):1040-55.

2. Pitta F, Troosters T, Spruit MA, Probst VS, Decramer M, Gosselink R. Characteristics of physical activities in daily life in chronic obstructive pulmonary disease. Am J Respir Crit Care Med 2005 May 1;171(9):972-7.

3. Singh S, Morgan MD. Activity monitors can detect brisk walking in patients with chronic obstructive pulmonary disease. J Cardiopulm Rehabil 2001 May;21(3):143-8.

4. Schonhofer B, Ardes P, Geibel M, Kohler D, Jones PW. Evaluation of a movement detector to measure daily activity in patients with chronic lung disease. Eur Respir J 1997 Dec;10(12):2814-9.

5. Coronado M, Janssens JP, de Muralt B, Terrier P, Schutz Y, Fitting JW. Walking activity measured by accelerometry during respiratory rehabilitation. J Cardiopulm Rehabil 2003 Sep;23(5):357-64.

6. Marshall SJ, Jones DA, Ainsworth BE, Reis JP, Levy SS, Macera CA. Race/ethnicity, social class, and leisuretime physical inactivity. Med Sci Sports Exerc 2007 Jan;39(1):44-51.

7. Ransdell LB, Wells CL. Physical activity in urban white, African-American, and Mexican-American women. Med Sci Sports Exerc 1998 Nov;30(11):1608-15.

8. Martinez-Gonzalez MA, Varo JJ, Santos JL, De Irala J, Gibney M, Kearney J, et al. Prevalence of physical activity during leisure time in the European Union. Med Sci Sports Exerc 2001 Jul;33(7):1142-6.

9. Crespo C), Ainsworth BE, Keteyian SJ, Heath GW, Smit E. Prevalence of physical inactivity and its relation to social class in U.S. adults: results from the Third National Health and Nutrition Examination Survey, 19881994. Med Sci Sports Exerc 1999 Dec;31(12):1821-7.

10. Parks SE, Housemann RA, Brownson RC. Differential correlates of physical activity in urban and rural adults of various socioeconomic backgrounds in the United States. J Epidemiol Community Health 2003 Jan;57(1):29-35.

11. Rabe KF, Hurd S, Anzueto A, Barnes PJ, Buist SA, Calverley P, et al. Global strategy for the diagnosis, management, and prevention of chronic obstructive pulmonary disease: GOLD executive summary. Am J Respir Crit Care Med 2007 Sep 15;176(6):532-55.

12. www.inmet.gov.br. Last accessed: July 2008.

13. www iapar br. Last accessed: July 2008.

14. wnw.diariopopularpr.com.br. Last accessed: July 2008.

15. www.zagm.ac.at. Last accessed: July 2008.

16. wuw.statistik.at . Last accessed: July 2008.

17. Pitta F, Troosters T, Spruit MA, Decramer M, Gosselink R. Activity Monitoring for Assessment of Physical Activities in Daily Life in Patients With Chronic Obstructive Pulmonary Disease. Arch Phys Med Rehabil 2005 Oct;86(10):1979-85.

18. Sandland CJ, Singh SJ, Curcio A, Jones PM, Morgan MD. A profile of daily activity in chronic obstructive pulmonary disease. J Cardiopulm Rehabil 2005 May;25(3):181-3.

19. Miller MR, Hankinson J, Brusasco V, Burgos F, Casaburi R, Coates A, et al. Standardisation of spirometry. Eur Respir J 2005 Aug;26(2):319-38.

20. Quanjer PH, Tammeling GJ, Cotes JE, Pedersen OF, Peslin R, Yernault JC. Lung volumes and forced ventilatory flows. Report Working Party Standardization of Lung Function Tests, European Community for Steel and Coal. Official Statement of the European Respiratory Society. Eur Respir J Suppl 1993 Mar;16:5-40.

21. Mahler DA, Wells CK. Evaluation of clinical methods for rating dyspnea. Chest 1988 Mar;93(3):580-6.

22. ATS statement: guidelines for the six-minute walk test. Am J Respir Crit Care Med 2002 Jul 1;166(1):111-7.

23. Troosters T, Gosselink R, Decramer M. Six minute walking distance in healthy elderly subjects. Eur Respir J 1999 Aug;14(2):270-4.

24. Celli BR, Cote CG, Marin JM, Casanova C, Montes dO, Mendez RA, et al. The body-mass index, airflow obstruction, dyspnea, and exercise capacity index in chronic obstructive pulmonary disease. N Engl J Med 2004 Mar 4;350(10):1005-12.

25. Pate RR, Pratt M, Blair SN, Haskell WL, Macera CA, Bouchard C, et al. Physical activity and public health. A recommendation from the Centers for Disease Control and Prevention and the American College of Sports Medicine. JAMA 1995 Feb 1;273(5):402-7.

26. Garcia-Aymerich J, Felez MA, Escarrabill J, Marrades RM, Morera J, Elosua R, et al. Physical activity and its determinants in severe chronic obstructive pulmonary disease. Med Sci Sports Exerc 2004 Oct;36(10):166773. 


\section{6। CHAPTER 8}

27. He XZ, Baker DW. Differences in leisure-time, household, and work-related physical activity by race, ethnicity, and education. J Gen Intern Med 2005 Mar;20(3):259-66.

28. Togo F, Watanabe E, Park H, Shephard RJ, Aoyagi Y. Meteorology and the physical activity of the elderly: the Nakanojo Study. Int J Biometeorol 2005 Nov;50(2):83-9.

29. Hakim AA, Petrovitch H, Burchfiel CM, Ross GW, Rodriguez BL, White LR, et al. Effects of walking on mortality among nonsmoking retired men. N Engl J Med 1998 Jan 8;338(2):94-9.

30. LaCroix AZ, Leveille SG, Hecht JA, Grothaus LC, Wagner EH. Does walking decrease the risk of cardiovascular disease hospitalizations and death in older adults? J Am Geriatr Soc 1996 Feb;44(2):113-20.

31. Martinez FJ, Foster G, Curtis JL, Criner G, Weinmann G, Fishman A, et al. Predictors of mortality in patients with emphysema and severe airflow obstruction. Am J Respir Crit Care Med 2006 Jun 15;173(12):1326-. 


\section{CHAPTER 9}

\section{Prevalence of metabolic syndrome in COPD patients and its consequences}

Breyer MK, Spruit MA, Rutten EPA, Franssen FME, Wouters EFM Submitted 



\section{Abstract}

\section{Objective}

The prevalence of metabolic syndrome in COPD and its impact on patient related outcomes has been little studied. We evaluated the prevalence of metabolic syndrome in patients with COPD and healthy subjects. Moreover clinical and functional characteristics were studied.

\section{Methods}

228 clinically stable COPD patients and 156 healthy subjects were included. Metabolic syndrome was defined using criteria of the International Diabetes Federation. In all patients spirometry, body composition, functional exercise performance, and mood and health status were assessed. Groups were stratified for $\mathrm{BMI}$ and gender.

\section{Results}

Metabolic syndrome was present in 57\% of the COPD patients and $40 \%$ of the healthy subjects. After stratification for BMI, presence of metabolic syndrome in patients with a $\mathrm{BMI} \geq 25 \mathrm{~kg} / \mathrm{m}^{2}$ was higher than in healthy peers. Patients with metabolic syndrome and a BMI $<25 \mathrm{~kg} / \mathrm{m}^{2}$ had higher BMI, fat free mass index and bone mineral density, and a lower 6MWD than the BMI matched patients without metabolic syndrome. Spirometry, maximal ergometry, mood and health status, and blood gasses were not different between those groups. In COPD patients with metabolic syndrome self-reported co-morbidities and medication use were higher than in those without.

\section{Conclusion}

Metabolic syndrome is more prevalent in overweight or obese COPD patients than in BMI matched healthy subjects, while comparable frequencies were observed in normal weight patients and healthy subjects. Metabolic syndrome did not additionally impact patients' related outcomes, like functional parameters, but did impact the prevalence of co-morbidities. The long-term impact of metabolic syndrome in COPD needs further studies. 


\section{Introduction}

Chronic obstructive pulmonary disease (COPD) is characterized by persistent airflow limitation that is usually progressive and associated with an enhanced chronic respiratory inflammatory response. Additionally, exacerbations and coexisting morbidities contribute to the overall severity in the individual patient ${ }^{1}$. Indeed, cardiovascular co-morbidities are common in COPD ${ }^{2}$ and are associated with increased mortality risk ${ }^{3,4}$. The mechanisms underlying the increased cardiovascular risk in COPD are only partially understood. In addition to smoking, other factors may contribute including advanced age, medications, systemic inflammation and metabolic disturbances.

Metabolic syndrome is a common metabolic disorder defined as a complex of interrelated cardiovascular risk factors ${ }^{5}$. Metabolic syndrome is age dependent ${ }^{6}$ and has been related to several other health conditions ${ }^{7}$ and increased mortality risk ${ }^{8}$. In addition, metabolic syndrome has clinically relevant negative effects on subjects exercise capacity 9 ,10, as well as on health status ${ }^{11-13}$, while protective effects are described on bone mineral density (BMD) ${ }^{14}$.

To date, the prevalence of metabolic syndrome in COPD patients has been studied scarcely. Marquis and colleagues reported an increased prevalence of metabolic syndrome in 38 COPD patients compared to 34 healthy subjects (47\% versus $21 \%$, respectively ${ }^{15}$. A comparable prevalence of metabolic syndrome in COPD was reported by Watz and colleagues, and metabolic syndrome was slightly less prevalent in moderate to severe patients compared to mild patients ${ }^{16}$. However, no healthy control group was included in this study.

COPD patients with metabolic syndrome are physically less active and have increased levels of systemic inflammation compared to COPD patients without metabolic syndrome ${ }^{16}$. To date it remains largely unknown whether and to what extent other clinical outcomes, like spirometry, functional exercise performance, mood and health status, and the prevalence of cardiovascular co-morbidity might differ between COPD patients with and without metabolic syndrome.

In the present study we evaluated the prevalence of metabolic syndrome in COPD patients compared to healthy subjects. In addition, clinical and functional characteristics of COPD patients with and without metabolic syndrome were studied. 


\section{Methods}

\section{Study population}

Data were prospectively collected in 228 clinically stable COPD patients who were referred to $\mathrm{ClRO}^{+}$, a center of expertise for chronic organ failure in Horn, the Netherlands for a 3-day pre-rehabilitation assessment ${ }^{17}$. In addition, 156 healthy subjects were recruited from November 2007 until December 2012. All patients and 55 healthy subjects were recruited as part of the CIROCO study (Study 1: Ethical approval number: 10-3-067) ${ }^{18}$, and 101 control subjects were recruited from another observational prospective study (Study 2: Ethical approval number: 10-3-033, www.controlled-trials.com, ISRCTN86049077). All participants gave written informed consent before participation. For both studies, inclusion criteria for the COPD patients were: diagnosis of COPD GOLD stage I to IV ${ }^{19}$ and no respiratory tract infection or exacerbation at least 4 weeks prior to the study (clinically stable). Exclusion criteria for both COPD and healthy subjects were any kind of oncologic pathology less than 5 years prior to the study.

\section{International Diabetes Federation (IDF) definition of metabolic syndrome}

Metabolic syndrome was diagnosed based on the latest IDF criteria ${ }^{5}$ an increased waist circumference (WC $\geq 94 \mathrm{~cm}$ in European men or $\geq 80 \mathrm{~cm}$ in European women)

Plus at least two of the following four criteria:

- glucose $>100 \mathrm{mg} / \mathrm{dL}(5.6 \mathrm{mmol} / \mathrm{L})$ or previously diagnosed type II diabetes;

- triglyceride $\geq 150 \mathrm{mg} / \mathrm{dL}(1.7 \mathrm{mmol} / \mathrm{L})$ or specific treatment for this lipid abnormality;

- high density lipoprotein $(\mathrm{HDL})<40 \mathrm{mg} / \mathrm{dL}(1.03 \mathrm{mmol} / \mathrm{L})$ in men or $<50 \mathrm{mg} / \mathrm{dL}$ $(1.29 \mathrm{mmol} / \mathrm{L})$ in women or specific treatment for this lipid abnormality;

- systolic blood pressure $\geq 130 \mathrm{mmHg}$ and/or diastolic blood pressure $\geq 85 \mathrm{mmHg}$ or treatment of previously diagnosed hypertension;

\section{Assessment of components of metabolic syndrome}

WC was measured at minimal inspiration and to the nearest $0.1 \mathrm{~cm}$, midway between the last rib and the iliac $\operatorname{crest}^{20}$. All blood samples were taken after a 12-hour fasting period. Plasma glucose was measured colorimetrically (Cobas Mira, Roche, Basel, Switzerland), triglycerides enzymatically after hydrolysation by lipase to glycerol and free fatty acids and HDL was measured automatically using a homogenous assay (the latter both analyses were performed on the Synchron LX20, Beckman Coulter, Brea CA device, Minneapolis, USA). LDL was calculated using the Friedewald equation ${ }^{21}$. Patients' blood pressure (BP) was measured after the patient had a standard relaxation time, seated comfortably with the back and arm supported, legs uncrossed, and not talking ${ }^{22}$. 


\section{Lung function and arterial blood gases}

Lung function parameters were collected using standardized spirometry (Masterlab, Viasys, Germany). The degree of severity of airflow limitation was classified according to the GOLD guidelines ${ }^{19}$. Arterial oxygen tension $\left(\mathrm{PaO}_{2}\right)$ and arterial carbon dioxide tension $\left(\mathrm{PaCO}_{2}\right)$ have been analyzed with a blood gas analyzer (ABL 700, Radiometer, Copenhagen, Denmark) in the patients only.

\section{Anthropometric parameters}

Body mass index (BMI) was calculated by body weight in kilogram divided by squared height in meters. Body composition [fat free mass index (FFMI), bone mineral density (BMD)] has been assessed using a dual $\mathrm{x}$-ray absorptiometry (DEXA) scan (Lunar Prodigy; GE Healthcare, Madison, WI, USA). Fat-free mass was calculated by summing up lean mass and bone mass. FFMI was calculated as: FFM in kilogram divided by squared height in meters. Low FFM was defined as FFMI $\leq 15$ (females) or $\leq 16$ (males) $\mathrm{kg} / \mathrm{m}^{2}$. To assess osteoporosis in the patients, $T$ score of the hip and the lumbar spine has been determined by DEXA scan. A normal BMD has been defined by a T-score $>-1$, Osteopenia by the lowest T-score between -2.5 and -1 , and osteoporosis by a T-score $\leq-2.523$.

\section{Exercise capacity and mood status}

In COPD patients peak cycling load has been assessed using an incremental ergometry cycling test and functional exercise capacity has been assessed using the longest distance of two six-minute walking distance tests (6MWD; including a practice walk ${ }^{24}$ ). The St. George Respiratory Questionnaire (SGRQ) has been used to assess disease-specific health status ${ }^{25}$. The SGRQ consists of three domains (symptoms, activity and impact) as well as a total score. Scores can range from 0 (=optimal) to 100 points (=worst). The Modified Medical Research Council (MRC) dyspnoea scale has been recorded. Assessment of mood status has been done using the Hospital Anxiety and Depression Scale (HADS) ${ }^{26}$.

\section{Additional parameters}

Subjects' smoking status (never, former, and current smoker) as well as the number of pack years were recorded. In patients only, the use of long-term oxygen therapy (LTOT), the Charlson Co-morbidity Index $(\mathrm{CCl})^{27}$ to evaluate the presence of self-reported co-existing morbidities like cardiovascular disease, peripheral vascular disease and type II diabetes, and patients' current pharmacological treatment (inhaled and oral corticosteroids, statins, B-blocker, anti-diabetics, insulin, blood pressure lowering drugs) were recorded. 


\section{Statistical analyses}

Besides whole group comparison, both the patient and healthy subject groups were stratified for BMI (with a cut-off of $25 \mathrm{~kg} / \mathrm{m}^{2}$ ) and for gender to evaluate the prevalence of the metabolic syndrome. Categorical variables are described as frequencies, while continuous variables were checked for normality and described as mean $\pm \mathrm{SD}$ or median (inter-quartile range; for pack years). Evaluation of group differences (patients vs. Healthy subjects, patients with vs. without metabolic syndrome) in means for continuous variables was done using the Unpaired Student's t-test, and for categorical variables the chi-square test. All analyses were performed using the Statistical Package for the Social Sciences (SPSS) version 20 for Windows. A p-value of $\leq 0.05$ was considered significant.

\section{Results}

\section{Prevalence of metabolic syndrome and its components}

The COPD patients were characterised by moderate to severe airflow limitation (Table 1). Compared to healthy subjects, COPD patients were slightly older, had a higher number of pack years and male gender was predominant. While BMI and FFMI were lower, WC was higher in the patients.

Plasma HDL concentration and diastolic blood pressure were lower in the COPD patients. Prevalence of a high systolic and diastolic blood pressure, one of the criteria of metabolic syndrome, was more prevalent in healthy subjects than in the patients, but metabolic syndrome was more prevalent in the patients than in healthy subjects. After stratification for BMI: the subgroup of patients with a BMI $\geq 25 \mathrm{~kg} / \mathrm{m}^{2}$ were matched for BMI with their healthy peers, but BMI was lower in the subgroup of patients with $\mathrm{BMI}<25 \mathrm{~kg} / \mathrm{m}^{2}$ compared to their healthy peers (Table 2). Further, in the subgroups of subjects with BMl $<25 \mathrm{~kg} / \mathrm{m}^{2}$, WC was higher and plasma HDL concentration was lower in patients than in healthy subjects, but the prevalence of the metabolic syndrome was comparable.

Figure 1 provides an overview of the prevalence of metabolic syndrome and its components in COPD and healthy subjects after stratification for gender and $\mathrm{BMI}$. The prevalence of none of the criteria as well as the prevalence of metabolic syndrome was significantly different between men and women with $\mathrm{BMI}<25 \mathrm{~kg} /$ $\mathrm{m}^{2}$. In the subjects with $\mathrm{BMI} \geq 25 \mathrm{~kg} / \mathrm{m}^{2}$. WC and plasma glucose concentration were higher and systolic and diastolic blood pressure were lower in the patients compared to the healthy subjects. Furthermore, the prevalence of a high WC and a high triglyceride level was higher while the prevalence of a high systolic and diastolic blood pressure was lower in the patients than in the healthy subjects. The prevalence of the metabolic syndrome was $77 \%$ in the patients and $50 \%$ in the healthy subjects $(p<0.01)$. Figure 1 shows that in the men with $B M I \geq 25 \mathrm{~kg} / \mathrm{m}^{2}$. 
The prevalence of high systolic and diastolic blood pressure was lower and the prevalence of high WC and metabolic syndrome was higher in COPD patients than in healthy subjects. In the women with $\mathrm{BMI} \geq 25 \mathrm{~kg} / \mathrm{m}^{2}$, a higher systolic blood pressure was more prevalent in the healthy subjects than in the patients while the prevalence of metabolic syndrome was more prevalent in the patients.

Table 1. Baseline characteristics of the total study population

\begin{tabular}{|c|c|c|}
\hline & COPD patients $(n=228)$ & healthy subjects $(n=156)$ \\
\hline Gender, \%male & 59 & $45 *$ \\
\hline age, years & $63.7 \pm 7.1$ & $60.1 \pm 7.4 *$ \\
\hline $\mathrm{FEV}_{1}$, \%pred & $52.8 \pm 18.6$ & $120.4 \pm 15.8^{*}$ \\
\hline FVC, \%pred & $96.1 \pm 19.1$ & $122.8 \pm 21.3^{*}$ \\
\hline $\mathrm{FEV}_{1} / \mathrm{FVC}$ & $40.9 \pm 12.2$ & $78.1 \pm 6.5^{*}$ \\
\hline \multicolumn{3}{|l|}{ smoking status } \\
\hline never smoker, \% & 0 & $77 *$ \\
\hline former smoker, \% & 73 & $23^{*}$ \\
\hline current smoker, \% & 27 & $0 *$ \\
\hline Pack years, $\mathrm{n}^{\#}$ & $43.0(29.4-58.5)$ & $3.5(0.0-15.3)^{*}$ \\
\hline $\mathrm{BMI}, \mathrm{kg} / \mathrm{m}^{2}$ & $26.2 \pm 5.1$ & $27.3 \pm 4.2^{\dagger}$ \\
\hline FFMI, kg/m² & $17.0 \pm 2.4$ & $17.9 \pm 3.6 *$ \\
\hline Waist circumference, $\mathrm{cm}$ & $98.5 \pm 14.3$ & $93.9 \pm 10.7^{*}$ \\
\hline Plasma glucose level, mmol/L & $5.8 \pm 1.2$ & $5.6 \pm 0.7$ \\
\hline Plasma triglyceride level, $\mathrm{mmol} / \mathrm{L}$ & $1.5 \pm 0.9$ & $1.5 \pm 1.1$ \\
\hline Plasma HDL level, mmol/L & $1.7 \pm 0.5$ & $1.8 \pm 0.5^{\dagger}$ \\
\hline Systolic blood pressure, mmHg & $138.6 \pm 21.4$ & $142.7 \pm 20.3$ \\
\hline Diastolic blood pressure, $\mathrm{mmHg}$ & $82.2 \pm 9.7$ & $84.3 \pm 9.1^{\dagger}$ \\
\hline High waist circumference ${ }^{\$}, \%$ & 79 & 79 \\
\hline High glucose level$\left.\right|^{\$}, \%$ & 49 & 45 \\
\hline High triglyceride level\$, \% & 31 & 22 \\
\hline High HDL level $\left.\right|^{\$} \%$ & 10 & 8 \\
\hline High systolic blood pressure, \% & 61 & $75 *$ \\
\hline High diastolic blood pressure $\$$ & 33 & $46 *$ \\
\hline Metabolic syndrome $\$$ \% & 57 & $40 *$ \\
\hline
\end{tabular}

Data are presented: mean $\pm \mathrm{SD}$, percentages or \#median (interquartile range) if data were not normal distributed. FEV1, forced expiratory volume in the first second; FVC, forced vital capacity; BMI, body mass index; FFMI, fat free mass index; HDL, high density lipoprotein. \$according to the IDF. Other symbols: ${ }^{*} p<0.01,{ }^{\dagger} p<0.05$ compared with COPD patients. 
Figure 1. Prevalence of metabolic syndrome and its components in COPD and healthy subjects by BMI and gender
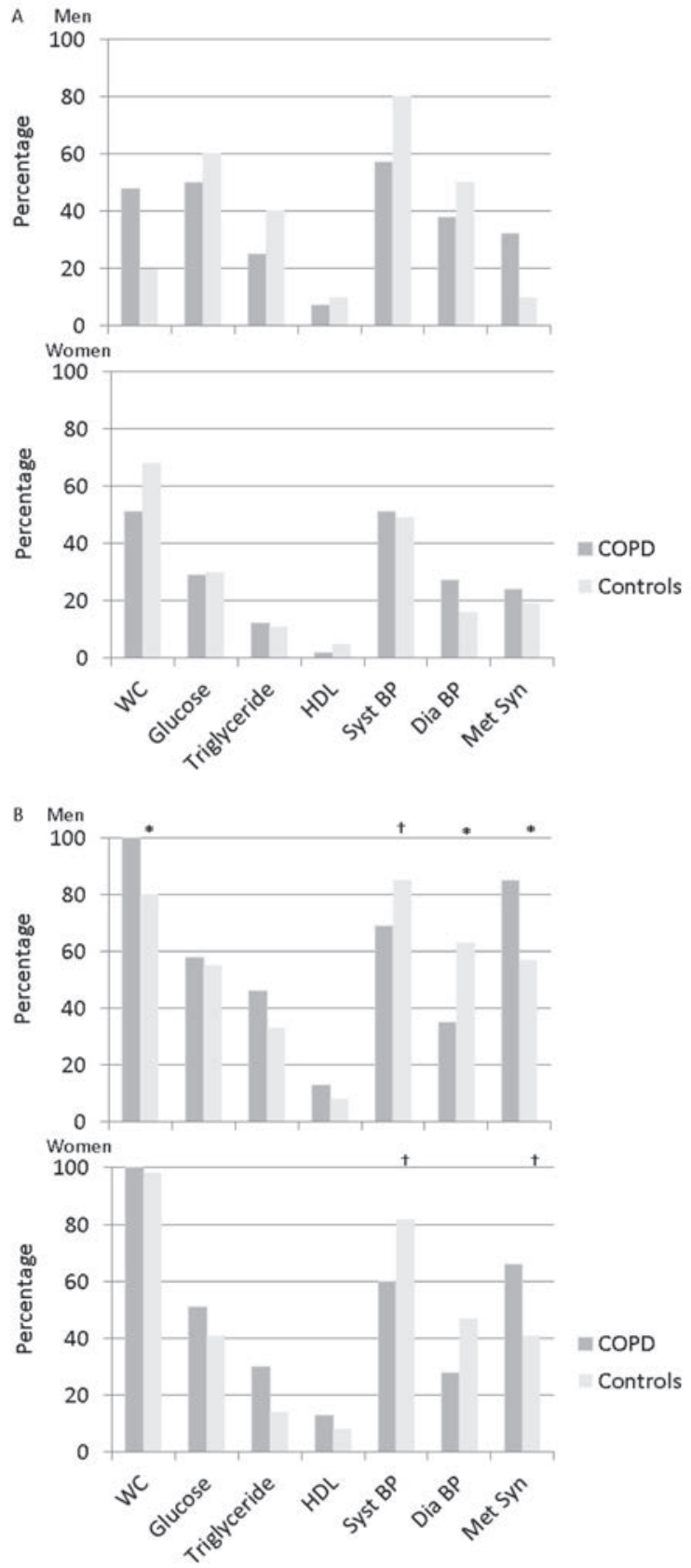

A: subjects with $\mathrm{BMI}<25 \mathrm{~kg} / \mathrm{m}^{2}$, B: subjects with $\mathrm{BMI} \geq 25 \mathrm{~kg} / \mathrm{m}^{2}$. WC, waist circumference; HDL, high density lipoprotein; Syst BP, systolic blood pressure; Dia BP, diastolic blood pressure; Met Syn, metabolic syndrome. ${ }^{*} p<0.01,{ }^{\dagger} p<0.05$ compared to COPD patients. 
Table 2: Body composition and criteria of metabolic syndrome of the study population by BMI

\begin{tabular}{|c|c|c|c|c|}
\hline & \multicolumn{2}{|l|}{$\mathrm{BMI}<25 \mathrm{~kg} / \mathrm{m}^{2}$} & \multicolumn{2}{|l|}{$\mathrm{BMI} \geq 25 \mathrm{~kg} / \mathrm{m}^{2}$} \\
\hline & $\begin{array}{l}\text { COPD } \\
\text { patients }(n=97)\end{array}$ & $\begin{array}{l}\text { healthy } \\
\text { subjects ( } n=47)\end{array}$ & $\begin{array}{l}\text { COPD } \\
\text { patients }(n=131)\end{array}$ & $\begin{array}{l}\text { healthy } \\
\text { subjects }(n=109)\end{array}$ \\
\hline $\mathrm{BMI}, \mathrm{kg} / \mathrm{m}^{2}$ & $21.7 \pm 2.4$ & $23.0 \pm 1.5^{*}$ & $29.4 \pm 3.9$ & $29.1 \pm 3.5$ \\
\hline $\mathrm{FFMI}, \mathrm{kg} / \mathrm{m}^{2}$ & $15.3 \pm 1.5$ & $15.8 \pm 1.9^{\dagger}$ & $18.3 \pm 2.1$ & $18.8 \pm 3.7$ \\
\hline $\begin{array}{l}\text { Waist } \\
\text { circumference, } \mathrm{cm}\end{array}$ & $87.4 \pm 10.6$ & $83.3 \pm 7.7^{\dagger}$ & $107 \pm 10.7$ & $98.5 \pm 8.2 *$ \\
\hline $\begin{array}{l}\text { Plasma glucose } \\
\text { level, } \mathrm{mmol} / \mathrm{L}\end{array}$ & $5.5 \pm 0.9$ & $5.4 \pm 0.6$ & $6.0 \pm 1.3$ & $5.7 \pm 0.7^{\dagger}$ \\
\hline $\begin{array}{l}\text { Plasma triglyceride } \\
\text { level, } \mathrm{mmol} / \mathrm{L}\end{array}$ & $1.3 \pm 0.6$ & $1.2 \pm 0.6$ & $1.7 \pm 1.0$ & $1.6 \pm 1.3$ \\
\hline $\begin{array}{l}\text { Plasma HDL level, } \\
\mathrm{mmol} / \mathrm{L}\end{array}$ & $1.8 \pm 0.5$ & $2.0 \pm 0.5^{\dagger}$ & $1.4 \pm 0.4$ & $1.7 \pm 0.4$ \\
\hline $\begin{array}{l}\text { Systolic blood } \\
\text { pressure, } \mathrm{mmHg}\end{array}$ & $136.5 \pm 19.9$ & $135.1 \pm 18.5$ & $140 \pm 22.3$ & $146 \pm 20.2^{\dagger}$ \\
\hline $\begin{array}{l}\text { Diastolic blood } \\
\text { pressure, } \mathrm{mmHg}\end{array}$ & $82.3 \pm 9.5$ & $80.2 \pm 8.9$ & $82.2 \pm 9.9$ & $86.1 \pm 8.6^{*}$ \\
\hline $\begin{array}{l}\text { High waist } \\
\text { circumference\$, } \%\end{array}$ & 49 & 57 & 100 & $88^{*}$ \\
\hline $\begin{array}{l}\text { High glucose level }{ }^{\$} \text {, } \\
\%\end{array}$ & 41 & 36 & 55 & 49 \\
\hline $\begin{array}{l}\text { High triglyceride } \\
\text { level } \$, \%\end{array}$ & 20 & 17 & 40 & $25^{\dagger}$ \\
\hline High HDL level$\$$, \% & 5 & 6 & 13 & 8 \\
\hline $\begin{array}{l}\text { High systolic blood } \\
\text { pressure } \$ \text {, \% }\end{array}$ & 55 & 55 & 66 & $83 *$ \\
\hline $\begin{array}{l}\text { High diastolic } \\
\text { blood pressure } \$ \text {, \% }\end{array}$ & 33 & 23 & 33 & $56^{\dagger}$ \\
\hline $\begin{array}{l}\text { Metabolic } \\
\text { syndrome } \$ \text {, \% }\end{array}$ & 29 & 17 & 77 & $50 *$ \\
\hline
\end{tabular}

Data are presented: mean \pm SD or percentages. BMI, body mass index; FFMI, fat free mass index; $\mathrm{HDL}$, high density lipoprotein. ${ }^{\$}$ according to the IDF. Other symbols: ${ }^{*} \mathrm{p}<0.01,{ }^{\dagger} \mathrm{p}<0.05$ compared with COPD patients. 


\section{Characteristics of patients with and without metabolic syndrome}

Even after stratification for BMI, the markers of body composition, BMI and FFMI were higher in patients with compared to those without metabolic syndrome (Table 3). Further, in the patients with $\mathrm{BMI}<25 \mathrm{~kg} / \mathrm{m}^{2}$, patients with metabolic syndrome had a lower prevalence of low muscle mass and a lower 6MWD compared to patients without metabolic syndrome. In addition, the proportion of patients using statins and blood pressure lowering drugs was higher when having metabolic syndrome. In the patients with $\mathrm{BMI} \geq 25 \mathrm{~kg} / \mathrm{m}^{2}$, male gender was predominant and BMD of the lumbar spine was higher in the patients with compared to those without metabolic syndrome. Also the proportion of patients with myocardial infarction, peripheral vascular disease, diabetes type II, and the proportion of patients using statins, B-blockers and blood pressure lowering drugs was higher in the patients with compared to those without metabolic syndrome. Other characteristics like spirometry, GOLD stages and combined COPD assessment, peak cycling load, prevalence of osteopenia/ osteoporosis, use of long term oxygen therapy, arterial blood gases, dyspnea, symptoms of anxiety and depression, and health status were similar between COPD patients with and without metabolic syndrome.

\section{Discussion}

The present study reports on two important findings: first, metabolic syndrome is more prevalent in overweight to obese patients with COPD compared to BMI matched healthy subjects. In the present cohort, no difference in the frequency of metabolic syndrome was observed in low to normal weight patients and healthy subjects. Second, the presence of metabolic syndrome in COPD patients had no functional consequences, but it coincided with more cardiovascular co-morbidity and type II diabetes.

Fifty seven percent of the COPD patients were diagnosed with metabolic syndrome, a prevalence comparable with previous studies ${ }^{15,16}$. However, this percentage was significantly higher compared to the healthy subjects, despite the presence of a lower BMI. Indeed, after stratification for BMI, the prevalence of metabolic syndrome was not significantly different in the subjects with BMI < $25 \mathrm{~kg} / \mathrm{m}^{2}$, but the prevalence of metabolic syndrome was significantly higher in the patients compared to the healthy subjects in the group with BMI $\geq 25 \mathrm{~kg} /$ $\mathrm{m}^{2}$. According to the IDF, the prevalence of metabolic syndrome is largely driven by abdominal obesity. In fact, it was recently shown that patients with obstructive lung disease have more visceral fat mass compared to healthy subjects ${ }^{28}$. Here, these findings are indirectly confirmed by the observation that even after stratification for BMI patients in both BMI sub-groups have higher WC than their 
Table 3. Clinical and functional characteristics of the COPD patients by metabolic syndrome

\begin{tabular}{|c|c|c|c|c|}
\hline & \multicolumn{2}{|l|}{$\mathrm{BMI}<25 \mathrm{~kg} / \mathrm{m}^{2}$} & \multicolumn{2}{|c|}{$\mathrm{BMI} \geq 25 \mathrm{~kg} / \mathrm{m}^{2}$} \\
\hline & $\begin{array}{l}\text { Metabolic synd } \\
\text { with }(n=28)\end{array}$ & $\begin{array}{l}\text { ome } \\
\text { without } \\
(n=69)\end{array}$ & $\begin{array}{l}\text { Metabolic synd } \\
\text { with ( } n=101)\end{array}$ & $\begin{array}{l}\text { ome } \\
\text { without } \\
(n=30)\end{array}$ \\
\hline age, years & $64.3 \pm 6.6$ & $62.9 \pm 7.2$ & $64.1 \pm 7.2$ & $63.7 \pm 7.3$ \\
\hline male, $\%$ & 64 & 55 & 65 & $40^{+}$ \\
\hline $\mathrm{FEV}_{1}, \%$ pred. & $45.2 \pm 18.9$ & $49.4 \pm 20.5$ & $57.5 \pm 17.0$ & $52.1 \pm 15.9$ \\
\hline FVC, \% pred. & $92.8 \pm 23.3$ & $97.5 \pm 17.7$ & $95.8 \pm 19.4$ & $97.1 \pm 16.9$ \\
\hline $\mathrm{FEV}_{1} / \mathrm{FVC}, \%$ pred. & $35.6 \pm 9.9$ & $37.8 \pm 13.4$ & $44.6 \pm 11.6$ & $40.2 \pm 9.3$ \\
\hline GOLD I, II, III, IV, \% & $0,43,36,21$ & $7,36,41,16$ & $8,59,27,6$ & $7,50,40,3$ \\
\hline $\begin{array}{l}\text { Combined COPD } \\
\text { assessment A, B, C, D, \% }\end{array}$ & $32,11,4,54$ & $18,23,17,42$ & $23,43,2,32$ & $27,30,10,33$ \\
\hline $\mathrm{BMI}, \mathrm{kg} / \mathrm{m}^{2}$ & $23.2 \pm 1.3$ & $21.1 \pm 2.5^{*}$ & $30.1 \pm 4.1$ & $27.3 \pm 2.2 *$ \\
\hline $\mathrm{FFMI}, \mathrm{kg} / \mathrm{m}^{2}$ & $15.9 \pm 1.3$ & $15.0 \pm 1.5^{*}$ & $18.6 \pm 2.2$ & $17.1 \pm 1.5^{*}$ \\
\hline Low muscle mass, $\%$ & 32 & $72 *$ & 4 & 7 \\
\hline BMD hip, g/cm² & $0.80 \pm 0.10$ & $0.80 \pm 0.15$ & $0.89 \pm 0.13$ & $0.89 \pm 0.23$ \\
\hline BMD lumbar spine, $\mathrm{g} / \mathrm{cm}^{2}$ & $1.04 \pm 0.16$ & $1.01 \pm 0.20$ & $1.14 \pm 0.18$ & $1.05 \pm 0.16^{\dagger}$ \\
\hline osteopenia , \% & 46 & 41 & 56 & 60 \\
\hline osteoporosis, \% & 50 & 49 & 19 & 20 \\
\hline 6MWD, m & $438.0 \pm 122.1$ & $491.9 \pm 97.3^{\dagger}$ & $460.4 \pm 95.5$ & $474.6 \pm 125.3$ \\
\hline 6MWD, \%pred & $73.7 \pm 21.3$ & $80.5 \pm 14.7$ & $82.4 \pm 16.6$ & $81.6 \pm 19.9$ \\
\hline peak load, watts & $68.0 \pm 19.4$ & $68.2 \pm 23.8$ & $81.7 \pm 28.6$ & $78.2 \pm 38.4$ \\
\hline peak load, \%pred & $56.6 \pm 31.5$ & $55.1 \pm 23.8$ & $61.9 \pm 25.8$ & $65.9 \pm 26.9$ \\
\hline \multicolumn{5}{|l|}{ smoking status } \\
\hline never smoker, \% & 0 & 0 & 0 & 3 \\
\hline former smoker, \% & 64 & 64 & 79 & 73 \\
\hline current smoker, \% & 36 & 36 & 21 & 23 \\
\hline pack years, $\mathrm{n}^{\#}$ & $\begin{array}{l}38.5 \\
(27.3-56.2)\end{array}$ & $\begin{array}{l}43.8 \\
(28.5-59.7)\end{array}$ & $\begin{array}{l}43.8 \\
(31.5-58.8)\end{array}$ & $\begin{array}{l}38.3 \\
(30.6-56.1)\end{array}$ \\
\hline LTOT, \% & 14 & 20 & 13 & 23 \\
\hline $\mathrm{pH}$ & $7.44 \pm 0.03$ & $7.43 \pm 0.03$ & $7.43 \pm 0.02$ & $7.44 \pm 0.09$ \\
\hline $\mathrm{PaCO}_{2}, \mathrm{kPa}$ & $5.3 \pm 0.7$ & $5.3 \pm 0.6$ & $5.3 \pm 0.6$ & $5.5 \pm 0.6$ \\
\hline $\mathrm{PaO}_{2}, \mathrm{kPa}$ & $9.3 \pm 1.1$ & $9.6 \pm 1.1$ & $9.5 \pm 1.0$ & $9.3 \pm 1.2$ \\
\hline
\end{tabular}




\begin{tabular}{|c|c|c|c|c|}
\hline & \multicolumn{2}{|c|}{$\mathrm{BMI}<25 \mathrm{~kg} / \mathrm{m}^{2}$} & \multicolumn{2}{|c|}{$\mathrm{BMI} \geq 25 \mathrm{~kg} / \mathrm{m}^{2}$} \\
\hline & $\begin{array}{l}\text { Metabolic sy } \\
\text { with }(n=28)\end{array}$ & $\begin{array}{l}\text { ome } \\
\text { without } \\
(n=69)\end{array}$ & $\begin{array}{l}\text { Metabolic sync } \\
\text { with }(n=101)\end{array}$ & $\begin{array}{l}\text { ome } \\
\text { without } \\
(n=30)\end{array}$ \\
\hline MRC & $2.3 \pm 1.3$ & $1.9 \pm 1.0$ & $2.2 \pm 1.1$ & $2.0 \pm 1.2$ \\
\hline HADS, anxiety & $6.0 \pm 3.8$ & $6.5 \pm 4.3$ & $6.0 \pm 3.8$ & $7.2 \pm 4.2$ \\
\hline depression & $5.4 \pm 3.6$ & $5.6 \pm 3.4$ & $5.8 \pm 3.7$ & $5.7 \pm 3.6$ \\
\hline SGRQ, total score & $52.2 \pm 16.2$ & $49.8 \pm 18.1$ & $52.7 \pm 16.9$ & $50.3 \pm 19.7$ \\
\hline symptom score & $54.8 \pm 18.8$ & $57.7 \pm 21.4$ & $55.2 \pm 19.9$ & $53.4 \pm 23.0$ \\
\hline activity score & $65.6 \pm 20.8$ & $65.6 \pm 23.2$ & $71.0 \pm 21.0$ & $66.7 \pm 21.6$ \\
\hline impact score & $39.3 \pm 21.4$ & $38.9 \pm 21.6$ & $41.2 \pm 18.0$ & $40.0 \pm 21.8$ \\
\hline \multicolumn{5}{|l|}{$\begin{array}{l}\text { Charlson Co-morbidity } \\
\text { Index }\end{array}$} \\
\hline CVD, $\%$ & 32 & 22 & 39 & 27 \\
\hline Myocardial infarct, \% & 4 & 6 & 18 & $0^{+}$ \\
\hline $\begin{array}{l}\text { Peripheral vascular } \\
\text { disease, } \%\end{array}$ & 14 & 13 & 22 & $13^{\dagger}$ \\
\hline Type II diabetes, \% & 7 & 3 & 8 & $3^{\dagger}$ \\
\hline \multicolumn{5}{|l|}{ Medication use } \\
\hline Inhaled CS, \% & 14 & 12 & 13 & 13 \\
\hline Oral CS, \% & 14 & 7 & 8 & 10 \\
\hline Statins, $\%$ & 46 & $7^{*}$ & 47 & $3 *$ \\
\hline Beta-blockers, \% & 21 & 9 & 26 & $7^{\dagger}$ \\
\hline Anti-diabetics, \% & 7 & 3 & 6 & 3 \\
\hline Insulin, \% & 0 & 0 & 3 & 3 \\
\hline $\begin{array}{l}\text { Blood pressure } \\
\text { lowering drugs, \% }\end{array}$ & 54 & $28^{\dagger}$ & 61 & $17 *$ \\
\hline
\end{tabular}

Data are mean \pm SD or percentages or \#median (interquartile range) if data were not normal distributed. FEV1, forced expiratory volume in the first second; FVC, forced vital capacity; BMI, body mass index; FFMI, fat free mass index; BMD, bone mineral density; 6MWD, six minute walking distance; LTOT, long term oxygen therapy; PaCO2, arterial carbon dioxide tension; PaO2, arterial oxygen tension; CVD, cardiovascular disease; inhaled and oral CS, inhaled and oral corticosteroids; MRC, modified Medical Research Council; HADS, Hospital Anxiety and Depression Scale; SGRQ, St. George Respiratory Questionnaire.

${ }^{*} p<0.01,{ }^{\dagger} p<0.05$ compared to patients without the metabolic syndrome. 
matched healthy peers. It is uncertain why abdominal obesity is more prevalent in COPD patients compared to healthy subjects, but various factors including poor nutrition and an inactive lifestyle may play an important role ${ }^{28}$. It is remarkable that the prevalence of metabolic syndrome is only higher in the patients with BMI $\geq$ $25 \mathrm{~kg} / \mathrm{m}^{2}$. Furthermore, cardiovascular co-morbidity was more prevalent in the patients with metabolic syndrome and $\mathrm{BMI} \geq 25 \mathrm{~kg} / \mathrm{m}^{2}$. These data imply that $\mathrm{BMI}$ contribute to the cardiovascular co-morbidity in COPD on top of metabolic syndrome.

The presence of metabolic syndrome was independent of the degree of airflow limitation. One other manuscript reported a slightly higher prevalence of metabolic syndrome in mild to moderate COPD patients ${ }^{16}$. In the present study most patients had COPD GOLD stage II or III, but no difference in the prevalence of metabolic syndrome within the various GOLD stages of COPD could be identified. Indeed, in the general population metabolic syndrome is associated with restrictive ventilatory patterns but not with obstructive lung function impairments ${ }^{29}$. This association is mainly driven by abdominal obesity, which is particularly present in patients with moderate airflow obstruction.

In patients with $\mathrm{BMI}<25 \mathrm{~kg} / \mathrm{m}^{2}$, patients with metabolic syndrome had lower 6MWD compared to the patients without metabolic syndrome. This is a surprising finding as the prevalence of low muscle mass, which is associated with decreased exercise tolerance ${ }^{30}$, was lower in the patients with metabolic syndrome. On the other hand, metabolic syndrome contributes to a lower exercise capacity assessed by treadmill test in healthy subjects ${ }^{9,10}$ and lower physical activity levels have been found in COPD patients with compared to those without metabolic syndrome ${ }^{16 .}$ However, differences in body composition were not taken into account as possible confounder. Interestingly, in the patients with $\mathrm{BMI} \geq 25 \mathrm{~kg} / \mathrm{m}^{2}$ metabolic syndrome did not affect functional exercise performance.

In the present study the prevalence of osteoporosis in COPD patients ranges from $20 \%$ up to $50 \%$ depending on BMI. To date no data are available on levels of BMD in COPD patients with metabolic syndrome. In the present study we did not find an association between the prevalence of metabolic syndrome and the prevalence of osteoporosis, but we did find a higher BMD of the lumbar spine in the patients with $\mathrm{BMI} \geq 25 \mathrm{~kg} / \mathrm{m}^{2}$ and metabolic syndrome. In the NHANES study, performed in the general population it was shown that subjects with metabolic syndrome have higher BMD compared to subjects without metabolic syndrome (after correcting for multiple confounders) and these results were mainly driven by an increased abdominal obesity ${ }^{14}$. Indeed, even a protective effect of criteria of metabolic syndrome against non-vertebral fractures has been described in patients with type II diabetes ${ }^{31}$. This effect could be partly explained by an increased 
mechanical load on the cortical skeleton ${ }^{32}$ and increased insulin levels promoting bone formation due to an increased fat mass ${ }^{33}$. There aside, in COPD it is already shown that circulating leptin, a cytokine produced and secreted by adipocytes, appears to act as a mediator between fat mass and bone mass ${ }^{34}$. More studies should be performed to investigate whether metabolic syndrome in COPD could have a protective effect on osteoporosis.

COPD is known to have a negative impact on the disease-specific health status and the effect increases even more with increased disease severity ${ }^{35}$. Even patients with COPD GOLD stage I can suffer from an impaired disease-specific health status ${ }^{35}$. Identifying factors related to a decreased disease-specific health status in COPD are, besides lung function impairment ${ }^{35}$, exercise intolerance ${ }^{36}$, dyspnoea, anxiety ${ }^{37}$, and body composition ${ }^{38}$. In general chronic conditions, such as type II diabetes, hypertension as well as dyslipidaemia are well known to affect patients' disease-specific health status. Thus, it can be expected that subjects having metabolic syndrome also suffer from impaired disease-specific health status ${ }^{12,13}$. In COPD co-morbid conditions might lead to a further decrease in disease-specific health status. However, results from our study show that COPD patients having metabolic syndrome are not additionally affected in their diseasespecific health status.

Finally the latest global strategy for the diagnosis, management and prevention of COPD (GOLD) highlighted the importance of co-morbidities in COPD. In particular, cardiovascular diseases, lung cancer, osteoporosis, depression, and metabolic disorders, such as type II diabetes, as they have a significant impact on prognosis and some of them even have been found to be the most frequent cause of death in mild COPD ${ }^{1}$. The here presented results indicate that having metabolic syndrome increases the co-morbidity index, particularly in those patients with an overweight or obese BMI. Therefore metabolic syndrome has to be identified and treated appropriately in patients with COPD. Future studies need to investigate the effect of treatment of metabolic syndrome on health outcomes in COPD, including cardiovascular risk reduction and mortality.

The following methodological considerations have to be taken into account: firstly, the healthy subjects were significantly, but slightly younger than the COPD patients. However, it is unlikely that a mean age difference of about 3 years explains the difference in the prevalence of the metabolic syndrome. Secondly, blood pressure of the healthy subjects was relatively high. Indeed, hypertension was the most mentioned co-morbidity among the healthy subjects. Further, subjects were not allowed to take their blood lowering drugs before the tests. Thirdly, no metabolic effects of metabolic syndrome are taken into account in the present study. Nevertheless, there is evidence that metabolic syndrome is associated with 
disturbed adipokine metabolism, insulin resistance ${ }^{39}$, and with increased systemic inflammation ${ }^{16}$. These studies did however not include a healthy subjects and future research has to unravel whether this is a COPD specific effect. Fourth, the present study had a cross-sectional study design and longitudinal studies are warranted to investigate the long term effects of metabolic syndrome on cardiovascular and other morbidities in patients with COPD.

In conclusion, in contrast to normal weight patients, metabolic syndrome is more prevalent in overweight and obese patients with COPD compared to BMI matched healthy subjects. Both, lung function impairment and functional parameters did not differ between COPD patients with and those without metabolic syndrome. Additionally, the prevalence of osteoporosis and disease-specific health status were not altered by the presence of metabolic syndrome, while metabolic syndrome has shown to contribute to an increased co-morbidity index. 


\section{References}

1. Barnes PJ, Celli BR. Systemic manifestations and comorbidities of COPD. Eur Respir J 2009:33:1165-85.

2. Curkendall SM, DeLuise $C$, Jones JK, et al. Cardiovascular disease in patients with chronic obstructive pulmonary disease, Saskatchewan Canada cardiovascular disease in COPD patients. Ann Epidemiol 2006;16:63-70.

3. Mannino DM, Thorn D, Swensen A, Holguin F. Prevalence and outcomes of diabetes, hypertension and cardiovascular disease in COPD. Eur Respir J 2008;32:962-9.

4. Divo M, Cote C, de Torres JP, et al. Comorbidities and risk of mortality in patients with chronic obstructive pulmonary disease. Am J Respir Crit Care Med 2012;186:155-61.

5. Alberti KG, Zimmet P, Shaw J. Metabolic syndrome--a new world-wide definition. A Consensus Statement from the International Diabetes Federation. Diabetic medicine : a journal of the British Diabetic Association 2006;23:469-80.

6. Eckel RH, Grundy SM, Zimmet PZ. The metabolic syndrome. Lancet 2005;365:1415-28.

7. Isomaa B, Almgren P, Tuomi T, et al. Cardiovascular morbidity and mortality associated with the metabolic syndrome. Diabetes Care 2001;24:683-9.

8. Lakka HM, Laaksonen DE, Lakka TA, et al. The metabolic syndrome and total and cardiovascular disease mortality in middle-aged men. Jama 2002;288:2709-16.

9. Ribisl PM, Lang W, Jaramillo SA, et al. Exercise capacity and cardiovascular/metabolic characteristics of overweight and obese individuals with type 2 diabetes: the Look AHEAD clinical trial. Diabetes Care 2007;30:2679-84.

10. Wong CY, O'Moore-Sullivan T, Fang ZY, Haluska B, Leano R, Marwick TH. Myocardial and vascular dysfunction and exercise capacity in the metabolic syndrome. Am J Cardiol 2005;96:1686-91.

11. Ford ES, Li C. Physical activity or fitness and the metabolic syndrome. Expert review of cardiovascular therapy 2006:4:897-915.

12. Roriz-Cruz M, Rosset I, Wada T, et al. Stroke-independent association between metabolic syndrome and functional dependence, depression, and low quality of life in elderly community-dwelling Brazilian people. J Am Geriatr Soc 2007;55:374-82.

13. Tsai AG, Wadden TA, Sarwer DB, et al. Metabolic syndrome and health-related quality of life in obese individuals seeking weight reduction. Obesity (Silver Spring) 2008;16:59-63.

14. Kinjo M, Setoguchi S, Solomon DH. Bone mineral density in adults with the metabolic syndrome: analysis in a population-based U.S. sample. J Clin Endocrinol Metab 2007;92:4161-4.

15. Marquis K, Maltais F, Duguay V, et al. The metabolic syndrome in patients with chronic obstructive pulmonary disease. Journal of cardiopulmonary rehabilitation 2005;25:226-32; discussion 33-4.

16. Watz H, Waschki B, Kirsten A, et al. The metabolic syndrome in patients with chronic bronchitis and COPD: frequency and associated consequences for systemic inflammation and physical inactivity. Chest 2009:136:1039-46.

17. Spruit MA, Vanderhoven-Augustin I, Janssen PP, Wouters EF. Integration of pulmonary rehabilitation in COPD. Lancet 2008;371:12-3.

18. Vanfleteren LE, Spruit MA, Groenen M, et al. Clusters of Comorbidities Based on Validated Objective Measurements and Systemic Inflammation in Patients with Chronic Obstructive Pulmonary disease. Am J Respir Crit Care Med 2013.

19. Vestbo J, Hurd SS, Agusti AG, et al. Global Strategy for the Diagnosis, Management, and Prevention of Chronic Obstructive Pulmonary Disease: GOLD Executive Summary. Am J Respir Crit Care Med 2013;187:34765.

20. Poirier P, Despres JP. Waist circumference, visceral obesity, and cardiovascular risk. Journal of cardiopulmonary rehabilitation 2003;23:161-9.

21. Friedewald WT, Levy RI, Fredrickson DS. Estimation of the concentration of low-density lipoprotein cholesterol in plasma, without use of the preparative ultracentrifuge. Clinical chemistry 1972;18:499-502.

22. Pickering TG, Hall JE, Appel LJ, et al. Recommendations for blood pressure measurement in humans and experimental animals: Part 1: blood pressure measurement in humans: a statement for professionals from the Subcommittee of Professional and Public Education of the American Heart Association Council on High Blood Pressure Research. Hypertension 2005;45:142-61.

23. Prevention and management of osteoporosis. World Health Organ Tech Rep Ser 2003;921:1-164,.

24. Hernandes NA, Wouters EF, Meijer K, Annegarn J, Pitta F, Spruit MA. Reproducibility of 6-minute walking test in patients with COPD. Eur Respir J 2011;38:261-7. 
25. Jones PW, Quirk FH, Baveystock CM, Littlejohns P. A self-complete measure of health status for chronic airflow limitation. The St. George's Respiratory Questionnaire. Am Rev Respir Dis 1992;145:1321-7.

26. Zigmond AS, Snaith RP. The hospital anxiety and depression scale. Acta Psychiatr Scand 1983;67:361-70.

27. Charlson ME, Pompei P, Ales KL, MacKenzie CR. A new method of classifying prognostic comorbidity in longitudinal studies: development and validation. J Chronic Dis 1987;40:373-83.

28. van den Borst B, Gosker HR, Koster A, et al. The influence of abdominal visceral fat on inflammatory pathways and mortality risk in obstructive lung disease. Am J Clin Nutr 2012;96:516-26.

29. Leone N, Courbon D, Thomas F, et al. Lung function impairment and metabolic syndrome: the critical role of abdominal obesity. Am J Respir Crit Care Med 2009;179:509-16.

30. Schols AM, Mostert R, Soeters PB, Wouters EF. Body composition and exercise performance in patients with chronic obstructive pulmonary disease. Thorax 1991;46:695-9.

31. Yamaguchi T, Kanazawa I, Yamamoto M, et al. Associations between components of the metabolic syndrome versus bone mineral density and vertebral fractures in patients with type 2 diabetes. Bone 2009;45:174-9.

32. Reid IR. Obesity and osteoporosis. Annales d'endocrinologie 2006;67:125-9.

33. Reid IR. Fat and bone. Arch Biochem Biophys 2010;503:20-7.

34. Pobeha P, Ukropec J, Skyba P, et al. Relationship between osteoporosis and adipose tissue leptin and osteoprotegerin in patients with chronic obstructive pulmonary disease. Bone 2011:48:1008-14.

35. Ferrer M, Alonso J, Morera J, et al. Chronic obstructive pulmonary disease stage and health-related quality of life. The Quality of Life of Chronic Obstructive Pulmonary Disease Study Group. Ann Intern Med 1997;127:1072-9.

36. Ketelaars CA, Schlosser MA, Mostert R, Huyer Abu-Saad H, Halfens RJ, Wouters EF. Determinants of health-related quality of life in patients with chronic obstructive pulmonary disease. Thorax 1996;51:39-43.

37. Hajiro T, Nishimura K, Tsukino M, Ikeda A, Koyama H, Izumi T. Comparison of discriminative properties among disease-specific questionnaires for measuring health-related quality of life in patients with chronic obstructive pulmonary disease. Am J Respir Crit Care Med 1998;157:785-90.

38. Shoup R, Dalsky G, Warner S, et al. Body composition and health-related quality of life in patients with obstructive airways disease. Eur Respir J 1997;10:1576-80.

39. Minas M, Kostikas K, Papaioannou Al, et al. The association of metabolic syndrome with adipose tissue hormones and insulin resistance in patients with COPD without co-morbidities. COPD 2011;8:414-20. 


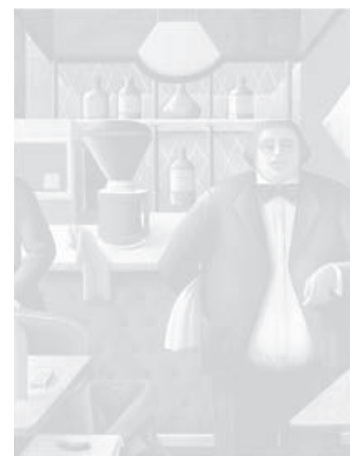

CHAPTER 10

General discussion 



\section{Introduction}

In earlier days the idea of a uniform state of systemic low-grade inflammation in every COPD patient was proposed ${ }^{1}$. This thesis deals with the nowadays most widely accepted heterogeneity of systemic low-grade inflammation in COPD 2,3 (chapter 4). Furthermore this thesis shows the adipose tissue as one of the origins of systemic low-grade inflammation in COPD; demonstrated by a relationship between the adipocyte derived adipokines and the COPD related systemic inflammatory biomarkers in particular C-reactive protein (CRP) and fibrinogen (chapter 2, 3, 5, and 6). In addition, host-related factors, such as BMI, age and physical inactivity, have been discussed as contributing factors to the heterogeneity of systemic low-grade inflammation in COPD (chapter 4, 7, and 8). Lastly, this thesis indicates the high prevalence of the metabolic syndrome in COPD compared to healthy subjects and its clinical and functional consequences (chapter 9 ).

\section{Heterogeneity of systemic low-grade inflammation}

Persistent systemic low-grade inflammation plays an important role in the pathogenesis of many chronic diseases, including COPD. ${ }^{4}$ Consensus is growing that the inflammatory processes that underlie COPD are probably mediated by a multitude of cytokines. Moreover different inflammatory systems, such as acute phase proteins and the TNF $\alpha$ system are linked to one another. TNF $\alpha$ stimulates the synthesis and secretion of IL-6 which in turn, stimulates the synthesis and secretion of CRP and fibrinogen from human hepatocytes ${ }^{5}$. Therefore, chapter 4 of this thesis suggests that a possible interrelationship between the acute phase markers and the markers of the TNF $\alpha$ system exists. A significant but weak relationship between the markers of the two systems is present in COPD. These findings are in line with research in a small COPD cohort $(n=58)$ reporting no correlation between CRP and the TNF $\alpha$ system ${ }^{6}$. Whether the failure to show an association is due to the short serum half life of a few minutes of TNF $\alpha$ or it is rather an illustration of the complexity of the role of systemic low-grade inflammation in the pathogenesis of COPD, remains uncertain.

Multiple small-sized, cross-sectional studies have investigated systemic low-grade inflammation in COPD. Most studies showed a large variability in the inflammatory values observed. The longitudinal relationship of inflammatory cytokines with clinical relevant outcomes has not been investigated so far. In connection with this, the ECLIPSE study (Evaluation of COPD Longitudinally to Identify Predictive Surrogate Endpoints) was initiated. The ECLIPSE study is a large observational study of COPD patients and healthy subjects conducted at 46 centres in 12 countries aiming to define COPD phenotypes and to identify biomarkers that help to predict disease progression? In 2012, the ECLIPSE study confirmed the hypothesis of heterogeneity of systemic low-grade inflammation in COPD ${ }^{3}$. White blood 
cells, CRP, IL-6, IL-8, fibrinogen and TNF $\alpha$ were determined in 1.755 COPD patients and 499 healthy subjects at baseline, and at one and three year follow-up. Systemic low-grade inflammation was not a constant feature of COPD. One-third of the COPD patients did not have any prove of elevated systemic inflammatory biomarker at baseline and about the same proportion remained 'non-inflamed' after one year follow-up'. 'Inflamed' patients were characterised as obese, dyspnoeic, with a decreased disease-specific health status and exercise tolerance and reported more cardiovascular disease, whereas most pulmonary characteristics such as the prevalence of chronic bronchitis, the degree of emphysema, and the annual decline of $\mathrm{FEV}_{1}$ during follow-up were comparable with the non-inflamed patients. Age, BMI, current smoking, and disease-specific health status were identified as risk factors for persistent systemic inflammation, while gender, cumulative smoking exposure, exacerbation rate, exercise tolerance, presence of chronic bronchitis or emphysema and the history of cardiovascular disease were not. These observations suggest that the severity of the respiratory impairment in COPD is not accompanied by systemic low-grade inflammation, questioning (again) the earlier on discussed 'spill over' theory of local inflammation into the circulation. Moreover as 'inflamed' patients were characterised as obese a possible other origin of systemic inflammation, the adipose tissue is proposed by the authors. This confirms in part the findings of chapter 2 , where obese patients with COPD had higher chances of having elevated CRP levels compared to normal weight peers. The observed all-cause mortality and the annual rate of COPD exacerbations at year three follow-up in the ECLIPSE study was higher in the persistently inflamed patients compared to the non-inflamed patients. These findings indicate that independent of the severity of disease; inflamed patients may have different outcomes compared to those without persistent systemic inflammation. This might have implications on pharmacological treatment of COPD patients as current therapy is mostly based on the degree of airflow limitation and the assumed inflammatory changes in the respiratory system. However, even inflammation in the respiratory system seems highly variable in COPD. Worth noting is the fact that 'inflamed' does not necessarily describe the frequent exacerbator phenotype ${ }^{8}$ as about onethird of the inflamed patients reported no exacerbation during year one follow up. In short, it seems reasonable to accept that systemic low-grade inflammation in COPD is heterogenic.

\section{Determinants of systemic low-grade inflammation}

Multiple attempts have been made to identify possible contributing factors determining systemic low-grade inflammation in COPD. Disease-related factors, in particular the degree of airflow limitation has been studied; based on the 'spill over' theory and an assumed progressive local (lung) inflammation with advanced airflow limitation ${ }^{9}$ a more accelerated systemic inflammatory response has been hypothesised. Some studies supported this hypothesis, but other couldn't. One 
study found decreasing circulating levels of the soluble TNF $\alpha$ receptor R1 with lower $\mathrm{FEV}_{1}$ values in multiple regression analysis ${ }^{10}$. One other study reported that by applying protein microarray platform technology systemic inflammatory biomarkers were associated with different clinical variables including the degree of airflow limitation ${ }^{11}$. Findings have to be interpreted cautiously as studies are cross-sectional and relatively small sized. Conversely, no relationship was found in chapter 4 between airflow limitation and systemic inflammatory biomarkers in an averaged sized study sample $(\mathrm{N}=295)$. This data was in line with other data, showing that systemic inflammatory markers could not discriminate between disease stages of COPD 2,12. Most recently the ECLIPSE study reported that the prevalence of chronic bronchitis and the extent of emphysema based on CT scans were similar between the 'inflamed' and 'non-inflamed' patients'. All together, these findings supported the concept that additional host-related factors, for example age and BMI, may contribute to the systemic low-grade inflammation in COPD.

\section{Body mass index and adipose tissue}

In the general population, overweight (BMI $>25 \mathrm{~kg} / \mathrm{m}^{2}$ ) and obese $\left(\mathrm{BMI}>30 \mathrm{~kg} / \mathrm{m}^{2}\right)$ subjects are reported to have increased levels of CRP compared to normal weight (BMI 21-24.9 kg/m²) peers, as shown in the Third National Health and Nutrition Examination Survey (NHANES III) ${ }^{13}$. In COPD first evidence suggests a positive association between CRP and BMI ${ }^{14,15}$. Therefore it seemed reasonable to hypothesise that overweight and obese COPD patients have increased CRP levels compared to normal weight COPD patients. Indeed, an increased likelihood of highly elevated CRP levels (CRP $>5 \mathrm{mg} / \mathrm{dL}$ ) was found in overweight and obese COPD patients compared to normal weight peers (chapter 2). These results remained significant after correcting for potential confounders, such as age, smoking status, disease severity, use of long term oxygen therapy, presence of co-exiting morbidities, fat free mass index (FFMI) and current pharmacological treatment. Furthermore results showed a clear reduction in the likelihood of having highly elevated CRP levels in COPD patients with a low BMI $\left(<21 \mathrm{~kg} / \mathrm{m}^{2}\right)$ compared to normal weight peers. This is in line with findings from chapters 4 and 5 , where increasing CRP levels with increasing BMI were found in a multivariate regression model. In chapter 3 , a total body dual-energy-x-ray-absorptiometry (DXA-scan) was performed in 295 stable COPD patients to obtain abdominal fat mass which was positively correlated with CRP. Even when patients with normal CRP levels were chosen, the direct association between CRP and abdominal fat mass remained. In line, COPD patients with increased CRP levels have been found to have a higher adipose tissue macrophage infiltration compared to COPD patients with low CRP levels ${ }^{16}$. These results highlight the systemic complexity of low-grade inflammation in COPD and emphasises a possible contributing role of the abdominal fat mass. 
These results encouraged us to proceed with investigating the role of the adipose tissue and particularly its adipokines in relation to various systemic inflammatory biomarkers in COPD. When setting up the investigations only little was known about circulating leptin and adiponectin in relation to COPD, the two main adipocytes studied. However from this few studies undertaken mainly in male COPD patients with a low BMI $\left(<21 \mathrm{~kg} / \mathrm{m}^{2}\right)$, it was concluded that leptin plays a physiological role in COPD, even in underweight patients ${ }^{17-19}$. Before the start of the current project, no data on a possible relationship of circulating leptin or adiponectin with different systemic inflammatory biomarkers was available. Chapter 5 showed higher circulating leptin levels in female COPD patients compared to male peers. Moreover, in chapter 6 we could confirm higher circulating leptin levels in female COPD patients and healthy subjects compared to male COPD patients and healthy subjects. Furthermore in female COPD patients, leptin was positively correlated with CRP and fibrinogen, while in COPD men leptin did not correlate with the systemic inflammatory biomarkers. In the multivariate regression analysis CRP was independently associated with leptin. This is in line with results from chapter 5 showing a positive correlation between CRP and leptin in COPD women. Taken together there seems to be a gender-dependent dysregulated adipokine metabolism in relation to systemic inflammatory biomarkers in COPD patients compared to BMI matched healthy subjects. The link between leptin and $\mathrm{CRP}$ in the general population and particularly in women is not clear. In general, women have higher circulating leptin levels compared to $\mathrm{men}^{20}$, which might be due to a higher circulating leptin secretion based on a higher fat mass percentage, particularly post-menopausal (decreased estrogens levels and an increased amount of body fat) ${ }^{21}$. Indeed, animal and in vitro studies confirmed an inhibitory effect of androgens on circulating leptin secretion ${ }^{22}$. However disturbances in the estrogen metabolism in women with COPD have not been investigated yet, although estrogens are thought to be involved in the biological difference in the susceptibility of the development of COPD ${ }^{23}$.

Increased circulating leptin levels are a strong predictor for myocardial infarction and first-ever hemorrhagic stroke in the general population ${ }^{24,25}$. This data suggests a possible link between the pro-inflammatory cytokine and the development of cardiovascular disease. Interestingly in chapter 6 COPD patients with self-reported cardiovascular co-morbidities were excluded from the study in order to avoid other chronic inflammatory diseases interfering with our results, although some patients still might have had unknown cardiovascular co-morbidity. To speculate, circulating leptin might therefore be one additional pro-inflammatory cytokine contributing to the increased cardiovascular morbidity and mortality observed in patients with COPD compared to healthy subjects ${ }^{26}$. Up until now this hypothesis has never been investigated.

In addition, increased adiponectin levels, an inverse relationship between adiponectin and BMI, as well as an inverse relationship between adiponectin and 
CRP have been found in COPD patients compared to BMI matched healthy subjects (chapter 6). These results may reflect the beneficial effects of adiponectin on decreasing cardiovascular risk as clinical studies have identified an association between low serum levels of adiponectin and coronary artery disease, hypertension, left ventricular hypertrophy and a greater risk of myocardial infarction ${ }^{27-29}$. In contrast, in patients with chronic heart failure as well as chronic renal failure, higher identified adiponectin levels have been associated with an increased cardiac and all-cause mortality ${ }^{30-32}$. Interestingly very recently higher levels of adiponectin were associated with an increased overall mortality in a rather small COPD cohort ${ }^{33}$. This data possibly suggests that adiponectin besides its beneficial biological effects, is an indirect marker of the multi-component severity in COPD. Further studies are needed to explore the potential role of adiponectin as a contributing factor in the disease progression.

Taken together we have demonstrated that obese COPD patients are more likely to have highly elevated CRP levels compared to normal weight peers and the abdominal fat mass is likely a contributing source of systemic low-grade inflammation in COPD. Indeed, the adipocyte-derived pro-inflammatory cytokine leptin is positively correlated with CRP and fibrinogen in female COPD patients; indicating a gender-dependent dysregulated adipokine metabolism in relation to systemic inflammatory biomarkers in COPD. Furthermore the anti-inflammatory cytokine adiponectin is increased in COPD patients and inversely related to CRP. This data suggests that the abdominal fat mass and its adipokines are involved in the complexity of systemic low-grade inflammation in COPD. However the exact role of circulating leptin as a potential contributing factor in the pathogenesis of cardiovascular morbidities and mortality as well as the exact role of adiponectin as a potential contributing factor in the disease progression of COPD still have to be investigated.

\section{Age}

'All diseases run into one - old age' the philosopher Ralph Waldo Emerson stated in his book 'Nature' in $1836^{34}$ and indeed multi-morbidity becomes progressively more common with age ${ }^{35}$. Very recently Barnett and colleagues published an analysis of a large, national representative primary care dataset (about 1.7 million Scots) showing that although the proportion of multi-morbidity subjects is much higher in older people than in young or middle-aged people, more than half of people with multi-morbidity were younger than 65 years $^{36}$. A population based cohort study of the general Dutch population older than 40 years of age revealed that the incidence of COPD is age dependent ${ }^{37}$. In general, aging is thought to be involved in inducing a chronic systemic inflammatory response which has been proposed as a key for all age-related diseases ${ }^{38,39}$. This phenomenon is called 'Inflammaging', the body's ability to deal with the up-regulation of various anti-stress 
responses at the cellular and molecular leve $\left.\right|^{40}$. Different aetiological factors likely contribute to this increased systemic low-grade inflammatory activity including smoking, arteriosclerosis, increased amount of fat tissue, as well as increased levels of circulating inflammatory mediators ${ }^{38}$. In particular an age-dependent increase of the acute phase protein fibrinogen, based on an age-related slower rate of fibrinogen disposal ${ }^{41}$, but also an increase of the TNF $\alpha$ system in the elderly population has been reported ${ }^{42}$. In chapter 4 age remained an independent determinant for the soluble TNF $\alpha$ receptor $\mathrm{R} 1$ and fibrinogen in the multivariate regression model in patients with COPD. Whether and to what extent this increased systemic inflammatory activity causes age-related pathologies, like COPD, or whether it rather reflects ongoing pathological processes remains unclear. Recently it has been hypothesised that COPD is a syndrome of accelerated 'lung aging't3 based on enhanced oxidative stress levels ${ }^{44}$ and shorter telomere lengths ${ }^{45}$ compared to age matched healthy subjects. Further research is needed to obtain more insight into the morphological but also functional age-related changes in COPD.

\section{Physical inactivity}

The World Health Organisation (WHO) defines physical activity as 'any bodily movement produced by skeletal muscles that requires energy expenditure' 46 . Physical inactivity has been identified as the fourth leading risk factor for global mortality causing an estimated 3.2 million deaths globally ${ }^{46}$. Regular moderate intensity physical activity such as walking, cycling, or participating in sports, has significant benefits for health. The risk of cardiovascular diseases, type II diabetes, colon and breast cancer, and depression can be reduced as well as adequate levels of physical activity can decrease the risk of hip or vertebral fractures and help to control weight ${ }^{46}$. All of which was already known thousands of years ago by Plato (428-348 BC), the Greek philosopher who stated 'Lack of activity destroys the good condition of every human being while movement and methodical physical exercise save it and preserve it'. Lee and colleagues estimated how much of the world's major non-communicable diseases (i.e. coronary heart disease, and breast and colon cancer) could be averted by increasing daily physical activity levels in inactive people, as well as how much gain in life expectancy could occur at the population level ${ }^{47}$. Unfortunately, Lee and colleagues did not present any data on chronic respiratory diseases. Most strikingly with elimination of physical inactivity, life expectancy of the world's population might be expected to increase by 0.68 years. These findings make physical inactivity similar to risk factors like smoking and obesity. One possible underlying cause for the negative impact of physical inactivity on health seems to be a state of systemic low-grade inflammation as regular exercise seems to have an anti-inflammatory effect ${ }^{48}$. More precisely, physical inactivity leads to accumulation of visceral fat and consequently to the activation of a network of inflammatory pathways which promotes development 
of insulin resistance, and arteriosclerosis, leading to the development of 'the diseasome of physical inactivity'49. Indeed, low physical activity levels were associated with markedly higher levels of IL-6 and CRP and, the other way around, levels of IL-6 and CRP are linearly associated with physical inactivity ${ }^{50}$ emphasising the hypothesis of physical inactivity to contribute to systemic low-grade inflammation. In COPD, patients have shown to be less active compared to healthy subjects ${ }^{51}$ and physical inactivity has been linked to increased systemic inflammatory biomarkers as increased CRP levels have been negatively correlated with physical activity levels ${ }^{52}$. Moreover physical inactivity has shown to be the strongest predictor of all-cause mortality in patients with COPD ${ }^{33}$. It therefore seems essential to increases physical activity levels not only in the general population but also in patients with COPD.

Comprehensive pulmonary rehabilitation programs have impressively shown to improve COPD patients' peripheral muscle function, functional exercise capacity, daily symptoms of dyspnoea, fatigue, anxiety and depression, and health status $^{53}$. However, most of studies lack to transfer these achievements into longterm observation ${ }^{54}$; indicating that an improvement in functional exercise capacity does not automatically turn into increased physical activity levels. Furthermore the effects of pulmonary rehabilitation on daily physical activity levels in COPD have hardly been touched upon in non-randomised and/ or non-controlled trials with no or modest effects ${ }^{55-57}$. Physical training modalities copying everyday-life activities may translate better into patients' physical activity pattern, as shown in chapter 7 . We determined the feasibility of Nordic Walking, by definition walking with specially designed poles, in patients with COPD and determined the longterm effect of Nordic Walking on COPD patients' daily physical activity pattern. We showed that a three-month supervised Nordic Walking training program is a safe training method that increases the daily physical activity level in clinically stable outpatients with COPD. In addition, Nordic Walking had a long-term effect on patients' daily physical activity pattern and a reduction in patients' daily symptoms. These results are of great interest as particularly Austrian COPD patients' do not reach the minimum amount of daily physical activity as recommended by the American College of Sports Medicine ${ }^{58}$ compared to COPD patients from Brazil as shown in chapter 8 indicating that pulmonary rehabilitation programs in Central Europe, even more than in South America, should prioritize the goal of enhancing daily physical activity levels.

Taken together the question arises whether, not only in general but also in COPD, an integrated management - a shift from physical exercise to physical activity might be the key to improving health substantially and sustainably. Once more to mention Lee and colleagues impressive study, where it was shown that in particular for the Austrian as well as for the Dutch population an increase in life expectancy of 0.59 and 0.29 years, respectively, if people would be more physically active ${ }^{47}$. Therefore in COPD in order to achieve one of the main goals of pulmo- 
nary rehabilitation - creating a long lasting effect by changing patients' lifestyle ${ }^{53}$ - an integrated pulmonary rehabilitation approach must be aimed at. Specialised pulmonary rehabilitation centres with core processes such as intake assessment, rehabilitation, education and aftercare, which are product and customer orientated, will lead to an improvement of patients physical status and quality of life and will lead to a cost reduction for health care providers ${ }^{59}$.

\section{Metabolic syndrome}

When starting this $\mathrm{PhD}$ only one small size study was available which investigated the metabolic syndrome in patients with COPD and healthy subjects ${ }^{60}$. The authors reported a prevalence of around $47 \%$ in a sample of 38 COPD patients and only $21 \%$ in the healthy subjects ${ }^{60}$. Based on this and the earlier mentioned incorporation of the metabolic syndrome into the panel of 'diagnostic components of the chronic systemic inflammatory syndrome'b1 - a panel targeting an overarching approach to diagnose, assess, and manage COPD and its frequent co-morbidities - chapter 9 was set up. Prospective data from 228 clinically stable COPD patients and 156 healthy subjects were collected. COPD and healthy subjects were matched for $\mathrm{BMI}$ and gender and stratified for BMI (below and above $25 \mathrm{~kg} / \mathrm{m}^{2}$ ). Therewith we could assure that possible differences in clinical and functional characteristics between patients with COPD and healthy subjects were not due to differences in BMI. The metabolic syndrome was diagnosed according to the most recent IDF guidelines ${ }^{62}$. In the total COPD group, $57 \%$ of the patients were diagnosed with the metabolic syndrome, which is comparable to previous studies ${ }^{60,63}$. When compared to healthy subjects, in which $40 \%$ had the metabolic syndrome, the prevalence in COPD patients was higher. In addition, after stratification for BMI the prevalence of metabolic syndrome was higher in the patients compared to the healthy subjects in the group with $B M I \geq 25 \mathrm{~kg} / \mathrm{m}^{2}$. In the subjects with $\mathrm{BMI}<25 \mathrm{~kg} / \mathrm{m}^{2}$ the prevalence of metabolic syndrome was not different. Recently it has been shown that patients with obstructive lung disease have more visceral fat mass compared to healthy subjects ${ }^{64}$. This data were confirmed in chapter 9. A poor nutritional diet and/ or an inactive lifestyle are only two factors influencing an increased prevalence of abdominal obesity in COPD compared to healthy subjects ${ }^{64}$. As expected the presence of the metabolic syndrome was independent of lung function impairment which is in line with findings from the general population where the metabolic syndrome is associated with restrictive ventilatory pattern (due to abdominal obesity) ${ }^{65}$. Besides the evaluation of the prevalence of the metabolic syndrome compared to healthy subjects, we were interested whether the metabolic syndrome contributes to patient related outcomes. This point is discussed further in chapter 9 which shows that COPD patients with metabolic syndrome are not additionally affected in their functional exercise capacity or in their disease-specific health status. Recently lower physical activity levels have been associated with the presence of the metabolic syndrome 
in patients with COPD ${ }^{66}$. Unfortunately daily physical activity levels have not been measured. Chapter 9 demonstrated for the first time a prevalence of osteoporosis of 20\% in patients with COPD having metabolic syndrome. Although this percentage was not higher compared to patients without the metabolic syndrome, a higher bone mineral density of the lumbar spine was found in the patients with the metabolic syndrome. In line data from the general population from the NHANES cohort show that subjects with the metabolic syndrome have a higher bone mineral density compared to subjects without ${ }^{67}$. The authors argue that due to an increased fat mass, increased insulin levels promote bone formation ${ }^{68}$ and an increased mechanical load on the cortical skeleton ${ }^{69}$ may even be protective against non-vertebral fractures ${ }^{70}$. Interestingly circulating leptin appears to act as a mediator between fat mass and bone mass ${ }^{71}$. More controlled trials should investigate this pathway. Finally, chapter 9 showed that the metabolic syndrome increases the co-morbidity index particularly in those patients with an overweight or obese BMI. In 2011 the latest global strategy for the diagnosis, management and prevention of COPD (GOLD) highlights the importance of co-morbidities in COPD72. In particular cardiovascular diseases, lung cancer, osteoporosis, depression, and metabolic disorders, such as type II diabetes have a significant impact on prognosis and some of them were even responsible for the most frequent cause of death in mild COPD ${ }^{72}$. Therefore the metabolic syndrome has to be identified and treated appropriately in every COPD patient.

\section{Methodological considerations}

The present thesis has some limitations that should be considered when interpreting the results. Firstly, most of studies reported have a cross-sectional design and thus causal relationships cannot be drawn and longitudinal data are needed to confirm the results. Secondly, in chapter 2, 3, 4, 7, and 8 no healthy control group was available therefore control based studies have to be conducted to confirm the present findings. Thirdly, although various clinically relevant findings were revealed in the different chapters more direct outcomes and possible consequences are necessary to obtain more insight into i.e. the gender-related differences in the adipokine metabolism and its association with systemic low-grade inflammation in patients with COPD (chapter 7). Fourthly, the investigated systemic inflammatory biomarkers are only a part of the pathological pathways proposed in the systemic low-grade inflammation in patients with COPD and other pathways might become identified to have a more prominent role in the systemic low-grade inflammation in COPD. 


\section{Clinical implications, conclusion and future perspectives}

Earlier on, every COPD patient was thought to be characterised by a homogenous systemic low-grade inflammation. Today however the heterogeneity of systemic low-grade inflammation is indubitable. This thesis has contributed to the insight in the heterogeneity of systemic low grade inflammation in COPD. We have shown a weak association between two important systemic inflammatory systems, the acute phase proteins and the markers of the TNF $\alpha$ system. Taken the ECLIPSE data into account one third of patients studied did not have any elevated systemic inflammatory biomarkers at baseline and after one year follow-up ${ }^{3}$. Furthermore this group of patients seems to have a better survival rate compared to the 'inflamed' ones. Importantly, when tailoring medical management as well as pharmacological treatment for COPD patients in clinic, BMI, particularly an obese BMI, but also age, current smoking, and disease-specific health status need to be taken into account. It was identified that most pulmonary characteristics such as the degree of emphysema and the annual decline of $\mathrm{FEV}_{1}$ during follow-up were inferior in determining systemic low-grade inflammation. Most importantly, the observed all-cause mortality and the annual rate of COPD exacerbations at year three follow-up was higher in the persistently inflamed patients compared to the non-inflamed patients. These findings indicate that independent of the severity of disease inflamed patients may have different outcomes compared to those without. This will have implications on pharmacological treatment of COPD patients as therapy is mostly guided based on local disease severity.

We have clearly shown that an overweight $\left(B M I \geq 25 \mathrm{~kg} / \mathrm{m}^{2}\right.$ ) or obese (BMI $\geq 30 \mathrm{~kg} / \mathrm{m}^{2}$ ) BMI contributes to the state of low-grade systemic inflammation present in COPD. Overweight and obese COPD patients have shown to have an increased likelihood of having highly elevated CRP levels compared to normal weight COPD patients. This finding implicates that every COPD patients' $\mathrm{BMI}$ and waist circumference should be measured in order to identify patients with an increased risk profile. We have demonstrated that abdominal fat mass could be one of the contributing sources of systemic low-grade inflammation in COPD. In addition, abdominal fat also produces and secrets various pro-, and anti-inflammatory mediators. Increased anti-inflammatory adiponectin levels have been found in COPD patients compared to healthy subjects as well as an inverse relationship between adiponectin and BMI and between adiponectin and CRP has been shown. These results may reflect the beneficial effects of adiponectin on decreasing cardiovascular risk ${ }^{73}$. Increased levels of circulating leptin and a positive association of circulating leptin with CRP and fibrinogen in female COPD patients were revealed, while in COPD men leptin correlated with none of the systemic inflammatory biomarkers. This data indicates a gender-dependent dysregulated adipokine metabolism in relation to systemic inflammatory biomarkers in COPD, 
which seems quite interesting as biological difference in the susceptibility of the development of COPD have already been suggested ${ }^{23}$. Although the direct clinical implications of these results still have to be elucidated, they seem worth investigating as circulating leptin levels are a strong predictor for myocardial infarction and first-ever hemorrhagic stroke in the general population ${ }^{24,25}$.

Besides BMI and circulating leptin we have established that age as a host-related factor determines systemic low-grade inflammation in COPD, which is in line with the findings of the ECLIPSE study. In addition, physical inactivity has been associated with increased levels of systemic inflammatory biomarkers in general ${ }^{50}$ but also in patients with COPD ${ }^{52}$. COPD patients are known to be less physically active compared to healthy controls $s^{51}$ and comprehensive pulmonary rehabilitation programs so far have shown no or only modest effects on patients physical activity levels ${ }^{55-57}$. We have been able to show that a three-month supervised Nordic Walking program increased the daily physical activity levels in clinically stable outpatients with COPD and had a long-term effect on patients' daily physical activity pattern and a reduction in patients' daily symptoms. This data illustrates that behaviour changes can be achieved in COPD patients. Considering the relative risks of smoking and physical inactivity, both behaviour attitudes need to be considered in an integrative management of COPD patients. Pulmonary rehabilitation programs and centres offering a dedicated, multidisciplinary rehabilitation program to realize these behaviour changes and accessibility to these programs will be very important to attenuate the societal consequences of COPD.

Lastly, in contrast to normal weight patients, the metabolic syndrome is more prevalent in overweight and obese COPD patients compared to BMI matched healthy subjects. In the overweight to obese subjects, 77\% of COPD and 50\% of healthy subjects were diagnosed with the metabolic syndrome according to the latest guidelines. In addition the presence of the metabolic syndrome had no independent impact on patients' functional exercise capacity and disease-specific health status, while the presence of the metabolic syndrome contributed to patients' co-morbidity status. Therefore it is clinically relevant to screen patients for the metabolic syndrome. According to the latest GOLD strategy, independently of severity of disease, COPD is associated with various co-morbidities which have to be assessed and treated appropriately in every patient ${ }^{72}$. 


\section{References}

1. Gan WQ, Man SF, Senthilselvan A, Sin DD. Association between chronic obstructive pulmonary disease and systemic inflammation: a systematic review and a meta-analysis. Thorax 2004:59:574-80.

2. Franciosi LG, Page CP, Celli BR, et al. Markers of disease severity in chronic obstructive pulmonary disease. Pulm Pharmacol Ther 2006;19:189-99.

3. Agusti A, Edwards LD, Rennard Sl, et al. Persistent systemic inflammation is associated with poor clinical outcomes in COPD: a novel phenotype. PLoS One 2012;7:e37483.

4. De Martinis M, Franceschi C, Monti D, Ginaldi L. Inflamm-ageing and lifelong antigenic load as major determinants of ageing rate and longevity. FEBS Lett 2005;579:2035-9.

5. Baumann H, Jahreis GP, Sauder DN, Koj A. Human keratinocytes and monocytes release factors which regulate the synthesis of major acute phase plasma proteins in hepatic cells from man, rat, and mouse. J Biol Chem 1984;259:7331-42.

6. Kolsum U, Roy K, Starkey C, et al. The repeatability of interleukin-6, tumor necrosis factor-alpha, and Creactive protein in COPD patients over one year. Int J Chron Obstruct Pulmon Dis 2009:4:149-56.

7. Vestbo J, Anderson W, Coxson HO, et al. Evaluation of COPD Longitudinally to Identify Predictive Surrogate End-points (ECLIPSE). Eur Respir J 2008;31:869-73.

8. Hurst JR, Vestbo J, Anzueto A, et al. Susceptibility to exacerbation in chronic obstructive pulmonary disease. N Engl J Med 2010;363:1128-38.

9. Hogg JC, Chu F, Utokaparch S, et al. The nature of small-airway obstruction in chronic obstructive pulmonary disease. N Engl J Med 2004;350:2645-53.

10. Eagan TM, Aukrust P, Ueland T, et al. Body composition and plasma levels of inflammatory biomarkers in COPD. Eur Respir J 2010;36:1027-33.

11. Pinto-Plata V, Toso J, Lee K, et al. Profiling serum biomarkers in patients with COPD: associations with clinical parameters. Thorax 2007;62:595-601.

12. Cazzola M, MacNee W, Martinez FJ, et al. Outcomes for COPD pharmacological trials: from lung function to biomarkers. Eur Respir J 2008;31:416-69.

13. Visser M, Bouter LM, McQuillan GM, Wener MH, Harris TB. Elevated C-reactive protein levels in overweight and obese adults. Jama 1999;282:2131-5.

14. Broekhuizen R, Wouters EF, Creutzberg EC, Schols AM. Raised CRP levels mark metabolic and functional impairment in advanced COPD. Thorax 2006;61:17-22.

15. Melbye $\mathrm{H}$, Halvorsen DS, Hartz I, et al. Bronchial airflow limitation, smoking, body mass index, and statin use are strongly associated with the C-reactive protein level in the elderly. The Tromso Study 2001. Respir Med 2007;101:2541-9.

16. van den Borst $B$, Gosker HR, Wesseling $G$, et al. Low-grade adipose tissue inflammation in patients with mild-to-moderate chronic obstructive pulmonary disease. Am J Clin Nutr 2011.

17. Tomoda $\mathrm{K}$, Yoshikawa $\mathrm{M}$, Itoh $\mathrm{T}$, et al. Elevated circulating plasma adiponectin in underweight patients with COPD. Chest 2007;132:135-40.

18. Sood A. Obesity, Adipokines and Lung Disease. J Appl Physiol 2009.

19. Schols AM, Creutzberg EC, Buurman WA, Campfield LA, Saris WH, Wouters EF. Plasma leptin is related to proinflammatory status and dietary intake in patients with chronic obstructive pulmonary disease. Am J Respir Crit Care Med 1999;160:1220-6.

20. Agrawal A, Lourenco EV, Gupta S, La Cava A. Gender-Based Differences in Leptinemia in Healthy Aging, Non-obese Individuals Associate with Increased Marker of Oxidative Stress. Int I Clin Exp Med 2008;1:305-9.

21. Tommaselli GA, Di Carlo C, Di Spiezio Sardo A, et al. Serum leptin levels and body composition in postmenopausal women treated with tibolone and raloxifene. Menopause 2006;13:660-8.

22. Machinal-Quelin F, Dieudonne MN, Pecquery R, Leneveu MC, Giudicelli Y. Direct in vitro effects of androgens and estrogens on ob gene expression and leptin secretion in human adipose tissue. Endocrine 2002;18:179-84.

23. Sin DD, Cohen SB, Day A, Coxson H, Pare PD. Understanding the biological differences in susceptibility to chronic obstructive pulmonary disease between men and women. Proc Am Thorac Soc 2007;4:671-4.

24. Soderberg S, Ahren B, Stegmayr B, et al. Leptin is a risk marker for first-ever hemorrhagic stroke in a population-based cohort. Stroke 1999;30:328-37. 
25. Soderberg S, Olsson T, Eliasson M, Johnson O, Ahren B. Plasma leptin levels are associated with abnormal fibrinolysis in men and postmenopausal women. J Intern Med 1999;245:533-43.

26. Sin DD, Man SF. Why are patients with chronic obstructive pulmonary disease at increased risk of cardiovascular diseases? The potential role of systemic inflammation in chronic obstructive pulmonary disease. Circulation 2003;107:1514-9.

27. Sattar N, Wannamethee G, Sarwar N, et al. Adiponectin and coronary heart disease: a prospective study and meta-analysis. Circulation 2006;114:623-9.

28. Iwashima $\mathrm{Y}$, Katsuya T, Ishikawa $\mathrm{K}$, et al. Hypoadiponectinemia is an independent risk factor for hypertension. Hypertension 2004:43:1318-23.

29. Pischon T, Girman CJ, Hotamisligil GS, Rifai N, Hu FB, Rimm EB. Plasma adiponectin levels and risk of myocardial infarction in men. Jama 2004:291:1730-7.

30. Cavusoglu E, Ruwende C, Chopra V, et al. Adiponectin is an independent predictor of all-cause mortality, cardiac mortality, and myocardial infarction in patients presenting with chest pain. Eur Heart J 2006;27:2300-9.

31. Kistorp C, Faber J, Galatius S, et al. Plasma adiponectin, body mass index, and mortality in patients with chronic heart failure. Circulation 2005;112:1756-62.

32. Ohashi N, Kato A, Misaki T, et al. Association of serum adiponectin levels with all-cause mortality in hemodialysis patients. Intern Med 2008:47:485-91.

33. Waschki B, Kirsten $A$, Holz $O$, et al. Physical activity is the strongest predictor of all-cause mortality in patients with COPD: a prospective cohort study. Chest 2011;140:331-42.

34. Emerson RW. Natur. Schaffhausen: Novalis Verlag; 1981.

35. van den Akker M, Buntinx F, Metsemakers JF, Roos S, Knottnerus JA. Multimorbidity in general practice: prevalence, incidence, and determinants of co-occurring chronic and recurrent diseases. J Clin Epidemiol 1998;51:367-75.

36. Barnett K, Mercer SW, Norbury M, Watt G, Wyke S, Guthrie B. Epidemiology of multimorbidity and implications for health care, research, and medical education: a cross-sectional study. Lancet 2012;380:37-43.

37. Afonso AS, Verhamme KM, Sturkenboom MC, Brusselle GG. COPD in the general population: prevalence, incidence and survival. Respir Med 2011;105:1872-84.

38. Licastro F, Candore G, Lio D, et al. Innate immunity and inflammation in ageing: a key for understanding age-related diseases. Immun Ageing 2005;2:8.

39. Provinciali M, Cardelli M, Marchegiani F. Inflammation, chronic obstructive pulmonary disease and aging. Curr Opin Pulm Med 2011;17 Suppl 1:S3-S10.

40. Franceschi $\mathrm{C}$, Bonafe $\mathrm{M}$, Valensin $\mathrm{S}$, et al. Inflamm-aging. An evolutionary perspective on immunosenescence. Ann N Y Acad Sci 2000;908:244-54.

41. Fu A, Nair KS. Age effect on fibrinogen and albumin synthesis in humans. Am J Physiol 1998;275:E1023-30.

42. Bruunsgaard $\mathrm{H}$, Pedersen BK. Age-related inflammatory cytokines and disease. Immunol Allergy Clin North Am 2003;23:15-39.

43. Faner R, Rojas M, Macnee W, Agusti A. Abnormal lung aging in chronic obstructive pulmonary disease and idiopathic pulmonary fibrosis. Am J Respir Crit Care Med 2012;186:306-13.

44. MacNee W. Pulmonary and systemic oxidant/antioxidant imbalance in chronic obstructive pulmonary disease. Proc Am Thorac Soc 2005;2:50-60.

45. Morla M, Busquets X, Pons J, Sauleda J, MacNee W, Agusti AG. Telomere shortening in smokers with and without COPD. Eur Respir J 2006;27:525-8.

46. WorldHeathOrganisation. WorldHealthOrganisation(WHO), Global strategy on Diet, Physical activity and Health; 2004

47. Lee IM, Shiroma EJ, Lobelo F, Puska P, Blair SN, Katzmarzyk PT. Effect of physical inactivity on major non-communicable diseases worldwide: an analysis of burden of disease and life expectancy. Lancet 2012;380:219-29.

48. Petersen AM, Pedersen BK. The anti-inflammatory effect of exercise. J Appl Physiol 2005;98:1154-62.

49. Pedersen BK. The diseasome of physical inactivity--and the role of myokines in muscle--fat cross talk. J Physiol 2009;587:5559-68.

50. Fischer CP, Berntsen A, Perstrup LB, Eskildsen P, Pedersen BK. Plasma levels of interleukin-6 and Creactive protein are associated with physical inactivity independent of obesity. Scand J Med Sci Sports 2007;17:580-7. 
51. Pitta F, Troosters T, Spruit MA, Probst VS, Decramer M, Gosselink R. Characteristics of physical activities in daily life in chronic obstructive pulmonary disease. Am J Respir Crit Care Med 2005;171:972-7.

52. Watz H, Waschki B, Boehme C, Claussen M, Meyer T, Magnussen H. Extrapulmonary effects of chronic obstructive pulmonary disease on physical activity: a cross-sectional study. Am J Respir Crit Care Med 2008;177:743-51.

53. Nici L, Donner C, Wouters E, et al. American Thoracic Society/European Respiratory Society statement on pulmonary rehabilitation. Am J Respir Crit Care Med 2006;173:1390-413.

54. Lacasse Y, Goldstein R, Lasserson TJ, Martin S. Pulmonary rehabilitation for chronic obstructive pulmonary disease. Cochrane Database Syst Rev 2006:CD003793.

55. Steele BG, Belza B, Hunziker J, et al. Monitoring daily activity during pulmonary rehabilitation using a triaxial accelerometer. J Cardiopulm Rehabil 2003;23:139-42.

56. Coronado M, Janssens JP, de Muralt B, Terrier P, Schutz Y, Fitting JW. Walking activity measured by accelerometry during respiratory rehabilitation. J Cardiopulm Rehabil 2003;23:357-64.

57. Pitta F, Troosters T, Probst VS, Langer D, Decramer M, Gosselink R. Are patients with COPD more active after pulmonary rehabilitation? Chest 2008;134:273-80.

58. Pate RR, Pratt M, Blair SN, et al. Physical activity and public health. A recommendation from the Centers for Disease Control and Prevention and the American College of Sports Medicine. Jama 1995;273:402-7.

59. Spruit MA, Vanderhoven-Augustin I, Janssen PP, Wouters EF. Integration of pulmonary rehabilitation in COPD. Lancet 2008;371:12-3.

60. Marquis K, Maltais F, Duguay V, et al. The metabolic syndrome in patients with chronic obstructive pulmonary disease. J Cardiopulm Rehabil 2005;25:226-32; discussion 33-4.

61. Fabbri LM, Rabe KF. From COPD to chronic systemic inflammatory syndrome? Lancet 2007;370:797-9.

62. Alberti KG, Zimmet P, Shaw J. The metabolic syndrome--a new worldwide definition. Lancet 2005;366:1059-62.

63. Watz H, Waschki B, Kirsten A, et al. The Metabolic Syndrome in Patients With Chronic Bronchitis and COPD: Frequency and Associated Consequences For Systemic Inflammation and Physical Inactivity. Chest 2009.

64. van den Borst B, Gosker HR, Koster A, et al. The influence of abdominal visceral fat on inflammatory pathways and mortality risk in obstructive lung disease. Am J Clin Nutr 2012;96:516-26.

65. Leone N, Courbon D, Thomas F, et al. Lung function impairment and metabolic syndrome: the critical role of abdominal obesity. Am J Respir Crit Care Med 2009;179:509-16.

66. Watz $\mathrm{H}$, Waschki B, Kirsten A, et al. The metabolic syndrome in patients with chronic bronchitis and COPD: frequency and associated consequences for systemic inflammation and physical inactivity. Chest 2009;136:1039-46.

67. Kinjo M, Setoguchi S, Solomon DH. Bone mineral density in adults with the metabolic syndrome: analysis in a population-based U.S. sample. J Clin Endocrinol Metab 2007;92:4161-4.

68. Reid IR. Relationships among body mass, its components, and bone. Bone 2002;31:547-55.

69. Reid IR. Obesity and osteoporosis. Ann Endocrinol (Paris) 2006;67:125-9.

70. Kao WH, Kammerer CM, Schneider JL, Bauer RL, Mitchell BD. Type 2 diabetes is associated with increased bone mineral density in Mexican-American women. Arch Med Res 2003;34:399-406.

71. Pobeha P, Ukropec J, Skyba P, et al. Relationship between osteoporosis and adipose tissue leptin and osteoprotegerin in patients with chronic obstructive pulmonary disease. Bone;48:1008-14.

72. Global Strategy for Diagnosis, Management, and Prevention of COPD (GOLD). 2011. (Accessed at http://www.goldcopd.org/.)

73. Ouchi N, Parker JL, Lugus JJ, Walsh K. Adipokines in inflammation and metabolic disease. Nat Rev Immunol 2011;11:85-97. 


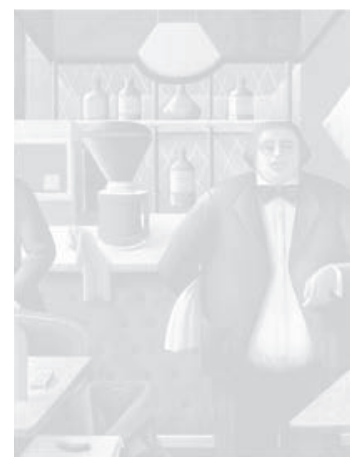

SUMMARY 



\section{Summary}

Chronic obstructive pulmonary disease (COPD) is a major cause of morbidity and mortality worldwide. Independent of its pulmonary effects COPD is considered as a multi-component disease and various extra-pulmonary features like systemic low-grade inflammation, cardiovascular disease, and also metabolic disorders contribute to the negative impact of COPD. Systemic low-grade inflammation is thought to be homogenous and present in every COPD patient. Recent evidence suggests, however that it is rather heterogeneous. Consistently the theory of a 'spill over' from local inflammation into the systemic circulation has not yet been confirmed. Other possible origins like adipose tissue have been proposed as the source of systemic low-grade inflammation in COPD. The adipose tissue is known to secrete various cytokines for example circulating leptin and adiponectin which are involved in the cascade of systemic inflammation in other chronic diseases. In order to better define systemic low-grade inflammation in COPD, possible host-related factors such as BMI, age, or physical inactivity have to be identified as they are thought to be clinically relevant. Finally, an increased abdominal fat mass is the corner stone defining the metabolic syndrome but today only little is known about the metabolic syndrome in COPD. To summarize, the aims of the present thesis were to investigate the heterogeneity of systemic low-grade inflammation in COPD, to elucidate the adipose tissue and its cytokines as a potential source of systemic low-grade inflammation and to find possible determining factors of systemic low-grade inflammation in COPD. In addition, this thesis aims to investigate the prevalence and possible functional consequences of the metabolic syndrome in COPD.

Chapter 2 shows that COPD patients with an overweight and obese BMI $\left(\geq 25 \mathrm{~kg} / \mathrm{m}^{2}\right)$ are more likely to have highly elevated CRP levels $(<5 \mathrm{mg} / \mathrm{dL}) \mathrm{com}-$ pared to normal weight COPD patients. In addition results showed a clear reduction in the likelihood of having highly elevated CRP levels in COPD patients with a low BMI $\left(<21 \mathrm{~kg} / \mathrm{m}^{2}\right)$ compared to normal weight peers $\left(21.0-24.9 \mathrm{~kg} / \mathrm{m}^{2}\right)$. These results might be explained by the fact that adipose tissue itself might be the source of CRP as well as an increased amount of adipose tissue induces increased levels of pro-inflammatory mediators which in turn may stimulate production of $\mathrm{CRP}$ in the liver and therefore contribute to systemic low-grade inflammation in COPD.

In chapter 3 a total body dual-energy-x-ray-absorptiometry (DXA-scan) was performed on 295 stable COPD patients to obtain abdominal fat mass which was positively correlated with CRP. Even when patients with normal CRP levels were chosen, the direct relationship between CRP and abdominal fat mass remained. These results emphasise a possible contributing role of the abdominal fat mass to the state of systemic low-grade inflammation in COPD. 
Consensus is growing that the inflammatory process underling COPD is probably mediated by a multitude of cytokines. The objective of chapter 4 was to investigate a possible interrelationship between the acute phase markers CRP and fibrinogen and the markers of the TNF $\alpha$ system. Results showed a significant but weak relationship between the markers of the two systems, illustrating the complex role of systemic low-grade inflammation in the pathogenesis of COPD. With regard to possible host-related factors determining systemic low-grade inflammation in COPD, chapter 4 showed age being an independent determinant for the soluble TNF $\alpha$ receptor $\mathrm{R} 1$ and fibrinogen in a multivariate regression model. The results of the previous chapters led to the main discussion topic of chapter 5 , comparing plasma levels of adipokines like leptin and adiponectin with systemic inflammatory biomarkers such as CRP, IL-6, TNF $\alpha$ in COPD and healthy subjects. Results showed higher circulating leptin levels in female COPD patients compared to male peers as well as positive correlation between CRP and leptin in COPD women.

Chapter 6 investigated 185 COPD and 115 healthy subjects from the ECLIPSE (Evaluation of COPD Longitudinally to Identify Predictive Surrogate End Points) cohort. The aim was to investigate the adipokine metabolism in relation to systemic inflammatory biomarkers such as CRP, IL-6 and fibrinogen and to evaluate possible gender related differences in adipokine metabolism in COPD and healthy subjects. Higher circulating leptin levels in female COPD patients and healthy peers compared to male COPD and healthy peers were found. Furthermore in female COPD patients' leptin was positively correlated with CRP and fibrinogen, while in COPD men leptin did not correlate with the systemic inflammatory biomarkers. In the multivariate regression analysis CRP was independently associated with circulating leptin. In addition increased adiponectin levels, an inverse relationship between adiponectin and $\mathrm{BMI}$, as well as an inverse relationship between adiponectin and CRP were found in COPD compared to BMI matched healthy subjects. Taken together a gender-dependent dysregulated adipokine metabolism in relation to systemic inflammatory biomarkers in COPD compared to BMI matched healthy subjects seems to be evident.

The effects of pulmonary rehabilitation on daily physical activity levels in COPD have only been barely touched upon in non-randomised and/ or non-controlled trials with no or modest effects. Chapter 7 investigated whether physical training modalities copying everyday-life activities may translate better into patients' physical activity pattern. It was concluded that a three-month supervised Nordic Walking training program is a safe training method and increases the daily physical activity levels in clinically stable outpatients with COPD. In addition, Nordic Walking has a long-term effect on patients' daily physical activity pattern and a reduction in patients' daily symptoms. 
Chapter 8 compares the daily physical activity pattern of patients with COPD from Brazil and Austria. Interestingly Austrian COPD patients' fail to reach the minimum amount of daily physical activity as recommended by the American College of Sports Medicine compared to COPD patients from Brazil. This result indicate that pulmonary rehabilitation programs in Central Europe, even more than in South America, should prioritize the goal of enhancing daily physical activity levels.

Chapter 9 focuses on the prevalence and a possible impact of the metabolic syndrome on patient related outcome parameters such as functional exercise capacity and disease-specific health status. The metabolic syndrome is more prevalent in patients with COPD compared to healthy subjects (57\% vs. 40\%, respectively). Interestingly after stratification for BMI, overweight and obese COPD patients had a higher prevalence of metabolic syndrome compared to healthy peers, while this was not seen in normal weight patients and healthy subjects. In addition COPD patients diagnosed with metabolic syndrome are not additionally affected in their functional exercise capacity or in their disease-specific health status. Having the metabolic syndrome increases the co-morbid index suggesting that the metabolic syndrome has to be identified and treated appropriately in every COPD patient.

In conclusion this thesis has contributed insight into the heterogeneity of systemic low grade inflammation as a weak association between two important systemic inflammatory systems; the acute phase proteins and the markers of the TNF $\alpha$ have been found. In addition, an overweight or obese BMI contributes to the state of low-grade systemic inflammation present in COPD as well as abdominal fat mass being one of the sources of systemic low-grade inflammation in COPD. Abdominal fat also produces and secrets various pro-, and anti-inflammatory mediators. Increased levels of circulating leptin and a positive association of circulating leptin with CRP and fibrinogen are present in female COPD patients. Increased anti-inflammatory adiponectin levels in COPD patients compared to healthy subjects as well as an inverse relationship between adiponectin and BMI, and between adiponectin and CRP have been found. In addition to BMI and circulating leptin, age is a host-related factor determining systemic low-grade inflammation in COPD. A three-month supervised Nordic Walking program increases the daily physical activity levels in clinically stable outpatients with COPD and has a long-term effect on patients' daily physical activity pattern and a reduction in patients' daily symptoms. Lastly, in COPD the prevalence of the metabolic syndrome is higher compared to healthy subjects, particularly in the overweight and obese patients. The presence of the metabolic syndrome has no independent impact on patients' functional exercise capacity and disease-specific health status, while the presence of the metabolic syndrome contributed to patients' co-morbidity status. 



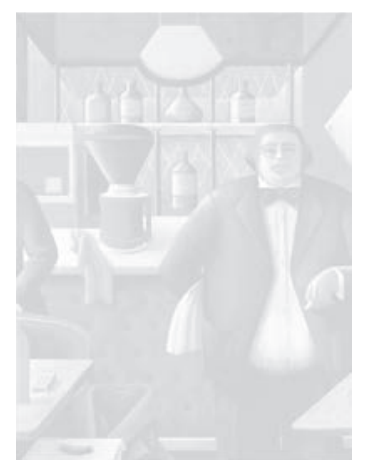

ZUSAMMENFASSUNG 



\section{Zusammenfassung}

Die chronisch obstruktive Lungenerkrankung (COPD) ist eine progredient verlaufende, jedoch verhinderbare und behandelbare Erkrankung, die durch eine lokale, abnorme Entzündungsreaktion (Inflammation) auf inhalative Noxen gekennzeichnet ist. Zusätzlich finden sich auch extra-pulmonale, sogenannte systemische Konsequenzen der COPD wie kardiovaskuläre und metabolische Erkrankungen oder aber auch eine systemische Inflammation. Anfangs wurde die ,spill over 'Theorie, ein Übertreten der lokalen Inflammation in den systemischen Kreislauf und damit eine homogene Inflammation bei jedem COPD Patienten vermutet. Jene Theorie wurde bis heute nicht bewiesen. Viel mehr zeigte sich, dass die systemische Inflammation heterogen ist. Als Quelle der systemischen Inflammation kommt zum Beispiel das Fettgewebe, im speziellen das abdominale Fettgewebe in Frage, da jenes nachweislich verschiedene Adipozytokine, beispielsweise Leptin und Adiponectin freisetzen kann. Um die systemische Inflammation besser definieren zu können müssen Faktoren, die einen potentiell klinisch relevanten Einfluss haben könnten identifiziert werden. Zu diesen Faktoren zählen der Body Mass Index (BMI), das Alter oder aber auch Altagsaktivitäten, die ein Patient pro Tag durchführt. Schließlich ist noch zu erwähnen, dass die Menge an abdominalem Fettgewebe ein Eckpfeiler für die Diagnose des metabolischen Syndroms darstellt. Dieses Syndrom ist bei Patienten mit COPD kaum erforscht. Zusammenfassend beschreibt diese Doktorarbeit die Heterogenität der systemischen Inflammation bei Patienten mit COPD, erläutert die Rolle des abdominalen Fettgewebes als Quelle verschiedener Zytokine und damit einer systemischen Inflammation und identifiziert verschiedene Faktoren, die die systemische Inflammation beeinflussen. Zusätzlich widmet sich diese Arbeit der Häufigkeit und den funktionellen Konsequenzen des metabolischen Syndroms bei Patienten mit COPD im Vergleich zu gesunden Personen.

Kapitel 2 zeigt, dass übergewichtige und adipöse COPD Patienten (BMI $>25 \mathrm{~kg} / \mathrm{m}^{2}$ ) im Vergleich zu normalgewichtigen COPD Patienten (BMI 21-24.9 kg/m²), eine deutlich höhere Wahrscheinlichkeit aufweisen erhöhte CRP Werte $(>5 \mathrm{mg} / \mathrm{dl})$ zu haben. Zusätzlich weisen untergewichtige COPD Patienten (BMI $\left.<21 \mathrm{~kg} / \mathrm{m}^{2}\right)$, ebenso im Vergleich zu normalgewichtigen, eine deutlich erniedrigte Wahrscheinlichkeit auf. Dies könnte durch eine erhöhte abdominale Fettmasse erklärt werden: ein Mehr an abdominalem Fettgewebe induziert die Freisetzung von pro-inflammatorische Zytokinen, die wiederum die Leber stimulieren zusätzliches Inflammatiosnmediatoren, wie zum Beispiel CRP zu produzieren.

In Kapitel 3 wurde bei 295 COPD Patienten ein DXA-Scan durchgeführt und somit die abdominale Fettmasse gemessen, welche in weiterer Folge mit den vorhandenen CRP Werten korrelierte. Sogar bei COPD Pateinten mit normalen 
CRP Werten konnte ein direkter Zusammenhang mit der abdominalen Fettmasse gezeigt werden. Diese Daten unterstreichen die Rolle des abdominalen Fettgewebes im Zusammenhang mit der systemischen Inflammation.

Kapitel 4 untersuchte einen möglichen Zusammenhang zwischen zwei verschiedenen Inflammationssystemen: den Akute Phase Proteinen, CRP und Fibrinogen sowie dem TNF $\alpha$ System. Es konnte ein signifikanter aber nur schwacher Zusammenhang dargestellt werden. Dies spiegelt die Komplexität der systemischen Inflammation in der Pathogenese der COPD wider. Zusätzlich konnte in Kapitel 4 gezeigt werden, dass das Alter einer der Faktoren ist, der die systemische Inflammation, im speziellen den TNF $\alpha$ Rezeptor 1 sowie Fibrinogen in einem multivariaten Regressionsmodell definiert.

Im Kapitel 5 wird der Zusammenhang von systemischen Inflammationsparametern wie zum Beispiel CRP, Interleukin 6 oder TNF $\alpha$ und den Adipozytokinen, Leptin und Adiponectin untersucht. Die Ergebnisse zeigen, dass weibliche COPD Patienten im Vergleich zu männlichen, höhere Leptin Werte aufweisen und diese mit den CRP Werten in Zusammenhang stehen.

Kapitel 6 untersuchte 185 COPD Patienten und 115 gesunde Personen aus der ECLIPSE Kohorte (Evaluation of COPD Longitudinally to Identify Predictive Surrogate End Points). Vorwiegend wurden (geschlechtsspezifische) Unterschiede zwischen diversen systemischen Inflammationsparametern und Adipozytokinen untersucht. Es zeigten sich höhere Leptin Werte sowohl bei weiblichen COPD Patienten als auch bei Gesunden. Im Gegensatz zu Männern korrelierte bei weiblichen COPD Patienten Leptin mit den systemischen Inflammationsparametern CRP und Fibrinogen. In einer multivariaten Regressionsanalyse zeigte sich ein unabhängiger Zusammenhang zwischen CRP und Leptin. Im Bezug auf Adiponectin zeigte sich eine Umkehrrelation mit CRP und BMI nur in COPD Patienten. Somit kann man von einem geschlechtsabhängigen Verhältnis zwischen den Adipozytokinen und den systemischen Inflammationsparametern bei Patienten mit COPD im Vergleich zu gesunden Personen ausgehen.

Mittels pulmonaler Rehabilitation wurde bereits mehrfach versucht den Lebensstil von Patienten mit COPD zu verbessern. Leider konnte bis jetzt eine Steigerung der alltäglichen Bewegungen wie zum Beispiel Gehen jedoch nicht erreicht werden. In Kapitel 7 wurde gezeigt, dass man mittels einer Bewegung, die ins alltägliche Leben leicht übernommen werden kann, dem Nordic Walking, die Alltagsaktivitäten von Patienten mit COPD kurz, aber auch langfristig steigern kann. Zusätzlich konnten Symptome der Atemnot oder aber auch Symptome einer Depression reduziert werden. 
In Kapitel 8 wurden die Alltagsaktivitäten von COPD Patienten zweier Kontinente, Südamerika und Europa verglichen. Interessanterweise zeigten österreichische COPD Patienten, dass sie in ihrem Alltagsleben weniger aktiv sind als COPD Patienten aus Brasilien.

Die Häufigkeit und funktionelle Auswirkungen des metabolischen Syndroms auf Patienten mit COPD im Vergleich zu gesunden Personen wurden in Kapitel 9 untersucht. Es zeigte sich, dass mehr COPD Patienten im Vergleich zu gesunden Personen an einem metabolischen Syndrom leiden. Interessanterweise, wenn man die Kohorte nach ihrem BMI aufteilt, litten mehr übergewichtige COPD Patienten an einem metabolischen Syndrom als übergewichtige gesunde Personen. Diese Ergebnisse fanden sich bei normalgewichtigen nicht. Im Bezug auf Leistungsfähigkeit und Gesundheitsstatus blieben Patienten mit COPD und metabolischem Syndrom von diesem unbeeinflusst, während der Komorbiditäten Index stieg. Daher sollten alle COPD Patienten hinsichtlich des Vorkommens eines metabolischen Syndroms untersucht werden und wenn notwendig auch konsequent therapiert werden.

Zusammenfassend trug diese Doktorarbeit zum Wissen um die Heterogenität der systemischen Inflammation bei Patienten mit COPD bei, da sich nur ein schwacher Zusammenhang zwischen verschiedenen Inflammationssystemen gezeigt hat. Ein übergewichtiger oder adipöser BMI sowie die abdominale Fettmasse konnten als Quelle der systemischen Inflammation identifiziert werden. Erhöhte Leptin Werte sowie ein positiver Zusammenhang zwischen Leptin und CRP und Fibrinogen zeigte sich bei weiblichen COPD Patienten. Erhöhte Adiponectin Werte wurden ebenso gemessen sowie eine Umkehrrelation zwischen Adiponectin und BMI und CRP. Zusätzlich konnten der BMI, Leptin und das Alter als Faktoren identifiziert werden, die die systemische Inflammation definieren. Drei Monate eines Nordic Walking Trainings erhöhen die Alltagsaktivitäten und können kurz- aber auch langfristig das Bewegungsmuster sowie Symptome der Atemnot oder Depression positiv beeinflussen. Abschließend ist die Häufigkeit des metabolischen Syndroms höher bei Patienten mit COPD im Vergleich zu Gesunden, vor allem bei übergewichtigen, wenngleich das Vorhandensein des metabolischen Syndroms keinen zusätzlichen negativen Einfluss auf die Leistungsfähigkeit und den Gesundheitsstatus von Patienten mit COPD gezeigt hat. Das Vorhandensein des metabolischen Syndroms erhöht den Komorbiditäten Index von Patienten mit COPD. 



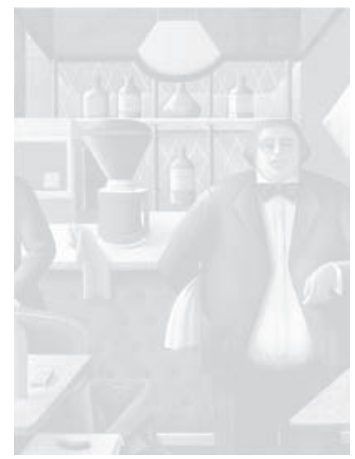

SAMENVATTING 



\section{Samenvatting}

Chronisch obstructief longlijden (COPD) is wereldwijd een grote oorzaak van een verhoogde morbiditeit en mortaliteit. COPD is, onafhankelijk van zijn pulmonale effecten, gezien als een multi-component aandoening en verschillende extrapulmonale kenmerken zoals systemische inflammatie, cardiovasculaire ziekten en metabole verstoringen dragen bij aan de negatieve impact van de ziekte. Recent onderzoek was niet in staat om de 'spill-over' theorie van de lokale pulmonale inflammatie naar de systemische circulatie te bevestigen en als mogelijke andere bron voor systemische inflammatie is het vetweefsel voorgesteld. Het is bekend dat het vetweefsel verschillende cytokines uitscheidt zoals leptine en adiponectine, die in andere chronische ziekten beide betrokken zijn in de cascade van systemische inflammatie. Om de systemische inflammatie in COPD beter in kaart te brengen zijn verschillende gerelateerde factoren zoals leeftijd, BMI en fysieke inactiviteit geïdentificeerd. Een verhoogd abdominaal vetmassa, gemeten met middelomtrek, is een primaire factor voor het bepalen van het metabool syndroom. Er is echter nog maar weinig bekend over de effecten van het metabool syndroom in COPD patiënten. Samengevat, het doel van deze thesis was om de heterogeniteit van de systemische inflammatie in COPD verder te onderzoeken, om de rol van adipokines (vetweefsel geïnduceerde cytokines) in de systemische inflammatie in kaart te brengen en om mogelijke bepalende factoren voor de systemische inflammatie te definiëren. Ten laatste is de prevalentie en mogelijke functionele en klinische consequenties van het metabool syndroom in COPD onderzocht.

Hoofdstuk 2 laat zien dat COPD patiënten met overgewicht of obesitas $\left(\mathrm{BMI} \geq 25 \mathrm{~kg} / \mathrm{m}^{2}\right.$ ) een verhoogde kans hebben op een verhoogd circulerend CRP concentratie in vergelijking met patiënten met een normaal gewicht. Tevens vonden we een duidelijk verlaagde kans op een verhoogd CRP concentratie in de patiënten met ondergewicht $\left(\mathrm{BMI}<21 \mathrm{~kg} / \mathrm{m}^{2}\right)$ in vergelijking met patiënten met normaal gewicht. Deze resultaten zouden mogelijks verklaard kunnen worden voor het feit dat een verhoogde hoeveelheid vetweefsel een verhoogde concentratie adipokines veroorzaakt die de productie van CRP uit de lever stimuleren en zo bijdragen in de systemische inflammatie in COPD.

In hoofdstuk 3 wordt een onderzoek beschreven waarin een DEXA scan was gemaakt van het hele lichaam in 295 COPD patiënten om de hoeveelheid abdominaal vet te meten. Dit abdominaal vet was positief gecorreleerd met de hoeveelheid CRP in het plasma. Zelfs als patiënten met normale (lage) CRP concentratie waren geselecteerd, was er een directe relatie tussen CRP en abdominaal vetmassa. Deze resultaten benadrukken dat het abdominaal vetweefsel mogelijks een bijdragende rol speelt in de systemische inflammatie bij patiënten met COPD. 
Er is groeiende consensus dat de inflammatoire processen bij COPD gemedieerd worden door een veelheid van cytokines. Daarom was het doel van hoofdstuk 4 om mogelijke relaties te onderzoeken tussen de acuut fase eiwitten CRP en fibrinogeen en markers van het TNF $\alpha$ systeem. De resultaten lieten een significante maar zwakke relatie zien tussen de markers van beide systemen. Deze relatie toont dat de systemische inflammatie bij COPD een complex mechanisme is. Met betrekking tot mogelijke gerelateerde factoren die systemische inflammatie kunnen bepalen, laat hoofdstuk 4 zien dat leeftijd een onafhankelijke determinant is voor de oplosbare TNF $\alpha$ receptor R1 en fibrinogeen bij COPD.

De resultaten van voorafgaande hoofdstukken hebben geleid tot hoofdstuk 5 , waar plasma concentraties van adipokines zoals leptine en adiponectine met systemische infammatoire markers zoals CRP, interleukine 6 (IL-6) en TNF $\alpha$ werden vergeleken in patiënten met COPD en gezonde controles. De resultaten toonden hogere leptine concentraties in vrouwelijke COPD patiënten in vergelijking met mannelijke patiënten en een positieve correlatie tussen CRP en leptine, enkel in vrouwelijke patiënten.

In hoofdstuk 6 worden de bevindingen van een secundaire analyse van de ECLIPSE (Evaluation of COPD Longitudinally to Identify Predictive Surrogate End Points) studie gepresenteerd. Het doel van de studie was om adipokines in relatie tot het inflammatoire metabolisme (CRP, IL-6 en fibrinogeen) verder te onderzoeken en om mogelijke geslacht gerelateerde verschillen te evalueren bij COPD patiënten en gezonde controles met een vergelijkbare BMI. Er werd opnieuw een verhoogde leptine concentratie bij vrouwelijke COPD patiënten en gezonde vrouwen gevonden in vergelijking met hun mannelijke tegenhangers. In vrouwelijke COPD patiënten was leptine positief gecorreleerd met CRP en fibrinogeen, terwijl dit niet gevonden werd in mannelijke COPD patiënten. In de multivariate analyse was CRP onafhankelijk geassocieerd met circulerend leptine. Tevens was plasma adiponectine verhoogd in COPD patiënten in vergelijking met gezonde controles. Bij COPD patiënten werd een inverse relatie gevonden tussen adiponectine en BMI en tussen adiponectine en CRP. Op basis van deze bevindingen werd besloten dat er evidentie is voor een geslachtsafhankelijke verstoring van het adipokine metabolisme in relatie tot systemische inflammatie bij COPD patiënten in vergelijking tot gezonde controles met een vergelijkbare BMI. De effecten van longrevalidatie op de mate van dagelijkse fysieke activiteit in patiënten met COPD zijn slechts beperkt onderzocht in niet-gerandomiseerde en/of niet-gecontroleerde onderzoeken met geen of slechts beperkte effecten. Hoofdstuk 7 onderzocht of fysieke trainingsmodaliteiten een betere fysiek activiteitspatroon in COPD patiënten te weeg kon brengen. Een drie maanden gesuperviseerd trainingsprogramma met Nordic walking was een veilige trainingsmethode en was in staat om de dagelijkse fysieke activiteit in klinisch stabiele COPD patiënten te verhogen. Verder was Nordic walking in staat om de dageli- 
jkse fysieke activiteit van COPD patiënten te verhogen en hun dagelijkse symptomen te verlagen.

In hoofdstuk 8 werd het dagelijkse fysieke activiteit patroon van COPD patiënten van Brazilië en Oostenrijk met elkaar vergeleken. Oostenrijkse COPD patiënten haalden, in vergelijking met Braziliaanse patiënten, de minimale hoeveelheid fysieke activiteit zoals aanbevolen door het Amerikaanse college van sportgeneeskunde niet. Deze data wijzen erop dat longrevalidatie, in Centraal Europa nog meer dan in Zuid Amerika, zou moeten focussen op het verhogen van de dagelijkse fysieke activiteit.

Hoofdstuk 9 richtte zich op het voorkomen van het metabool syndroom en op de mogelijke impact van het metabool syndroom op patiënt gerelateerde uitkomst parameters zoals inspanningscapaciteit en ziekte specifieke gezondheidsstatus. Het metabool syndroom kwam meer voor bij COPD patiënten dan bij gezonde controles (57\% vs. 40\% respectievelijk). Na stratificatie voor BMI kwam het metabool syndroom meer voor bij patiënten met overgewicht of obesitas in vergelijking met gezonde mensen met overgewicht of obesitas, maar dit was niet het geval bij patiënten met een normaal gewicht of ondergewicht in vergelijking met gezonden met vergelijkbare BMI. Verder had het hebben van het metabool syndroom geen additionele effecten op de functionele inspanningscapaciteit of op ziekte specifieke gezondheidstoestand. Echter, het metabool syndroom verhoogd de mate van co-morbiditeit, erop wijzend dat het metabool syndroom moet gedetecteerd en behandeld worden in elke patiënt.

Samenvattend heeft deze thesis bijgedragen aan de inzichten in de heterogeniteit van systemische inflammatie bij COPD. De bijdrage van een verhoogd BMI en het abdominaal vetweefsel aan de systemische inflammatie van COPD patiënten is beter in kaart gebracht. Het vetweefsel produceert en scheidt verschillende pro- en anti-inflammatoire mediators uit. Een verhoogde concentratie van leptine en een positieve correlatie met inflammatoire markers zoals CRP en fibrinogeen is gevonden in vrouwelijke COPD patiënten. Verhoogde concentratie van adiponectine en een inverse relatie met BMI en CRP is aangetoond bij COPD patiënten in vergelijking met gezonde personen met vergelijkbare BMI. Naast $\mathrm{BMI}$ en leptine is leeftijd ook een bepalende factor voor systemische inflammatie bij COPD. Een 3 maand durend programma dat Nordic walking bevatte was in staat om het dagelijkse fysieke activiteit patroon -zowel op korte als op lange termijn- bij COPD patiënten te verhogen en hun dagelijkse symptomen te verlagen. Ten laatste, de prevalentie van het metabool syndroom is hoger bij COPD patiënten dan bij gezonde ouderen, voornamelijk bij patiënten met overgewicht en obesitas. Het metabool syndroom heeft echter geen bijkomende impact op de functionele inspanningscapaciteit en ziekte specifieke gezondheidstoestand, terwijl het wel bijdraagt tot een verhoogde mate van co-morbiditeit. 
